\title{
Use of Cyclodextrins in Anticancer Photodynamic Therapy Treatment
}

\author{
Amina Ben Mihoub ${ }^{1}$, Ludivine Larue ${ }^{1,2}$, Albert Moussaron ${ }^{1}$, Zahraa Youssef ${ }^{2}$, \\ Ludovic Colombeau ${ }^{1,2}$, Francis Baros ${ }^{2}$, Céline Frochot ${ }^{2}$ (D), Régis Vanderesse ${ }^{1}$ \\ and Samir Acherar 1,* \\ 1 Laboratoire de Chimie Phusique Macromoléculaire, Université de Lorraine, CNRS, LCPM, \\ F-54000 Nancy, France; amina.ben-mihoub@univ-lorraine.fr (A.B.M.); \\ ludivine.larue@univ-lorraine.fr (L.L.); albert.moussaron@univ-lorraine.fr (A.M.); \\ ludovic.colombeau@univ-lorraine.fr (L.C.); regis.vanderesse@univ-lorraine.fr (R.V.) \\ 2 Laboratoire Réactions et Génie des Procédés, Université de Lorraine, CNRS, LRGP, \\ F-54000 Nancy, France; zahraa.youssef@univ-lorraine.fr (Z.Y.); \\ francis.baros@univ-lorraine.fr (F.B.); celine.frochot@univ-lorraine.fr (C.F.) \\ * Correspondence: samir.acherar@univ-lorraine.fr; Tel.: +33-037-274-3687
}

Received: 28 June 2018; Accepted: 28 July 2018; Published: 2 August 2018

\begin{abstract}
Photodynamic therapy (PDT) is mainly used to destroy cancerous cells; it combines the action of three components: a photoactivatable molecule or photosensitizer (PS), the light of an appropriate wavelength, and naturally occurring molecular oxygen. After light excitation of the PS, the excited PS then reacts with molecular oxygen to produce reactive oxygen species (ROS), leading to cellular damage. One of the drawbacks of PSs is their lack of solubility in water and body tissue fluids, thereby causing low bioavailability, drug-delivery efficiency, therapeutic efficacy, and ROS production. To improve the water-solubility and/or drug delivery of PSs, using cyclodextrins (CDs) is an interesting strategy. This review describes the in vitro or/and in vivo use of natural and derived CDs to improve antitumoral PDT efficiency in aqueous media. To achieve these goals, three types of binding modes of PSs with CDs are developed: non-covalent CD-PS inclusion complexes, covalent CD-PS conjugates, and CD-PS nanoassemblies. This review is divided into three parts: (1) non-covalent CD-PS inclusion complexes, covalent CD-PS conjugates, and CD-PS nanoassemblies, (2) incorporating CD-PS systems into hybrid nanoparticles (NPs) using up-converting or other types of NPs, and (3) CDs with fullerenes as PSs.
\end{abstract}

Keywords: cylodextrin; photosensitizer; photodynamic therapy; cancer; inclusion complex; conjugate; nanoassembly; nanoparticle; porphyrinoid; fullerene

\section{Introduction}

\subsection{Cancer and Treatments}

Cancer has more than 277 different types and is the second leading cause of global death after cardiovascular diseases [1]. Through its GLOBOCAN project, the International Agency for Research on Cancer (IARC), a semi-autonomous unit of the World Health Organization (WHO), has estimated in 2012 approximately 14.1 million new global cases of cancer and 8.2 million global deaths, with slightly more incidence cases and death effects on men than women (men:women ratios of 53:47 and 57:43 for cases and deaths, respectively) [2]. The top five killer cancers for both sexes combined are reported in Table 1 , and these data revealed that lung (19.4\% of the total), liver $(9.1 \%)$, stomach $(8.8 \%)$, colorectal $(8.5 \%)$ and breast $(6.4 \%)$ are the five most common causes of cancer death. Based on these estimates and on the prediction that the number of new global cancer cases is expected to increase by $70 \%$ 
over the next two decades, the Global action plan for the prevention and control of noncommunicable diseases 2013-2020 was endorsed in 2013 by the World Health Assembly [3]. This global action plan has nine goals, including a 25\% reduction in global premature mortality by 2025 from the four types of noncommunicable diseases, i.e., cardiovascular and chronic respiratory diseases, cancer, and diabetes, relying in particular on greater coordinated and coherent actions at all levels (local, national, and international). Cancer as a whole is responsible of nearly one-sixth of global deaths and the latest available estimates of cancer mortality from the Institute for Health Metrics and Evaluation (IHME) indicate 8.9 million global deaths in 2016, whose most common causes of death are the cancers of lung (19.2\% of the total), stomach $(9.4 \%)$, colorectal $(9.3 \%)$, liver $(9.3 \%)$, and breast $(6.1 \%)$ (Table 1) [4]. As a general point, it is noted that around $70 \%$ of global cancer deaths occur in low and middle-income countries, and one-third of global deaths are due to the five-leading behavioral and dietary risk factors, which are obesity, low intakes of fruit and vegetables, physical inactivity, tobacco use, and alcohol consumption.

Table 1. Estimated cancer deaths worldwide and top five killer cancers for both sexes combined, 2012 (International Agency for Research on Cancer (IARC) data) and 2016 (Institute for Health Metrics and Evaluation (IHME) data).

\begin{tabular}{|c|c|c|c|c|c|c|}
\hline \multirow{2}{*}{ Year } & \multirow{2}{*}{ Global Cancer Death } & \multicolumn{5}{|c|}{ Top Five Killer Cancers } \\
\hline & & Lung ${ }^{1}$ & Liver & Stomach & Colorectal & Breast \\
\hline 2012 & 8.2 million & 1.59 million & 745,517 & 723,027 & 693,881 & 521,817 \\
\hline 2016 & 8.9 million & 1.71 million & 828,945 & 834,171 & 829,558 & 545,590 \\
\hline Rates of change $^{2}$ & $+8.6 \%$ & $+7.6 \%$ & $+11.2 \%$ & $+15.4 \%$ & $+19.6 \%$ & $+4.6 \%$ \\
\hline
\end{tabular}

There are many types of cancer treatment [5,6], and the health care team is going to establish a treatment plan for cancer depending on various parameters, such as the type, stage, and spread of cancer, and the patient's age and general health. The aim of the treatment planning for cancer, with the use of a single or combination therapy, is to treat and cure cancer but in other cases to control the cancer's proliferation or minimize symptoms for as long as possible. The most common cancer treatments are surgery [7,8], radiation therapy $[9,10]$, and chemotherapy [11]. Surgery can be used to diagnose and treat many types of cancer, and consists in removing all or part of a tumor, especially when the cancer has not spread to other parts of the body. Radiation therapy is intended to deprive the cancer cells of their cell division and multiplication processes with the aim of damaging or destroying cancer cells using radiation, such as X-rays, gamma rays, electron beams, or protons. Chemotherapy, for its part, can be implemented for killing or controlling the growth of cancer cells, and is based on the use of one drug or a combination of drugs. These three cancer treatments have side effects, and are not always effective to treat and cure cancer. In addition, the duration, frequency, and the number of chemotherapy or radiation therapy cycles produce negative side effects that tend to gradually get worse over time. Based on these findings, researchers have developed further cancer therapies to improve the effectiveness of treatments while reducing undesired side effects, such as immunotherapy [12,13], hormone therapy [14], gene therapy [15,16], cryotherapy [17], targeted cancer therapies [18,19], stem cell transplant [20,21], thermal therapy [22,23], and photodynamic therapy [2426].

\subsection{Photodynamic Therapy for Cancer Treatment}

The basic principle of photodynamic therapy (PDT) is to combine the action of three components: (1) a photoactivatable molecule or photosensitizer (PS), (2) a certain kind of light typically in the visible spectrum, and (3) naturally occurring molecular oxygen (triplet oxygen, ${ }^{3} \mathrm{O}_{2}$ ) [27]. The PDT as cancer treatment (Figure 1) involves the administration of a PS to patients, followed by visible light excitation. 
The excited PS then reacts with molecular oxygen to produce reactive oxygen species (ROS) [28,29], including singlet oxygen $\left({ }^{1} \mathrm{O}_{2}\right)$ [30], leading to cellular damage [31,32].

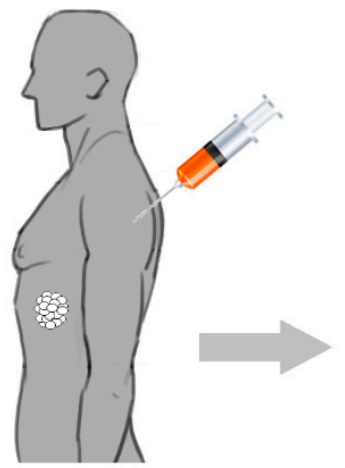

(a)

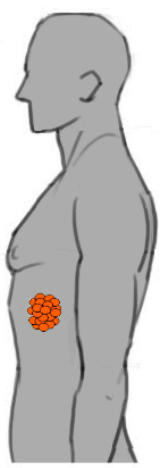

(b)

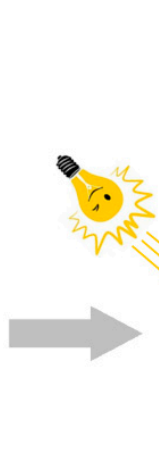

(c)

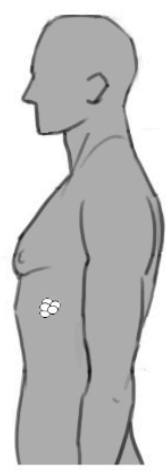

(d)

Figure 1. Two-step photodynamic therapy (PDT) cancer treatment process involving: (a) photosensitizer (PS) injection; (b) PS accumulation in the tumor; (c) PS activation by light; (d) reactive oxygen species (ROS) production and tumor damage response.

The PDT story is well-documented [33,34], and the light is known for its therapeutic effect for millennia with the first uses of light in Chinese, Egyptian, or Indian civilizations for the treatment of numerous diseases such psoriasis, vitiligo, and rickets dating back to over 3000 years ago $[35,36]$. PS employed in PDT are divided into four categories, namely, first, second, third, and fourth-generation PS, according to the chronological development and the evolution of conceptual approaches to reduce their disadvantages for a PDT treatment. Although there are various types of PSs, most of them belong to the porphyrinoid groups (Figure 2).

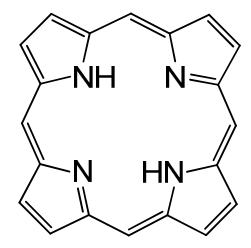

Porphyrin

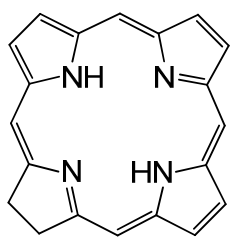

Chlorin

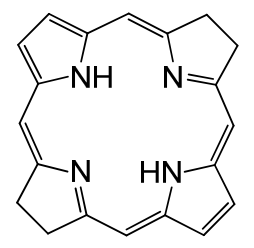

Bacteriochlorin

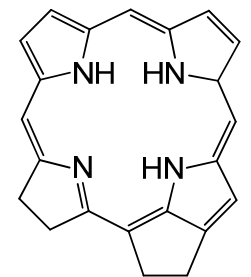

Pheophorbide

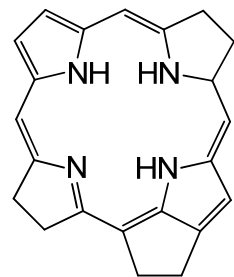

Bacteriopheophorbide<smiles>C1=CC(=Nc2ccc(/N=C3/C=C/C(=N/c4ccc[nH]4)N3)[nH]2)C=C1</smiles>

Porphyrazin

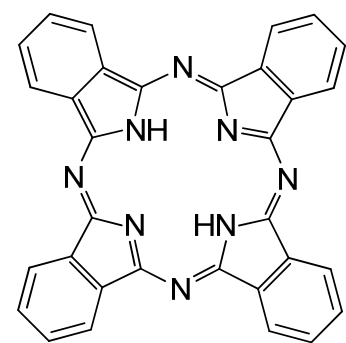

Phthalocyanine<smiles></smiles>

Texaphyrin

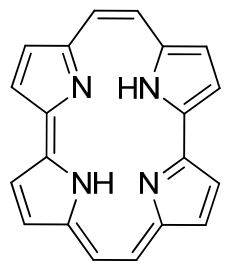

Porphycene

Figure 2. Examples of molecular skeletons of porphyrinoid-based PSs.

Historically and from a clinical point of view, the use of PDT for cancer in humans began in the 1970s with the study of the effects of hematoporphyrin derivatives (HpD) and light on five patients with bladder cancer [37] and on 25 patients with a large series of malignant tumors [38]. The findings of these studies have paved the way in 1993 for the first clinically approved PS (Photofrin ${ }^{\circledR}$, a purified fraction of $\mathrm{HpD}$ ) to treat bladder cancer in Canada. However, the use of Photofrin ${ }^{\circledR}$ (a first-generation 
PS) for PDT cancer treatments is confronted by several limitations, such as a fairly low absorption band close to $630 \mathrm{~nm}$ driving the need for high PS injection to produce enough ROS to result in tumor destruction. Ideally, a good PS (second-generation PS) should have a strong absorption band in the $650 \mathrm{~nm}$ to $800 \mathrm{~nm}$ range with a high extinction coefficient $\left(\varepsilon_{\max }\right.$ above $\left.50,000 \mathrm{M}^{-1} \cdot \mathrm{cm}^{-1}\right)$ allowing light penetration deeper into tissue up to $1 \mathrm{~cm}$, and thus offering the possibility of producing ROS to kill tumor cells under centimeter-thick tissue. In addition, an ideal PS (third-generation PS, i.e., second-generation PS conjugated with a targeting agent) should also be able to specifically accumulate in cancer tissues compared with in healthy tissues. Finally, concerning the theranostic approach, an optimal PS (fourth-generation PS, i.e., third-generation PS conjugated with an imaging agent) should also be able to combine tumor-targeted PDT treatment and precise tumor diagnosis. To date, hundreds clinical trials concerning PDT (alone or in combination with other therapies) were investigated, and there are several reviews in the literature relating to the use of PDT in clinical trials or preclinical studies $[26,39,40]$. An overview of the few clinically approved PSs for PDT as a cancer treatment are listed in Table 2.

Table 2. Overview of clinically approved PSs for PDT as cancer treatment.

\begin{tabular}{|c|c|c|c|c|}
\hline PS & Trademark & Approved & $\lambda_{\text {exc. }}(\mathrm{nm})$ & Application \\
\hline Porfimer sodium & Photofrin & $\mathrm{WW}^{9}$ & 632 & Bladder, esophogeal, lung, cervical, endobronchial, and gastric cancers \\
\hline 5-ALA ${ }^{1}$ & Levulan/Ameluz & WW $^{9}$ & 635 & Actinic keratosis \\
\hline $\mathrm{MAL}^{2}$ & Metvix/Metvixia & WW $^{9}$ & $570-670$ & Actinic keratosis and basal cell carcinoma \\
\hline $\mathrm{mTHPC}^{4}$ & Foscan & $\mathrm{EU}^{10}$ & 652 & Head and neck cancer \\
\hline $\mathrm{NPe}^{5}$ & Laserphyrin & Japan & 664 & Lung cancer \\
\hline Synthetic hypericin & SGX301 ${ }^{8}$ & $\mathrm{EU}^{10} / \mathrm{USA}$ & $570-650$ & Cutaneous T-cell lymphoma \\
\hline LUZ11 & Redaporfin $^{8}$ & $\mathrm{EU}^{10}$ & 749 & Biliary tract cancer \\
\hline
\end{tabular}

${ }^{1}$ 5-Aminolevulinic acid. ${ }^{2}$ Methyl aminolevulinate. ${ }^{3}$ Hexyl aminolevulinate. ${ }^{4}$ Meta-tetra(hydroxyphenyl)chlorin.

${ }^{5} \mathrm{~N}$-aspartyl chlorin e6. ${ }^{6}$ Aluminium phthalocyanine tetrasulfonate. ${ }^{7}$ Pd-bacteriopheophorbide. ${ }^{8}$ Orphan status.

${ }^{9}$ Worldwide. ${ }^{10}$ European Union.

Another problem faced by many PSs is their lack of solubility in water and the body's tissue fluids, thereby causing amongst other things the low bioavailability, drug-delivery efficiency, and therapeutic efficacy of PSs in vivo, which restricts their clinical applications.

Among various strategies to improve the water solubility and/or drug delivery of PSs [25], e.g., by using hydrophilic substituents (cationic or anionic groups [41-43], amino acids [44,45], peptides [46,47], sugars [48-50], polyethylene glycol derivatives [51], liposomes [52,53], or organic and inorganic nanoparticles [54-60], cyclodextrins (CDs) represent interesting hydrophilic substituents to resolve these challenges and help in the development of drugs with enhanced water solubility [61] as well as enhanced drug delivery [62-65].

\subsection{Cyclodextrins for Enhancing Drug Solubility and Delivery}

CDs are a class of natural cyclic oligosaccharides produced during the bacterial digestion of cellulose that consist of $(\alpha-1,4)$-linked $\alpha$-D-glucopyranose units. There are three types of natural CDs, named $\alpha-C D, \beta-C D$, and $\gamma-C D$ (Figure 3), depending on the number of glucopyranose units (six to eight units) linked together. CDs are water-soluble, biocompatible, crystalline, and non-hygroscopic substances. From a structural point of view and due to the chair conformation of glucopyranose units, CDs are toroidal (truncated cone), with a nonpolar tapered cavity and a hydrophilic tapered surface (primary hydroxyl groups at the narrow edge and secondary hydroxyl groups at the wider edge). 


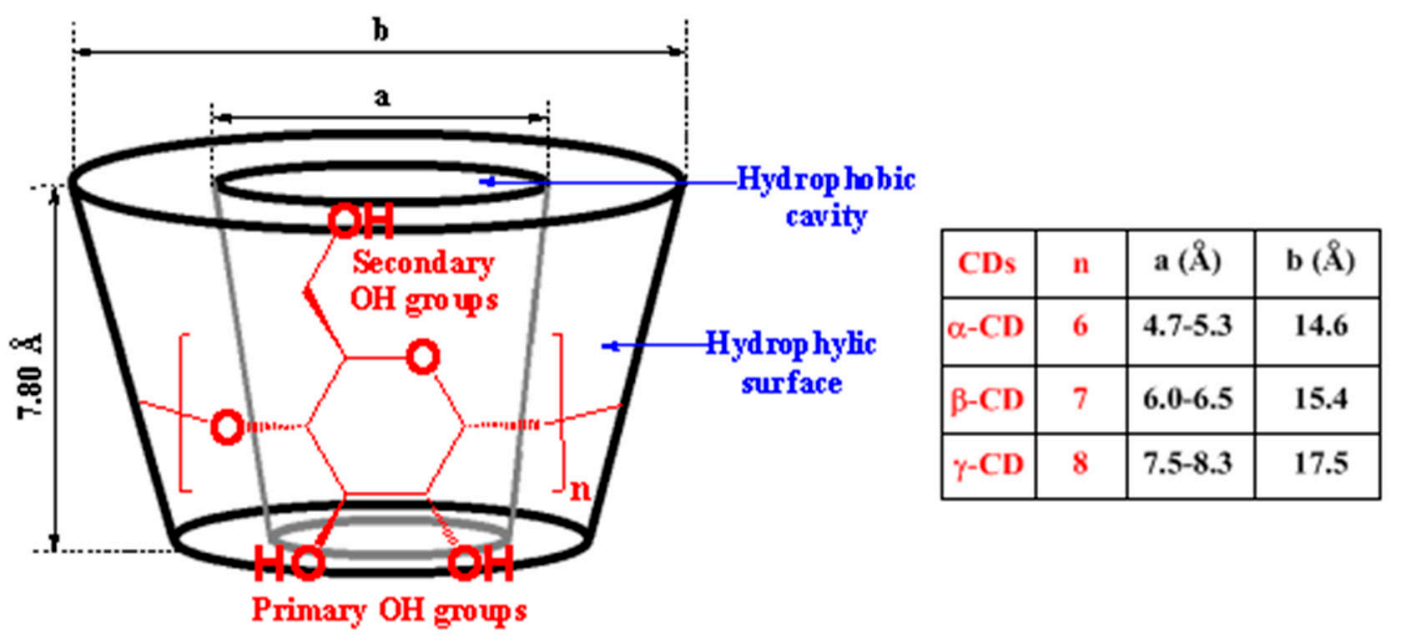

Figure 3. Chemical structure of natural $\alpha, \beta$, and $\gamma$-cyclodextrins.

The discovery of CD by Villiers was made in 1891 from the fermentation of potato starch by the butyric ferment Bacillus amylobacter, and the story of CDs is well-documented [66-68]. It was not until the 1980s that the first CD applications in the pharmaceutical and food industries would appear thanks to the possible industrial-scale production of the three natural CDs, making CDs commercially available at a reasonable price. From the 1980s to date, CDs (especially $\beta-C D$ ) are found applications in various industrial sectors [69-73] such as medicine [74], pharmacy [62,75-77], food [78-81], cosmetics [82], chromatography [83-88], catalysis [89-91], biotechnology [92,93], textiles [94-96], and the environment $[97,98]$.

The use of CDs in the medicinal and pharmaceutical applications comes from, among other things, their ability to (1) encapsulate hydrophobic drugs, i.e., the formation of CD-drug inclusion complexes, and (2) formulate orodispersible tablets of poorly-soluble drugs, i.e., CDs as vehicles in tabletting. These two important factors make the drug available at the surface of the biological barrier, and thereby lead to an improvement of the water solubility, stability, bioavailability, release, and under certain conditions, permeability of the drug. In addition to these natural CDs, researchers also developed derived CDs by the modification and polymerization of natural CDs with the aim of improving biopharmaceutical and physicochemical drug properties, and the complexation efficiency of natural CDs. An overview of natural and derived CDs and their characteristics (water solubility and molecular weight) is listed in Table 3.

Table 3. Overview of natural and derived cyclodextrins (CDs).

\begin{tabular}{|c|c|c|}
\hline Type of CD & Water Solubility $(\mathrm{mg} / \mathrm{mL})$ & Molecular Weight (Da) \\
\hline \multicolumn{3}{|l|}{ Natural CDs } \\
\hline$\alpha-C D$ & 145 & 972 \\
\hline$\beta-C D$ & 18.5 & 1135 \\
\hline$\gamma-\mathrm{CD}$ & 232 & 1297 \\
\hline \multicolumn{3}{|l|}{ Chemically modified CDs } \\
\hline $\mathrm{HP}-\beta-\mathrm{CD}^{1}$ & $\geq 600$ & 1400 \\
\hline SBE- $\beta-\mathrm{CD}^{2}$ & $\geq 500$ & 2163 \\
\hline $\mathrm{RM}-\beta-\mathrm{CD}^{3}$ & $\geq 500$ & 1312 \\
\hline $\mathrm{HP}-\gamma-\mathrm{CD}^{4}$ & $\geq 500$ & 1576 \\
\hline \multicolumn{3}{|l|}{ Polymerized CDs } \\
\hline ECH- $\beta-\mathrm{CD}^{5}$ & $>500$ & $1.12 \times 10^{5}$ \\
\hline $\mathrm{ECH}-\mathrm{CM}-\beta-\mathrm{CD}^{6}$ & $>250$ & $2 \times 10^{6}-15 \times 10^{6}$ \\
\hline
\end{tabular}

\footnotetext{
${ }^{1}$ Hydroxypropyl- $\beta$-cyclodextrin. ${ }^{2}$ Sulfobutyl ether- $\beta$-cyclodextrin. ${ }^{3}$ Randomly methylated- $\beta$-cyclodextrin. ${ }^{4}$ Hydroxypropyl- $\gamma$-cyclodextrin. ${ }^{5}$ Epichlorohydrin cross-linked $\beta$-cyclodextrin polymers. ${ }^{6}$ Epichlorohydrin cross-linked carboxymethyl- $\beta$-cyclodextrin polymers.
} 
As stated above, one main interest of CDs both in research and applications stem from CDs (hosts) being able to selectively and reversibility form host-guest inclusion complexes with a large variety of guest molecules in aqueous solutions [99-104]. The host-guest inclusion complex formation is based on the insertion (encapsulation) of the guest molecule into the internal cavity of $C D$, which is driven by the release of enthalpy-rich water molecules from the CD's cavity, the release of conformational strain, and the establishment of several interactions between the guest molecule and $C D$ via hydrogen bonds, van der Waals forces, electrostatic interactions, hydrophobic interactions, and charge-transfer interactions. The ability of CDs to form reversible host-guest inclusion complexes was first described by Cramer in the early 1950s [105], and is governed by two key factors: the steric effect, and the thermodynamic interactions between the size/shape of the CD's cavity and the guest molecule. Depending on the structure and properties of the drug (guest molecule), different host-guest inclusion complexes and stoichiometry can be obtained (Figure 4). The host-guest complexes provide refuge and protection for guest molecules in the biological environment, leading to an enhancement in the water solubility, stability, and bioavailability of the guest molecules.



1:1 Inclusion complex
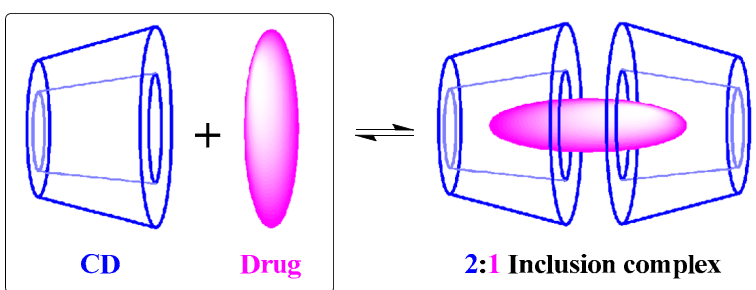

2:1 Inclusion complex

Figure 4. Two examples of stoichiometry adopted by CD-drug inclusion complexes.

\section{Cyclodextrins for Anticancer Photodynamic Therapy}

\subsection{General}

CDs made their appearance in the field of cancer treatment in the 1990s. The use of natural and derived CDs as drug delivery carriers for various poorly water-soluble chemotherapeutic cytotoxic anticancer drugs was recently discussed in an exhaustive review [106].

Concerning CDs in anticancer PDT treatment, the first results of these researches were introduced in 1992 by Morgan et al. during the 6th International Cyclodextrin Symposium held in Chicago [107], and aimed to use $\gamma-\mathrm{CD}$ and $\mathrm{HP}-\gamma-\mathrm{CD}$ as solubilizing agents instead of Chremophore to improve in vivo the solubility and concentration efficiency of the synthetic PS, tin etiopurpurin, in the tumor cells.

This review focuses only on the use of CDs to improve the in vitro or/and in vivo biological effect of PSs in anticancer PDT treatment without including the addition of active targeting ligands.

\subsection{Cyclodextrin-Photosensitizer Systems}

CD-PS systems can be formed by three types of binding modes of PSs with CDs. This paragraph will focus on the CD-PS system formation by non-covalent binding (CD-PS inclusion complexes, Section 2.2.1.), covalent binding (CD-PS conjugates, Section 2.2.2.), and non-specific external binding (CD-PS nanoassemblies, Section 2.2.3.)

\subsubsection{Non-Covalent Cyclodextrin-Photosensitizer Inclusion Complexes}

CDs are known as an attractive option for the PDT of cancers due to their ability to interact with a large variety of PSs, leading to the formation of non-covalent inclusion complexes. This part of the review focuses on the in vitro or/and in vitro biological effect of CD-PS inclusion complexes in anticancer PDT. However, with respect to articles involving the potential use of CD-PS inclusion complexes in anticancer PDT (without in vitro and/or in vivo biological studies), we can emphasize that several studies have estimated benefit of CD-PS inclusion complexes on 
the physicochemical properties of PSs. For porphyrinoid PSs, various studies showed that CD-PS inclusion complexes could (1) increase some of the photophysical properties of PSs (fluorescence intensity [108,109], tripling the lifetime in neutral aqueous solutions [110], ${ }^{1} \mathrm{O}_{2}$ production [111], and quantum yield [112] in aqueous solutions), (2) reduce some drawbacks of PSs (such as poor water solubility [113], self-aggregation [111,114], protonation of pyrrole nitrogens [110], metalation [110], thermal degradation [115]), and (3) enhance drug delivery [110,115] and lipid membrane penetration [116]. Similar results were also obtained for non-porphyrinoids PSs, i.e., the improvement of photophysical properties (fluorescence lifetime, emission, and quantum yield) [117], drug delivery [117,118], and photostability [119]. The studies that have presented an in vitro or/and in vivo biological anticancer PDT evaluation of CD-PS inclusion complexes are summarized below.

\section{- $\quad$ Porphyrinoid Photosensitizers}

Generally, host-guest inclusion complexes between CDs and porphyrinoid PSs are formed by encapsulating the "aryl" substituent portion of the PS into the fairly large cavity of CD. Across all three natural types of $\mathrm{CD}, \alpha-\mathrm{CD}$ does not allow the formation of inclusion complexes due to its small cavity, while $\beta-C D$ and $\gamma-C D$ can generate inclusion complexes typically through the primary face of the $\beta$-CD cavity and the secondary face of the $\gamma$-CD (Figure 5). Different CD-PS inclusion complexes' stoichiometry can be obtained, but 1:1 and 2:1 stoichiometries are the most common.
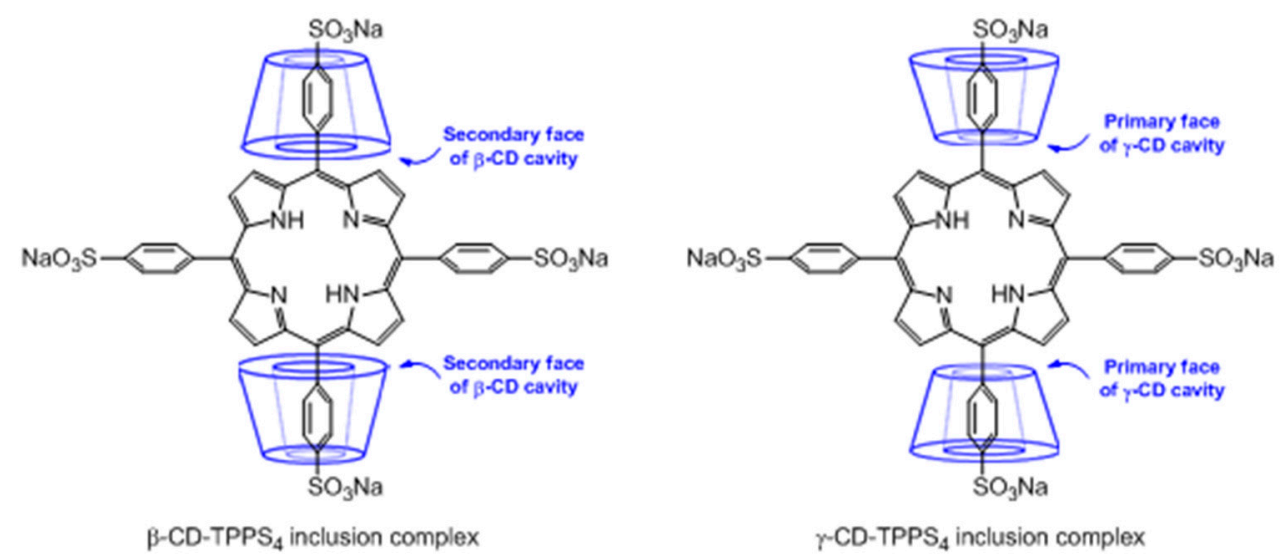

Figure 5. Two examples of typical geometry adopted by CD-PS inclusion complexes between $\beta-C D$ and $\gamma$-CD with a porphyrinoid PS (meso-tetrakis(4-sulfonatophenyl)porphyrin, $\mathrm{TPPS}_{4}$ ). Adapted from Ribó; Farrera; Valero; Virgili [114].

In 2003, Kolàrovà et al. [120] studied the in vitro phototoxicity of two PSs models: meso-tetrakis(4-sulphonatophenyl)porphyrin $\left(\mathrm{TPPS}_{4}\right)$ and its zinc metallocomplex $\left(\mathrm{ZnTPPS}_{4}\right)$ on G361 human melanoma cells in the presence and absence of 2-hydroxypropyl- $\beta$-cyclodextrin (HP- $\beta$-CD). Based on the biological studies performed on G361 human melanoma cells, the inclusion complexes of each PS with HP- $\beta$-CD showed a lower cytotoxicity and higher phototoxicity compared to the PSs alone. They already found that the most effective system was the HP- $\beta-C D-Z n T P P S_{4}$ inclusion complex, since the $\mathrm{IC}_{50}$ value was $12.5 \mathrm{mg} / \mathrm{mL}$ at a light radiation dose of of $10 \mathrm{~J} / \mathrm{cm}^{2}$.

In 2005, the same team [121] investigated the influence of the HP- $\beta-C D-Z n T P P S_{4}$ inclusion complex on the in vitro phototoxic properties of $\mathrm{ZnTPPS}_{4}$ using the same G361 human melanoma cells. According to the cellular uptake studies, the prepared HP- $\beta$-CD-ZnTPPS 4 inclusion complex showed a good penetration through the cell membrane. Indeed, the inclusion complex accumulation was dependent of PS concentration and incubation time, and the best uptake was found at $3 \mu \mathrm{M}$ of the inclusion complex after $48 \mathrm{~h}$ of incubation. The in vitro phototoxicity efficiency after $24 \mathrm{~h}$ of incubation of G361 cells with ZnTPPS $4(10 \mu \mathrm{M})$ and HP- $\beta-C D(1 \mathrm{mM})$ and under light irradiation $\left(12.5 \mathrm{~J} / \mathrm{cm}^{2}\right.$, 
$24 \mathrm{~V} / 250 \mathrm{~W}$ ) showed DNA breaks in G361 cells. The authors concluded that binding ZnTPPS 4 to HP- $\beta$-CD may improve its PDT efficiency against malign melanoma.

In 2007, Lo et al. [122] studied the supramolecular hetero-arrays of tetrapyrrole derivatives held by host-guest interactions (1:1 stoichiometric ratio). The nanostructure contained heptakis(2,3,6-tri-O-methyl)- $\beta$-cyclodextrin-conjugated silicon(IV) phthalocyanine (TMe- $\beta$-CD-Si ${ }^{\mathrm{IV}} \mathrm{Pc}$ ) complexed with the tetrasulfonated porphyrin $\left(\mathrm{TPPS}_{4}\right)$ (Figure 6).

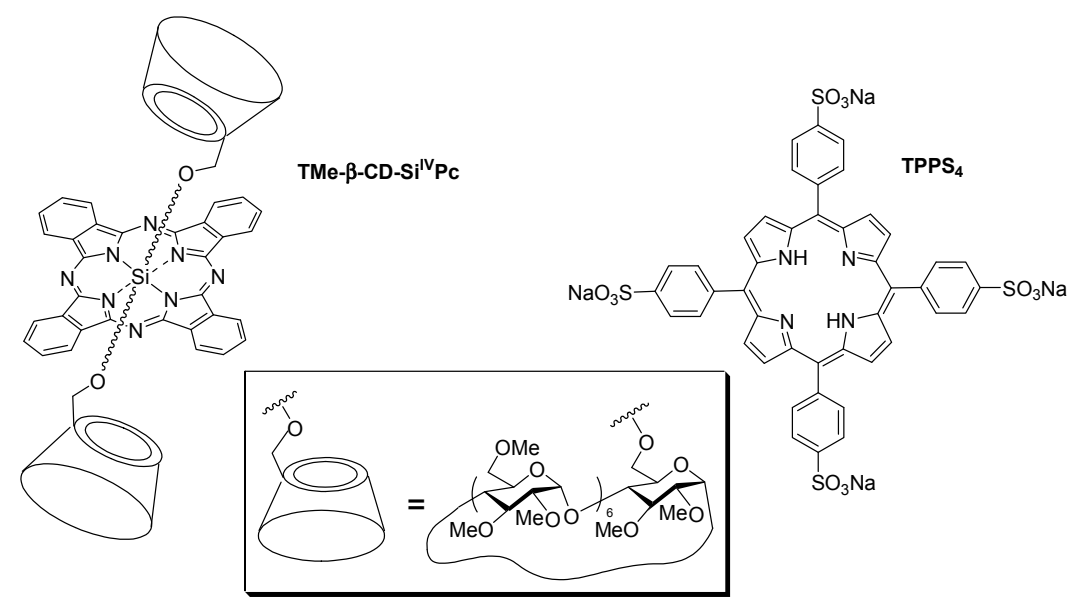

Figure 6. Schematic representation of TMe- $\beta-\mathrm{CD}-\mathrm{Si}^{\mathrm{IV}} \mathrm{Pc}$ and $\mathrm{TPPS}_{4}$. Adapted from Leng; Choi; $\mathrm{Lo} ; \mathrm{Ng}$ [122].

The authors studied briefly the in vitro PDT efficiency of TMe- $\beta-\mathrm{CD}-\mathrm{Si}^{\mathrm{IV}} \mathrm{Pc}$ and $\mathrm{TPPS}_{4}$, and the 1:1 inclusion complex on HT29 human colon adenocarcinoma cells upon illumination with a red light $\left(\lambda>610 \mathrm{~nm}\right.$, total fluence $=48 \mathrm{~J} / \mathrm{cm}^{2}$; Figure 7). They concluded that the porphyrin enhances the water solubility and facilitates the formulation of phthalocyanine through complex formation.

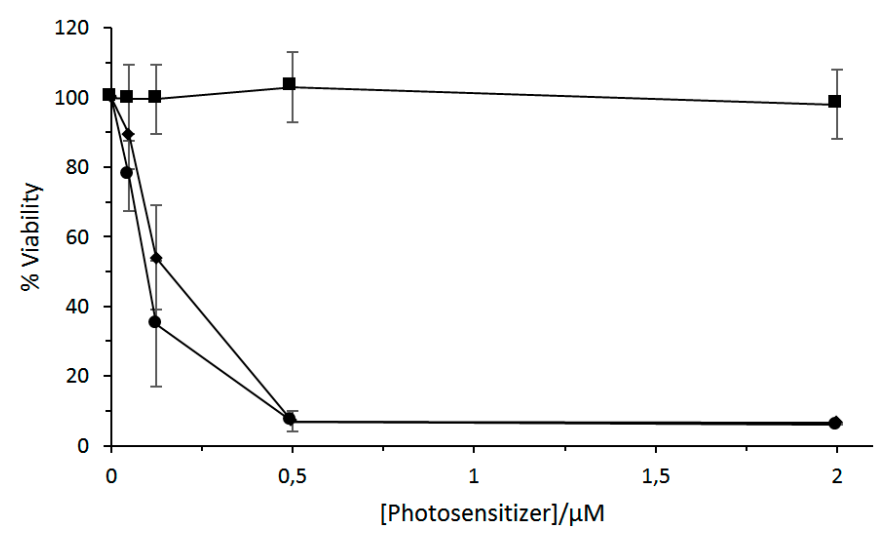

Figure 7. In vitro photocytotoxicity of $\mathrm{TMe}-\beta-\mathrm{CD}-\mathrm{Si}^{\mathrm{IV}} \mathrm{Pc}(\boldsymbol{\vee}), \mathrm{TPPS}_{4}(\boldsymbol{\square})$, and the 1:1 host-guest complex (•) against HT29 cells under red light illumination $\left(\lambda>610 \mathrm{~nm}\right.$, total fluence $\left.=48 \mathrm{~J} / \mathrm{cm}^{2}\right)$. Adapted from Leng; Choi; Lo; $\mathrm{Ng}$ [122].

In 2011, Silva et al. [123] studied a complex 2:1 of $\beta$-CD or HP- $\beta-C D$ with a chloro-aluminum phthalocyanine (ClAlPc). The photophysical properties of the inclusion complexes in deuterated ethanol showed a fluorescence quantum yield of 0.38 and 0.09 for $C l A l P c / \beta-C D$ and $C l A l P c / H P-\beta-C D$, respectively, and a ${ }^{1} \mathrm{O}_{2}$ quantum yield of 0.65 and 0.80 for ClAlPc/ $\beta-C D$ and ClAlPc/HP- $\beta-C D$, respectively; the authors concluded that the ClAlPc/Hp- $\beta-\mathrm{CD}$ inclusion complex should be the best candidate for PDT application. An in vitro study on J774 mouse macrophage tumor cells with a CIAlPc/HP- $\beta$-CD inclusion complex under various irradiation $\left(70 \mathrm{~mJ} / \mathrm{cm}^{2}, 140 \mathrm{~mJ} / \mathrm{cm}^{2}\right.$, 
and $700 \mathrm{~mJ} / \mathrm{cm}^{2}$ ) indicated a decrease of the cell viability depending on the applied dose light (Figure 8).


Figure 8. Cellular viability of J774-A1 after treatment with (a) CIAlPc/HP- $\beta-\mathrm{CD}$ and (b) CIAlPc/ $\beta-\mathrm{CD}$ complexes under various irradiation. The cells were exposed to increasing doses of light at $70 \mathrm{~mJ} / \mathrm{cm}^{2}$, $140 \mathrm{~mJ} / \mathrm{cm}^{2}$, and $700 \mathrm{~mJ} / \mathrm{cm}^{2}$ (a) $p$-values $<0.001$ and (b) $p$-values $<0.05$ in relation to the respective control. Data is expressed as means $\pm \operatorname{SD}(n=3)$. Adapted from Silva; Simioni; Tedesco [123].

In 2014, Lu et al. [124] prepared and studied a 4:1 inclusion complex of zinc phthalocyanine $(\mathrm{ZnPc})$ with HP- $\beta-\mathrm{CD}\left((\mathrm{HP}-\beta-\mathrm{CD})_{4}-\mathrm{ZnPc}\right)$ to improve the PDT efficiency of ZnPc by increasing the water solubility and decreasing the aggregation in the physiological environment of ZnPc. No obvious toxicity was observed on human cervical carcinoma (HeLa) cells at a high concentration of $80 \mu \mathrm{M}$. The inclusion complex exhibited superior ${ }^{1} \mathrm{O}_{2}$ production, intracellular $\mathrm{ROS}$ generation cellular uptake ability, and phototoxicity to cancer cells compared to free $\mathrm{ZnPc}$. The first results are presented in Figure 9.
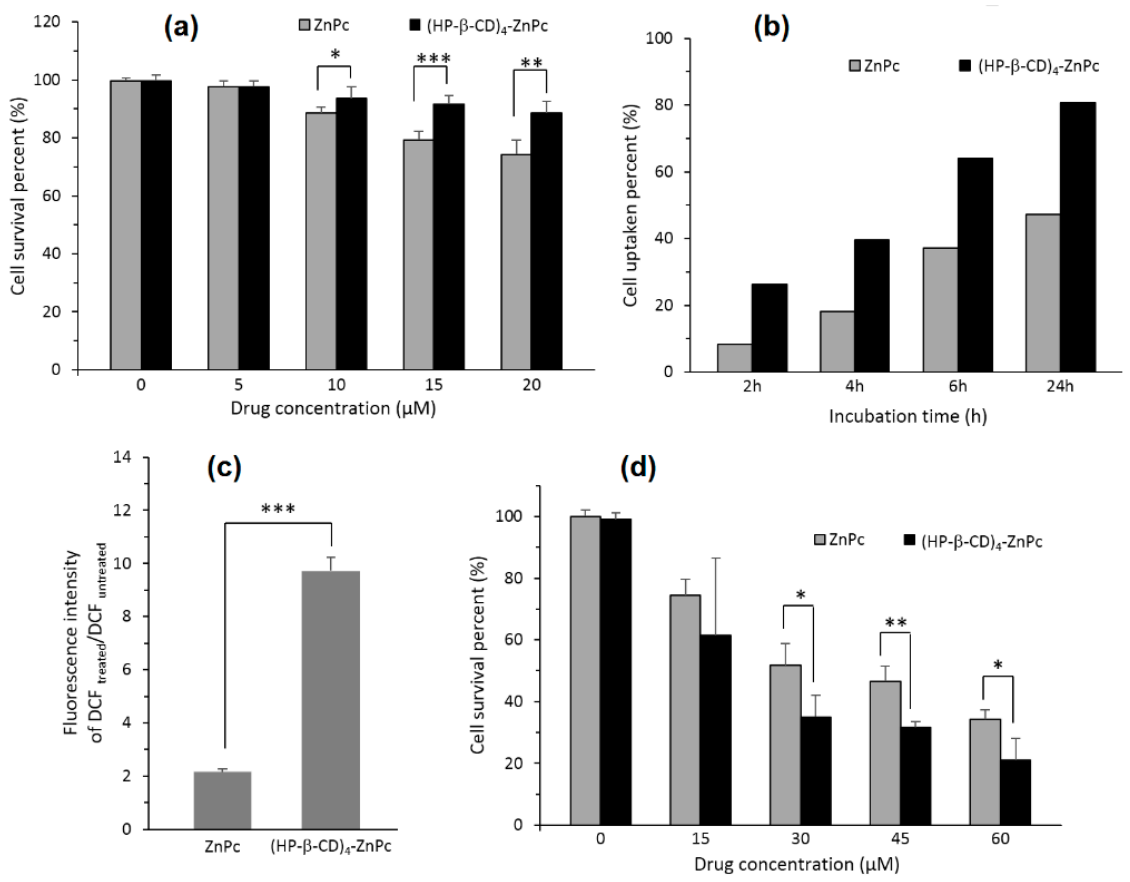

Figure 9. (a) Dark toxicity of zinc phthalocyanine $(\mathrm{ZnPc})$ and $(\mathrm{HP}-\beta-\mathrm{CD})_{4}-\mathrm{ZnPc}$ (drug concentration was calculated by ZnPc. ${ }^{*} p<0.05,{ }^{* *} p<0.01,{ }^{* * *} p<0.001 \mathrm{ZnPc}$ vs. (HP- $\left.\beta-\mathrm{CD}\right)_{4}-\mathrm{ZnPc}$ ). (b) Human cervical carcinoma (HeLa) cellular uptake of $\mathrm{ZnPc}$ and $(\mathrm{HP}-\beta-\mathrm{CD})_{4}-\mathrm{ZnPc}\left([\mathrm{ZnPc}]=\left[(\mathrm{HP}-\beta-\mathrm{CD})_{4}-\mathrm{ZnPc}\right]=5 \mu \mathrm{M}\right)$. (c) In vitro ROS production induced by $\mathrm{ZnPc}$ and $(\mathrm{HP}-\beta-\mathrm{CD})_{4}-\mathrm{ZnPc}\left([\mathrm{ZnPc}]=\left[(\mathrm{HP}-\beta-\mathrm{CD})_{4}-\mathrm{ZnPc}\right]=5 \mu \mathrm{M}\right.$, irradiation time $=5 \mathrm{~min},{ }^{* * *} p<0.001 \mathrm{ZnPc}$ vs. $\left.(\mathrm{HP}-\beta-\mathrm{CD})_{4}-\mathrm{ZnPc}\right)$. (d) Light toxicity of $\mathrm{ZnPc}$ and $(\mathrm{HP}-\beta-\mathrm{CD})_{4}-\mathrm{ZnPc}$ with different drug doses and $5 \mathrm{~min}$ irradiation $\left({ }^{*} p<0.05,{ }^{* *} p<0.01, \mathrm{ZnPc}\right.$ vs. $\left.(\mathrm{HP}-\beta-\mathrm{CD})_{4}-\mathrm{ZnPc}\right)$. Adapted from Lu; Ma; Xuan; Wang; Zhao; Li; Zhou; Lin; Zhou; Wei [124]. 
Two years later, the same group [125] studied the influence of the size of CD and synthesized 4:1 inclusion complexes: $(\alpha-C D)_{4}-Z n P c,(\beta-C D)_{4}-Z n P c$, and $(\gamma-C D)_{4}-Z n P c$. Based on extracellular ${ }^{1} \mathrm{O}_{2}$ generation ability studies, $(\beta-C D)_{4}-\mathrm{ZnPc}$ appeared to be the best generator of ${ }^{1} \mathrm{O}_{2}$. The cellular uptake of the inclusion complexes was increased when compared with free ZnPc and particularly with $(\beta-C D)_{4}-Z n P c$. They also compared the PDT efficiency of these different compounds using Hela cells, and Figure 10 shows the better in vitro PDT efficiency of the inclusion complexes compared to free $\mathrm{ZnPc}$.
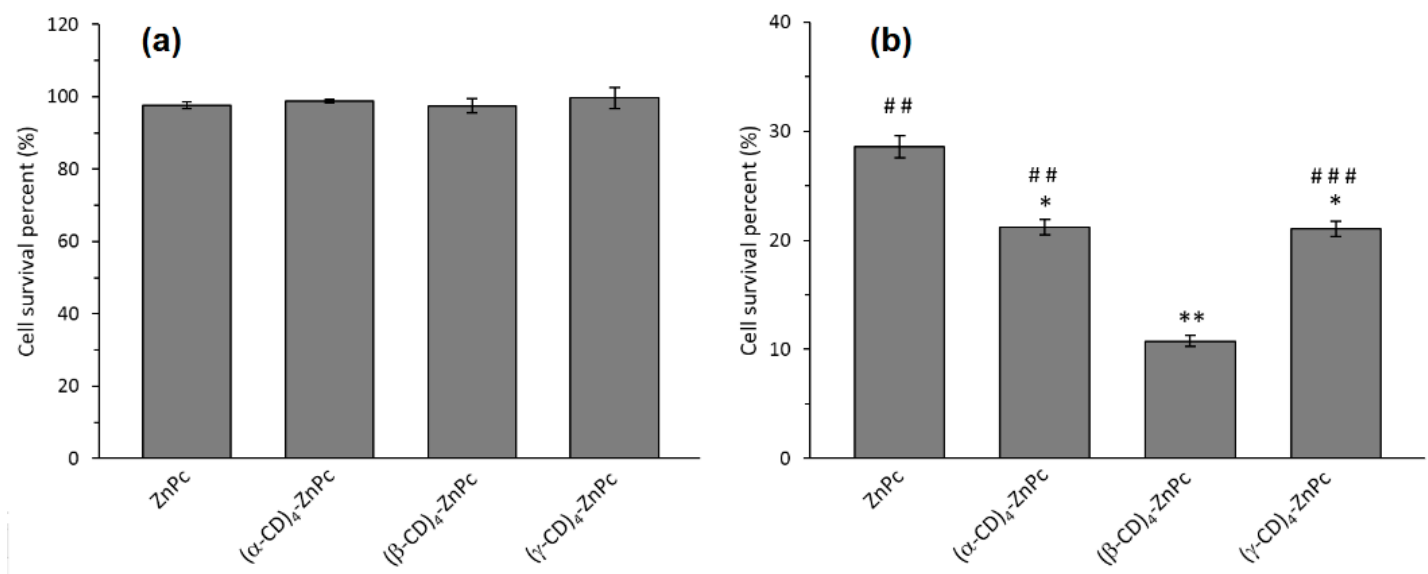

Figure 10. (a) Dark toxicity and (b) light toxicity of $\mathrm{ZnPc},(\alpha-\mathrm{CD})_{4}-\mathrm{ZnPc},(\beta-\mathrm{CD})_{4}-\mathrm{ZnPc}$, and $(\gamma-C D)_{4}-Z n P c$ on Hela cells. For dark toxicity study, the cells were incubated for $24 \mathrm{~h}$, and their survival percent were studied by 3-(4,5-dimethylthiazol-2-yl)-2,5-diphenyl tetrazolium bromide (MTT) assay. For light toxicity study, after $4 \mathrm{~h}$ of incubation by drugs (drug concentration was $5 \mu \mathrm{M}$, which was calculated by $\mathrm{ZnPc}$ ), the cells were irradiated using $665 \mathrm{~nm}$ LED for $5 \mathrm{~min}$, and then laid back into an incubator for $24 \mathrm{~h}$ before cell viability measurement by MTT assay $\left({ }^{*} p<0.05,{ }^{* *} p<0.01\right.$, host-guest complex vs. ZnPc. ${ }^{\# \#} p<0.01,{ }^{\# \# \#} p<0.001 \mathrm{ZnPc},(\alpha-\mathrm{CD})_{4}$-ZnPc, and $(\gamma-\mathrm{CD})_{4}-\mathrm{ZnPc}$ vs. $\left.(\beta-\mathrm{CD})_{4}-\mathrm{ZnPc}\right)$. Adapted from Lu; Wang; Ma; Xuan; Zhao; Li; Zhou; Zhou; Wei [125].

In 2015, Paul and his coworker [126] described the incorporation of chlorin e6 (Ce6) into the HP- $\beta-C D$ cavity, and a 1:1 stoichiometric ratio was found. The authors showed that the complexation of $\mathrm{Ce} 6$ with HP- $\beta$-CD enhanced the Ce6 solubility, decreased its aggregation in water, and enhanced its ${ }^{1} \mathrm{O}_{2}$ yield at the $\mathrm{pH}$ tumor environment compared to the free Ce6. However, the in vitro cellular uptake of the Ce6-HP- $\beta$-CD inclusion complex performed on human oral squamous carcinoma (OSC) indicated that Ce6-HP- $\beta$-CD with a higher HP- $\beta-C D$ concentration decreased their cellular uptake due to the higher viscosity of the microenvironment in the presence of a significant amount of HP- $\beta-C D$. Finally, the in vitro phototoxicity studies of the Ce6-HP- $\beta-C D$ inclusion complex (Ce6:HP- $\beta-C D=1: 25$, $\mathrm{pH} 6.2,30 \mathrm{~mW} / \mathrm{cm}^{2}$ for $5 \mathrm{~min}$ ) were performed on the OSC cells. The obtained results highlighted the important role of HP- $\beta-C D$ in affecting the phototoxicity and PDT efficiency of Ce6 against tumors (Figure 11). The authors concluded that CDs derivatives of larger size such HP- $\beta-C D$ could be a successful formulation excipient to deliver monomeric Ce6 with improved PDT efficiency.

Recently, Yankovsky et al. [127] studied the effect of two $\beta$-CDs derivatives, i.e., methyl- $\beta$-cyclodextrin $(\mathrm{Me}-\beta-\mathrm{CD})$ and $\mathrm{HP}-\beta-\mathrm{CD}$, at a wide range of concentrations on the in vitro and in vivo distribution of meta-tetra(hydroxyphenyl)chlorin (mTHPC). The authors found that the association of mTHPC with the $\beta$-CDs prevents its aggregation after introduction into blood, and enhanced its diffusion movement between biological structures. In addition, they demonstrated that the mTHPC distribution in blood serum and its accumulation in cellular culture medium were highly dependent on the $\beta$-CDs concentrations (maximal mTHPC accumulation at $10 \mu \mathrm{M}$ of Me- $\beta$-CD and $200 \mu \mathrm{M}$ of HP- $\beta-C D$ ) (Figure 12a). Furthermore, photosensitization studies showed that the addition of $\beta$-CDs affect the intracellular distribution of mTHPC and enhance its photocytotoxicity effect 
toward HT29 human adenocarcinoma cultured cells inclusion complexes (Me- $\beta-C D$ LD $50: 70 \mathrm{~mJ} / \mathrm{cm}^{2}$ and $14 \mathrm{~mJ} / \mathrm{cm}^{2}$ at $3 \mathrm{~h}$ and $24 \mathrm{~h}$, and in the case of HP- $\beta-C D 27 \mathrm{~mJ} / \mathrm{cm}^{2}$ and $8 \mathrm{~mJ} / \mathrm{cm}^{2}$ ) (Figure 12a). Finally, the in vivo fluorescence kinetics studies and fluorescent imaging of the mTHPC distribution in different tissues (Figure 12b) confirm that the use of $\beta$-CDs modifies the mTHPC distribution process in tumor-bearing animals with a decreased level of MTHPC in skin and muscles, and an increased mTHPC accumulation in tumor were observed.
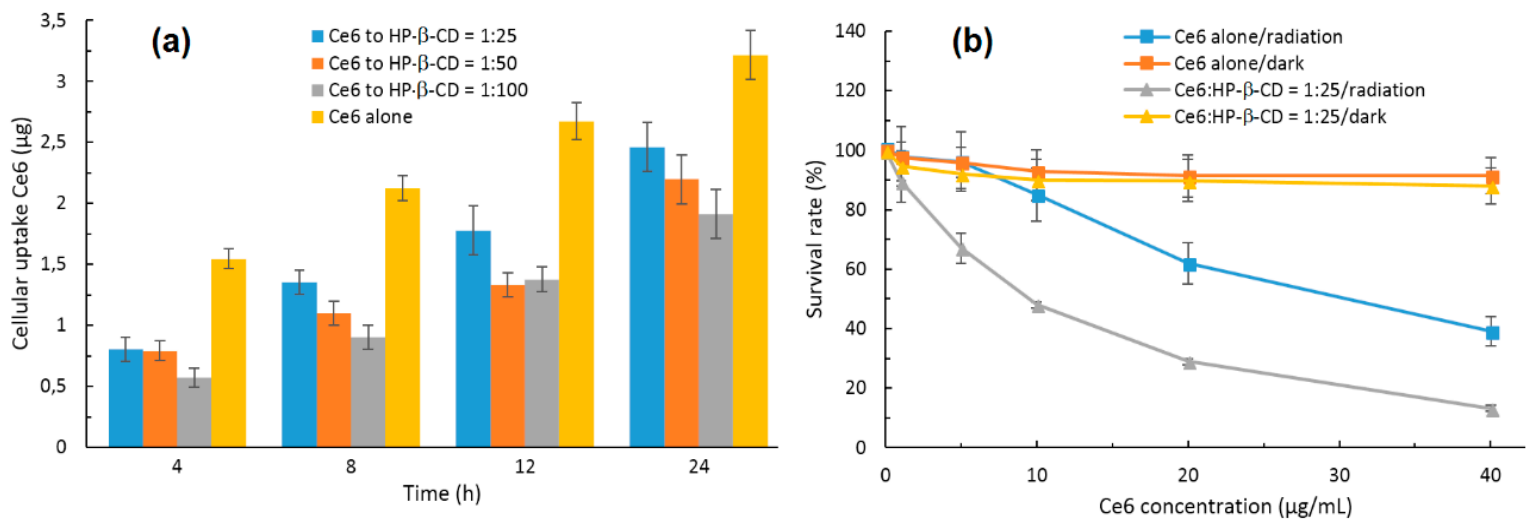

Figure 11. (a) In vitro cellular uptake of the Ce6-HP- $\beta-C D$ inclusion complex by oral squamous carcinoma (OSC) cells for different Ce6 to HP- $\beta$-CD ratios and (b) phototoxicity of optimized inclusion complex and control formulations against OSC cells. Adapted from Paul; Heng; Chan [126].
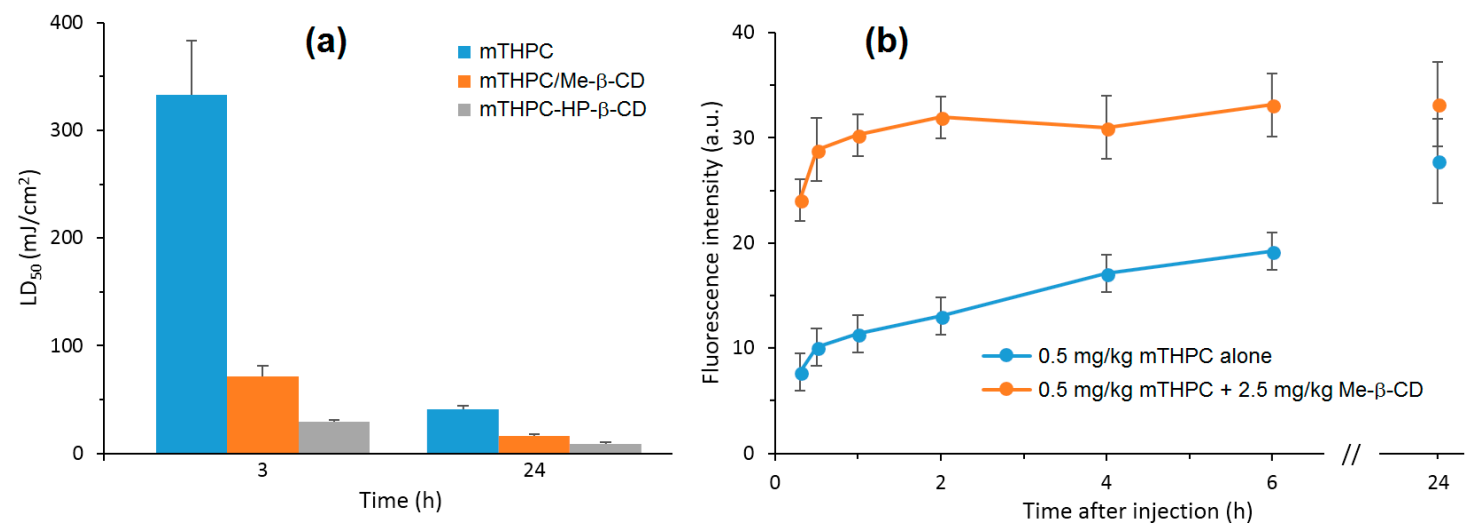

Figure 12. (a) Influence of $10 \mu \mathrm{M}$ methyl- $\beta$-cyclodextrin (Me- $\beta-\mathrm{CD}$ ) and $200 \mu \mathrm{M} \mathrm{HP}-\beta-\mathrm{CD}$ on the photosensitivity of HT29 cells incubated in the presence of $1.47 \mu \mathrm{M}$ meta-tetra(hydroxyphenyl)chlorin (mTHPC) over $3 \mathrm{~h}$ and $24 \mathrm{~h}$. $\mathrm{LD}_{50}$ was determined in three independent experiments and expressed as the mean with the vertical bar showing SD. (b) Kinetics of in vivo fluorescence $\left(\lambda_{\text {exc }}=405 \mathrm{~nm}\right.$, $\lambda_{\mathrm{em}}=600-700 \mathrm{~nm}$ ) from the surface of the HT29 tumor grafted to NMRI ${ }^{\mathrm{nu}} / \mathrm{nu}$ mice after injection of $0.5 \mathrm{mg} / \mathrm{kg} \mathrm{mTHPC}$ alone in the tail vein or with $2.5 \mathrm{mg} / \mathrm{kg}$ Me- $\beta-\mathrm{CD}$. Results are expressed as the mean of three to four measurements with the vertical bar showing SD. Adapted from Yankovsky; Bastien; Yakavets; Khludeyev; Lassalle; Gräfe; Bezdetnaya; Zorin [127].

More recently, the same group published a work concerning the distribution and PDT efficiency of Me- $\beta-C D$ or HP- $\beta-C D$ encapsulating mTHPC on multicellular HT29 tumor spheroids [128]. The 2:1 inclusion (Me- $\beta-\mathrm{CD} / \mathrm{mTHPC}$ or HP- $\beta-\mathrm{CD} / \mathrm{mTHPC}$ ) induced showed two and three times higher mTHPC accumulation in spheroids than MTHPC alone. The authors highlighted the different distribution of the two inclusion complexes: whereas HP- $\beta-C D / m$ THPC accumulated at the spheroid periphery, Me- $\beta-\mathrm{CD} / \mathrm{mTHPC}$ penetrated deeper, with a more homogeneous distribution into the 
spheroid. At a low light dose such as $20 \mathrm{~J} / \mathrm{cm}^{2}$, the Me- $\beta-\mathrm{CD} / \mathrm{mTHPC}$ inclusion complex presented a phototoxicity that was $25 \%$ higher than mTHPC alone (Figure 13).

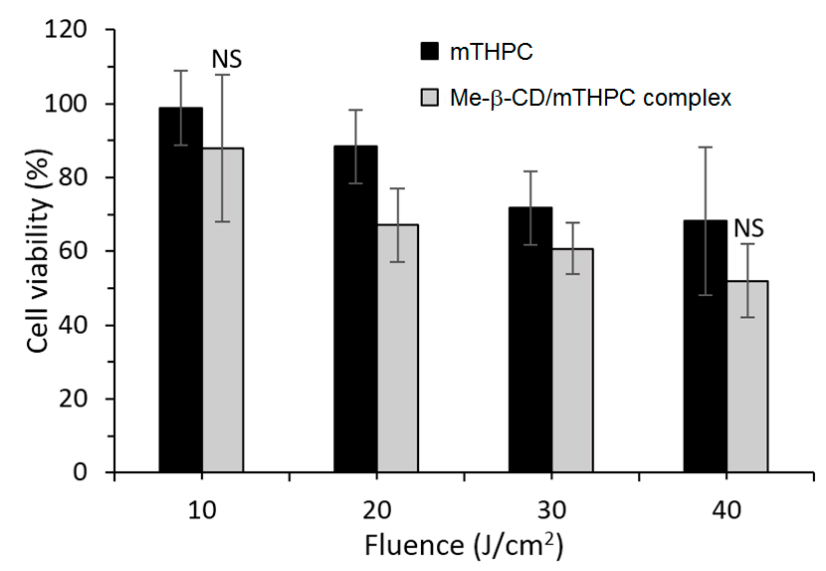

Figure 13. Cell viability of spheroids incubated $24 \mathrm{~h}$ with free mTHPC and Me- $\beta-\mathrm{CD} / \mathrm{mTHPC}$ inclusion complex. The percentage of cell survival was counted by means of clonogenic assay 15 days after PDT. mTHPC concentration was $4.5 \mu \mathrm{M}$. Statistically different from mTHPC alone treatment at the given fluence, $p<0.05$; NS: no significant differences from mTHPC alone treatment at the given fluence, $p<0.05$. Adapted from Yakavets; Yankovsky; Millard; Lamy; Lassalle; Wiehe; Zorin; Bezdetnaya [128].

In 2017, Ikeda et al. [129] described the PDT effect of 2:1 inclusion complexes 1-6 of trimethyl- $\beta$-CD (TMe- $\beta-C D$ ) with different porphyrins, as described in Figure 14.
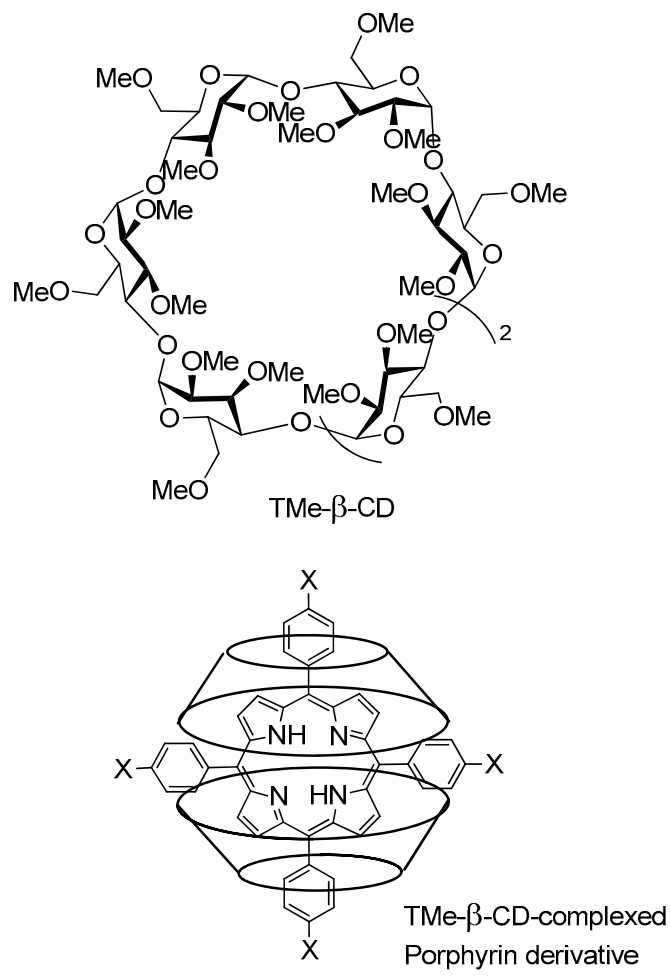
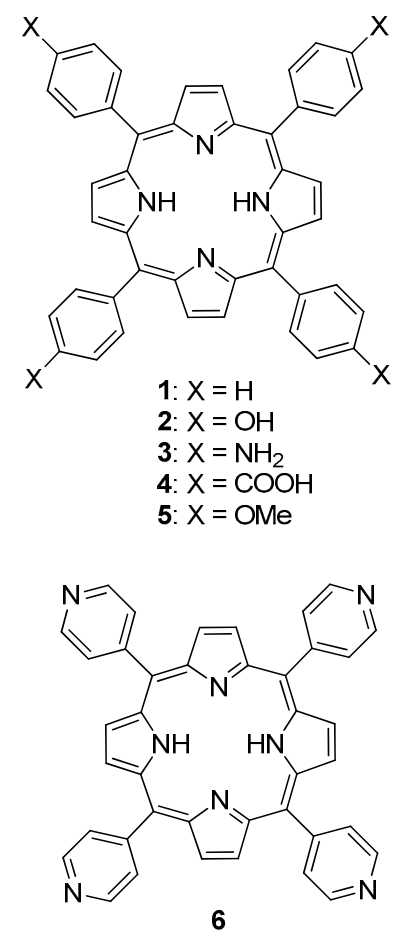

Figure 14. Chemical structure and schematic illustration of the trimethyl- $\beta-C D(T M e-\beta-C D)$ complexed with porphyrin derivatives.

For photostability reasons and ${ }^{1} \mathrm{O}_{2}$ generation ability, only $2-4$ were selected for in vitro PDT study. Inclusion complexes 1, 2, and $\mathbf{6}$ were unstable under light irradiation. Inclusion complexes 
2-4 generated ${ }^{1} \mathrm{O}_{2}$ in the order $\mathbf{3}>\mathbf{2} \approx \mathbf{4}$. PDT experiments were done with the HeLa cell line after irradiation of $610-740 \mathrm{~nm}$ for $30 \mathrm{~min}$ under $9 \mathrm{~mW} / \mathrm{cm}^{2}$ of light power. The order of PDT activity was $3>2>>4$, suggesting that the PDT effect is more due to the higher intracellular uptake of inclusion complexes $\mathbf{2}$ and $\mathbf{3}$ (endocytosis) than ${ }^{1} \mathrm{O}_{2}$ formation. The authors could check the formation of ${ }^{1} \mathrm{O}_{2}$ in Hela cells by inclusion complexes 2 and 3, which presented 14 and 26 times higher PDT activity than Photofrin ${ }^{\circledR}$.

- $\quad$ Non-Porphyrinoid photosensitizers

Many of the approved PDT PSs for clinical use are porphyrinoid derivatives. However, their usefulness in PDT can sometimes be limited by various factors such as relatively poor water solubility and photostability. As a consequence, major efforts are made to develop new non-porphyrinoid PSs [130].

In 2005, Bruzell et al. compared the PDT efficiency of different formulations of curcumin (curc) into DMSO, non-ionic micelles liposomes (LP), HP- $\beta-C D$, or alginate viscous solution [131]. PDT efficiency was evaluated by two techniques: PI/Hoechst staining and fluorescence technique, and 3-(4,5-dimethylthiazol-2-yl)-2,5-diphenyl tetrazolium bromide (MTT) assay. By MTT assay, no effect of light could be observed after $350 \mathrm{~nm}$ to $550 \mathrm{~nm}$ of light irradiation $\left(1.6 \mathrm{~J} / \mathrm{cm}^{2}\right.$ and $3.6 \mathrm{~J} / \mathrm{cm}^{2}$ per well) of HP- $\beta$-CD/curcumin inclusion complex ( $5 \%$ HP- $\beta-C D)$, whereas curcumin in HP- $\beta-C D$ increased the apoptotic SM10-12 cells by 20-40-fold compared to non-irradiated cells or irradiated cells without curcumin (Figure 15).

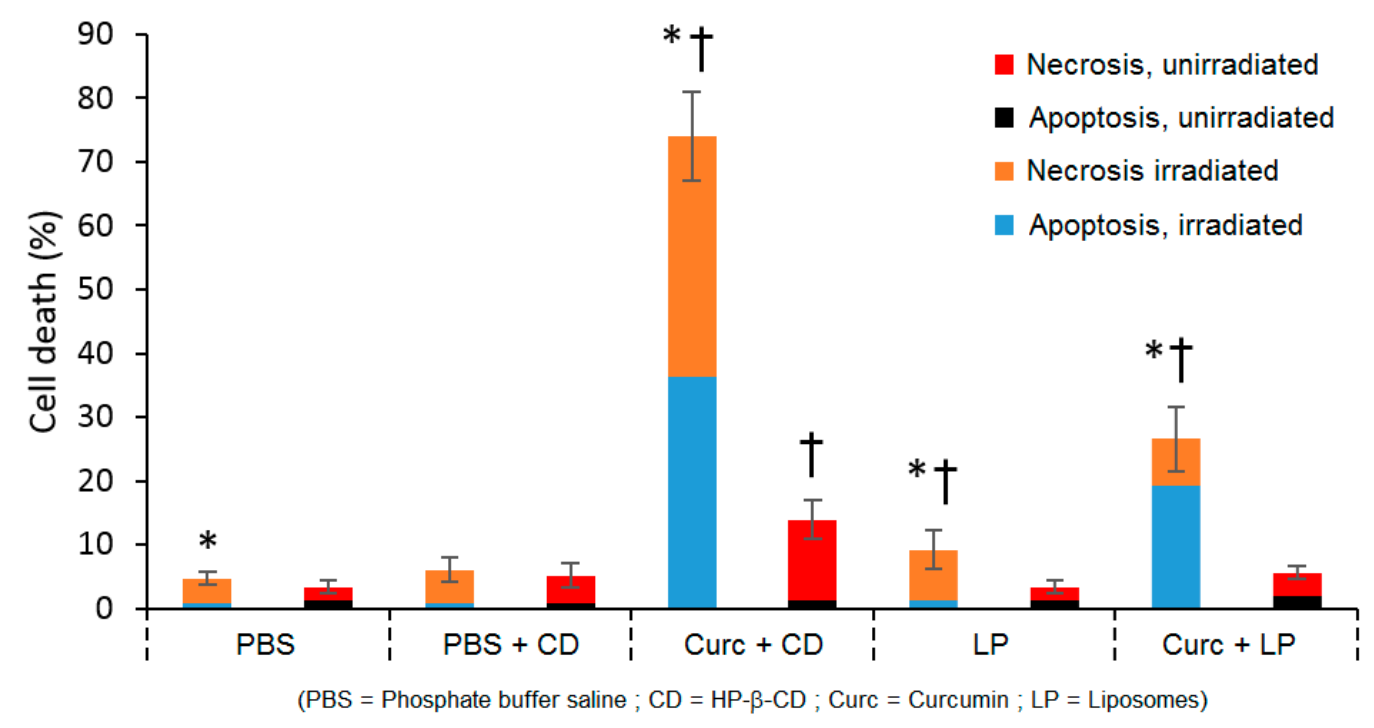

Figure 15. Cytotoxicity expressed as percentage of salivary gland acinar cells SM 10-12 cell death in terms of apoptosis and necrosis assayed by the PI/Hoechst staining and fluorescence technique. The cells were irradiated with blue light of a $6 \mathrm{~J} / \mathrm{cm}^{2}$ beam area or kept for $5 \mathrm{~min}$ in the dark in the presence of $13.5 \mu \mathrm{M}$ natural curcumin in $5 \%$ cyclodextrin (CD) or $0.4 \mu \mathrm{M}$ in $5 \mu \mathrm{g} / \mathrm{mL}$ liposomes (LP). Data are means \pm SEM $(n \geq 6)$. Significantly different from corresponding unirradiated samples (for phosphate buffered saline (PBS): necrosis only) $\left(^{*}\right)$; significantly different from irradiated vehicle in PBS and PBS only (for CD samples: also different from unirradiated vehicle) $\left({ }^{\dagger}\right) ; p \leq 0.05$. Adapted from Bruzell; Morisbak; Tonnesen [131].

As a conclusion, except for viscous alginate solution, all of the formulations were suitable for using curcumin in damaging submandibular acinar cells. The phototoxic effect can be detected at low curcumin concentration $(13.5 \mu \mathrm{M})$ with low light doses $\left(1.6 \mathrm{~J} / \mathrm{cm}^{2}\right.$ and $3.6 \mathrm{~J} / \mathrm{cm}^{2}$ per well) and a short incubation time $(3 \mathrm{~h})$. Unfortunately, the authors did not continue their study on anticancer 
PDT, and focused their efforts on antimicrobial PDT (see Valeron Bergh; Hjorth Tonnesen. [113] and references cited therein.)

The non-porphyrinoid PS Corannulene (Cora) is known to produce ROS in a controlled manner, but the use of Cora is limited because of its low water solubility. Very recently, Zhang et al. [132] designed two types of water-soluble Cora systems, i.e., methoxy poly(ethylene glycol)-corannulene (mPEG-Cora) micelle and a $\gamma$-CD/Cora inclusion complex (Figure 16).

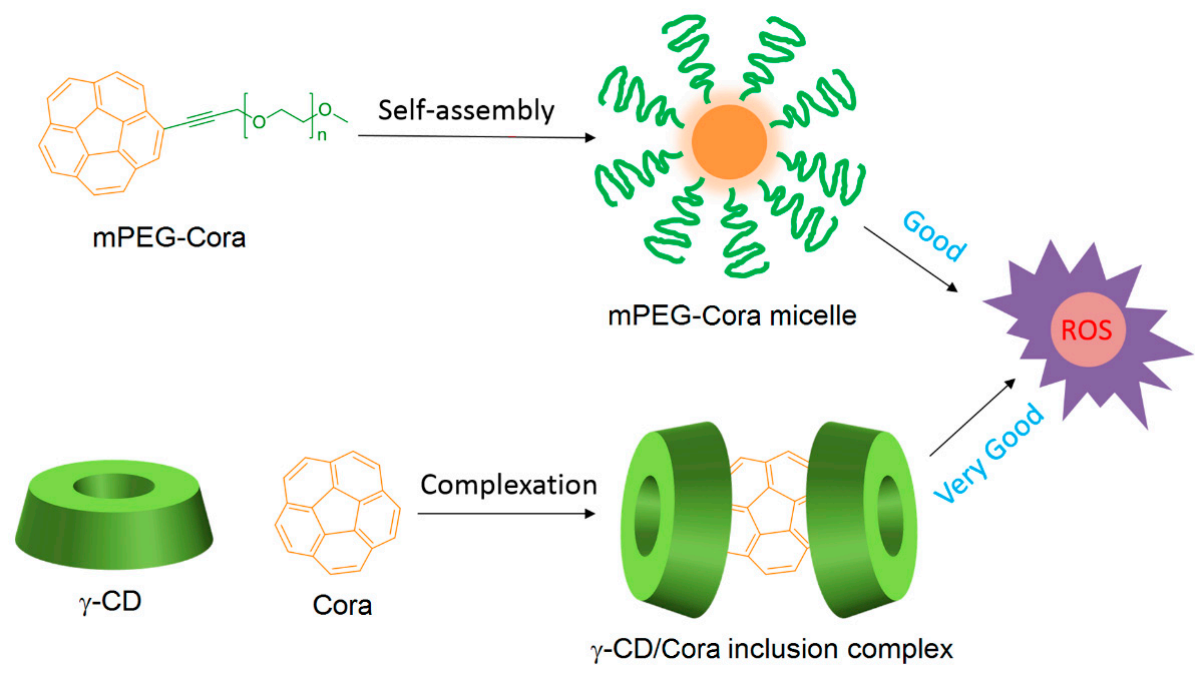

Figure 16. Two types of Corannulene (Cora) solubilization vehicles. The $\gamma$-CD/Cora inclusion complex is proposed to have a better ability for apparent ROS generation compared to the self-assembling methoxy poly(ethylene glycol)-corannulene (mPEG-Cora) micelle. Adapted from Zhang; Dong; Lu; Liu; Ding; Kong; Fan; Wang; Zhao [132].

Subsequently, the vehicle effect on the ROS production by Cora contained in mPEG-Cora and $\gamma$-CD/Cora systems at the cellular level was studied using confocal laser scanning microscopy ( $365 \mathrm{~nm}$, $95 \mathrm{~mW} / \mathrm{cm}^{2}, 20 \mathrm{~min}$ ). It was found that both systems can produce ROS, but the $\gamma-\mathrm{CD} /$ Cora inclusion complex was the most effective system.

The PDT effect (type I, $365 \mathrm{~nm}, 95 \mathrm{~mW} / \mathrm{cm}^{2}$ for $5 \mathrm{~min}, 10 \mathrm{~min}$, and $15 \mathrm{~min}$ ) of each system on PC-3 cells were studied. At the same irradiation circumstance and Cora dose, the authors found that $\gamma-\mathrm{CD} /$ Cora inclusion complex could induce a higher extent of photocytotoxicity (e.g., for $15 \mathrm{~min}$ of irradiation, $\mathrm{IC}_{50}$ of $\gamma$-CD/Cora $=9.2 \pm 4.7 \mu \mathrm{M}, \mathrm{IC}_{50}$ of m-PEG-Cora $=22.5 \pm 2.6 \mu \mathrm{M}$ ), indicating more satisfactory therapeutic outcomes (Figure 17).
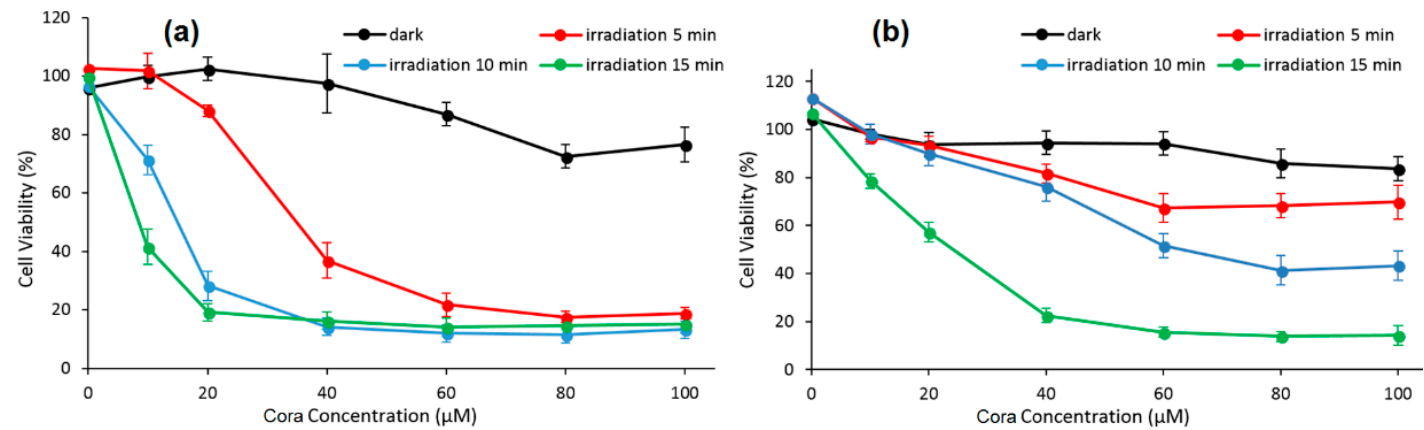

Figure 17. The dose-dependent viability of PC-3 cells in response to (a) $\gamma$-CD/Cora inclusion complex and (b) mPEG-Cora micelle in the absence or presence of light irradiation $\left(365 \mathrm{~nm}, 95 \mathrm{~mW} / \mathrm{cm}^{2}\right)$. Three irradiation times were set at $5 \mathrm{~min}, 10 \mathrm{~min}$, and $15 \mathrm{~min}(n=3)$. Adapted from Zhang; Dong; Lu; Liu; Ding; Kong; Fan; Wang; Zhao [132]. 
Finally, the vehicles' effect on the mitochondria targeting behavior of Cora was studied on PC-3 cells (365 nm, $\left.95 \mathrm{mM} / \mathrm{cm}^{2}, 20 \mathrm{~min}\right)$. It was found that the $\gamma-\mathrm{CD} / \mathrm{Cora}$ complex has shown superior ability to deliver more Cora to mitochondria compared with the m-PEG-Cora micelle. The authors concluded that the CD complexation approach prevailed over the PEGylation method for PDT applications.

\subsubsection{Cyclodextrin-Photosensitizer Conjugates}

A second possible way to improve the photophysical properties of PSs for an anticancer PDT application would be to bind the CD and PS by a covalent link, i.e., the formation of a CD-PS conjugate. This binding mode has shown its potential validity for anticancer PDT application in various studies. This part of the review focuses on the in vitro or/and in vitro biological effect of CD-PS conjugates in anticancer PDT. However, with respect to articles involving the potential use of CD-PS conjugates in anticancer PDT (without in vitro and/or in vivo biological studies), we can emphasize the use of $\mathrm{CD}$ dimers as potential carriers with a ${ }^{1} \mathrm{O}_{2}$-responsive linker that would allow either the PS release [133-135] or the PS concentration in the light beam and water solubility [136]. In addition, the conjugation of $\beta-C D$ with a PS via a non-cleavable ether bond showed an improvement of the water solubility and in vitro fluorescent intensity of PS [137]. Other CD-PS conjugates with a dithienylethene linker have an enhanced water solubility and biocompatibility of PS, while also resulting in photo-controlled ${ }^{1} \mathrm{O}_{2}$ generation in aqueous solution [138]. The studies that have presented an in vitro and/or in vivo biological anticancer PDT evaluation of CD-PS conjugates are summarized below.

- Porphyrinoid photosensitizers

In 2006, Králová et al. [139] synthesized two new perfluorinated porphyrin derivatives conjugated to one or two $\beta-C D$ units $\left(P(\beta-C D)_{1}\right.$ and $P(\beta-C D)_{2}$, as shown in Figure 18).

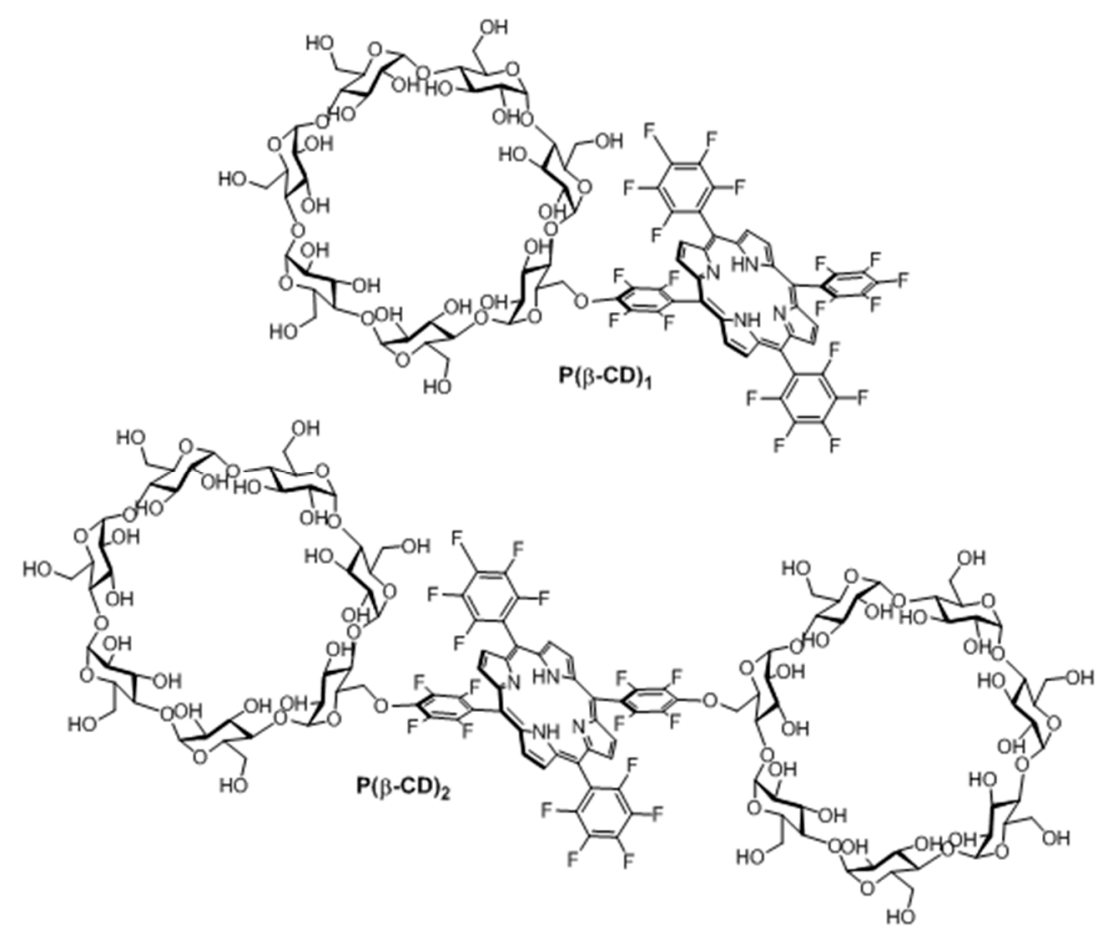

Figure 18. Chemical structure of $\mathrm{P}(\beta-C D)_{1}$ and $\mathrm{P}(\beta-C D)_{2}$.

With the aim of estimating the pharmacokinetic and photosensitizing properties of $\mathrm{P}(\beta-\mathrm{CD})_{1}$ and $\mathrm{P}(\beta-C D)_{2}$, in vitro studies were performed on different cell lines, i.e., human promyelotic leukemia 
(HL-60), mouse mammary carcinoma (4T1), mouse colon carcinoma (CT26.CL25), and human cervical carcinoma (HeLa). The phototoxicity of $\mathrm{P}(\beta-\mathrm{CD})_{1}$ and $\mathrm{P}(\beta-\mathrm{CD})_{2}$ at concentrations of $5 \mu \mathrm{M}$ and $10 \mu \mathrm{M}$ were investigated with HL-60 and 4T1 cells under irradiation at various doses of light $\left(0\right.$ to $\left.4.2 \mathrm{~J} / \mathrm{cm}^{2}\right)$. No dark cytotoxicity was detected; nevertheless, an increased cell death was seen in both cell lines when concentration and light dose increased. It was found that $P(\beta-C D)_{2}$ was less efficient compared to $\mathrm{P}(\beta-C D)_{1}$. A similar effect was observed with the other cell lines (CT26.CL25 and HeLa), along with an increase in cell death over time. Furthermore, the accumulation in the tumor is higher and faster for $\mathrm{P}(\beta-\mathrm{CD})_{2}$.

Finally, in vivo studies were realized using a 4 T1 mouse-tumor model. $P(\beta-C D)_{1}$ and $P(\beta-C D)_{2}$ were injected into mice $(5 \mathrm{mg} / \mathrm{kg})$ and then exposed to light illumination $\left(100 \mathrm{~J} / \mathrm{cm}^{2}\right)$ at various times between $0.5 \mathrm{~h}$ and $35 \mathrm{~h}$ after injection. It was found that $\mathrm{P}(\beta-C D)_{2}$ was the most efficient at totally inhibiting the tumor growth for a drug-light interval of $6 \mathrm{~h}$ (Figure 19).
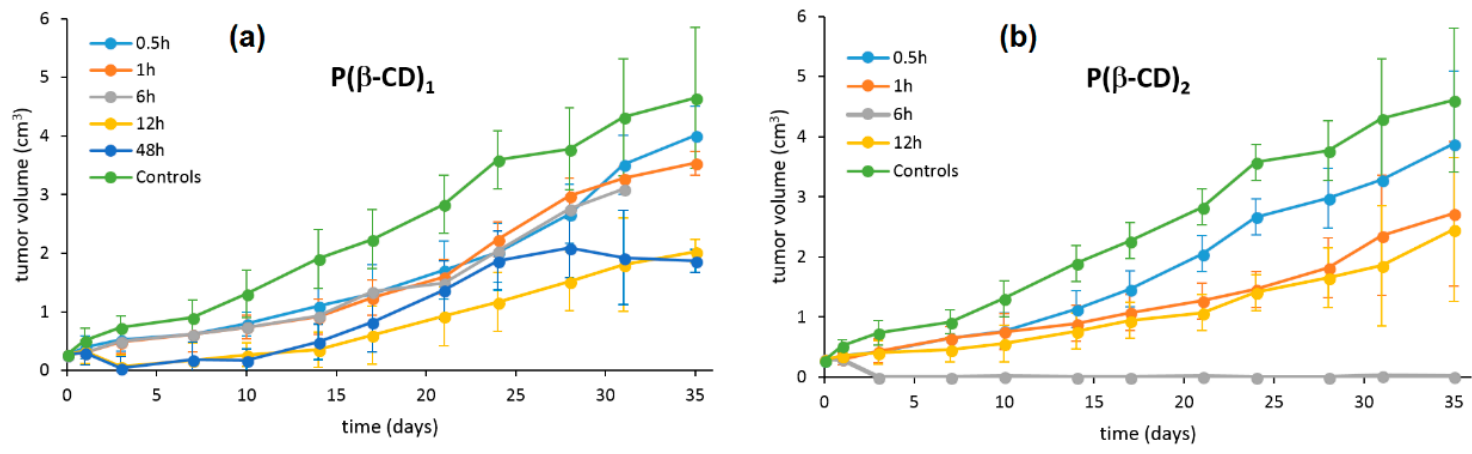

Figure 19. Effects of $(\mathbf{a}) \mathrm{P}(\beta-C D)_{1}$ - and (b) $\mathrm{P}(\beta-C D)_{2}$-mediated PDT on tumor growth. BALB/c mice bearing subcutaneously growing $4 \mathrm{~T} 1$ mammary carcinoma $(n=$ six per each group) received a single dose of the drug $(5 \mathrm{mg} / \mathrm{kg})$ and were then irradiated $\left(100 \mathrm{~J} / \mathrm{cm}^{2}, 200 \mathrm{~mW} / \mathrm{cm}^{2}\right)$ at indicated time points. The control group consisted of untreated tumor bearing mice. Adapted from Králová; Synytsya; Pouckova; Koc; Dvorak; Kral [139].

In 2010, the same team synthesized a new Lego-like system composed of perfluorinated porphyrin-CD conjugates $\left(\mathrm{P}(\mathrm{CD})_{\mathrm{x}}\right)$ and various chemotherapy drugs [140]. The perfluorinated porphyrins were first conjugated to CDs ( $\beta-C D$ or $\gamma-C D)$ by covalent ether bond (Figure 20) using the same strategy as described in their previous study [139]. The chemotherapy drugs were then encapsulated into the cavity of CDs by non-covalent bond, i.e., inclusion complexes.



$\begin{array}{llll} & \mathbf{R}_{\mathbf{1}} & \mathbf{R}_{\mathbf{2}} & \mathbf{R}_{\mathbf{3}} \\ \mathbf{P}(\beta-C D)_{1} & \mathrm{~F} & \mathrm{~F} & \beta-C D \\ \mathbf{P}(\beta-C D)_{2} & \mathrm{~F} & \beta-C D & \beta-C D \\ \mathbf{P}(\gamma-C D)_{2} & \mathrm{~F} & \gamma-C D & \gamma-C D \\ \mathbf{P}(\beta-C D)_{4} & \beta-C D & \beta-C D & \beta-C D\end{array}$

Figure 20. Chemical structure of porphyrin-CD conjugates $\left(\mathrm{P}(\mathrm{CD})_{\mathrm{x}}\right)$.

Due to the low affinity of $\mathrm{P}(\beta-C D)_{1}$ conjugate with the various chemotherapy drugs, the authors only investigated $\mathrm{P}(\beta-C D)_{2}, \mathrm{P}(\gamma-C D)_{2}$, and $\mathrm{P}(\beta-C D)_{4}$ conjugates for in vitro and in vivo studies using mouse mammary carcinoma (4T1) and human chronic myelogenous leukemia (K562) cell lines. 
The dark cytotoxicity and phototoxicity $\left(\lambda=500-520 \mathrm{~nm}, 4 \mathrm{~J} / \mathrm{cm}^{2}, 0.7 \mathrm{~mW} / \mathrm{cm}^{2}\right)$ of cells treated with chemotherapy drugs alone or their corresponding inclusion complexes with $\left(\mathrm{P}(\mathrm{CD})_{\mathrm{x}}\right.$ conjugates were compared. They found that compared to the non-irradiated cells, the irradiated ones were much efficient in cancer cell killing. Furthermore, the authors observed a synergistic effect between PDT and a large fraction of chemotherapy drugs compared to chemotherapy or PDT alone.

Finally, in vivo studies were also done in a mouse cancer model. The $P(\beta-C D)_{2}, P(\gamma-C D)_{2}$, and $\mathrm{P}(\beta-\mathrm{CD})_{4}$ conjugates or their corresponding inclusion complexes with two chemotherapy drug models (doxorubicin and paclitaxel) were injected to the mouse followed by light irradiation $\left(100 \mathrm{~J} / \mathrm{cm}^{2}\right.$, $\left.200 \mathrm{~mW} / \mathrm{cm}^{2}\right)$. The highest decrease of tumor growth was observed for inclusion complexes of $\mathrm{P}(\beta-C D)_{2}$ and $\mathrm{P}(\gamma-\mathrm{CD})_{2}$ with chemotherapy drugs (paclitaxel and doxorubicin, respectively). These results are in agreement with those of in vitro studies indicating the usefulness of the synthesized conjugates for both targeted chemotherapy drug delivery and combined cancer therapy.

One year after and being encouraged by the results obtained in the last study [140], the same team developed another "Lego"-like system based on a combination of therapeutic protein, metallo-cyclodextrin-porphyrin, and chemotherapy drugs in order to enhance the inhibition of tumor progress [141]. The authors used the previous $\mathrm{P}(\beta-\mathrm{CD})_{2}$ and $\mathrm{P}(\gamma-\mathrm{CD})_{2}$ conjugates with the encapsulation of chemotherapy drugs (paclitaxel, doxorubicin), but this time by metalating the porphyrin core with $\mathrm{Zn}$ to coordinate therapeutic proteins (Figure 21).

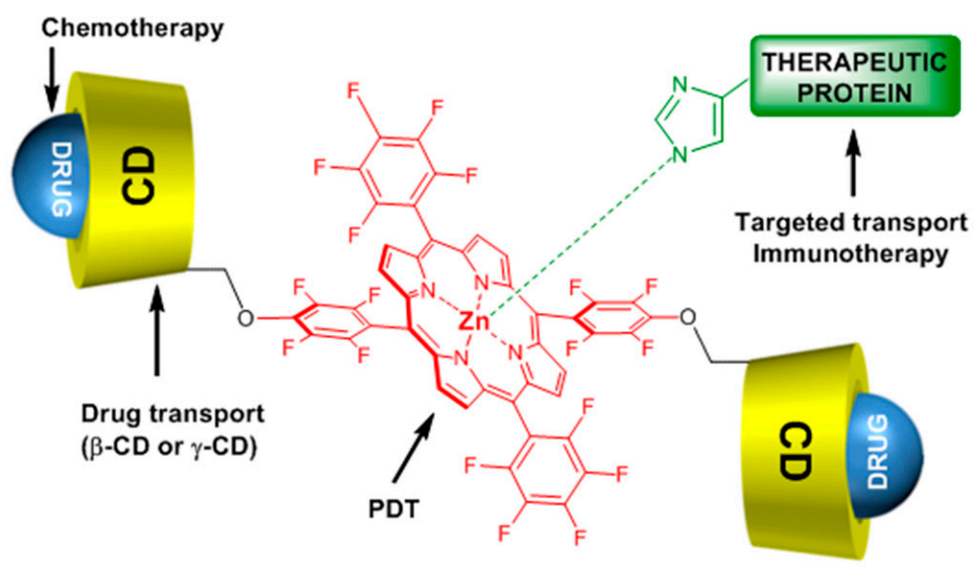

Figure 21. Schematic representation of Lego-like systems (including three parts: therapeutic protein, $\mathrm{ZnP}(\beta-\mathrm{CD})_{2}$ or $\mathrm{ZnP}(\gamma-\mathrm{CD})_{2}$ conjugates, and a chemotherapy drug) for targeted and combined therapy. Adapted from Kejik; Briza; Kralova; Pouckova; Kral; Martasek; Kral [141].

The authors prepared two types of Lego-like systems based on $\mathrm{ZnP}(\beta-\mathrm{CD})_{2} /$ paclitaxel/ endoglobulin or $\mathrm{ZnP}(\gamma-\mathrm{CD})_{2} /$ doxorubicin/endoglobulin. The effect of combined therapy with both systems on the tumor volume of human amelanotic melanoma C32 in the in vivo nude mouse was studied. They found that compared to the $\mathrm{ZnP}(\beta-C D)_{2} /$ paclitaxel/endoglobulin system, the $\mathrm{ZnP}(\gamma-\mathrm{CD})_{2} /$ doxorubicin/endoglobulin system was most efficient in the case of PDT treatment alone $\left(\lambda=500-700 \mathrm{~nm}, 100 \mathrm{~J} / \mathrm{cm}^{2}, 200 \mathrm{~mW} / \mathrm{cm}^{2}\right)$ or combined therapy. Moreover, they found that by combining $\mathrm{ZnP}(\beta-\mathrm{CD})_{2}$ or $\mathrm{ZnP}(\gamma-\mathrm{CD})_{2}$ conjugates, the chemotherapy drug and endoglobulin enhanced the tumor destruction (Figure 22).

In 2011, Ng et al. designed a new series of analogous complexes [142,143]. In the first study [142], they studied the influence of the linker's size (Figure 23) on the photophysical properties and in vitro PDT activity. 

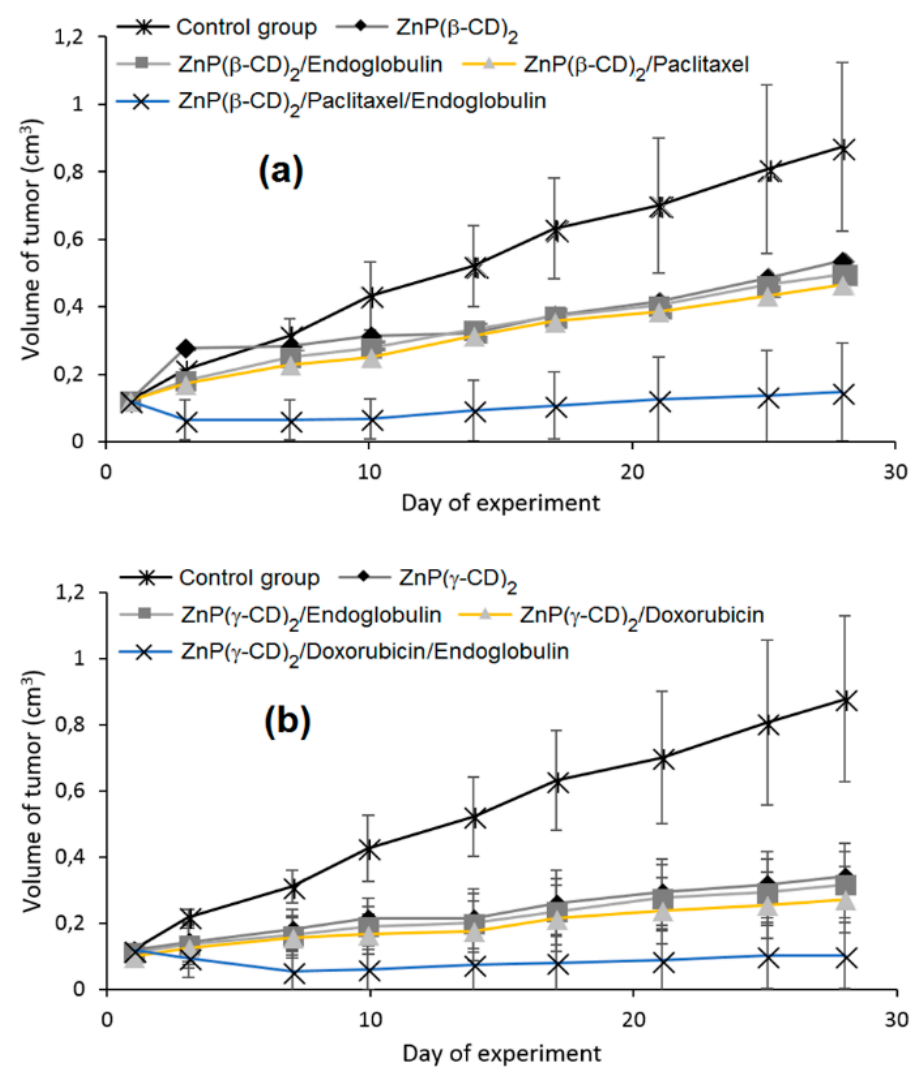

Figure 22. Effect of combined therapy with $\mathrm{ZnP}(\beta-\mathrm{CD})_{2}$ or $\mathrm{ZnP}(\gamma-\mathrm{CD})_{2}$ conjugates, chemotherapy drugs (paclitaxel or doxorubicin), and endoglobulin on the tumor volume of human amelanotic melanoma $\mathrm{C} 32$ in an in vivo nude mouse model. (a) $\mathrm{ZnP}(\beta-\mathrm{CD})_{2} /$ paclitaxel/endoglobulin or (b) $\mathrm{ZnP}(\gamma-\mathrm{CD})_{2} /$ doxorubicin/endoglobulin ( $n=6$ at each group). Adapted from Kejik; Briza; Kralova; Pouckova; Kral; Martasek; Kral [141].

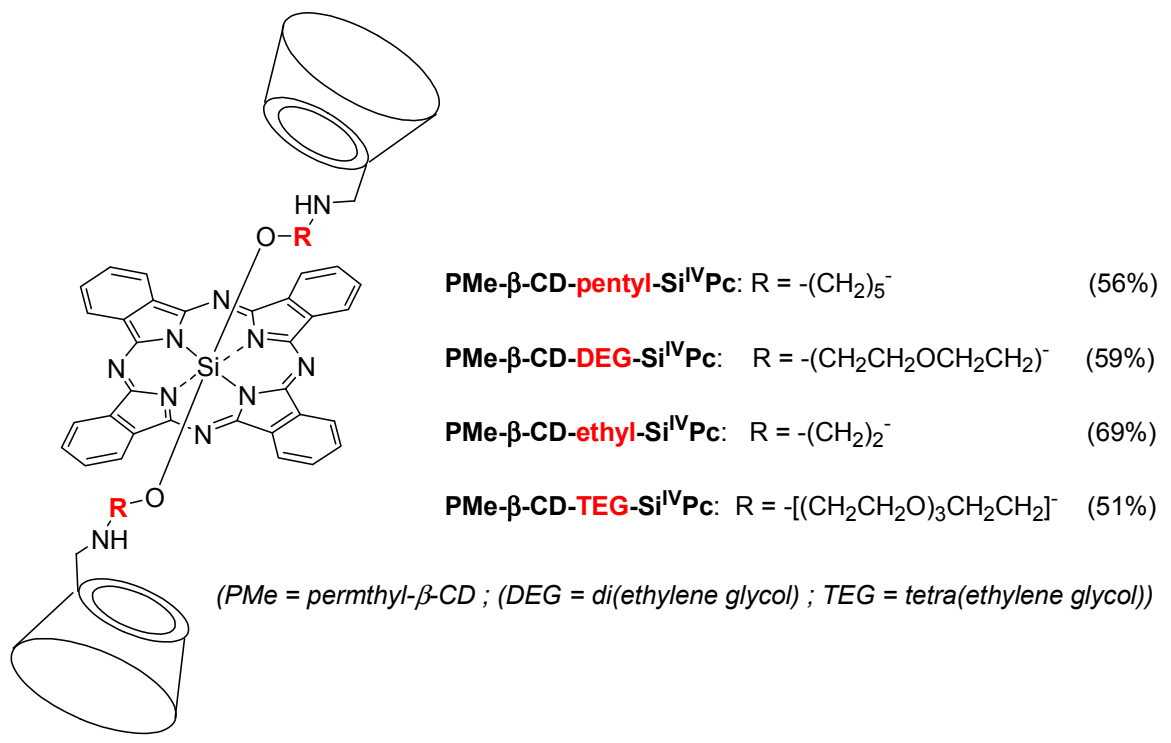

Figure 23. Chemical structure of PMe- $\beta-\mathrm{CD}-\mathrm{R}-\mathrm{Si}^{\mathrm{IV}} \mathrm{Pc}$ conjugates.

All of the conjugates, except PMe- $\beta-\mathrm{CD}$-ethyl-Si ${ }^{\mathrm{IV}} \mathrm{Pc}$ due to a photoinduced electron transfer (PET) process, have the ability to greatly enhance the water solubility of the phtalocyanine core and 
reduce its self-aggregation in water. In vitro PDT activity using human colon adenocarcinoma (HT29) and human hepatocarcinoma (HepG2) cells was evaluated and summarized in Table 4.

Table 4. $\mathrm{IC}_{50}$ value comparison of all conjugates against human colon adenocarcinoma (HT29) and human hepatocarcinoma (HepG2) cells.

\begin{tabular}{|c|c|c|}
\hline Compound & $\mathrm{IC}_{50}(\mu \mathrm{m}) \mathrm{HT} 29$ & $\mathrm{IC}_{50}(\mu \mathrm{m})$ HepG2 \\
\hline PMe- $\beta-C D-h e x y l-S i^{I V} P_{C}$ & 0.04 & 0.05 \\
\hline PMe- $\beta-C D-D E G-S i^{I V}{ }^{I C}$ & 0.16 & 0.17 \\
\hline PMe- $\beta$-CD-ethyl-Si ${ }^{\mathrm{IV}} \mathrm{Pc}$ & 0.91 & 1.32 \\
\hline PMe- $\beta-C D-T E G-S i^{I V}$ Pc & 0.14 & 0.15 \\
\hline
\end{tabular}

The PMe- $\beta$-CD-hexyl-Si ${ }^{\mathrm{IV}}$ Pc conjugate showed the best photocytotoxicity, which was explained by the difference in ROS production efficiency and cellular uptake by the lysosomes of the cells. It was shown by flow cytometry that cells in the early apoptotic state increase to $80 \%$ upon red light illumination. In vivo PDT activity was performed using nude mice with an HT29 tumor, $\mathrm{PMe}-\beta-\mathrm{CD}-\mathrm{hexyl}-\mathrm{Si}^{\mathrm{IV}} \mathrm{Pc}$, and irradiation at $675 \mathrm{~nm}\left(30 \mathrm{~J} / \mathrm{cm}^{2}\right)$. Figure 24 shows the relative tumor size for 15 days, and clearly indicates that the PMe- $\beta-\mathrm{CD}-\mathrm{hexyl-Si}{ }^{\mathrm{IV}} \mathrm{Pc}$ conjugate is a promising system for anticancer PDT.

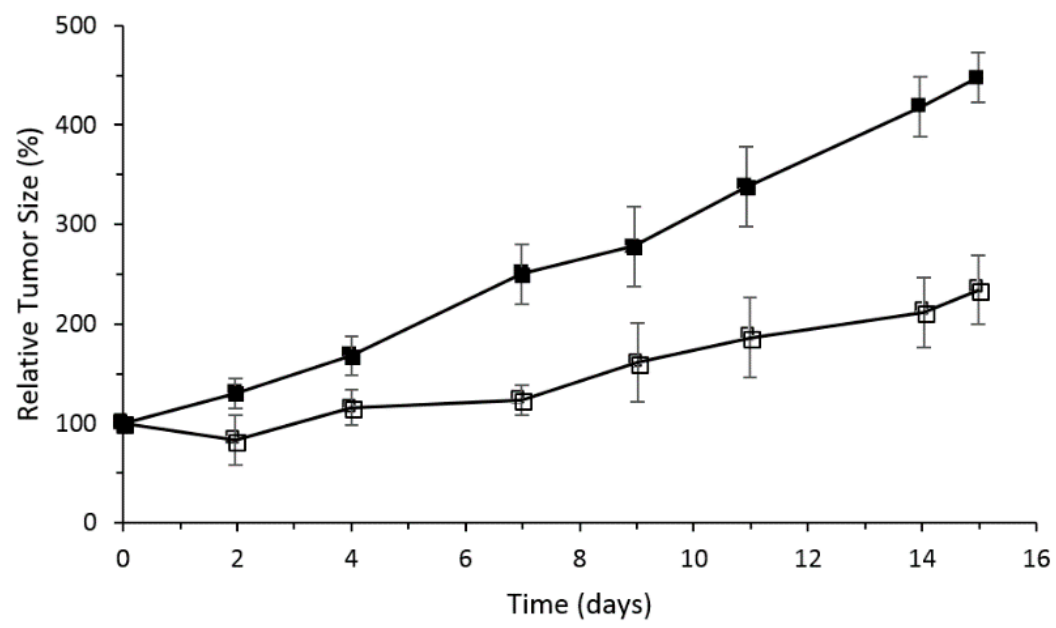

Figure 24. Tumor growth delay after PDT treatment with PMe- $\beta-\mathrm{CD}-h$ exyl-Si ${ }^{\mathrm{IV}}$ Pc under illumination $\left(\lambda=635 \mathrm{~nm}, 30 \mathrm{~J} / \mathrm{cm}^{2}\right)(\square)$ and mice kept in darkness for control ( $\left.\square\right)$. Adapted from Lau; Lo; Fong; $\mathrm{Ng}$ [142].

In their second study [143], the authors Lau; Lo; Fong; Ng reported the synthesis of unsymmetrical PMe- $\beta-C D-S i^{I V}$ Pc conjugates using Leng's procedure [122] (Figure 25). The Q-band was sharp for PMe- $\beta$-CD-hexyl-Si ${ }^{I V}$ Pc conjugates 1 and 4 , and significantly broadened for PMe- $\beta$-CD-hexyl-Si ${ }^{i V} P_{c}$ conjugates 2 and 3 , suggesting that the sugar units are less effective at reducing the aggregation.

The in vitro studies were performed on HT29 and HepG2 cells with PMe- $\beta-C D-S i^{\mathrm{IV}}$ Pc conjugates 1-4. No dark cytotoxicity was observed for all of the compounds, but high cytotoxicity upon illumination $\left(\lambda=610 \mathrm{~nm}, 40 \mathrm{~mW} / \mathrm{cm}^{2}, 48 \mathrm{~J} / \mathrm{cm}^{2}\right)$ was highlighted. It was found also that the replacement of $C D$ moieties in $\mathbf{1}$ by sugar or diamino groups enhance greatly the phototoxicity of the conjugates. The $\mathrm{IC}_{50}$ value comparison of conjugates 1-4 against HT29 and HepG2 cells are summarized in Table 5. 


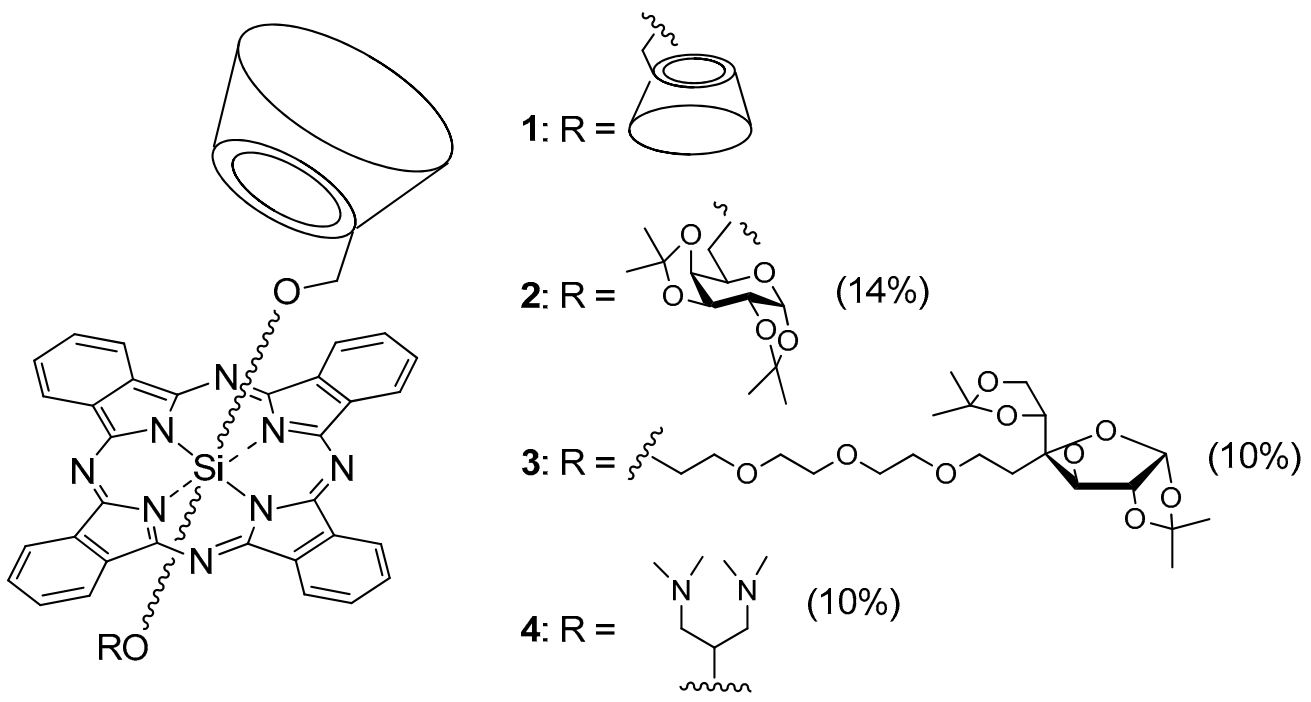

Figure 25. Chemical structure of PMe- $\beta-\mathrm{CD}-\mathrm{Si}^{\mathrm{IV}}$ Pc conjugates 1-4.

Table 5. $\mathrm{IC}_{50}$ value comparison of PMe- $\beta-\mathrm{CD}-\mathrm{Si}^{\mathrm{IV}}$ Pc conjugates $\mathbf{1 - 4}$ against $\mathrm{HT} 29$ and HepG2 cells.

\begin{tabular}{ccc}
\hline PMe- $\beta-C D-S i^{I V}$ Pc Conjugates & IC $_{\mathbf{5 0}}(\mathbf{n m}) \mathbf{H T 2 9}$ & IC $_{\mathbf{5 0}}$ (nm) HepG2 \\
\hline $\mathbf{1}$ & 150 & 190 \\
$\mathbf{2}$ & 21 & 26 \\
$\mathbf{3}$ & 23 & 35 \\
$\mathbf{4}$ & 28 & 94 \\
\hline
\end{tabular}

The in vivo study was also performed by injection of PMe- $\beta-\mathrm{CD}-\mathrm{Si}^{\mathrm{IV}} \mathrm{Pc}$ conjugate 2 in the nude mice bearing (HT29) tumor using the same protocol conditions as described in Lau; Lo; Fong; Ng [142]. Similarly, the same PDT effect was observed, indicating that the PMe- $\beta-C D-h e x y l-\mathrm{Si}^{\mathrm{IV}}$ Pc conjugate $\mathbf{2}$ is a promising system for anticancer PDT.

In 2013, Aggelidou et al. [144] described a new bimodal conjugate constituted of protoporphyrin IX (PpIX) covalently linked through amide bond to $\beta-\mathrm{CD}(\mathrm{PpIX}+\beta-\mathrm{CD})$. Spectroscopy studies were used to confirm the formation of two conjugates (PpIX- $\beta-C D$ "Major" and PpIX-2 $\beta-C D$ "Minor"). The photophysical studies of PpIX alone compared to conjugates revealed that the presence of $\beta$-CD in the conjugates enhanced the water solubility of PpIX. Furthermore, the authors found also that both conjugates have the ability to host an anticancer drug ( $N$-desmethyltamoxifen, NDMTAM.HCl) by its complexation in the empty cavity of $\beta-C D$, which shows that $P p I X+\beta C D$ could efficaciously solubilize and transport NDMTAM.

The in vitro phototoxic properties of PpIX $+\beta-\mathrm{CD}$ compared to PpIX alone were performed on human prostate carcinoma (DU145) and breast adenocarcinoma (MCF7) cell lines. PpIX $+\beta-C D$ displayed less toxicity in the dark than PpIX (15\% against $25 \%$, respectively) in both cell lines, which could be explained by $\beta-C D$ improving the solubility of PpIX, and thus reducing its ability to aggregate. The in vitro evaluation of the phototoxicity depending of the light dose $(\lambda=610 \mathrm{~nm}$, 0 to $15 \mathrm{~J} / \mathrm{cm}^{2}, 15 \mathrm{~mW} / \mathrm{cm}^{2}$ ) is given in Figure 26a. There were no significant differences between PpIX and PpIX $+\beta-C D$, indicating that $\beta-C D$ had no impact on the phototoxicity properties of PpIX. 

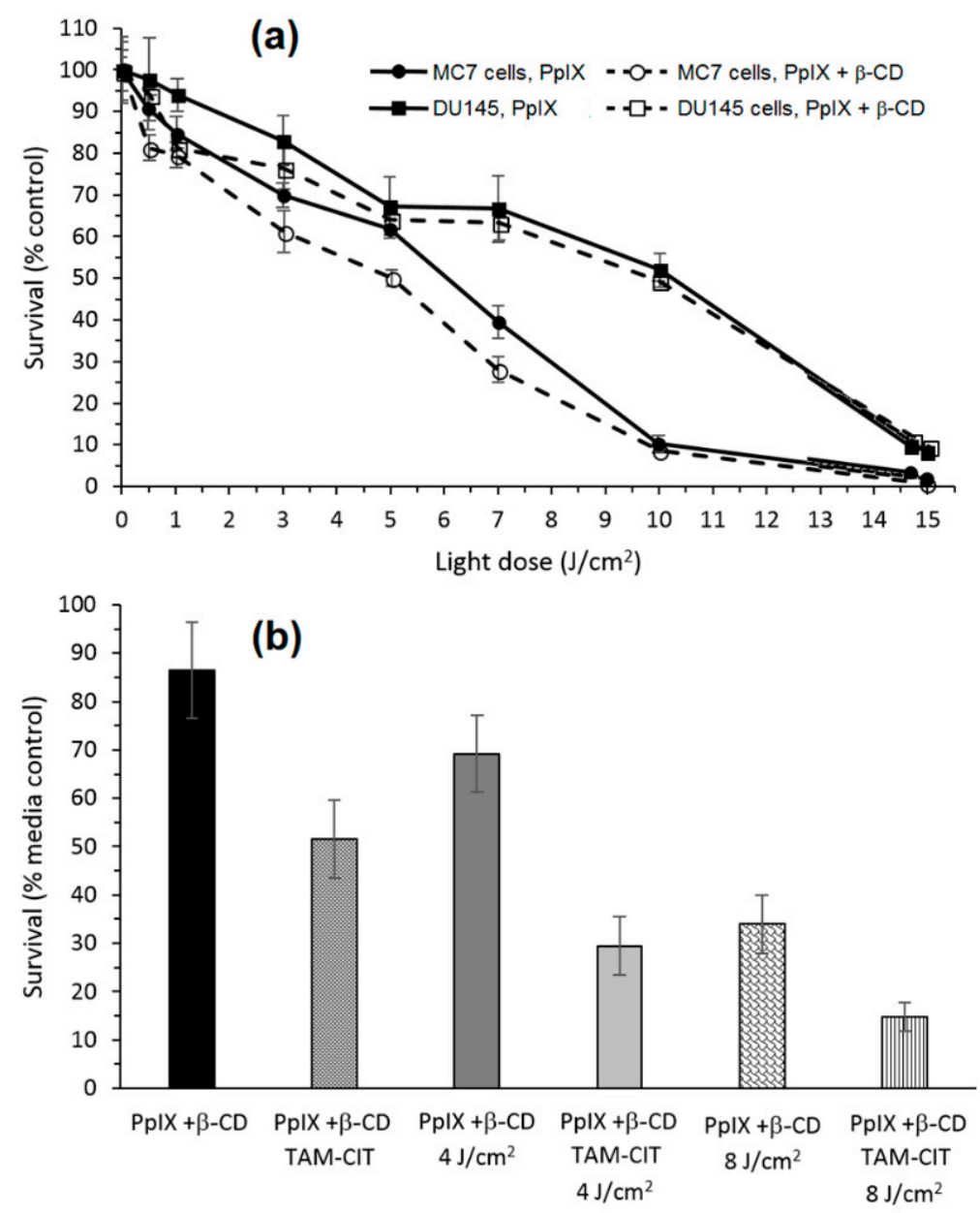

Figure 26. (a) Phototoxicity $24 \mathrm{~h}$ following $3 \mathrm{~h}$ of cell incubation with $7 \mu \mathrm{M}$ of protoporphyrin IX (PpIX) and PpIX $+\beta-C D$ and irradiation through a Schott RG610 long-pass filter $\left(\mathrm{LD}_{50}\right.$ values for PpIX were $10 \mathrm{~J} / \mathrm{cm}^{2}$ and $7 \mathrm{~J} / \mathrm{cm}^{2}$ for MCF7 and DU145 cells, respectively, whereas the corresponding values for $\mathrm{PpIX}+\beta-\mathrm{CD}$ were $10 \mathrm{~J} / \mathrm{cm}^{2}$ and $6 \mathrm{~J} / \mathrm{cm}^{2}$, respectively). (b) Bimodal action of PpIX $+\beta-C D$ complexed with tamoxifen citrate (TAM-CIT) in MCF7 cells. Phototoxicity $48 \mathrm{~h}$ following $3 \mathrm{~h}$ of cell incubation with $7 \mu \mathrm{M}$ of PpIX $+\beta-\mathrm{CD}$ and PpIX $+\beta-\mathrm{CD}$ complexed with TAM-CIT and irradiation through a Schott RG610 long-pass filter at $4 \mathrm{~J} / \mathrm{cm}^{2}$ and $8 \mathrm{~J} / \mathrm{cm}^{2}$. Adapted from Aggelidou; Theodossiou; Yannakopoulou [144].

Finally, the ability of PpIX $+\beta-C D$ conjugates to host and transport a therapeutic molecule was investigated using NDMTAM. The PpIX $+\beta-C D$ seemed to be a good drug carrier for the intracellular transport of this drug. Finally, the bimodal action of $\mathrm{PpIX}+\beta-\mathrm{CD}$ complexed to tamoxifen citrate (TAM-CIT) was investigated using the MCF7 cell line (Figure 26b). Under an irradiation of $4 \mathrm{~J} / \mathrm{cm}^{2}$, the PpIX $+\beta-C D$ complexed to TAM-CIT had a toxicity of $70 \%$ against $30 \%$ for PpIX $+\beta-C D$ alone, and under $8 \mathrm{~J} / \mathrm{cm}^{2}$, the toxicity was $85 \%$ against $67 \%$. These observations highlighted that there was a synergistic effect of the toxicity of the chemotherapy drug and the phototoxicity of the PpIX+ $\beta$-CD conjugates.

In the same year, Fraix et al. [145] synthesized and investigated the properties of a new supramolecular assembly as a bimodal agent for PDT and imaging composed of meta-(3-hydroxyphenyl)- porphyrin (mTHPP) conjugated to $\beta$-CD (mTHPP- $\beta$-CD conjugate) by an ether bond, and a nitric oxide photodonor (NO phodonor) tailored to fit the $\beta$-CD cavity (Figure 27). 

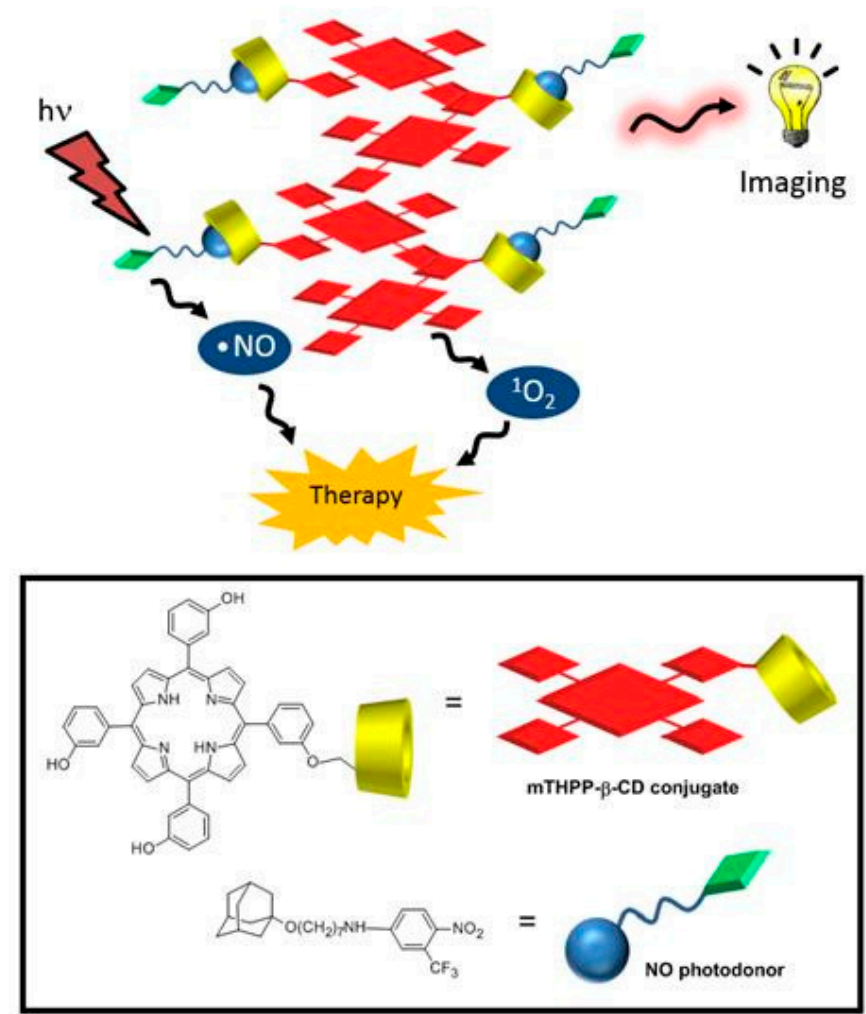

Figure 27. Schematic representation of the photoresponsive supramolecular nanoaggregate. Adapted from Fraix; Goncalves; Cardile; Graziano; Theodossiou; Yannakopoulou; Sortino [145].

They found that compared to the free mTHPP, the mTHPP- $\beta-C D$ conjugate has shown less aggregation in an aqueous environment, and formed small nanoassemblies with diameters of around $13 \mathrm{~nm}$. Furthermore, the empty cavity of $\beta-C D$ in the mTHPP- $\beta-C D$ conjugate also had the ability to a host a nitroaniline derivative (NO photodonor) while maintaining the nanometer character of the aggregate and the fluorescence of the porphyrin core. In addition, bichromophoric nanoassemblies ( $\beta$-CD-mTHPP/NO photodonor) were found to be able to generate both $\mathrm{NO}$ and ${ }^{1} \mathrm{O}_{2}$ upon excitation with visible light $\left(\lambda_{\text {exc }}>400 \mathrm{~nm}\right)$.

By in vitro studies, the internalization in a human amelanotic melanoma cell line (A375) was evaluated for the conjugate and the bichromophoric nanaoassemblies at a concentration of $8 \mu \mathrm{M}$ after $4 \mathrm{~h}$ of incubation, and the authors found a localization mainly in cytoplasm. The in vitro ability of the conjugate and the bichromophoric nanaoassemblies to induce A375 cell mortality upon light irradiation was compared. No dark toxicity was found, but a high phototoxicity was observed for both compounds, with a slight difference between them explained by the liberation of $\mathrm{NO}$ and ${ }^{1} \mathrm{O}_{2}$ for the nanoassemblies (Figure 28).

Being encouraged by the potential properties of the mTHPP- $\beta C D$ conjugate, recently, the same team [146] investigated the photochemical internalization (PCI) potential of the same conjugate with the NDMTAM drug as the guest molecule. In order to improve the water solubility of the mTHPP core in the conjugate, the authors encapsulated the mTHPP core in the empty cavity of heptakis(2,3,6-O-methyl)- $\beta-C D$ (pM- $\beta-C D)$, leading to the formation of a new mTHPP- $\beta$-CD/pM- $\beta$-CD nanosystem. The obtained nanosystem has shown the ability to host the NDMTAM drug through either one of its unsubstituted phenyl groups (Figure 29). 


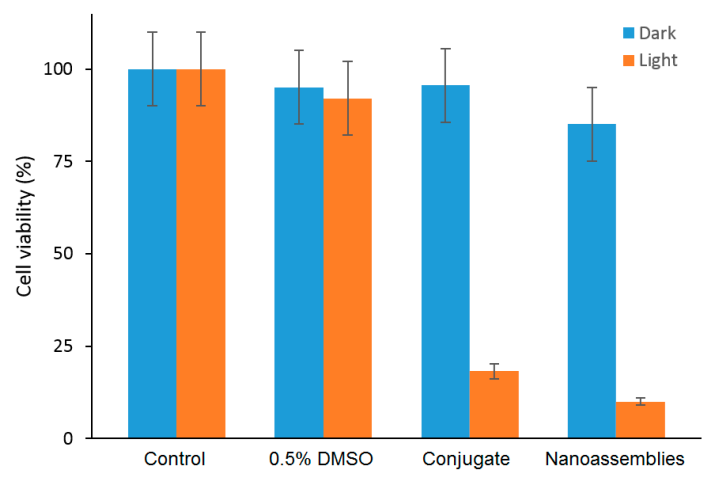

Figure 28. Dark and photoinduced mortality of A375 cells treated with meta-(3-hydroxyphenyl)porphyrin (mTHPP)- $\beta-C D$ conjugate and $\mathrm{mTHPP}-\beta-\mathrm{CD} /$ nitric oxide (NO) photodonor assemblies (ca. $8 \mathrm{~mm}$ ) in culture medium containing $0.5 \%$ DMSO compared to dark and photoinduced mortality in culture medium in the absence and the presence of $0.5 \%$ DMSO. Adapted from Fraix; Goncalves; Cardile; Graziano; Theodossiou; Yannakopoulou; Sortino [145].

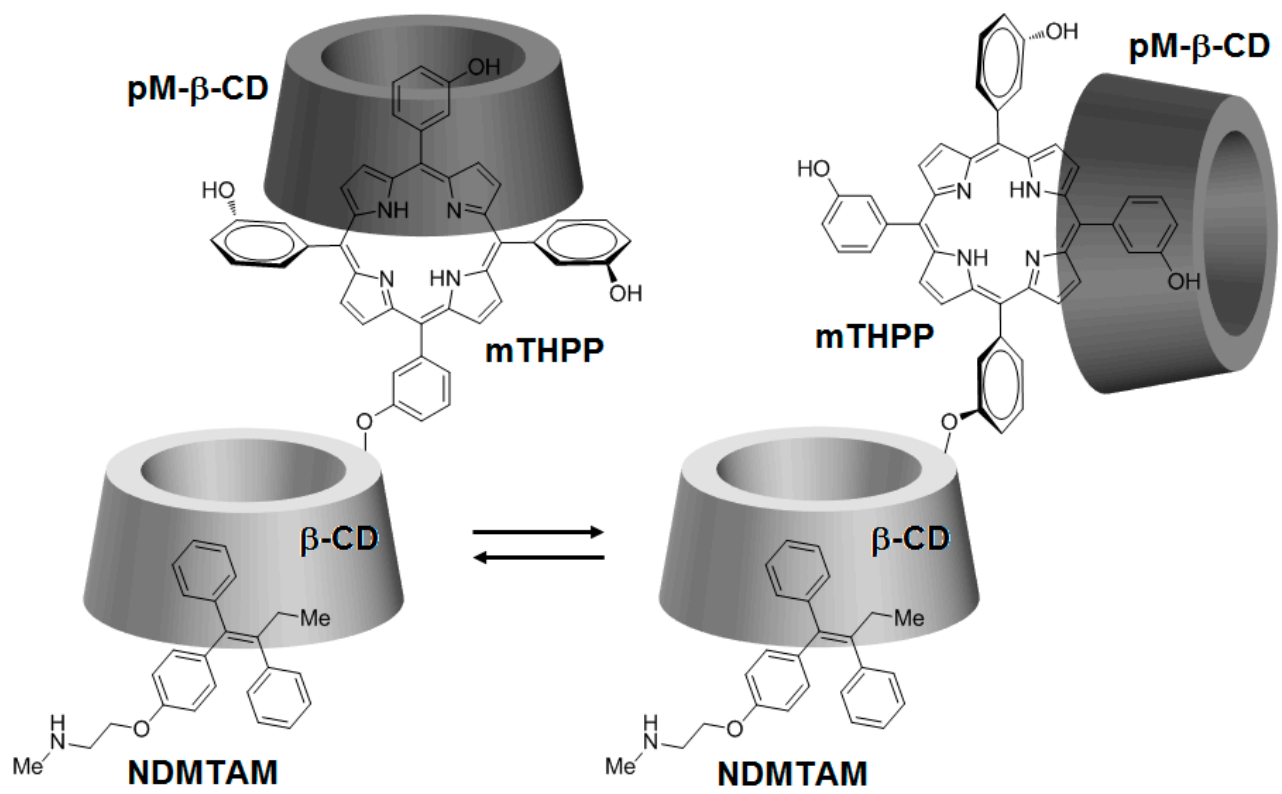

Figure 29. Solution structure of mTHPP- $\beta-C D / p M-\beta-C D / N$-desmethyltamoxifen (NDMTAM) as a 1:1 mixture of diastereoisomeric complexes, as derived from NMR spectroscopic data. Adapted from Theodossiou; Goncalves; Yannakopoulou; Skarpen; Berg [146].

According to confocal microscopy studies, it was found that under irradiation, the porphyrin core of mTHPP- $\beta-C D$ expedited endosomal membrane rupture and NDMTAM release into the cytosol. Furthermore, the authors also investigated the in vitro photocytotoxicity efficiency on breast human carcinoma (MDA-MB-231) and MCF7 cell lines of the mTHPP- $\beta$-CD conjugate, tamoxifen (4-OHT), and the resulting mTHPP- $\beta-\mathrm{CD} / 4-\mathrm{OHT}$ complex. Upon irradiation at $\mathrm{LD}_{50}$ light doses, in the case of cells treated with the conjugate, phototoxicity around $70 \%$ was observed, which was annulled after $48 \mathrm{~h}$ and $72 \mathrm{~h}$. Concerning cells irradiated after treatment with the complex, they showed a cell death of $80 \%$, with no change even after $48 \mathrm{~h}$ and $72 \mathrm{~h}$ (Figure 30 ). 

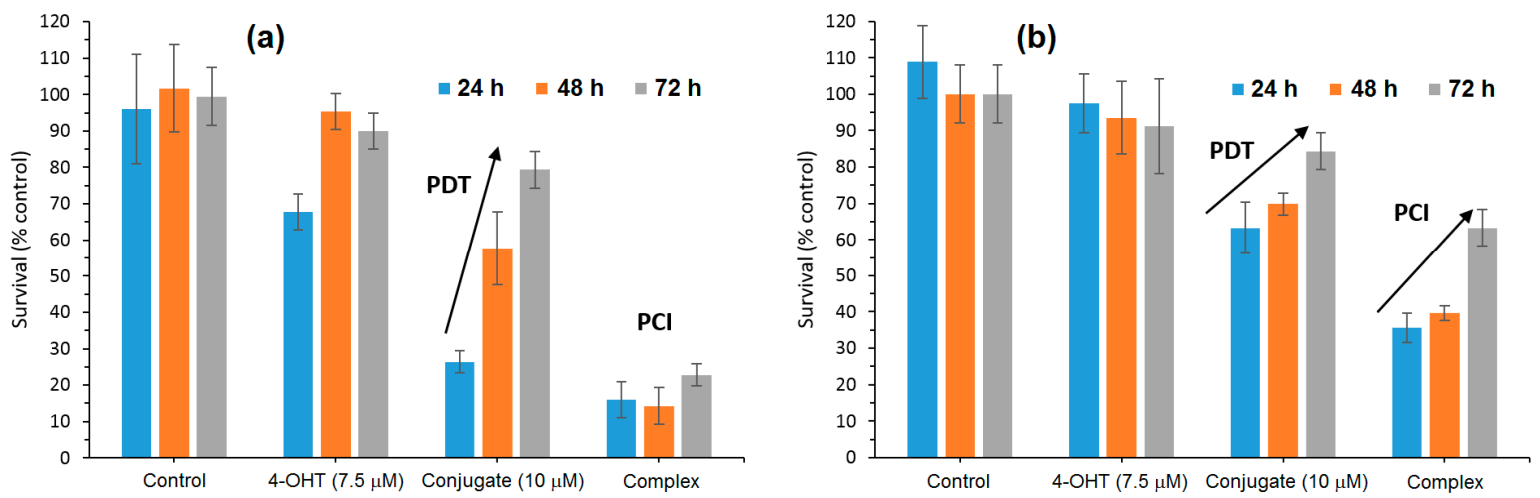

Figure 30. Photocytotoxicity to (a) breast adenocarcinoma (MCF7) and (b) breast human carcinoma (MDA-MB-231) cells following overnight $(16 \mathrm{~h})$ incubation with medium only (Control), tamoxifen (4-OHT) $(7.5 \mu \mathrm{M})$, mTHPP- $\beta-C D$ conjugate $(10 \mu \mathrm{M})$, and mTHPP- $\beta-\mathrm{CD}(10 \mu \mathrm{M})-4-\mathrm{OHT}(7.5 \mu \mathrm{M})$ complex. Adapted from Theodossiou; Goncalves; Yannakopoulou; Skarpen; Berg [146].

In 2014, Lourenço et al. described the synthesis and PDT properties of CD-PS conjugates (ZnPc- $\alpha-C D, Z n P c-\beta-C D$, and $\mathrm{ZnPc}-\gamma-\mathrm{CD})$ constituted by a zinc perfluorinated phthalocyanine $(\mathrm{ZnPc})$ covalently linked through ether bonds to various types of $\mathrm{CDs}(\alpha-\mathrm{CD}, \beta-\mathrm{CD}$, and $\gamma-\mathrm{CD})$ (Figure 31) [147].

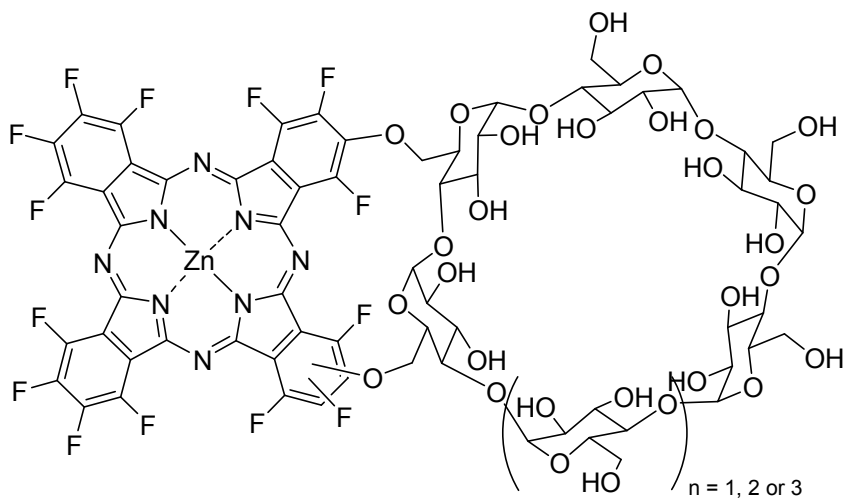

$\mathrm{ZnPc}-\alpha-\mathrm{CD}(\mathrm{n}=1), \mathrm{ZnPc}-\beta-\mathrm{CD}(\mathrm{n}=2), \mathrm{ZnPc}-\boldsymbol{- C D}(\mathrm{n}=3)$

Figure 31. Chemical structure of $\mathrm{ZnPc}-\alpha-\mathrm{CD}, \mathrm{ZnPc}-\beta-\mathrm{CD}$, and $\mathrm{ZnPc}-\gamma-\mathrm{CD}$ conjugates.

It was found that $\mathrm{ZnPc}-\alpha-\mathrm{CD}$ and $\mathrm{ZnPc}-\gamma-\mathrm{CD}$ have a better solubility compared to $\mathrm{ZnPc}-\beta-\mathrm{CD}$ due to the lesser solubility of the $\beta-C D$ unity itself in water compared to $\alpha-C D$ and $\gamma-C D$. The ability of each $\mathrm{ZnPc}-\mathrm{CD}$ conjugate to generate ${ }^{1} \mathrm{O}_{2}$ was evaluated using 1,3-diphenylisobenzofuran as a probe. The authors found a similar effectiveness for $\mathrm{ZnPc}-\alpha-\mathrm{CD}$ and $\mathrm{ZnPc}-\gamma-\mathrm{CD}$ conjugates compared to $\mathrm{ZnPc}$ alone, but $\mathrm{ZnPc}-\beta-\mathrm{CD}$ seemed to be less effective, which was maybe due to the same reasons mentioned before.

The human cancer cell line derived from the transitional cell carcinoma of the bladder (UM-UC-3) was selected as a cancer cell model to study the in vitro photosensitizing efficiency. No dark toxicity was observed for the different conjugates at concentrations up to $10 \mu \mathrm{M}$ and $4 \mathrm{~h}$ of incubation time. Under light irradiation (white or red-light source, $50 \mathrm{~mW} / \mathrm{cm}^{2}$ ), after incubation with various concentrations of conjugates $(0-1 \mu \mathrm{M})$, only ZnPc- $\alpha-\mathrm{CD}$ and $\mathrm{ZnPc}-\gamma-\mathrm{CD}$ conjugates have shown a phototoxic effect, and this effect was irradiation time and concentration-dependent. In addition, this effect was found to be more efficient under white-light irradiation compared to the red one. To better understand these results, the authors investigated the ROS production capacity of the 
conjugates under white or red-light irradiation using a $2^{\prime}, 7^{\prime}$-dichlorodihydrofluorescein diacetate (DCFDA) probe. They found that all of the conjugates produced ROS under white or red irradiation, and intracellular ROS production was higher in the case of $\mathrm{ZnPc}-\alpha-\mathrm{CD}$ and $\mathrm{ZnPc}-\gamma-\mathrm{CD}$ conjugates. Indeed, they accumulated more in cells than $\mathrm{ZnPc}-\beta-\mathrm{CD}$, proving again their higher potential compared to $\mathrm{ZnPc}-\beta-\mathrm{CD}$ for PDT.

Recently, Barata et al. [148] described and investigated the photosensitizing properties of corrole $\beta$-cyclodextrin conjugates $\left(\operatorname{Cor}(\beta-C D)_{1}\right.$ and $\left.\operatorname{Cor}(\beta-C D)_{2}\right)$, which were composed of $5,10,15$-tris(pentafluorophenyl)corrole (Cor) and one or two $\beta$-CD units (Figure 32).

The authors found that the presence of $\beta-C D$ units in both conjugates improved the hydrophicility of the corrole core. It was found also that all of the conjugates are highly photostable and able to produce ${ }^{1} \mathrm{O}_{2}$.

In vitro studies were performed on human cervical cancer cell line (HeLa). The cytotoxicity of each compound $\left(\operatorname{Cor}(\beta-C D)_{1}, \operatorname{Cor}(\beta-C D)_{2}\right.$, and $\left.\operatorname{Cor}\right)$ was evaluated by using MTT assay at different concentrations (from $10^{-7} \mathrm{M}$ to $10^{-4} \mathrm{M}$ ) in the dark. No cytotoxicity was found for both Cor and $\operatorname{Cor}(\beta-C D)_{1}$ conjugate in contrast to the $\operatorname{Cor}(\beta-C D)_{2}$ conjugate, which conduced to $14 \%$ of cytotoxicity in cells. Upon red-light irradiation $\left(3 \mathrm{~J} / \mathrm{cm}^{2}, 6 \mathrm{~J} / \mathrm{cm}^{2}, 9 \mathrm{~J} / \mathrm{cm}^{2}\right.$, and $\left.12 \mathrm{~J} / \mathrm{cm}^{2}, 5 \mathrm{~mW} / \mathrm{cm}^{2}\right)$, all of the compounds showed concentration-dependent and light-dose dependent cell-destruction ability. Therefore, as shown in Table 6, Cor seems to be the most effective compound to be used as a PS for PDT.

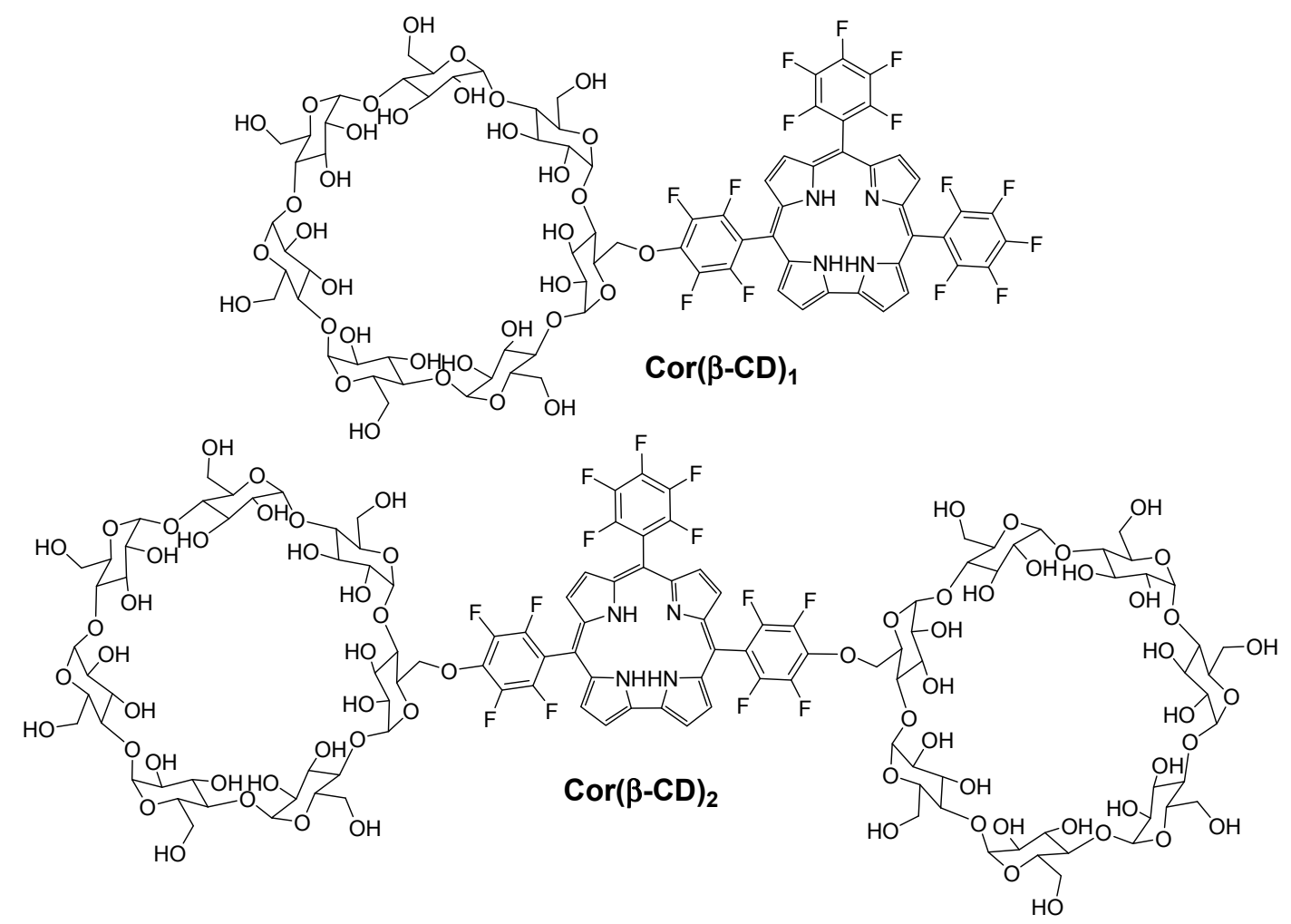

Figure 32. Chemical structure of $\operatorname{Cor}(\beta-C D)_{1}$ and $\operatorname{Cor}(\beta-C D)_{2}$ conjugates.

Table 6. Percent survival of Hela cells at different light doses (irradiance of $5 \mathrm{~mW} / \mathrm{cm}^{2}$ ) of Cor $(\beta-C D)_{1}$, $\operatorname{Cor}(\beta-C D)_{2}$, and Cor at a concentration of $10^{-5} \mathrm{M}(n=3)$.

\begin{tabular}{cccc}
\hline \multirow{2}{*}{ Compound } & \multicolumn{3}{c}{ Surviving Hela Cells Fraction $\mathbf{( \%} \pm \mathbf{S D})$ at Light Dose } \\
\cline { 2 - 4 } & $\mathbf{6 ~} \mathbf{~ J} \mathbf{c m}^{\mathbf{2}}$ & $\mathbf{9} \mathbf{~ J} \mathbf{c m}^{\mathbf{2}}$ & $\mathbf{1 2} \mathbf{~} / \mathbf{c m}^{\mathbf{2}}$ \\
\hline $\operatorname{Cor}(\beta-C D)_{1}$ & $95.6 \pm 0.6$ & $81.6 \pm 3.2$ & $81.6 \pm 3.1$ \\
$\operatorname{Cor}(\beta-C D)_{2}$ & $120.7 \pm 3.5$ & $110.8 \pm 0.5$ & $110.4 \pm 3.9$ \\
$\operatorname{Cor}$ & $80.9 \pm 3.0$ & $44.5 \pm 2.3$ & $38.5 \pm 1.4$ \\
\hline
\end{tabular}


Due to the dark cytotoxicity of the $\operatorname{Cor}(\beta-C D)_{2}$ conjugate, the authors selected only Cor and $\operatorname{Cor}(\beta-C D)_{1}$ compounds for the next studies. According to the subcellular localization study, Cor was found to be mainly accumulated in lysosomes, whereas $\operatorname{Cor}(\beta-C D)_{1}$ conjugate accumulated in the Golgi apparatus. Finally, they investigated the PDT effect of Cor and $\operatorname{Cor}(\beta-C D)_{1}$ compounds on the cytoskeleton by combination of the injection of Cor or $\operatorname{Cor}(\beta-C D)_{1}$ compounds $\left(10^{-5} \mathrm{M}\right)$ upon red-light irradiation $\left(12 \mathrm{~J} / \mathrm{cm}^{2}\right)$ on microtubules in HeLa cells. They observed changes on microtubules for both Cor and $\operatorname{Cor}(\beta-C D)_{1}$ compounds, but a higher PDT efficiency was observed in the case of Cor, which may be due to its localization in lysosomes.

\section{- Non-Porphyrinoid photosensitizers}

In 2002, Ou et al. [149] synthesized a modified non-porphyrinoid PS (hypocrellin B, HB) conjugated to the $\beta-C D$ (HB- $\beta-C D$ conjugate) (Figure 33), and studied its water solubility and PDT properties. They found that the HB- $\beta-C D$ conjugate had a higher water solubility compared to free HB. They also proved that the HB- $\beta$-CD conjugate can produce different ROS such as $\mathrm{O}_{2}{ }^{\bullet-}, \bullet \mathrm{OH}$, and ${ }^{1} \mathrm{O}_{2}$ species. Furthermore, the authors found that the $\beta$-CD unit present in the HB- $\beta$-CD conjugate reinforced their affinity for calf thymus DNA (CT DNA), leading to the stronger photodamage of CT DNA compared to free HB. The authors concluded that the introduction of $\beta-C D$ units enhanced the water solubility and PDT properties of HB.

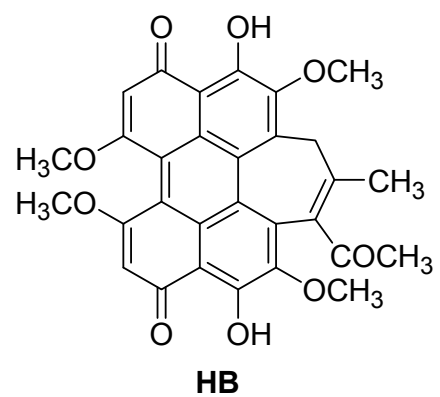

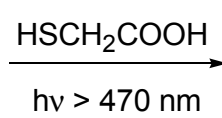

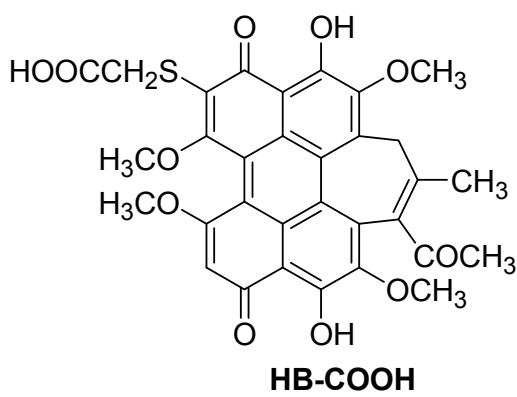<smiles>OCC1C2CC3CC(C2)C1C3</smiles><smiles>Cc1ccc(S(=O)(=O)CC2C3CC4CC(C3)CC2C4)cc1</smiles>

$\mathrm{H}_{2} \mathrm{NCH}_{2} \mathrm{CH}_{2} \mathrm{NH}_{2}$
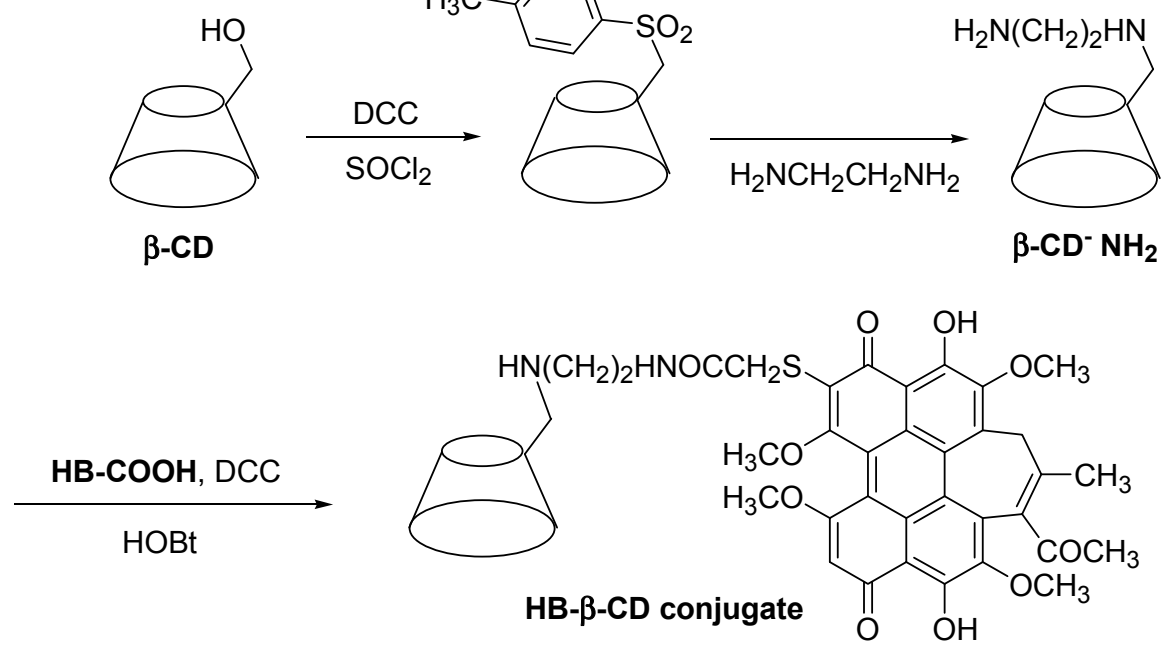

Figure 33. Synthesis of HB- $\beta-C D$ conjugate.

In 2017, Cao et al. [150] developed a new PDT agent (MMMPB(PMe- $\beta-C D)_{2}$ conjugate) by conjugation of a non-porphyrinoid PS (a mono-mannose modified perylene bisimide, MMMPB) to two permethyl $\beta$-CDs (PMe- $\beta$-CDs) via click triazole links (Figure 34), and evaluated its PDT properties. 


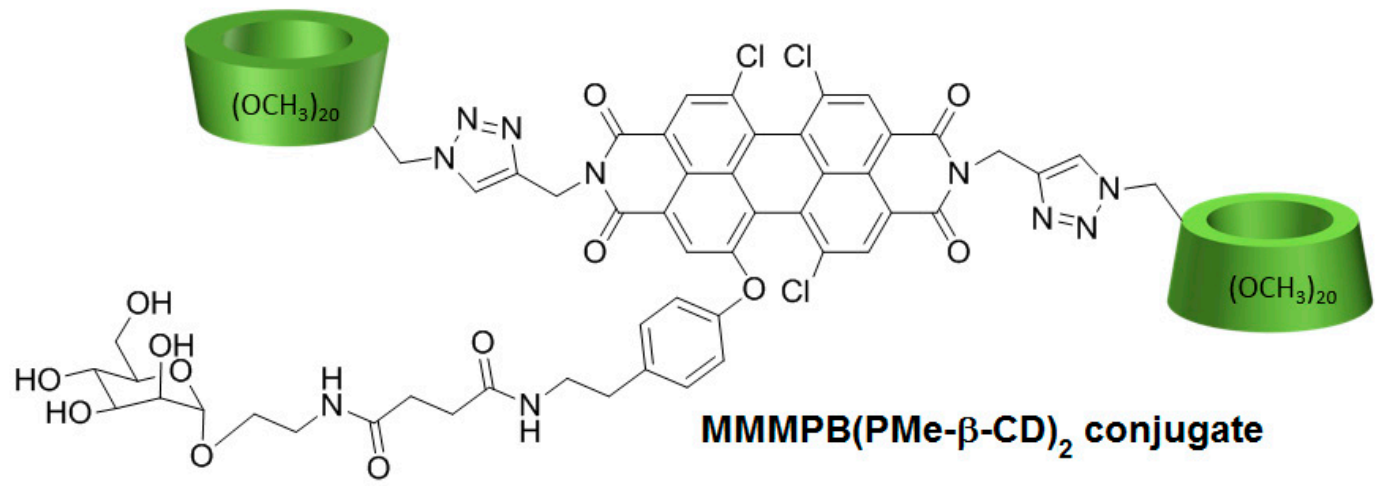

Figure 34. Chemical structure of mono-mannose modified perylene bisimide (MMMPB)/(PMe- $\beta-\mathrm{CD})_{2}$ conjugate.

In vitro studies were performed to investigate the PDT activity of the MMMPB(PMe- $\beta-C D)_{2}$ conjugate using four cell lines (A549, Hela, MCF-7, and Hep G2) at various concentrations of MMMPB(PMe- $\beta-C D)_{2}$ conjugate, TPPS $_{4}$, and cisplatin as controls $(0.2 \mu \mathrm{M}, 1 \mu \mathrm{M}, 5 \mu \mathrm{M}, 25 \mu \mathrm{M}$, and $100 \mu \mathrm{M})$. The conjugate showed no dark toxicity, but was highly phototoxic under irradiation $\left(20 \mathrm{~mW} / \mathrm{cm}^{2}\right)$ with better $\mathrm{IC}_{50}$ than controls. The ability to produce ${ }^{1} \mathrm{O}_{2}$ was evaluated by using 1,3-diphenylisobenzofuran as a trap, and the production of ${ }^{1} \mathrm{O}_{2}$ was highlighted. Fluorescence imaging was performed in MCF-7 cells by incubation with the conjugate $(10.0 \mu \mathrm{M})$ to localize the distribution of the conjugate in cells, and it was found mainly in cytoplasm. They finally found that the cell death was induced with an apoptotic pathway.

\subsubsection{Cyclodextrins-Photosensitizer Nanoassemblies}

The last type of binding between CD and PS refers to CD-PS nanoassemblies. These nanoassemblies are supramolecular colloidal systems involving non-specific external links between the external sites of CDs and PSs. Chemical modifications of either narrow or wide edges of natural $C D$ s by various substituents make them possible to produce ionic or nonionic $C D$ derivatives that are capable of forming supramolecular buildings such as vesicles, micelles, or nanoparticles (NPs) that have the capacity to host PSs. With regard to the anticancer PDT application, it has been shown in vitro that this type of vector can improve PS administration and PDT efficacy [151,152]. However, to date, no in vivo PDT study has been devoted to PS-CD nanoassemblies.

- Nanoassemblies using amphiphilic cyclodextrines

Among the various types of $\mathrm{CD}$ derivatives, amphiphilic $\mathrm{CDs}$ are largely used to form supramolecular nanoassemblies, and have had many applications in the biomedical field [153-157]. Researchers have developed the concept of amphiphilic CDs to adjust the hydrophobic/hydrophilic balance of their construction, leading to the formation of various types of supramolecular nanoassemblies (vesicles, micelles, NPs ... ) [158-161]. Amphiphilic CDs can be obtained by enzymatic pathways or by grafting various substituent groups via amino, amido, thio, ester, and ether bonds [155].

All the studies described below are drawn from the work of Mazzaglia et al.

In two articles published in 2003 and 2005 [162,163], Mazzaglia et al. investigated the development of a new carrier-PS system $\mathrm{TPPS}_{4} / \mathrm{SC}_{6}-\beta-\mathrm{CD}-\mathrm{NH}_{2}$ composed of amphiphilic heptakis(2-o-amino-O-oligo(ethylene oxide)-6-hexylthio)- $\beta-\mathrm{CD} \quad\left(\mathrm{SC}_{6}-\beta-\mathrm{CD}-\mathrm{NH}_{2}, \quad\right.$ Figure 35) self-assembled into vesicles and an encapsulated water-soluble porphyrin $\left(\mathrm{TPPS}_{4}\right)$. The authors showed that TPPS $4 / \mathrm{SC}_{6}-\beta-\mathrm{CD}-\mathrm{NH}_{2}$ nanoaggregates produced ${ }^{1} \mathrm{O}_{2}$, but in lower amounts than free $\mathrm{TPPS}_{4}$. However, it was found that $\mathrm{SC}_{6}-\beta-\mathrm{CD}-\mathrm{NH}_{2}$ vesicles seemed to be an efficient carrier for intracellular PS delivery. 


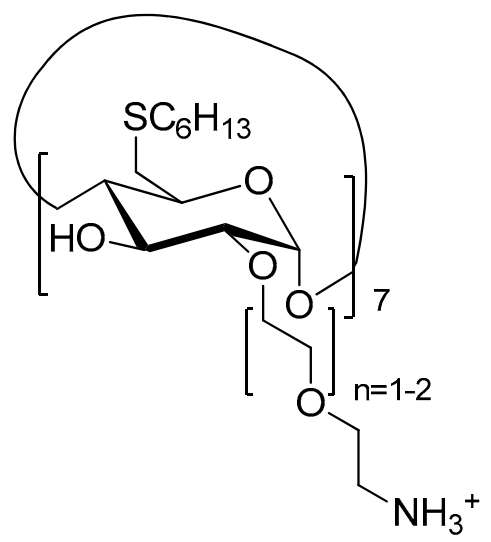

Figure 35. Chemical structure of $\mathrm{SC}_{6}-\beta-\mathrm{CD}-\mathrm{NH}_{2}$ vesicles.

In 2006, Mazzaglia et al. [164] investigated the PDT activity of $\mathrm{TPPS}_{4} / \mathrm{SC}_{6}-\beta-\mathrm{CD}-\mathrm{NH}_{2}$ nanoassemblies. It was found that they had a size ranging from $100 \mathrm{~nm}$ to $1000 \mathrm{~nm}$, and that ${ }^{1} \mathrm{O}_{2}$ generation was highly dependent on the $\mathrm{SC}_{6}-\beta-\mathrm{CD}-\mathrm{NH}_{2}$ concentration in nanoassemblies. Based on in vitro studies, the $\mathrm{TPPS}_{4}$ internalization and PDT efficiency of nanoassemblies using HeLa cells were found to be highly dependent on the $\mathrm{TPPS}_{4} / \mathrm{SC}_{6}-\beta-\mathrm{CD}-\mathrm{NH}_{2}$ molar ratio. Molar ratio of 1:10 seemed to be the best ratio in terms of $\mathrm{TPPS}_{4}$ internalization, which is the highest percentage of cells alive before irradiation and a considerably high percentage of cell death after irradiation (Figure 36). The authors concluded that $\mathrm{TPPS}_{4} / \mathrm{SC}_{6}-\beta-\mathrm{CD}-\mathrm{NH}_{2}$ nanoassemblies can be used as potential candidates for PDT application.

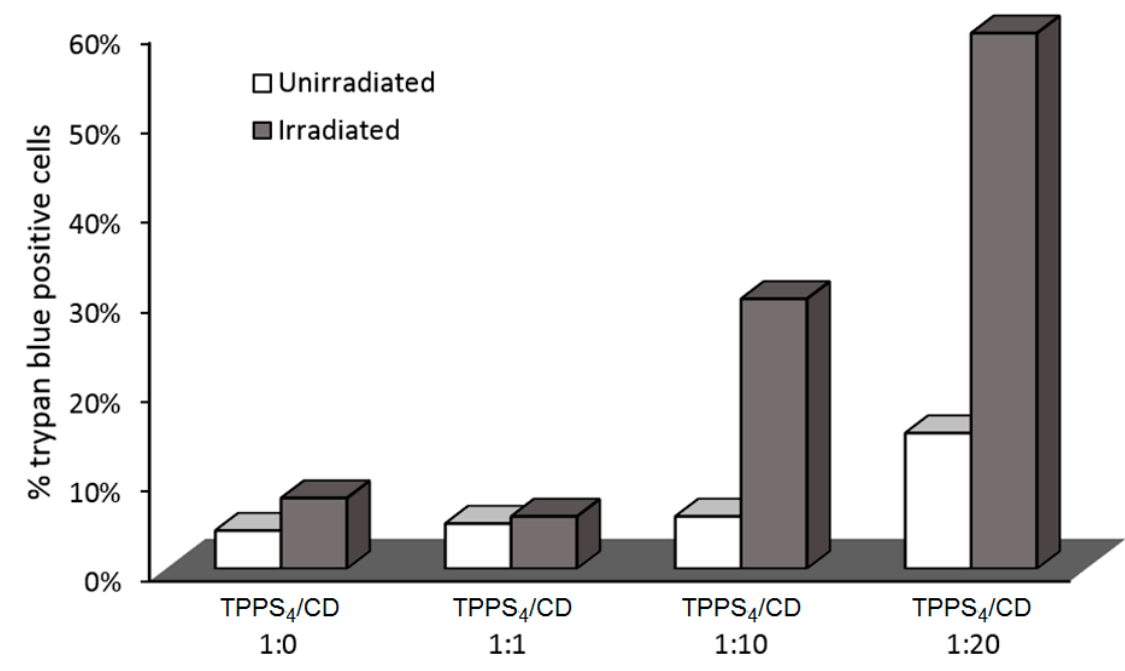

Figure 36. Cell death percentage in HeLa through trypan blue assay. HeLa cells treated with $\mathrm{TPPS}_{4}$ alone as a control, and with $\mathrm{TPPS}_{4} / \mathrm{SC}_{6}-\beta-\mathrm{CD}-\mathrm{NH}_{2}$ nanoassemblies at 1:2, 1:10, and 1:20 molar ratios, respectively before and after exposition to visible light irradiation for $30 \mathrm{~min}$. Adapted from Sortino; Mazzaglia; Scolaro; Merlo; Valveri; Sciortino [164].

In 2011, the same team [165] used the above amphiphilic TPPS $4 / \mathrm{SC}_{6}-\beta-\mathrm{CD}-\mathrm{NH}_{2}$ nanoassemblies covalently functionalized by the dansyl fluorophore. The resulting supramolecular system showed a good PS delivery while allowing a simultaneously detection of carrier and PS in tumor cells (Figure 37). 


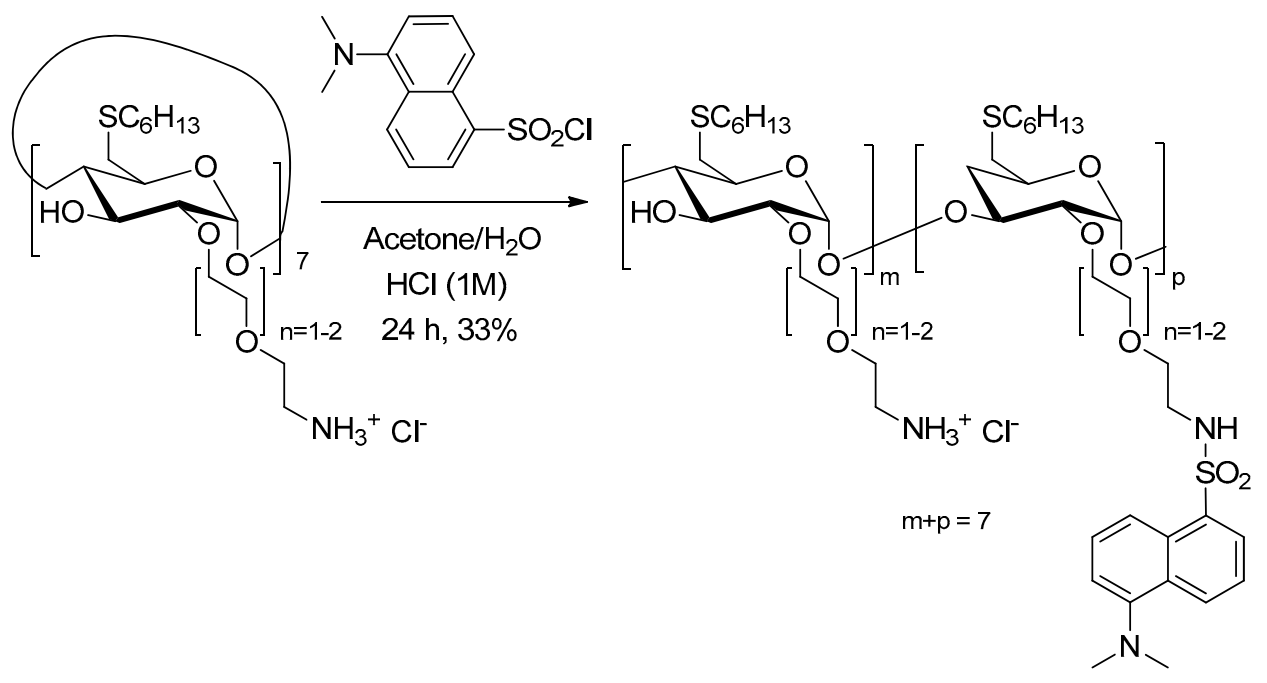

Figure 37. Functionalization of $\mathrm{SC}_{6}-\beta-\mathrm{CD}-\mathrm{NH}_{2}$ with the dansyl fluorophore.

In 2014, Mazzaglia et al. [166] synthesized the hydroxylated analog of $\mathrm{SC}_{6}-\beta C D-\mathrm{NH}_{2}$ (noted $\mathrm{SC}_{16}-\beta \mathrm{CD}-\mathrm{OH}$ ), and developed a novel biodegradable phototherapeutic nanoassembly $\mathrm{ZnPc} / \mathrm{SC}_{16}-\beta-\mathrm{CD}-\mathrm{OH}$ based on the self-assembly in aqueous media of heptakis(2-oligo(ethylene-oxide)-6-hexadecylthio-)- $\beta-\mathrm{CD}\left(\mathrm{SC}_{16}-\beta \mathrm{CD}-\mathrm{OH}\right)$ and zinc-phthalocyanine (ZnPc) (Figure 38). $\mathrm{ZnPc} / \mathrm{SC}_{16}-\beta-\mathrm{CD}-\mathrm{OH}$ nanoassemblies have a hydrodynamic diameter of around 200 $\mathrm{nm}$, and a shown ability to produce ${ }^{1} \mathrm{O}_{2}$.

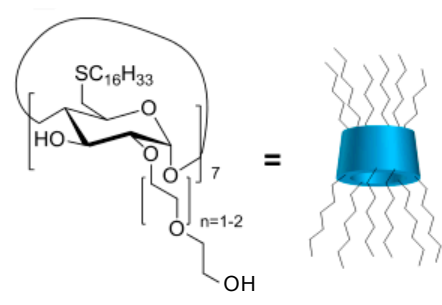

$$
\mathrm{SC}_{16}-\beta-\mathrm{CD}-\mathrm{OH}
$$

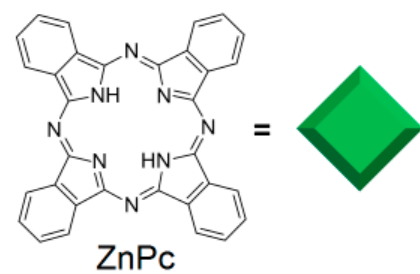

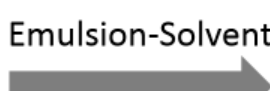

evaporation

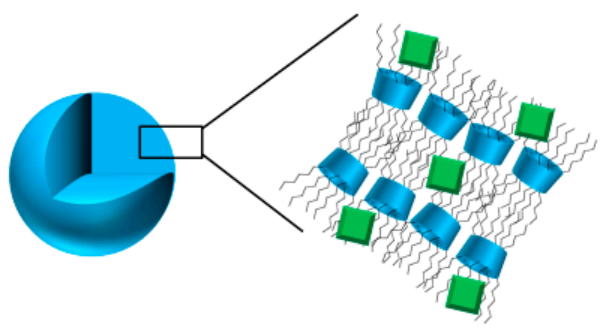

$\mathrm{ZnPc} / \mathrm{SC}_{16}-\beta-\mathrm{CD}-\mathrm{OH}$ nanoassemblies

Figure 38. Molecular structure of $\mathrm{SC}_{16}-\beta-\mathrm{CD}-\mathrm{OH}, \mathrm{ZnPc}$, and corresponding $\mathrm{ZnPc} / \mathrm{SC}_{16}-\beta-\mathrm{CD}-\mathrm{OH}$ nanoassembly. Adapted from Conte; Scala; Siracusano; Leone; Patane; Ungaro; Miro; Sciortino; Quaglia; Mazzaglia [166].

The nanoassemblies' formation was assessed by Dynamic Light Scattering (DLS), zeta potential, ${ }^{1} \mathrm{H}$ NMR, TEM, and Scanning Near-Field Optical Luminescence (SNOL) spectroscopy. $\mathrm{ZnPc} / \mathrm{SC}_{16}-\beta-\mathrm{CD}-\mathrm{OH}$ nanoassemblies have a hydrodynamic diameter of around $200 \mathrm{~nm}$ and a shown ability to produce ${ }^{1} \mathrm{O}_{2}$. Cellular uptake and cytotoxicity was investigated in HeLa cancer cells. The in vitro studies showed that $\mathrm{ZnPc} / \mathrm{SC}_{16}-\beta-\mathrm{CD}-\mathrm{OH}$ can be internalized in HeLa cells at $37^{\circ} \mathrm{C}$, and their uptake was mediated by endocytosis, which is strongly temperature-dependent. Furthermore, the PDT efficiency of $\mathrm{ZnPc} / \mathrm{SC}_{16}-\beta-\mathrm{CD}-\mathrm{OH}$ was performed using HeLa cells under 
irradiation $\left(\lambda=340 \mathrm{~nm}, 5 \mathrm{~J} / \mathrm{cm}^{2}, 30 \mathrm{~min}\right)$, and $\mathrm{ZnPc} / \mathrm{SC}_{16}-\beta-\mathrm{CD}-\mathrm{OH}$ showed a better phototoxic activity against HeLa cells than free ZnPc in DMSO (Figure 39).

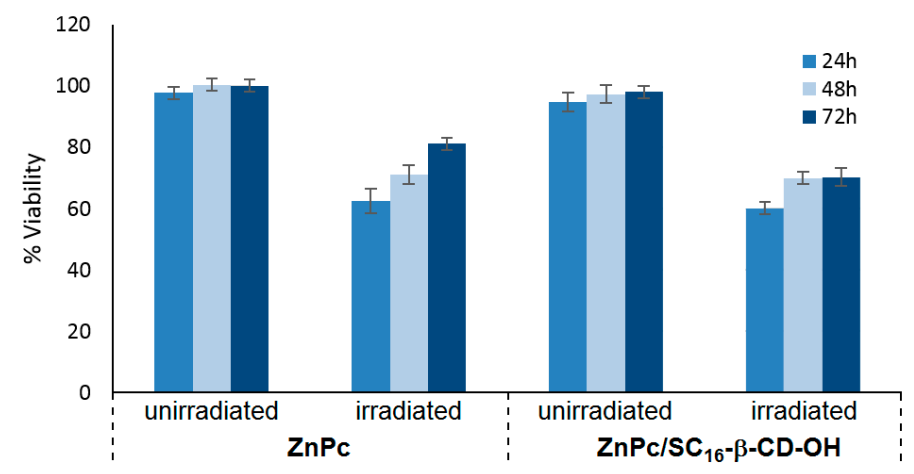

Figure 39. Effects of $\mathrm{ZnPc}$ and $\mathrm{ZnPc} / \mathrm{SC}_{16}-\beta-\mathrm{CD}-\mathrm{OH}$ nanoassemblies on HeLa cells viability at $24 \mathrm{~h}$, $48 \mathrm{~h}$, and $72 \mathrm{~h}$. $\mathrm{ZnPc}$ concentration was set at $0.012 \mu \mathrm{g} / \mathrm{mL}$ in all of the samples. Cell viability was quantified before (dark) and after irradiation $\left(\lambda=340 \mathrm{~nm}, 5 \mathrm{~J} / \mathrm{cm}^{2}, 30 \mathrm{~min}\right)$ by using MTS assay. Adapted from Conte; Scala; Siracusano; Leone; Patane; Ungaro; Miro; Sciortino; Quaglia; Mazzaglia [166].

Encouraged by the promising results of their previous work, the authors investigated the possibility of using the same nanoasemblies for combined cancer therapies (PDT and chemotherapy) [167]. The new nanoassemblies (hydrodynamic size of $200 \mathrm{~nm}$ ) were formed as previously described [166] in aqueous medium in the presence of docetaxel (DTX) as the chemotherapeutic drug (ZnPc/DTX/SC $16-\beta-\mathrm{CD}-\mathrm{OH}$, Figure 40$)$.

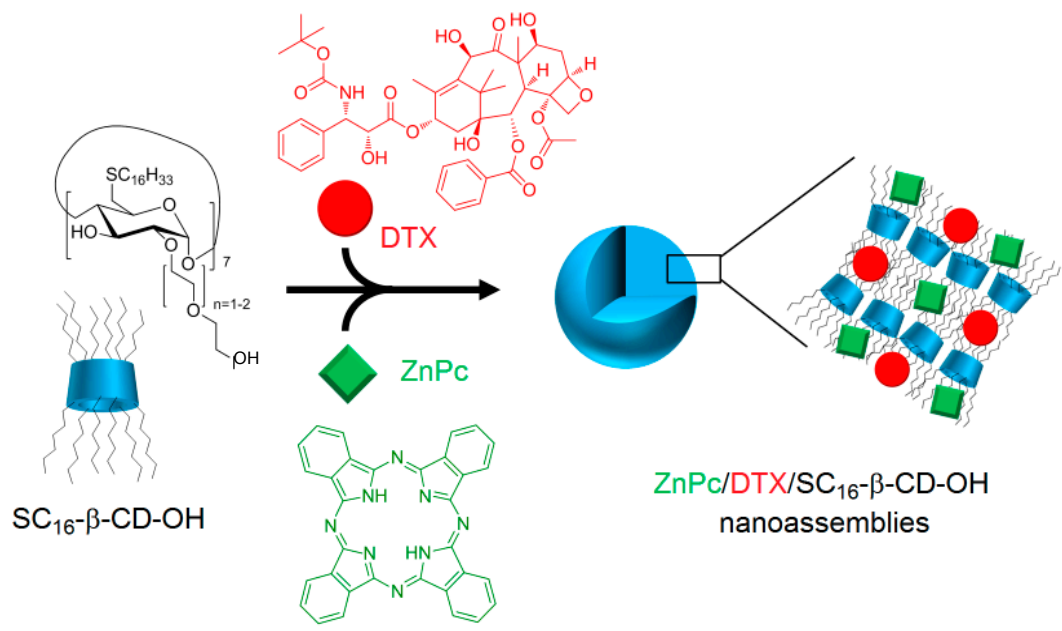

Figure 40. Molecular structure of $\mathrm{SC}_{16}-\beta-\mathrm{CD}-\mathrm{OH}, \mathrm{ZnPc}$, docetaxel (DTX), and corresponding $\mathrm{ZnPc} / \mathrm{DTX} / \mathrm{SC}_{16}-\beta-\mathrm{CD}-\mathrm{OH}$ nanoassembly. Adapted from Conte; Scala; Siracusano; Sortino; Pennisi; Piperno; Miro; Ungaro; Sciortino; Quaglia; Mazzaglia [167].

The new $\mathrm{ZnPc} / \mathrm{DTX} / \mathrm{SC}_{16}-\beta-\mathrm{CD}-\mathrm{OH}$ nanoassemblies were characterized as previously described [166]. These NPs have a hydrodynamic diameter of around $200 \mathrm{~nm}$, and no specific interaction with the $\mathrm{SC}_{16}-\beta-\mathrm{CD}-\mathrm{OH}$ cavity was shown. Finally, the PDT efficiency of $\mathrm{ZnPc} / \mathrm{DTX} / \mathrm{SC}_{16}-\beta-\mathrm{CD}-\mathrm{OH}$ NPs using HeLa cells was investigated and compared to free drugs. Based on in vitro studies using HeLa cells, no dark cytotoxicity was detected in all of the treated cells in the dark, but under irradiation $\left(\lambda=340 \mathrm{~nm}, 5 \mathrm{~J} / \mathrm{cm}^{2}, 30 \mathrm{~min}\right)$, a similar phototoxic effect was observed for $\mathrm{ZnPc} / \mathrm{DTX} / \mathrm{SC}_{16}-\beta-\mathrm{CD}-\mathrm{OH} \mathrm{NPs}$, and exhibited a comparable phototoxic effect to that of irradiated free $\mathrm{ZnPc}$ in DMSO (Figure 41). 


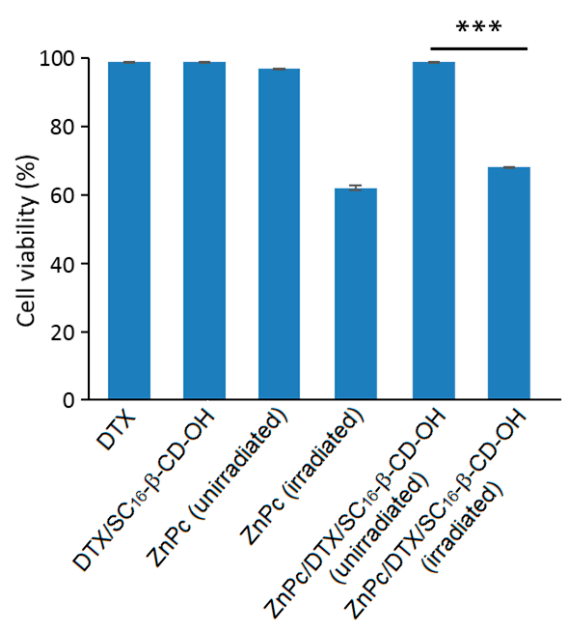

Figure 41. HeLa cell viability (MTS assay, ${ }^{* * *} p<0.01$ by Student's $t$-test) in the dark and after light irradiation $\left(\lambda=340 \mathrm{~nm}, 5 \mathrm{~J} / \mathrm{cm}^{2}, 30 \mathrm{~min}\right)$. The cells were treated with free DTX, free ZnPc, DTX/SC $16-\beta-C D-O H$ nanoparticles (NPs), and ZnPc/DTX/SC $16-\beta-C D-O H$ NPs $(10 \mu \mathrm{g} / \mathrm{mL}$ for all samples) and collected at $24 \mathrm{~h}$. Adapted from Conte; Scala; Siracusano; Sortino; Pennisi; Piperno; Miro; Ungaro; Sciortino; Quaglia; Mazzaglia [167].

Finally, Mazzaglia et al. in 2017 [168] described the elaboration of a novel nanophototherapeutic using the same emulsion-solvent evaporation procedure in a water environment as described in their previous studies [162,163,165-167]. For this novel nanoassembly (hydrodynamic size of around $40 \mathrm{~nm}$ ) and as reported in their previous work [164], the authors used the same water-soluble anionic PS $\left(\mathrm{TPPS}_{4}\right)$, but this time with a new cationic amphiphilic CD, i.e., heptakis[6-(2-aminoethylthio)-6-deoxy-2,3-di-O-hexanoyl] cyclomaltoheptaose (CD-N) (Figure 42).

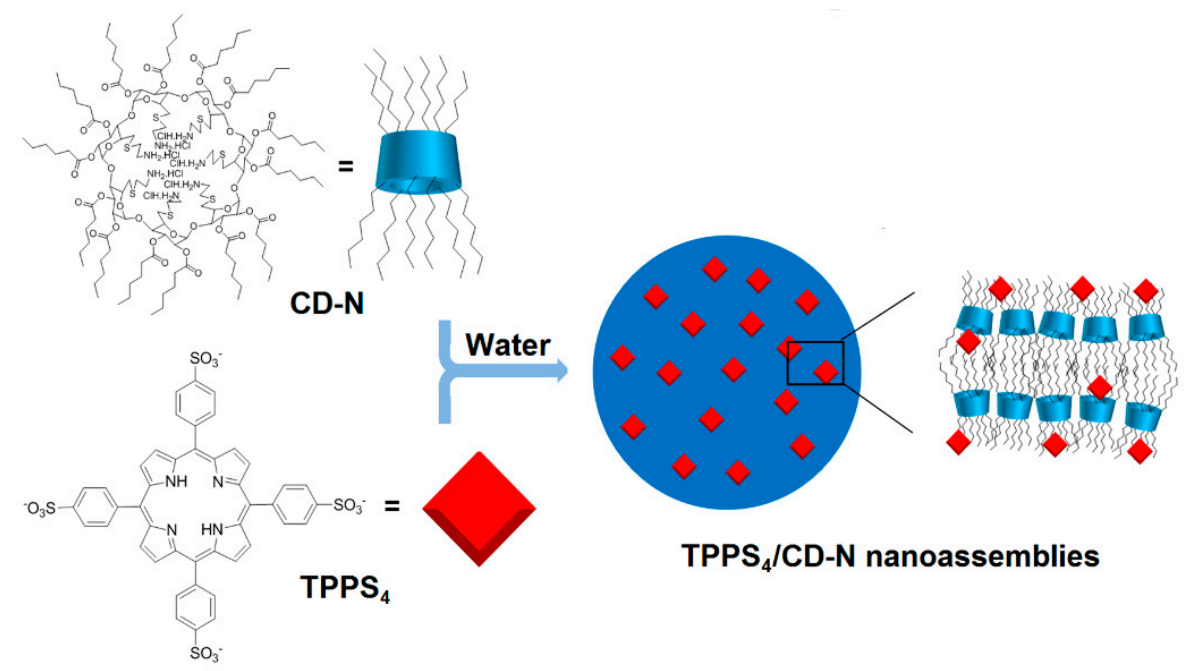

Figure 42. Molecular structure of cyclomaltoheptaose (CD-N), TPPS $_{4}$ and corresponding TPPS $_{44} / \mathrm{CD}-\mathrm{N}$ nanoassembly. Adapted from Mazzaglia; Micali; Villari; Zagami; Pennisi; Mellet; Fernandez; Sciortino; Scolaro [168].

Cellular uptake was performed on HeLa cells treated with TPPS $_{4} / \mathrm{CD}-\mathrm{N}$ nanoassemblies, and the authors showed that amphiphilic CD-N was able to promote the intracellular delivery of $\mathrm{TPPS}_{4}$. The in vitro PDT efficiency of TPPS $_{4} / \mathrm{CD}-\mathrm{N}$ nanoassemblies on the same cell lines model upon visible light irradiation $\left(\lambda=340 \mathrm{~nm}, 5 \mathrm{~J} / \mathrm{cm}^{2}, 30 \mathrm{~min}\right)$ were also investigated. In the absence of light, higher dark cytotoxicity was observed in the case of cells treated with the $\mathrm{TPPS}_{4} / \mathrm{CD}-\mathrm{N}$ nanosystem 
compared to those treated with $\mathrm{TPPS}_{4}$ alone, which may be due to a higher $\mathrm{TPPS}_{4}$ uptake. Interestingly, the TPPS 4 /CD-N nanosystem was found to be more efficient than free $\mathrm{TPPS}_{4}$ to induce photodamage upon light irradiation (Figure 43).

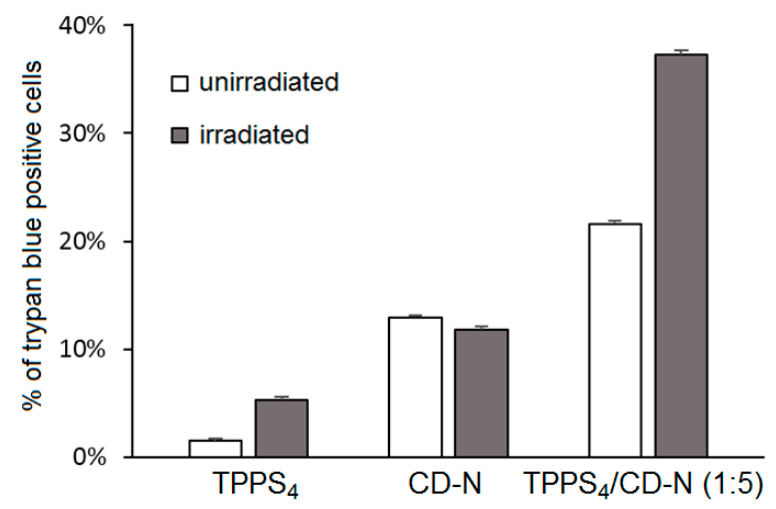

Figure 43. Cell death percentage in HeLa using trypan blue assay. HeLa cells were treated with free $\mathrm{TPPS}_{4}(1.7 \mu \mathrm{M})$ and unloaded CD-N as controls, and with $\mathrm{TPPS}_{4} / \mathrm{CD}-\mathrm{N}$ nanoassemblies prepared at 1:5 molar ratios, respectively. $\mathrm{TPPS}_{4}$ amount was fixed at $1.7 \mu \mathrm{M}$. Samples were exposed to visible light irradiation $\left(\lambda=340 \mathrm{~nm}, 5 \mathrm{~J} / \mathrm{cm}^{2}, 30 \mathrm{~min}\right)$. Adapted from Mazzaglia; Micali; Villari; Zagami; Pennisi; Mellet; Fernandez; Sciortino; Scolaro [168].

The development of supramolecular self-assemblies using amphiphilic CDs as drug delivery nanocarriers may suffer from the conjugate's lack of stability [169-171]. In fact, the chemical bonds that are often used to bind CDs to the drugs can be labile, and thus cause the premature loss of drugs [156,172]. To deal with this problem, Xiong et al. [173] in 2017 used the high affinity of carboranes (CBs) for the $\beta-C D$ and developed two stable amphiphilic supramolecular nanossemblies based on $\beta$-CDs and CBs, and loaded with PS (5-(4-hydroxy-phenyl)-10,15,20-triphenyl-porphyrin, TPP). Host-guest interactions between amphiphilic PEG-modified $\beta$-CD (PEG- $\beta$-CD) and octyl-carborane $\left(\mathrm{C}_{8}-\mathrm{CB}\right)$ led to the formation of $1: 1$ and 2:1 inclusion complexes named PEG- $\beta-\mathrm{CD} / \mathrm{C}_{8}-\mathrm{CB}$ and 2 PEG- $\beta$-CD $/ \mathrm{C}_{8}$-CB. These inclusion complexes self-assembled into spherical NPs and finally loaded with TPP to afford TPP@PEG- $\beta-C D / C_{8}-C B$ and TPP@2PEG- $\beta-C D / C_{8}-C B$ NPs with hydrodynamic sizes of $113 \mathrm{~nm}$ and $93 \mathrm{~nm}$, respectively. The in vitro behavior of TPP@PEG- $\beta-C D / C_{8}-C B$ NPs was investigated on human liver cancer cells (HepG2) using confocal microscopy and flow cytometry. The authors showed that NPs were mainly localized in the cytoplasm region, in close vicinity to the nuclei, and provided higher fluorescent signals compared to cells treated with free TPP or with the physical mixture of PEG- $\beta-C D / C_{8}-C B$ and TPP. In vitro cell viability on normal human bronchial epithelial (BEAS-2B) cells, and HepG2 and HeLa cancer cells was investigated by MTT assay under irradiation $\left(\lambda=620 \mathrm{~nm}, 16 \mathrm{~mW} / \mathrm{cm}^{2}\right)$. No dark cytotoxicity was observed, even at an $\mathrm{NP}$ concentration of $8 \mu \mathrm{g} / \mathrm{mL}$. For TPP@PEG- $\beta$-CD/C 8 -CB NPs, it was found that the viability of cancer cells (HepG2 and HeLa) after irradiation was 10 times lower compared to TPP alone or to the physical mixture of PEG- $\beta-C D / C_{8}-C B$ and TPP. Finally, the stability in solution and the photostability of TPP@PEG- $\beta$-CD $/ \mathrm{C}_{8}$-CB NPs were evaluated, and the authors estimated that less than $5 \%$ of TPP leaked after five days in physiological solution ( $10 \%$ fetal bovine serum), and only a $5.2 \%$ absorbance decrease was observed after 90 min of irradiation.

As complementary information and concerning the elaboration of the nanoassemblies of amphiphilic CDs and porphyrinoid PSs, we can mention also an article published in 2013 by Voskuhl et al. [174]. The authors investigated the self-assembly of a supramolecular ${ }^{1} \mathrm{O}_{2}$ photosensitizing system based on host-guest interactions between an adamantane-functionalized $\mathrm{ZnPc}$ (Ada-ZnPc) and $\beta-C D$ vesicles ( $\beta$-CDVs). The resulted Ada-ZnPc/ $\beta-C D V$ nanoassemblies allowed an increase of the ${ }^{1} \mathrm{O}_{2}$ photosensitizing ability of $\mathrm{ZnPc}$, while preventing its self-aggregation. These results reflect the 
possible use of this supramolecular assembly as a biocompatible photoactive platform for the design of phototherapeutic agents. Concerning non-porphyrinoid PSs, only one article has been found in the literature. In 2016, Kauscher et al. [175] described the immobilization of photoreactive squaraines (non-porphyrinoid PS) on a supramolecular amphiphilic CD nanoassemblies, and highlighted the ${ }^{1} \mathrm{O}_{2}$ production under irradiation and an improvement in the photochemical activity of squaraines. However, no in vitro biological study has yet been made of the impact of these nanoassemblies on the PDT efficiency.

- Nanoassemblies using polymeric cyclodextrines

Besides the supramolecular nanoassemblies based on amphiphilic $C D$, the researchers are studying new $\mathrm{CD}$ derivatives, and some works deal with the use of polymeric CDs for new stable and efficient buildings that can be used for PDT [176].

In 2014, Sortino et al. [177] engineered supramolecular nanoassemblies that were composed of four different components, i.e., a poly $(\beta-C D)$ polymer, a hydrophobically modified dextran (hDex), an anionic zinc phthalocyanine $(\mathrm{ZnPc})$, and a NO photodonor. The assembly occurred spontaneously in aqueous medium forming a "Lock and Key" hydrogel, since the alkyl chains of hDex were included in the cavity of poly ( $\beta$-CD) (Figure 44). The authors described for the first time a hydrogel system that was suitable for (1) producing both red and green fluorescence signals, (2) photoreleasing simultaneously two cytotoxic species $\left({ }^{1} \mathrm{O}_{2}\right.$ and $\left.\mathrm{NO}^{\bullet}\right)$, and (3) inducing an amplified cancer cell death (Figure 44).

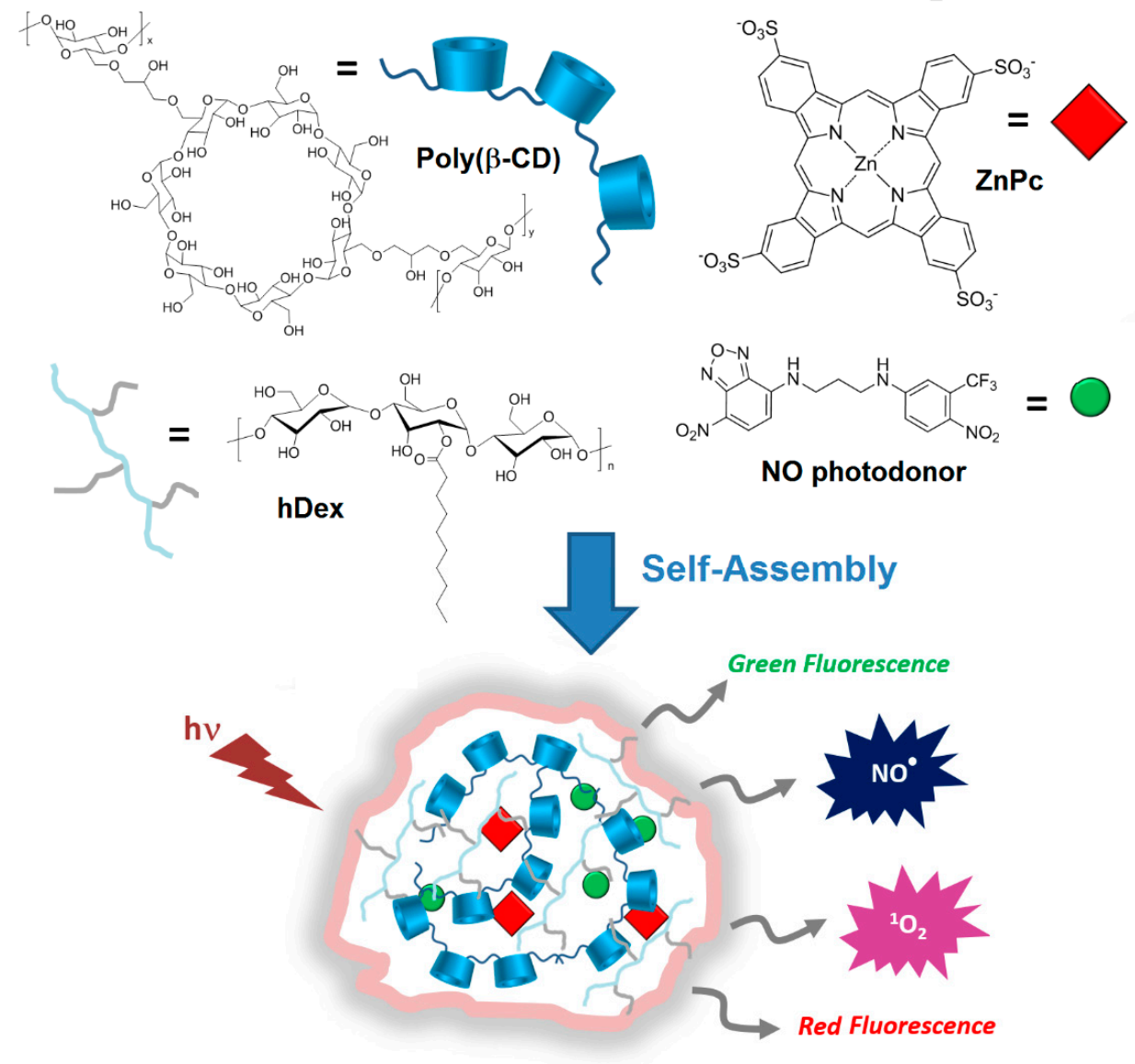

ZnPc/NO photodonor/hDex/Poly( $\beta-C D)$ hydrogel

Figure 44. Molecular structure of $\mathrm{Poly}(\beta-\mathrm{CD})$, ZnPc, hydrophobically modified dextran (hDex), NO photodonor, and corresponding ZnPc/NO photodonor/hDex/Poly( $\beta-\mathrm{CD})$ hydrogel. Adapted from Fraix; Gref; Sortino [177]. 
In that same year, Sortino et al. [178] engineered supramolecular nanoassemblies composed of three different components, i.e., a poly $(\beta-\mathrm{CD})$ polymer, an anionic zinc phthalocyanine ( $\mathrm{ZnPc})$, and an NO photodonor attached to an adamantane moiety (NO photodonor-Ada). The adamantane unit is known to form an inclusion complex with the cavity of $\beta-C D$. The self-assembly led to the formation of $\mathrm{ZnPc} / \mathrm{NO}$ photodonor-Ada/Poly $(\beta-\mathrm{CD}) \mathrm{NPs}$ with an average hydrodynamic diameter of $35 \mathrm{~nm}$ (Figure 45).

To validate the feasibility of $\mathrm{ZnPc} / \mathrm{NO}$ photodonor-Ada/Poly $(\beta-\mathrm{CD})$ NPs as bimodal phototherapeutic agents, an in vitro PDT study were performed using human squamous carcinoma (A431) cells (Figure 46). The authors thereby showed that the irradiation of $\mathrm{ZnPc} / \mathrm{NO}$ photodonor-Ada/Poly ( $\beta-C D)$ NPs with visible light (405-nm and 633-nm light to target the NO photodonor and $\mathrm{ZnPc}$, respectively) triggered the simultaneous delivery of cytotoxic ${ }^{1} \mathrm{O}_{2}$ and $\mathrm{NO}^{\bullet}$ species, resulting in an amplified cell photomortality due to the synergistic effect of both cytotoxic agents. It was shown also that $\mathrm{ZnPc} / \mathrm{NO}$ photodonor-Ada/poly $(\beta-\mathrm{CD}) \mathrm{NPs}$ could act as two photon emission (TPE) imaging agents.

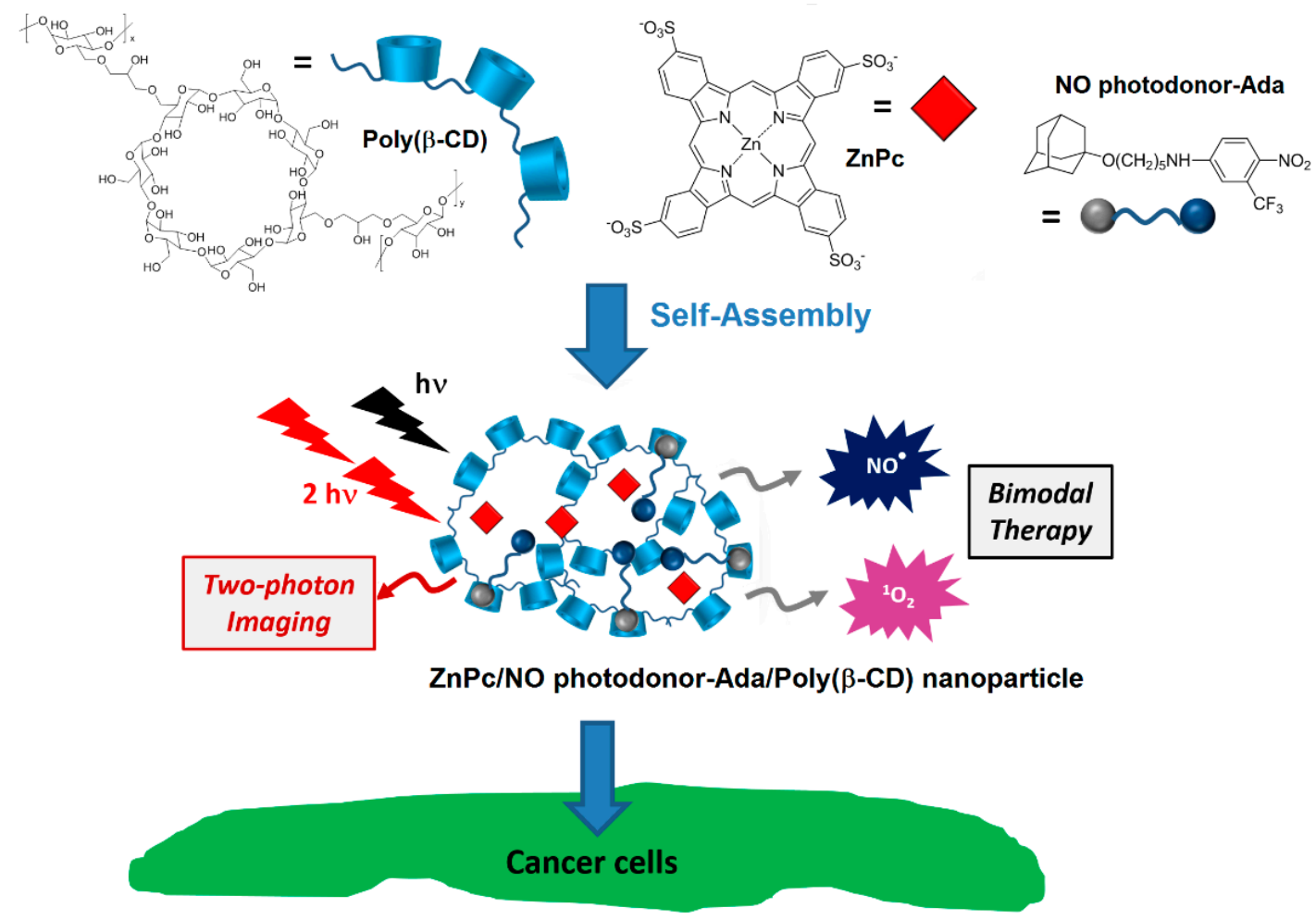

Figure 45. Molecular structure of Poly $(\beta-\mathrm{CD}), \mathrm{ZnPc}$, an $\mathrm{NO}$ photodonor attached to an adamantane moiety (NO photodonor-Ada), and corresponding ZnPc/NO photodonor-Ada/Poly( $\beta-C D)$ nanoparticle. Adapted from Kandoth; Kirejev; Monti; Gref; Ericson; Sortino [178].

In 2015, Lee et al. [179] developed a new biocompatible nanoassembly that was constituted of poly $(\beta-C D)$ linked by carbonate bonds to cholesteryl chloroformate (CC) and chlorin e6 (Ce6). The self-assembly induced the formation of core-shell poly $(\beta-C D)-g-C C-g-C e 6$ NPs (average particle size of $61 \mathrm{~nm}$ ) in which the hydrophobic CC and Ce6 core is enclosed with a layer of hydrophilic poly $(\beta-C D)$ shell. The authors found that the poly $(\beta-C D)-g-C C-g-C e 6$ properties as drug carrier were highly $\mathrm{pH}$-dependent. It was also found that at an acidic $\mathrm{pH}$, poly( $\beta-\mathrm{CD})-g-\mathrm{CC}-g-\mathrm{Ce} 6 \mathrm{NPs}$ disintegration happened due to the carbonate linkages cleavage producing $\mathrm{CO}_{2}($ Figure 47$)$. 


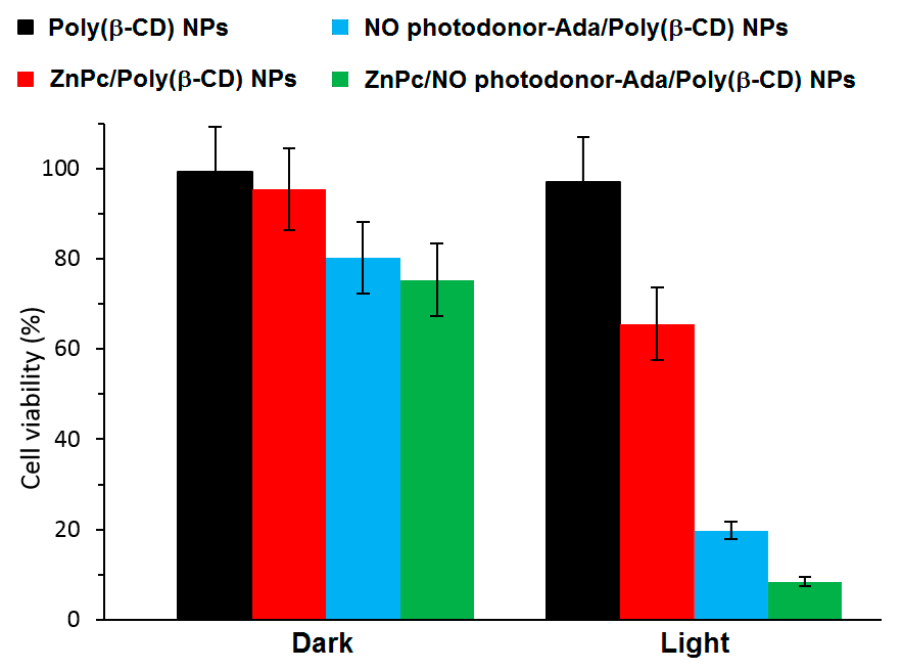

Figure 46. Dark and photoinduced mortality of A431 cells incubated with aqueous dispersion of Poly $(\beta-C D), \mathrm{ZnPc} / \mathrm{Poly}(\beta-\mathrm{CD})$, NO photodonor-Ada/Poly $(\beta-C D)$, and ZnPc/NO photodonor-Ada / Poly $(\beta-C D)$ NPs. The samples were simultaneously irradiated with $405 \mathrm{~nm}\left(10 \mathrm{~J} / \mathrm{cm}^{2}\right)$ and $633 \mathrm{~nm}\left(10 \mathrm{~J} / \mathrm{cm}^{2}\right)$ LED sources. [Poly $\left.(\beta-\mathrm{CD})\right]=11 \mu \mathrm{M}(7.75 \mathrm{mM}$ in $\beta-\mathrm{CD}),[\mathrm{ZnPc}]=15 \mu \mathrm{M}$, [NO photodonor-Ada] $=40 \mu \mathrm{M}$. Adapted from Kandoth; Kirejev; Monti; Gref; Ericson; Sortino [178].

Chlorin e6 (Ce6)

Cholesteryl chloroformate (CC)

$\operatorname{Poly}(\beta-C D)$

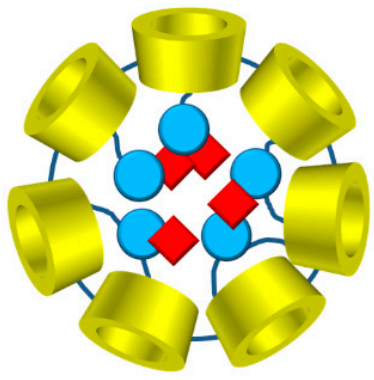

Auto-quenched Ce6 (at pH 7.4)

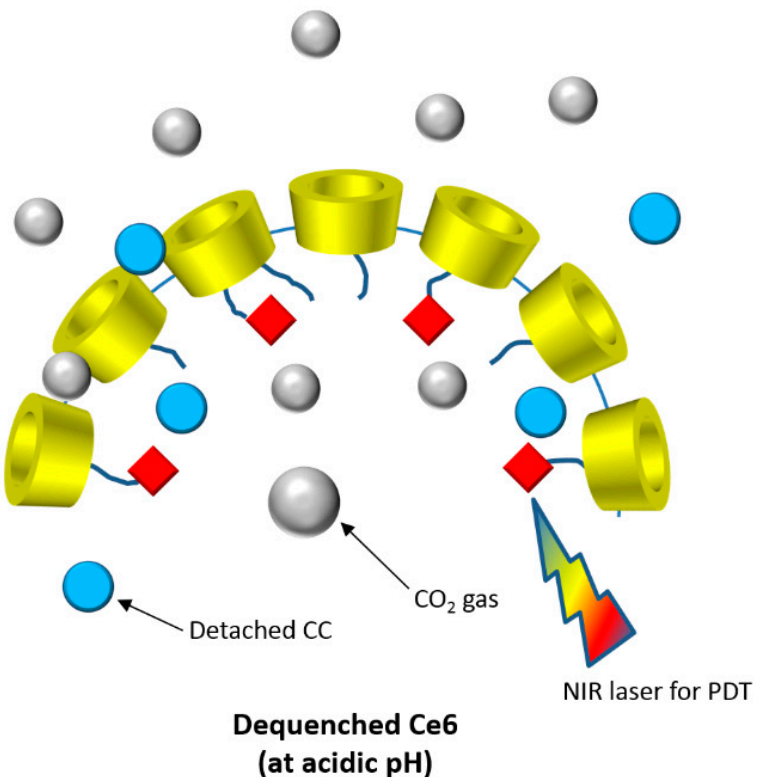

(at acidic pH)

Figure 47. Schematic concept of the poly( $\beta-C D)-g-C C-g-C e 6$ NPs responding to an acidic $p H$. Adapted from Lee; Oh; Youn; Lee [179]. CC: cholesteryl chloroformate, Ce6: chlorin e6.

Furthermore, they found that upon irradiation $\left(\lambda=670 \mathrm{~nm}, 5.2 \mathrm{~mW} / \mathrm{cm}^{2}\right.$ during $\left.10 \mathrm{~min}\right)$, poly $(\beta-\mathrm{CD})-g$-CC- $g$-Ce6 NPs have the ability to produce more ${ }^{1} \mathrm{O}_{2}$ at acidic $\mathrm{pH}$ (tumor environment, $\mathrm{pH}$ 6.5) compared to the physiological $\mathrm{pH}(\mathrm{pH}$ 7.4). The in vitro studies performed on the human nasopharyngeal epidermal carcinoma (KB) cell line showed that compared to Ce6 alone, a highest cellular uptake at acidic $\mathrm{pH}$ and mainly in nucleus for poly( $\beta$-CD)-g-CC-g-Ce6 NPs was observed. No dark cytotoxicity was detected for the poly $(\beta-C D)-g-C C-g$-Ce6 NPs. However, upon irradiation $\left(\lambda=670 \mathrm{~nm}, 5.2 \mathrm{~mW} / \mathrm{cm}^{2}\right.$, during $\left.10 \mathrm{~min}\right)$, poly $(\beta-C D)-g-C C-g-C e 6$ NPs exhibited stronger phototoxicity at $\mathrm{pH} 6.5$ compared to that at $\mathrm{pH} 7.4$ (Figure 48). These results highlighted the potential usefulness of poly $(\beta-\mathrm{CD})-g-\mathrm{CC}-g-\mathrm{Ce} 6 \mathrm{NPs}$ in anticancer PDT treatment. 

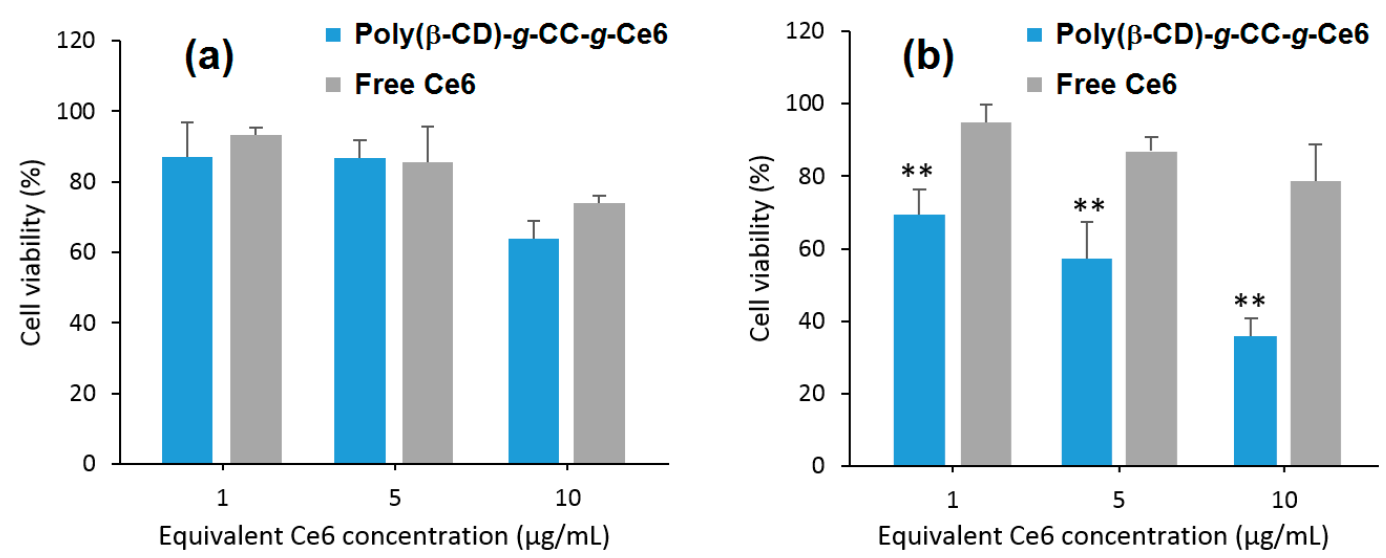

Figure 48. Photoinduced mortality of the human nasopharyngeal epidermal carcinoma (KB) cell line treated with Poly $(\beta-C D)-g-C C-g-C e 6$ NPs (equivalent Ce6 1-10 $\mu \mathrm{g} / \mathrm{mL})$ or free ZnPc $(1-10 \mu \mathrm{g} / \mathrm{mL}$ ) upon irradiation $\left(\lambda=670 \mathrm{~nm}, 5.2 \mathrm{~mW} / \mathrm{cm}^{2}\right.$ for $\left.10 \mathrm{~min}\right)$ at (a) $\mathrm{pH} 7.4$ and (b) $\mathrm{pH}$ 6.5. ${ }^{* *} p<0.01$ compared to free Ce6. Results are expressed as the mean of seven measurements with the vertical bar showing SD. Adapted from Lee; Oh; Youn; Lee [179].

As complementary information concerning the elaboration of nanoassemblies polymeric CDs and non-porphyrinoid PSs, only one article has been found in the literature. In 2014, Kirakci et al. [180] described three supramolecular nanoassemblies composed by poly $(\beta-C D)$ and octahedral molybdenum cluster complexes (non-porphyrinoid PSs). The resulting assemblies afforded hydrogel particles (hydrodynamic diameter from $160 \mathrm{~nm}$ to $240 \mathrm{~nm}$ ) without adversely affecting the photophysical properties of the octahedral molybdenum cluster complexes (red luminescence and high quantum yield). The photophysical properties of these hydrogel particles were associated with the oxygen sensitivity of the luminescence, making them interesting for a usefulness as potential dual agents for PDT/boron neutron capture therapy.

- Other cyclodextrin-photosensitizer nanoassemblies

Aside from the supramolecular CD-PS nanoassemblies based on PSs and chemically modified $\mathrm{CDs}$, some teams wished to reverse this strategy by forming nanoassemblies with CDs and chemically modified PSs.

In 2015, Liu et al. [181] synthesized a supramolecular system using poly(ethylene glycol 400)- $\beta$-CD $\left(\mathrm{PEG}_{400}-\beta-\mathrm{CD}\right)$ and a porphyrin derivative containing a disulfide bond (S-S) and an adamantane (Ada) group (TPPC 6 -SS-Ada, Figure 49).

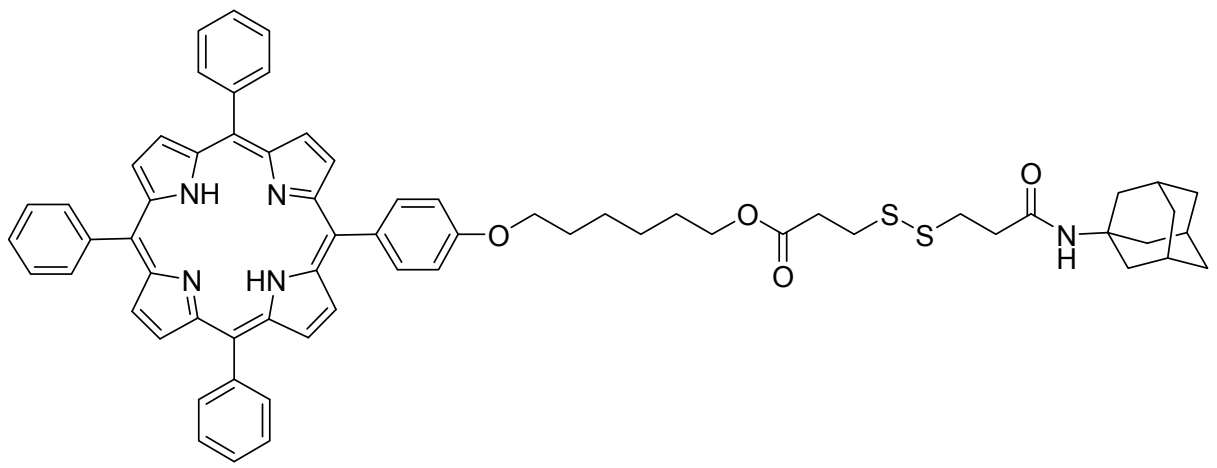

Figure 49. Chemical structure of a porphyrin derivative containing a disulfide bond (S-S) and an adamantane (Ada) group (TPPC 6 -SS-Ada). 
The host-guest interactions between $\mathrm{PEG}_{400}-\beta-\mathrm{CD}$ and $\mathrm{TPPC}_{6}$-SS-Ada led to the formation of $\mathrm{TPPC}_{6}$-SS-Ada/PEG $400-\beta-\mathrm{CD}$ polypseudorotaxanes (PPRs) that were able to self-assemble into spherical micelles in aqueous solution (average particle size of around $72 \mathrm{~nm}$, Figure 50). The S-S linkage can be cleaved in reducing intracellular microenvironment. The high level of glutathione (GSH) in cytosol could allow the PS release.

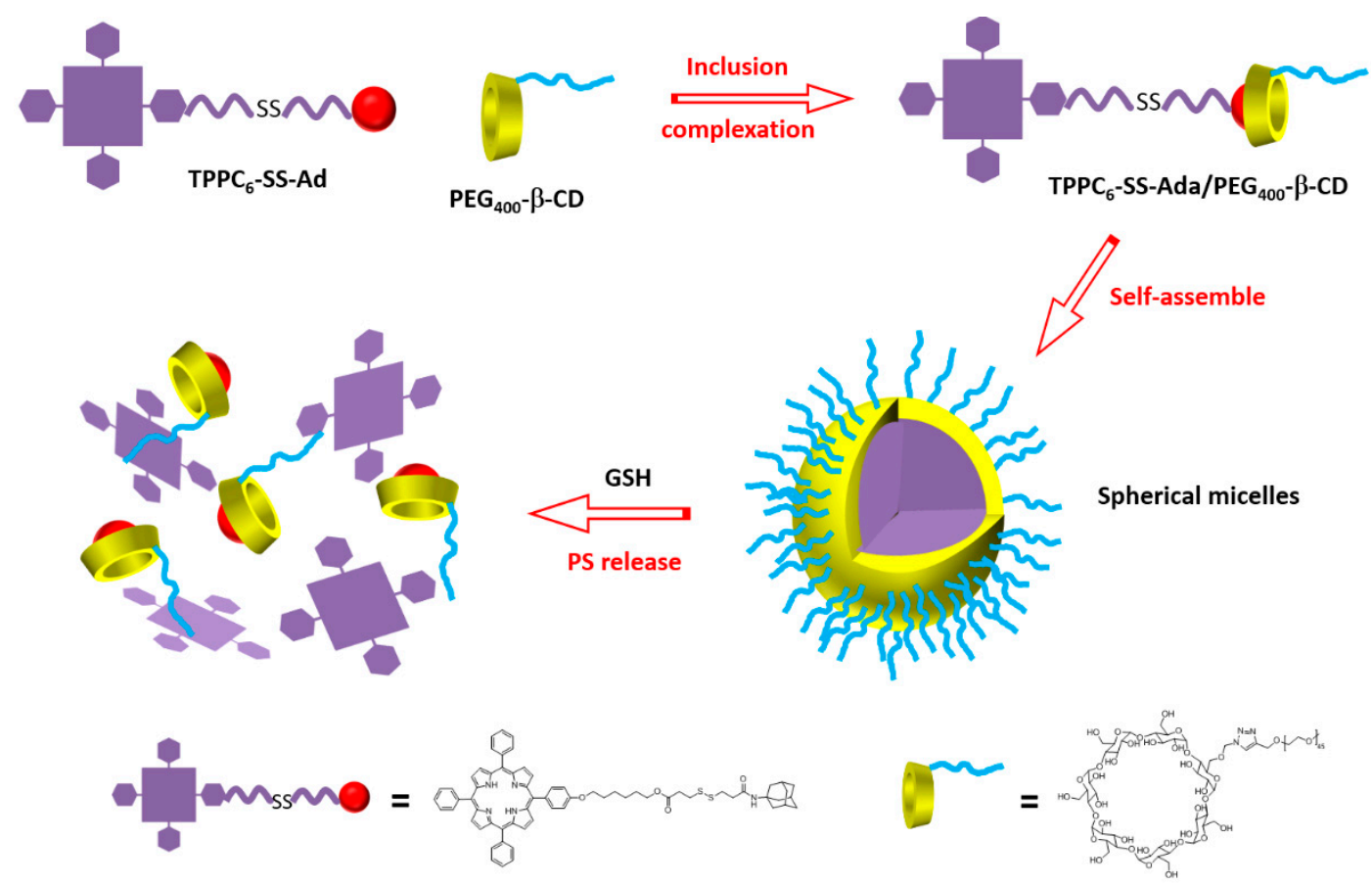

Figure 50. Self-assembly and disaggregation process of $\mathrm{TPPC}_{6}$-SS-Ada/PEG $400-\beta-\mathrm{CD}$ micelles. Adapted from Liu; Ma; Xu; Liu; Zhang [181].

For comparison, the authors also synthesized the $\mathrm{TPPC}_{6}$-Ada/PEG- $\beta$-CD analog without the disulfide bridge. The authors proved that the $\mathrm{S}-\mathrm{S}$ bond could be cleaved upon the addition of GSH. Moreover, an in vitro study using MCF-7 cells showed that free porphyrin accumulated less than $\mathrm{TPPC}_{6}$-SS-Ada $/ \mathrm{PEG}_{400}-\beta-\mathrm{CD}$, which might be taken up through an endocytosis process. No dark toxicity could be observed for free porphyrin, TPPC $_{6}$-SS-Ada/PEG- $\beta$-CD, and $\mathrm{TPPC}_{6}$-Ada/ $/ \mathrm{PEG}_{400}-\beta-\mathrm{CD}$ micelles, even up to $100 \mathrm{mg} / \mu \mathrm{L}$ of porphyrin. The phototoxic effect upon irradiation with a visible light LED lamp $\left(400 \mathrm{~mW} / \mathrm{cm}^{2}\right)$ for $20 \mathrm{~min}$ was the best for TPPC $_{6}$-SS-Ada $/$ PEG $_{400}-\beta$-CD with an $\mathrm{IC}_{50}$ of $31 \mu \mathrm{g} / \mathrm{mL}$. At $100 \mathrm{mg} / \mu \mathrm{L}$ of porphyrin, cell viability was $60 \%$ for $\mathrm{TPPC}_{6}-\mathrm{Ada} / \mathrm{PEG}_{400}-\beta-\mathrm{CD}$, and around $35 \%$ for $\mathrm{TPPC}_{6}-\mathrm{SS}-\mathrm{Ada} / \mathrm{PEG}_{400}-\beta-\mathrm{CD}$. This better result is due to the release of the porphyrin upon cleavage of the S-S bond with GSH. The authors were the first to report the utilization of polypseudorotaxanes (PPRs) for PDT.

Based on the work above described about PPRs for PDT [181], Tong et al. [182] used a similar strategy in 2016 to develop GSH activatable PS-conjugated PPR nanocarriers (Ce6-SS- $\alpha$-CD/PEG- $b$-PMPC with an average size of $60 \mathrm{~nm}$ ) for photodynamic theranostics. This time, the supramolecular system was based on host-guest interactions between PEG-b-poly (2-methacryl-oyloxyethyl phosphorylcholine) (PEG- $b$-PMPC) block copolymers and a chlorin e6 derivative containing a disulfide bond and $\alpha-\mathrm{CD}$ (Ce6-SS- $\alpha-\mathrm{CD})$. The in vitro cellular redox activatable behavior of Ce6-SS- $\alpha$-CD/PEG- $b$-PMPC NPs was investigated on human oral epidermoid carcinoma (KB) cells using confocal microscopy and flow cytometry. The authors observed (1) a clear red fluorescence of $\mathrm{Ce} 6$ in KB cells without any treatment, indicating an efficient internalization of NPs, (2) the strongest intracellular Ce6 fluorescence in the presence of high GSH concentration, which became weakest in the presence of low GSH concentration. The in vitro study of KB cells 
under irradiation $\left(\lambda=660 \mathrm{~nm}, 50 \mathrm{~mW} / \mathrm{cm}^{2}\right)$ showed a better phototoxic effect on cells treated with Ce6-SS- $\alpha$-CD/PEG- $b$-PMPC NPs compared to cells treated with free Ce6. Finally, in vivo fluorescence imaging-guided PDT of Ce6-SS- $\alpha$-CD/PEG- $b$-PMPC NPs in tumor-bearing mice (tumor size of $250 \mathrm{~mm}^{3}$ ) highlighted an impressive PDT effect on the tumor size after 14 days of therapy. All of these results demonstrated the ability of Ce6-SS- $\alpha$-CD/PEG- $b$-PMPC NPs to exhibit redox activatable fluorescence signal and ROS generation for photodynamic theranostics.

In 2017, $\mathrm{Xu}$ et al. [183] developed polypseudorotaxane NPs (mPEG-PpIX/ $\alpha$-CD) based on self-assembly of mPEG-protoporphyrin IX (mPEG-PpIX) conjugate and $\alpha$-CDs via host-guest interactions, followed by a chemotherapy drug (doxorubicin, DOX) encapsulation (DOX/mPEG-PpIX/ $\alpha$-CD NPs) with an average size of $89 \mathrm{~nm}$, as shown in Figure 51.

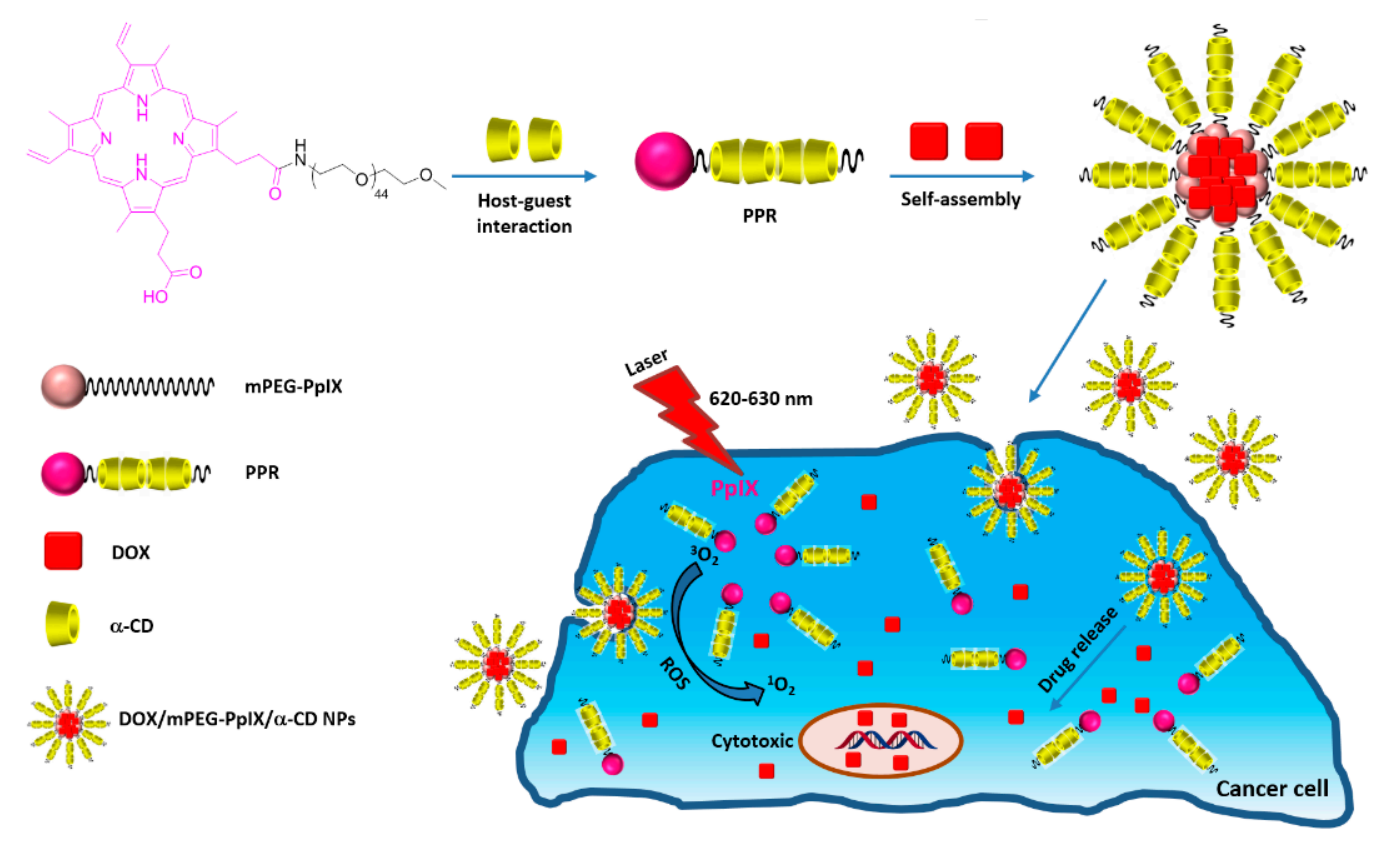

Figure 51. Illustration of polypseudorotaxane doxorubicin (DOX)/mPEG-PpIX/ $\alpha$-CD NPs with dual PDT/chemotherapy effect. Adapted from Xu; Li; Cheng; Zhang; Cao; Gao; He [183].

A cytotoxicity study of mPEG-PpIX/ $\alpha$-CD NPs using L929 fibroblasts cells was performed, and low dark cytotoxicity was found after the $48 \mathrm{~h}$ incubation of cells with mPEG-PpIX/ $\alpha$-CD NPs, even with a high concentration of NPs $(80 \%$ cell viability at a NP concentration of $300 \mu \mathrm{g} / \mathrm{mL})$. The in vitro PDT efficiency of mPEG-PpIX / $\alpha$-CD and DOX/mPEG-PPIX / $\alpha$-CD NPs was evaluated with different NP concentrations $(4.0 \mu \mathrm{g} / \mathrm{mL}, 12.1 \mu \mathrm{g} / \mathrm{mL}$, and $36.2 \mu \mathrm{g} / \mathrm{mL})$ with diiode laser irradiation $(\lambda=620-630 \mathrm{~nm})$ using HepG2 cells (Figure 52). For mPEG-PpIX/ $\alpha$-CD NPs, no dark cytotoxicity was observed, whatever the concentration used. However, the cell viability upon irradiation was found to be NP concentration-dependent with a higher impact in the presence of DOX. These results revealed that DOX/mPEG-PpIX / $\alpha$-CD NPs exhibited synergistic PDT/chemotherapy effects under laser irradiation.

As complementary information and concerning the elaboration of supramolecular nanoassemblies based on CDs and chemically modified PSs, we can also mention the work of Jin et al. [184] in 2015. This work described the development of supramolecular hydrogels based on host-guest interactions between amphiphilic PS cored and $\alpha$-CD leading to the formation of PPRs, which were subsequently self-assembled into hydrogels and loaded with DOX (chemotherapy drug). The resulted supramolecular DOX@PS / $\alpha$-CD hydrogel exhibited efficient DOX release and ${ }^{1} \mathrm{O}_{2}$ generation upon light irradiation, which makes this promising for both cancer chemotherapy drug delivery systems and as a potential PDT agent. 


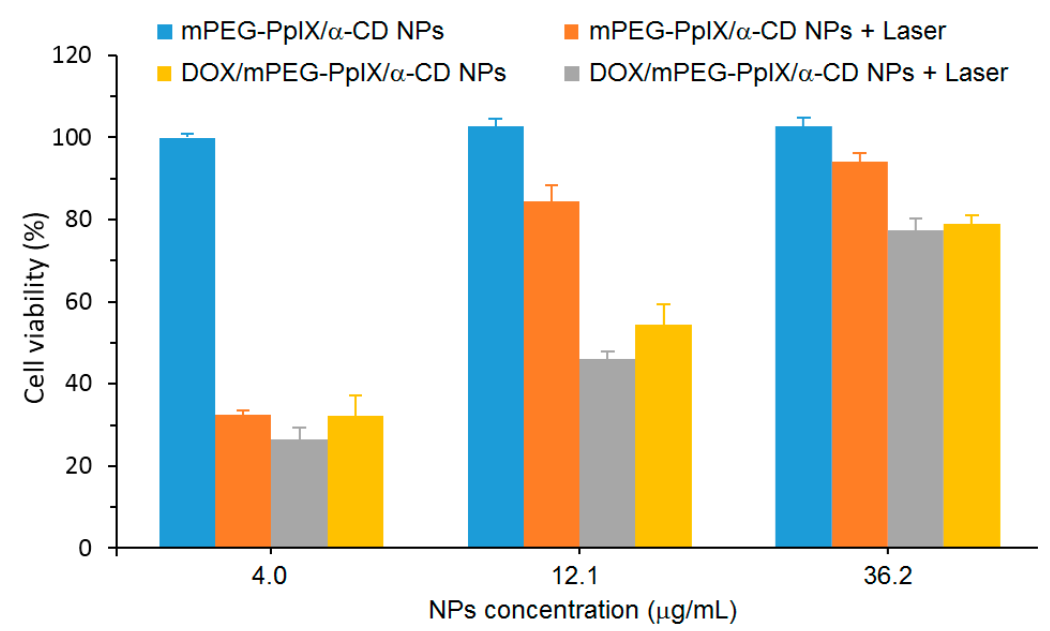

Figure 52. Cell viability of HepG2 cells incubated with mPEG-PpIX/ $\alpha-C D$ and $\mathrm{DOX} / \mathrm{mPEG}-\mathrm{PpIX} / \alpha-\mathrm{CD}$ NPs before and after laser irradiation $(\lambda=620-630 \mathrm{~nm})$ at different NPs concentration. Adapted from Xu; Li; Cheng; Zhang; Cao; Gao; He [183].

Aside from the supramolecular CD-PS nanoassemblies based on PSs (or chemically modified PSs) and chemically modified CDs (or CDs), another strategy employed by Zhang et al. [171] involved the use of platinium(IV) prodrug bridged $\beta-\mathrm{CD}$ dimer $\left(\mathrm{Pt}^{\mathrm{IV}}(\beta-\mathrm{CD})_{2}\right)$ and 5,10,15,20-tetrakis(1-adamantyl-pyridinium-4-yl)porphyrin (TPyP-(Ada) 4 ). The authors investigated the formation of $\mathrm{Pt}^{\mathrm{IV}}(\beta-\mathrm{CD})_{2} / \mathrm{TPyP}-(\mathrm{Ada})_{4} \mathrm{NPs}$ (average size of around $100 \mathrm{~nm}$ ) by host-guest interactions (stable 2:1 CD-PS inclusion complex) for chemo-photodynamic dual therapy against cisplatin-resistant cancer cells. The in vitro behavior of $\mathrm{Pt}^{\mathrm{IV}}(\beta-\mathrm{CD})_{2} / \mathrm{TPyP}-(\mathrm{Ada})_{4} \mathrm{NPs}$ was investigated on cisplatin-resistant human lung adenocarcinoma epithelial cells (A549R) using confocal microscopy and flow cytometry. $\mathrm{Pt}^{\mathrm{IV}}(\beta-\mathrm{CD})_{2} / \mathrm{TPyP}-(\mathrm{Ada})_{4}$ NPs were internalized by A549R cells in the form of NPs, and a rapid spread of $\mathrm{Pt}^{\mathrm{IV}}(\beta-\mathrm{CD})_{2} / \mathrm{TPyP}-(\mathrm{Ada})_{4} \mathrm{NPs}$ happened in the whole cytoplasm under light irradiation. An in vitro cytotoxicity study on A549R cells in the dark or with light irradiation $\left(\lambda=430 \mathrm{~nm}, 10 \mathrm{~mW} / \mathrm{cm}^{2}\right.$ for $\left.2 \mathrm{~min}\right)$ showed that $\mathrm{Pt}^{\mathrm{IV}}(\beta-\mathrm{CD})_{2} / \mathrm{TPyP}-(\mathrm{Ada})_{4} \mathrm{NPs}$ were much more cytotoxic than cisplatin, even in the dark. The cytotoxicity of $\mathrm{Pt}^{\mathrm{IV}}(\beta-\mathrm{CD})_{2} / \mathrm{TPyP}-(\mathrm{Ada})_{4}$ NPs was better under light irradiation, owing to the PDT effect (Table 7). All of these results highlighted a further synergistic effect by the combination of PDT treatment.

Table 7. Cytotoxicity of the compounds toward A549R cells ${ }^{1}$.

\begin{tabular}{cccc}
\hline & \multicolumn{3}{c}{$\mathrm{IC}_{\mathbf{5 0}}(\mu \mathrm{M})$} \\
\cline { 2 - 4 } & Cisplatin & $\mathbf{P t}^{\mathrm{IV}}(\boldsymbol{\beta}-\mathrm{CD})_{\mathbf{2}}$ / $\mathbf{T P y P}-(\mathbf{A d a})_{\mathbf{4}}$ & $\mathbf{P t}^{\mathrm{IV}}(\boldsymbol{\beta}-\mathbf{C D})_{\mathbf{2}}$ \\
\hline Dark & 23.2 & 4.6 & $>20$ \\
Light $^{2}$ & 22.8 & 1.5 & $>20$ \\
\hline were calculated based on $\mathrm{Pt}^{\mathrm{IV}}$ & concentration. ${ }^{2}$ Light irradiation $\left(\lambda=430 \mathrm{~nm}, 10 \mathrm{~mW} / \mathrm{cm}^{2}\right.$ for $\left.2 \mathrm{~min}\right)$.
\end{tabular}

\subsection{Cyclodextrin-Photosensitizer Systems into Hybrid Nanoparticles}

As mentioned in Section 2.2, various CD-PS systems, i.e., inclusion complexes, conjugates, and nanoassemblies, were investigated by researchers to improve some PS properties such as drug delivery, water solubility, stability, and ${ }^{1} \mathrm{O}_{2}$ production in aqueous media. The main goal of all of these improvements was to obtain the most adapted PDT agent for anticancer therapy. However, CDs alone cannot solve all of the problems related to PSs, and various studies aimed to combine nanoparticles to CD-PS systems to overcome a part of these limitations. 


\subsubsection{Cyclodextrin-Photosensitizer Systems into Up-Conversion Nanoparticles}

One of the problems limiting the use of many PSs, and that cannot be addressed by using only CD-PS systems, is the limited light penetration depth in biological tissues. This limitation is due to the light absorption and scattering by biological tissue, resulting in ineffective PDT effect in cases where cancer cells are located deeply in the body [185-187]. Irradiations in the near-infrared (NIR) region are known to have a penetration depth that is greater than UV visible light, but PSs that can efficiently absorb NIR light are still rare [188]. As a consequence, major efforts are made to develop CD-PS systems such as up-converting NPs (UCNPs), which are known for their ability to absorb and convert NIR light to visible photons efficiently [189-191].

In 2013, Tian et al. [73] synthesized red-emitting oleic acid-capped $\mathrm{NaYF}_{4}: \mathrm{Yb} / \mathrm{Er}$ UCNPs (OA-UCNPs) functionalized with $\alpha$-CD and loaded by different PSs (Figure 53). Firstly, functionalizing the OA-UCNPs with $\alpha$-CD aimed to tune the hydrophobic character of the OA-UCNPs and make it water-soluble in a host-guest strategy. The hydrophobic cavity of $\alpha$-CD interacted with the hydrophobic oleic acid surfactants that occupied the surface of the OA-UCNPs.

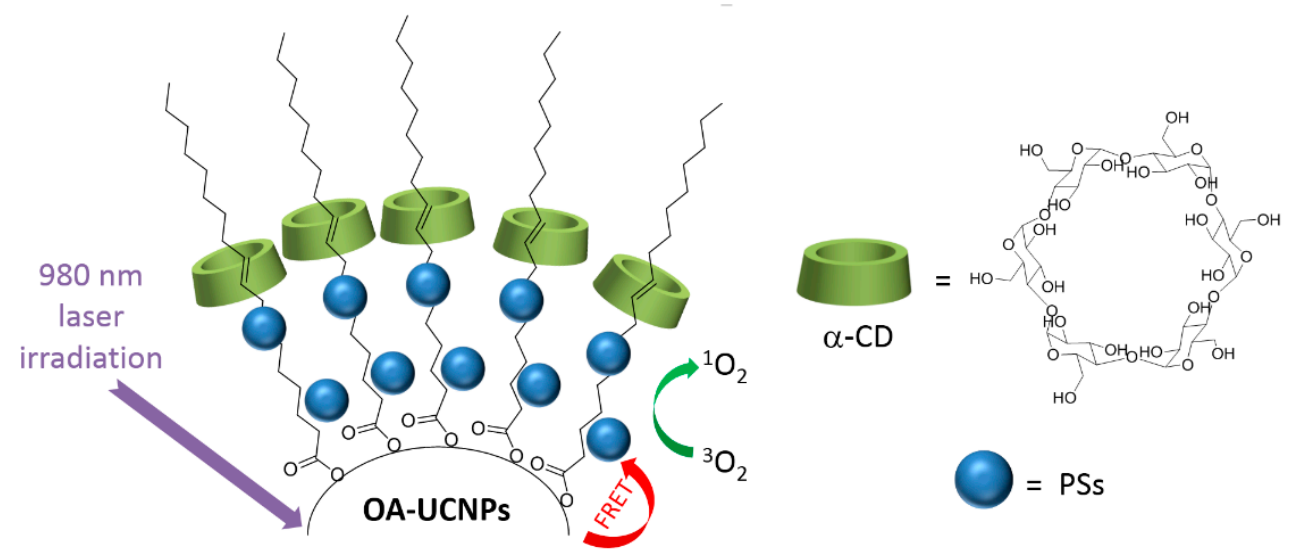

Figure 53. Schematic illustration of 980-nm near-infrared (NIR)-induced PDT using PS@ $\alpha$-CD/oleic acid-capped $\mathrm{NaYF}_{4}: \mathrm{Yb} / \mathrm{Er}$ up-converting nanoparticle (OA-UCNP) complexes. Adapted from Tian; Ren; Yan; Jian; Gu; Zhou; Jin; Yin; Li; Zhao [73].

The biocompatibility of the yielded $\alpha$-CD/OA-UCNPs was assessed by exposing the human epithelial lung cancer (A549) cells to different concentrations of the UCNPs (12.5 $\mu \mathrm{g} / \mathrm{mL}$ to $400 \mu \mathrm{g} / \mathrm{mL}$ ) in the dark. The $\alpha$-CD/OA-UCNPs left more than $90 \%$ of the cells alive. Moreover, the efficacy of $\alpha$-CD/OA-UCNPs in the in vivo imaging of deep tissues was further demonstrated through their inoculation into a Kunming mouse (10 mm depth) and observing their red emission under 980-nm NIR excitation. After those validations, and for their efficient use in PDT, OA-capped $\mathrm{Mn}^{2+}$-doped NaYF ${ }^{4}$-based UCNPs (OA-UCNPs) were loaded by three PSs, i.e., chlorine e6 (Ce6), zinc phthalocyanine $(\mathrm{ZnPc})$, and methylene blue $(\mathrm{MB})$ via hydrophobic interactions to form a stable donor-acceptor system (PS@ $\alpha$-CD/OA-UCNPs). The NIR irradiation of PS@ $\alpha$-CD/OA-UCNPs could indirectly activate the loaded PSs that in their turn generated large levels of ${ }^{1} \mathrm{O}_{2}$ in contrast to the free PS and the bare $\alpha$-CD/OA-UCNPs. The ${ }^{1} \mathrm{O}_{2}$ production was time and dose-dependent for all three PSs, with different levels, which were probably due to their different absorption profiles or loading capacities. The pre-mentioned advantageous properties of the PS@ $\alpha$-CD/OA-UCNPs enabled this system to reduce the viability of A549 cells under NIR irradiation at $980 \mathrm{~nm}$ while keeping a very low dark toxicity for all the three PSs (Figure 54a). It is noteworthy to mention that Ce6@ $\alpha-C D / O A-U C N P s$ yielded the largest phototoxicity among the three tested PSs. Encouraged by these phototoxicity results, the authors co-loaded a PDT agent (Ce6) and a chemotherapy drug (DOX) into their $\alpha$-CD/OA-UCNPs to estimate their efficiency in a combined therapy. In response to 
the change in $\mathrm{pH}$ from more basic to a more acidic media, DOX showed a high tendency to detach as it became more hydrophilic. On the contrary, Ce6 was barely released from the $\alpha-C D / O A-U C N P s$ under the same conditions. This behavior of Ce6 conserved the PDT effect that was based on the proximity of both $\alpha$-CD/OA-UCNPs and Ce6 to guarantee the latter's activation by Förster Resonance Energy Transfer (FRET). Although the presence of DOX in the Ce6/DOX@ $\alpha-C D / O A-U C N P s$ triggered a larger phototoxicity toward A549 cells under $980 \mathrm{~nm}-\mathrm{NIR}$ excitation, in parallel, it caused a higher dark toxicity (Figure 54b).
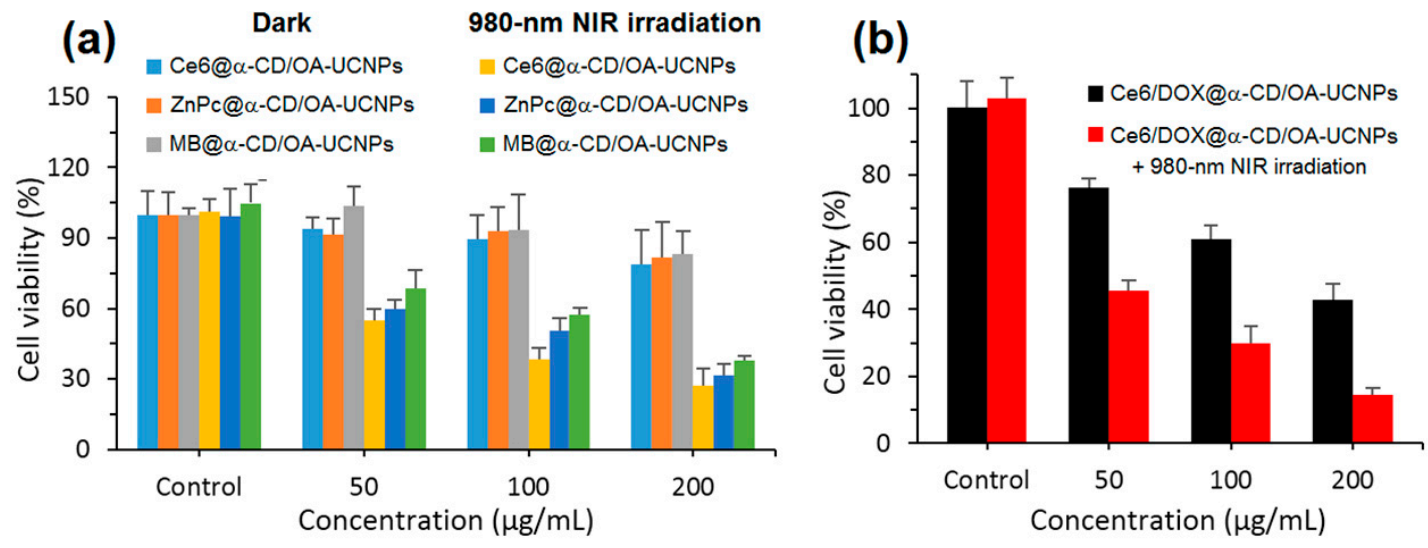

Figure 54. Dark and photoinduced $\left(\lambda=980 \mathrm{~nm}, 1 \mathrm{~W} / \mathrm{cm}^{2}\right.$ for $\left.5 \mathrm{~min}\right)$ mortality of A549 cells treated with (a) $\alpha$-CD/OA-UCNPs as control, Ce6@ $\alpha-C D / O A-U C N P s, Z n P c @ \alpha-C D / O A-U C N P s$, MB@ $\alpha-C D / O A-U C N P s$, and (b) Ce6/DOX@ $\alpha-C D / O A-U C N P s$ at different concentrations. Adapted from Tian; Ren; Yan; Jian; Gu; Zhou; Jin; Yin; Li; Zhao. [73].

Conjugating the CD to the UCNPs aims to confine the PSs, prevent their release, and maintain their accessibility to the UCNPs to ensure the activation of the PS through the pre-mentioned FRET process. Thus, to avoid the liberation of $\mathrm{ZnPc}$ and strengthen the interactions between $\mathrm{ZnPc}$ and CD/UCNPs, Wang et al. [192] functionalized $\mathrm{ZnPc}$ with adamantane (Ada-ZnPc) and synthetized a stable Ada-ZnPc@ß-CD-COOH/UCNP complex (Figure 55). The prepared Ada-ZnPc@ $\beta-\mathrm{CD}-\mathrm{COOH} / \mathrm{UCNPs}$ had the advantageous properties of $\beta-\mathrm{CD}-\mathrm{COOH}$, especially its good water solubility. In addition, under NIR excitation $(980 \mathrm{~nm})$, the $\beta-\mathrm{CD}-\mathrm{COOH} / \mathrm{UCNPs}$ emitted in red at about $660 \mathrm{~nm}$, which enabled the excitation of Ada-ZnPc through FRET.

The ability of Ada-ZnPc@ $\beta-C D-C O O H / U C N P s$ to produce ${ }^{1} \mathrm{O}_{2}$ in water was indirectly detected using anthracene-9,10-dipropionic acid (ADPA) as a fluorescent probe. Based on the in vitro ${ }^{1} \mathrm{O}_{2}$ production results using HeLa cells when exposed to NIR irradiation, a significant level of ${ }^{1} \mathrm{O}_{2}$ was generated by Ada-ZnPc@ $\beta-\mathrm{CD}-\mathrm{COOH} / \mathrm{UCNPs}$ compared to $\beta-\mathrm{CD}-\mathrm{COOH} / \mathrm{UCNPs}$ and Ada-ZnPc. The amount of ${ }^{1} \mathrm{O}_{2}$ increased proportionately with the time of light exposure. Separately, the components of the Ada-ZnPc@ $\beta-C D-C O O H / U C N P$ complex could not produce any ROS; yet, a lower level of ${ }^{1} \mathrm{O}_{2}$ was generated when $\beta$-CD-COOH/UCNPs and Ada-ZnPc were physically mixed together. The superior ${ }^{1} \mathrm{O}_{2}$ production in the case of Ada-ZnPc@ $\beta-\mathrm{CD}-\mathrm{COOH} / \mathrm{UCNPs}$ was attributed to the short distance between the $\beta-\mathrm{CD}-\mathrm{COOH} / \mathrm{UCNPs}$ and Ada-ZnPc that was convenient to establish an efficient FRET, which was not the case when those two components were only mixed together. However, when the intracellular generation of ${ }^{1} \mathrm{O}_{2}$ was assessed after NIR irradiation using a SOSG (singlet oxygen sensor green) probe and HeLa cells, all of the cells treated with $\beta-\mathrm{CD}-\mathrm{COOH} / \mathrm{UCNPs}$, Ada-ZnPc, and Ada-ZnPc@ $\beta-\mathrm{CD}-\mathrm{COOH} / \mathrm{UCNPs}$ exhibited a fluorescence of the probe that was strongest in the case of Ada-ZnPc@ $\beta-\mathrm{CD}-\mathrm{COOH} / \mathrm{UCNPs}$ (Figure 56a). These results assured their capability of elaborating ${ }^{1} \mathrm{O}_{2}$ inside the cells. The Ada-ZnPc@ $\beta-\mathrm{CD}-\mathrm{COOH} / \mathrm{UCNP}$ complex was proved to localize into the cytoplasm of the cells, similarly to the unmodified $\beta-\mathrm{CD}-\mathrm{COOH} / \mathrm{UCNPs}$. Thus, under NIR excitation, FRET between $\beta-\mathrm{CD}-\mathrm{COOH} / \mathrm{UCNPs}$ and $\mathrm{ZnPc}$ 
took place; consequently, $\mathrm{ZnPc}$ became excited and produced ${ }^{1} \mathrm{O}_{2}$, which finally caused the massive destruction of the cells that appeared stained in blue due to their chromatin damage (Figure 56(bF)).
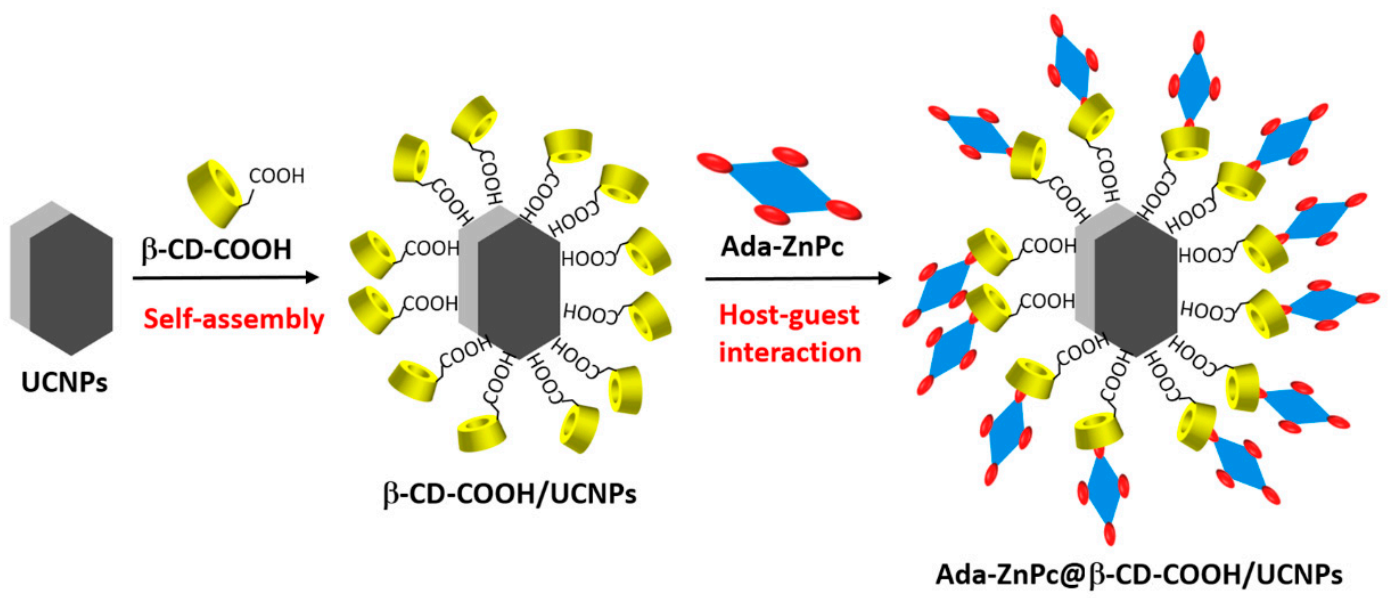

Figure 55. Schematic representation of Ada-ZnPc@ $\beta-\mathrm{CD}-\mathrm{COOH} / \mathrm{UCNP}$ complex. Adapted from Wang; Jin; Chen; Zhou; Zhou; Wei [192].

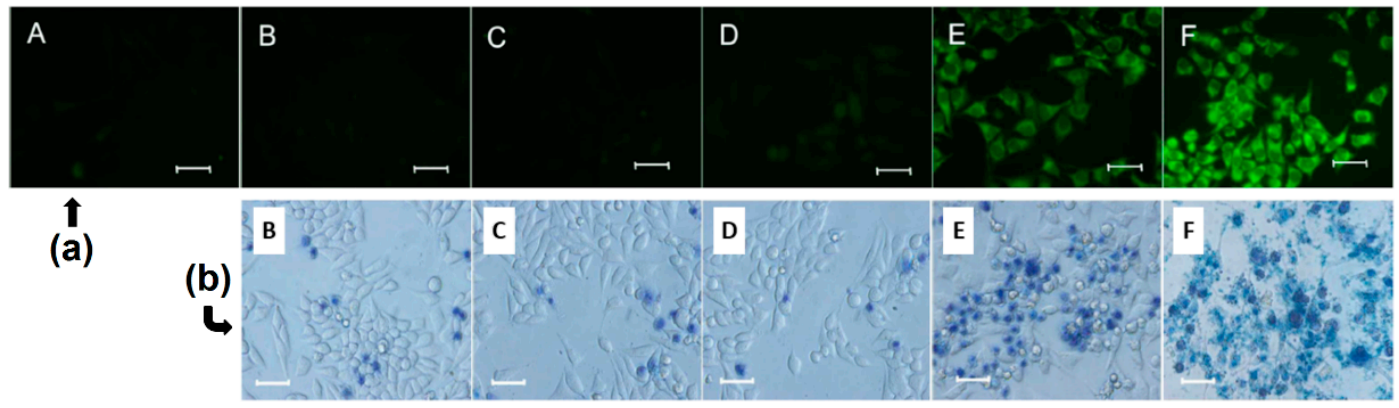

Figure 56. (a) Singlet oxygen sensor green (SOSG) fluorescence images of HeLa cells. (b) Micrographs of HeLa cells stained with trypan blue of (A) control cells, and when exposed to (B) $\beta-\mathrm{CD}-\mathrm{COOH} / \mathrm{UCNPs}$, (C) $\beta-\mathrm{CD}-\mathrm{COOH}$, (D) Ada-ZnPc, (E) $\beta-\mathrm{CD}-\mathrm{COOH} / \mathrm{UCNPs}+\mathrm{Ada}-\mathrm{ZnPc}$, and (F) Ada-ZnPc@ $\beta-C D-C O O H / U C N P s$ after 980-nm laser irradiation. Bar = $100 \mu \mathrm{m}$. Reproduced by permission of The Royal Society of Chemistry [192].

The PDT efficiency of the different components was evaluated by trypan blue, excluding experiments and MTT assay. It is noteworthy to mention that this PDT effect also took place with the cells exposed to $\beta-\mathrm{CD}-\mathrm{COOH} / \mathrm{UCNPs}$ and Ada-ZnPc together, but to a much lower extent than with the complex. The PDT effect appeared to be drug and light dose-dependent (Figure 57). This research effort proved that the intervention of CD made these $\beta-\mathrm{CD}-\mathrm{COOH} / \mathrm{UCNPS}$ efficient as drug-delivery systems for NIR-triggered PDT.

In 2016, Wang et al. [193] developed new core-shell NPs constituted of a $\mathrm{NaYF}_{4}: \mathrm{Yb} / \mathrm{Er}$ UCNP core (UCNP), a methylene Blue (MB)-loaded silica shell (@SiO $2(\mathrm{MB}), \mathrm{MB}$ as PS), and a rhodamine B-anchored mesoporous silica shell (@ $\mathrm{mSiO}_{2}(\mathrm{RhB})$, rhodamine B $(\mathrm{RhB})$ as model drug). The resulted $\mathrm{UCNP} @ \mathrm{SiO}_{2}(\mathrm{MB}) @ \mathrm{mSiO}_{2}(\mathrm{RhB})$ NPs were functionalized on the surface with an adamantane- ${ }^{1} \mathrm{O}_{2}$-sensitive linker (Ada-linker) which forms an inclusion complex with $\beta$-CD (Figure 58). The inclusion complexes served to enhance water dispersion of resulting NPs and as « gatekeepers » to prevent PS release. The UCNP@SiO $2(\mathrm{MB}) @ \mathrm{mSiO}_{2}(\mathrm{RhB})-\mathrm{Ada}$-linker- $\beta-\mathrm{CD}$ NPs (hydrodynamic diameter of $75 \mathrm{~nm}$ ) could be used for simultaneous photo-responsive drug release, PDT and cell imaging. 

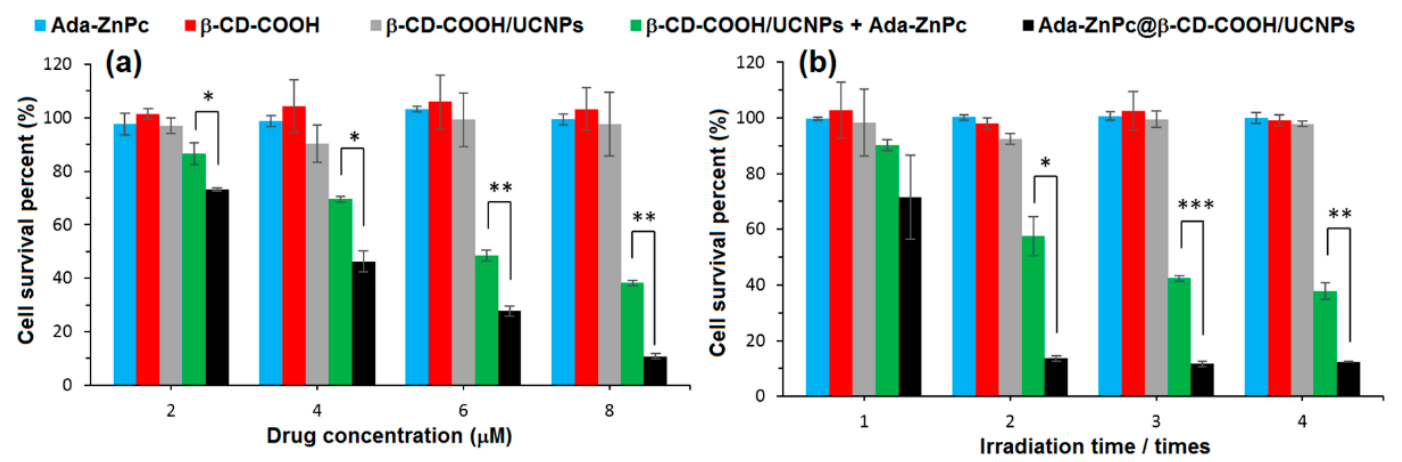

Figure 57. (a) Drug dose and (b) light dose-dependent in vitro PDT activity for $\beta$-CD-COOH/UCNPs, $\beta-\mathrm{CD}-\mathrm{COOH}$, Ada-ZnPc, $\beta-\mathrm{CD}-\mathrm{COOH} / \mathrm{UCNPs}+$ Ada-ZnPc, and Ada-ZnPc@ $\beta-C D-C O O H / U C N P s$ after 980-nm laser irradiation. ${ }^{*} p<0.05,{ }^{* *} p<0.01,{ }^{* * *} p<0.0001$. Adapted from Wang; Jin; Chen; Zhou; Zhou; Wei [192].
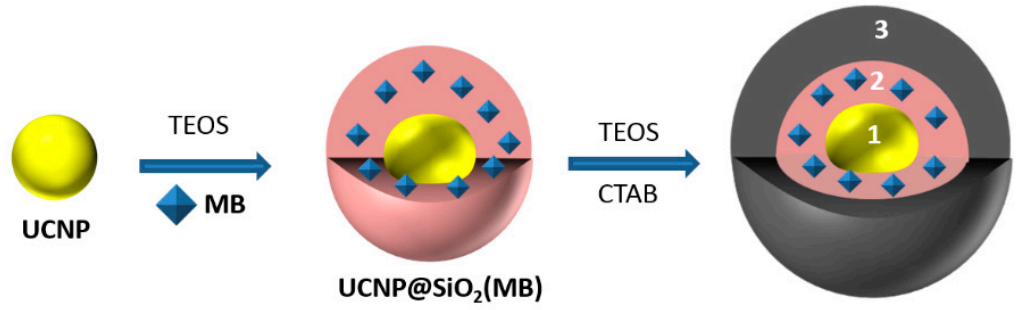

UCNP@SiO

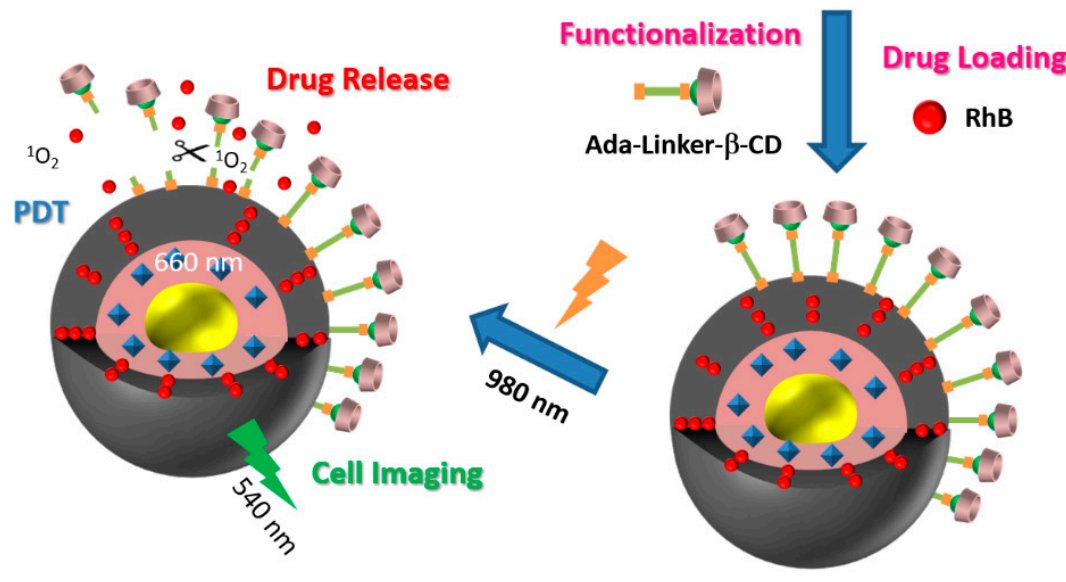

UCNP@SiO 2 (MB)@mSiO 2 (RhB)-Ada-Linker- $\beta-C D$

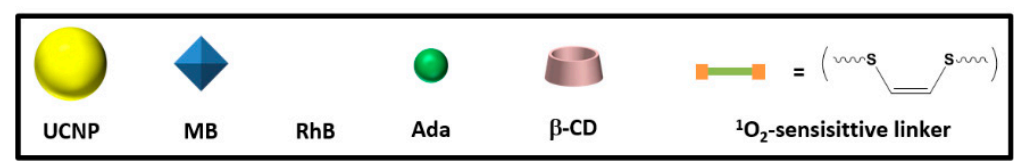

Figure 58. Schematic diagram showing the synthetic procedure of $\mathrm{UCNP} @ \mathrm{SiO}_{2}(\mathrm{MB}) @ \mathrm{mSiO}_{2}(\mathrm{RhB})-$ Ada-linker- $\beta$-CD NPs. Adapted from Wang; Han; Yang; Shi; Liu; Hu; Wang; Liu; Gan [193]. @ $\mathrm{mSiO}_{2}(\mathrm{RhB})$ : Ada-linker: adamantane- ${ }^{1} \mathrm{O}_{2}$-sensitive linker, RhB: rhodamine B-anchored mesoporous silica shell.

Photoluminescence and UV-vis analysis revealed that $\mathrm{UCNP} @ \mathrm{SiO}_{2} @ \mathrm{mSiO}_{2}(\mathrm{RhB})$-Ada-linker- $\beta$-CD NPs have a strong emission in the red upon 980-nm NIR excitation, and MB absorbs intensely in the range between $650-670 \mathrm{~nm}$. The sound emission-absorption match at around $660 \mathrm{~nm}$ may prompt a FRET. This FRET was proved to exist by observing a decrease of emission intensity at $660 \mathrm{~nm}$ when UCNP@SiO ${ }_{2} @ \mathrm{mSiO}_{2}(\mathrm{RhB})$-Ada-linker- $\beta$-CD NPs were loaded with MB under 980-nm NIR 
excitation. Interestingly, the emission spectra of $\mathrm{UCNP@SiO} \mathrm{S}_{2}(\mathrm{MB}) @ \mathrm{mSiO}_{2}(\mathrm{RhB})$-Ada-linker- $\beta$-CD NPs showed also a strong emission peak at $540 \mathrm{~nm}$ (green light), offering the feasibility of in vitro cell imaging. In vitro cytotoxicity on human lung adenacarcinoma (A549) cells were evaluated by MTT assay after the incubation of $\mathrm{UCNP} @ \mathrm{SiO}_{2}(\mathrm{MB}) @ \mathrm{mSiO}_{2}(\mathrm{RhB})$-Ada-linker- $\beta$-CD NPs. A study of the influence of both UCNP@SiO ${ }_{2}(\mathrm{MB}) @ \mathrm{mSiO}_{2}(\mathrm{RhB})$-Ada-linker- $\beta-\mathrm{CD}$ NPs concentration and laser treatment (exposure time at the power density of $2.0 \mathrm{~W} / \mathrm{cm}^{2}$ ) allowed authors to determine safe conditions, i.e., [UCNP@SiO ${ }_{2}(\mathrm{MB}) @ \mathrm{mSiO}_{2}(\mathrm{RhB})$-Ada-linker- $\left.\beta-\mathrm{CD} \mathrm{NPs}\right]=32 \mu \mathrm{g} / \mathrm{mL}$ with 980-nm NIR irradiation at $2.0 \mathrm{~W} / \mathrm{cm}^{2}$ during $50 \mathrm{~s}$, for performing cell imaging and PDT studies. The use of $\mathrm{UCNP@SiO} 2(\mathrm{MB}) @ \mathrm{mSiO}_{2}(\mathrm{RhB})$-Ada-linker- $\beta$-CD NPs as cell imaging agents was checked via confocal Upconversion Luminescence (UCL)/fluorescence in vitro imaging of A549 cells incubated with $\mathrm{UCNP} @ \mathrm{SiO}_{2}(\mathrm{MB}) @ \mathrm{mSiO}_{2}(\mathrm{RhB})$-Ada-linker- $\beta$-CD NPs upon 980-nm NIR excitation and in bright field mode. The in vitro imaging study of human lung adenacarcinoma (A549) cells treated with $\mathrm{UCNP} @ \mathrm{SiO}_{2}(\mathrm{MB}) @ \mathrm{mSiO}_{2}(\mathrm{RhB})$-Ada-linker- $\beta$-CD NPs $(32 \mu \mathrm{g} / \mathrm{mL})$ upon 980-nm NIR excitation $\left(2.0 \mathrm{~W} / \mathrm{cm}^{2}\right.$ during $\left.50 \mathrm{~s}\right)$ results showed an intense green luminescence and a successful cell uptake of $\mathrm{UCNP@SiO}{ }_{2}(\mathrm{MB}) @ \mathrm{mSiO}_{2}(\mathrm{RhB})$-Ada-linker- $\beta$-CD NPs mainly located at the cytoplasmic regions. The in vitro PDT efficiency of $\mathrm{UCNP@SiO}{ }_{2}(\mathrm{MB}) @ \mathrm{mSiO}_{2}(\mathrm{RhB})$-Ada-linker- $\beta-\mathrm{CD}$ NPs was evaluated on A549 cells under the previously determined as safe mentioned conditions, and showed a cell viability reaching $50 \%$. Finally, the authors highlighted the photo-release of RhB from $\mathrm{UCNP@SiO} \mathrm{O}_{2}(\mathrm{MB}) @ \mathrm{mSiO}_{2}(\mathrm{RhB})$-Ada-linker- $\beta$-CD NPs induced by the ${ }^{1} \mathrm{O}_{2}$-labile linkers thanks to a periodic $980-\mathrm{nm}$ NIR ON/OFF illumination $\left(2.0 \mathrm{~W} / \mathrm{cm}^{2}\right.$, periodicity of $\left.10 \mathrm{~min}\right)$.

One year later, the same team [194] described a novel PDT nanoplatform (RB-NH $\left.{ }_{2}-\mathrm{UCNP} @ \mathrm{mSiO}_{2}(\mathrm{Ada})-\beta-\mathrm{CD}\right)$ constituted of a $\mathrm{NaYF}_{4}: \mathrm{Yb} / \mathrm{Er} / \mathrm{Nd} @ \mathrm{NaYF}_{4}: \mathrm{Nd} \mathrm{UCNP}$ core (UCNP, $40 \mathrm{~nm}$ ), a Ada-anchored silica shell (@mSiO 2 (Ada), $12 \mathrm{~nm}$ ), positive amino groups into inner channels of $\mathrm{mSiO}_{2}$, a negatively charged PS (Rose Bengal, $\mathrm{RB}$ ), and $\beta-\mathrm{CD}$ as a solubilizing agent and « gatekeeper » to prevent PS release via an inclusion complex with Ada. Fluorescence microscopy imaging of HeLa cells incubated with RB-NH ${ }_{2}-\mathrm{UCNP} @ \mathrm{mSiO}_{2}$ (Ada)- $\beta-\mathrm{CD}$ NPs showed that NPs were uptaken by HeLa cells through either endocytosis or micropinocytosis with a localization mainly in cytoplasm. No dark cytotoxicity of $\mathrm{RB}-\mathrm{NH}_{2}-\mathrm{UCNP} @ \mathrm{mSiO}_{2}$ (Ada)- $\beta$-CD NPs was observed, even with high NP concentrations $(250 \mu \mathrm{g} / \mathrm{mL})$. The in vitro PDT activity of $\mathrm{RB}-\mathrm{NH}_{2}-\mathrm{UCNP} @ \mathrm{mSiO}_{2}(\mathrm{Ada})-\beta-\mathrm{CD}$ NPs using HeLa cells under 808-nm NIR excitation increased with the increasing irradiation time exposure ( $0 \mathrm{~min}$ to $10 \mathrm{~min}$ ), laser power density $\left(0\right.$ to $\left.4 \mathrm{~W} / \mathrm{cm}^{2}\right)$, and NPs concentration ( 0 to $250 \mu \mathrm{g} / \mathrm{mL}$ ). The in vitro results highlighted that under 808-nm NIR irradiation, the green $540 \mathrm{~nm}$ up-conversion from UNCP could activate RB to efficiently generate ${ }^{1} \mathrm{O}_{2}$ and promote cancer cell death, enabling a high efficient anticancer PDT treatment upon the low heat effect 808-nm excitation.

\subsubsection{Cyclodextrin-Photosensitizer Systems into Other Types of Nanoparticles}

As well as the UCNPs being used for improving CD-PS system properties, some studies are devoted to the use of other types of nanoparticles, and are briefly discussed below.

In 2011, Dong et al. [195] developed supramolecular polymer micelles (SMPMs) as intelligent drug delivery systems. SMPMs were constructed from ethylcellulose-graft-poly( $\varepsilon$-caprolactone (EC-g-PCL) and maleic anhydride modified $\alpha-C D($ Mah- $\alpha-C D)$ derivative via host-guest and hydrophobic interactions. The resulted Mah- $\alpha$-CD/EC-g-PCL SMPMs were loaded with a PS (5,10,15,20-tetrakis(4-hydroxyphenyl)-21H,23H-porphyrin, THPP). The in vitro behavior of THPP-loaded SMPMs was investigated on breast tumor (MCF-7) cells using confocal microscopy, and it was found that THPP can be internalized in the MCF-7 cells via SMPMs. In vitro trigger-controlled THPP release was evaluated, and THPP was efficiently released from SMPMs by the addition of L-phenylalanine. The in vitro cell viability on MCF-7 cells was investigated by MTT assay under irradiation $\left(\lambda=400 \mathrm{~nm}\right.$, Xe lamp with total light dose of $\left.120 \mathrm{~J} / \mathrm{cm}^{2}\right)$. No dark cytotoxicity was observed and the photomortality of MCF-7 cells was clearly demonstrated, which increases as the trigger L-phenylalanine concentration increases (from $0 \mathrm{mM}$ to $3 \mathrm{mM}$ ). All of these results showed 
a promising application of the THPP-loaded SMPMs in cancer treatment as a drug delivery and controlled release system.

In 2013, Ma et al. [196] described the covalent conjugation of Ada onto both the surface and nanochannels of mesoporous silica NPs (MSNPs). Hydrophobic ZnPc was then loaded into the nanochannels of the resulted Ada-MSNPs (ZnPc/Ada-MSNPs) and capped with $\beta-C D$, which forms an inclusion complex with Ada. The inclusion complexes served to enhance water solubility of $\beta-\mathrm{CD} / \mathrm{ZnPc} / \mathrm{Ada}-\mathrm{MSNPs}$ and act as « gatekeepers » to prevent $\mathrm{ZnPc}$ release. In vitro PDT activity on HeLa cells used MTT assay with light irradiation $\left(\lambda=675 \mathrm{~nm}, 2.5 \mathrm{~mW} / \mathrm{cm}^{2}\right)$. No dark cytotoxicity was observed, and the authors showed a higher phototoxicity after $60 \mathrm{~min}$ of light irradiation compared with $30 \mathrm{~min}$. Furthermore, in the case of $30 \mathrm{~min}$ of light irradiation, an $\mathrm{IC}_{50}$ value of $10 \mu \mathrm{g} / \mathrm{mL}$ was determined.

In 2013 also, Mazzaglia et al. [197] built on their results achieved in 2006 [164] concerning the PDT effect of $\mathrm{TPPS}_{4} / \mathrm{SC}_{6}-\beta-\mathrm{CD}-\mathrm{NH}_{2}$ nanoassemblies (results previously described in Section 2.2.3.). In this new work, the authors investigated the coating of gold nanoparticles (AuNPs) with their previous $\mathrm{TPPS}_{4} / \mathrm{SC}_{6}-\beta-\mathrm{CD}-\mathrm{NH}_{2}$ nanoassemblies to afford new hybrid assemblies AuNPs@TPPS $4 / \mathrm{SC}_{6}-\beta-\mathrm{CD}-\mathrm{NH}_{2}$ (average size of around $200 \mathrm{~nm}$, Figure 59). AuNPs were added to the previous $\mathrm{TPPS}_{4} / \mathrm{SC}_{6}-\beta-\mathrm{CD}-\mathrm{NH}_{2}$ nanoassemblies for the purpose of generating an in vitro dual photothermal (PTT)-PDT effect on HeLa cells.

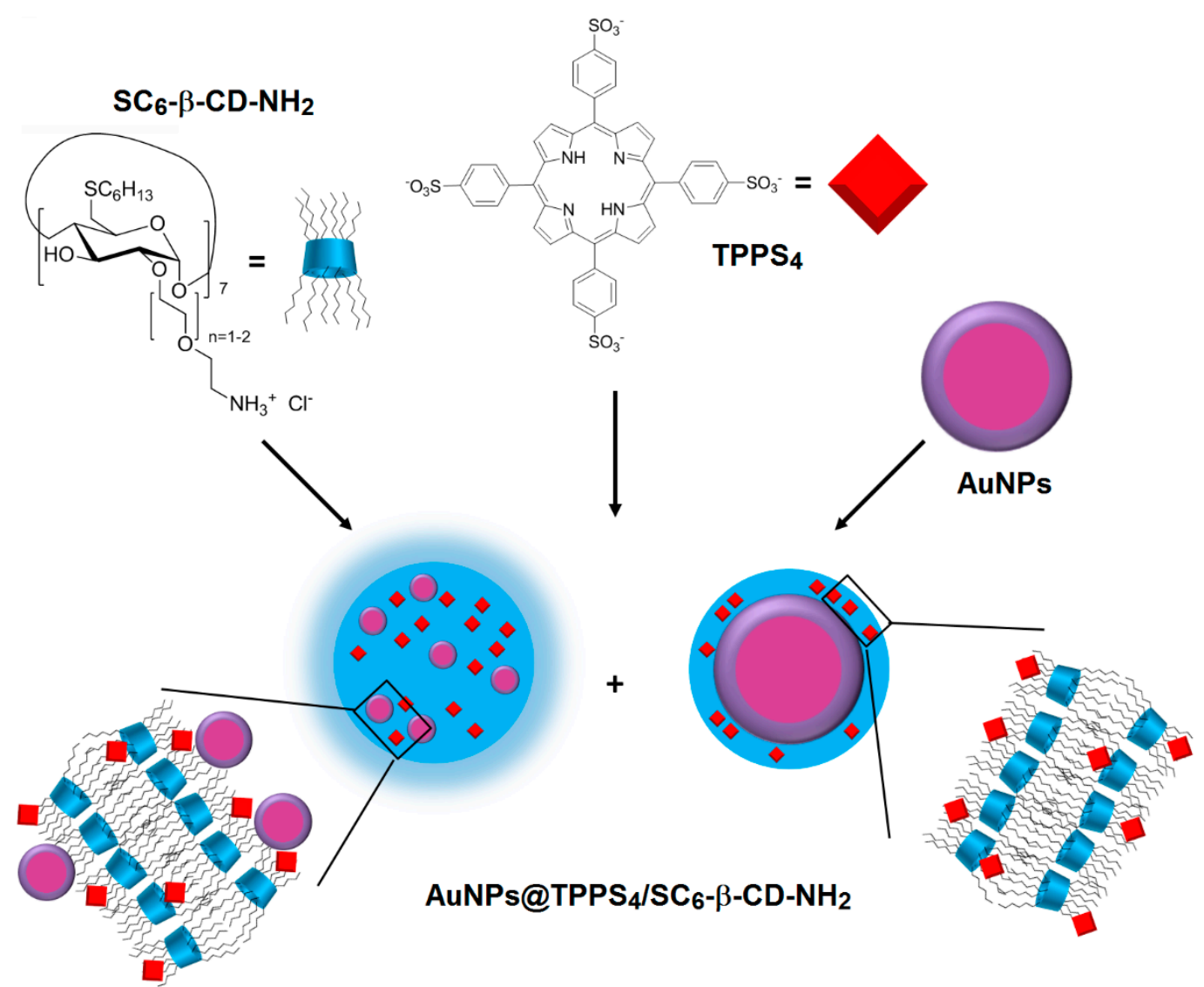

Figure 59. Sketch (not to scale) of the two typologies of ternary AuNPs@TPPS $4 / \mathrm{SC}_{6}-\beta-\mathrm{CD}_{-} \mathrm{NH}_{2}$ systems presumably formed in aqueous solution. Adapted from Trapani; Romeo; Parisi; Sciortino; Patane; Villari; Mazzaglia [197].

The in vitro behavior of supramolecular AuNPs@TPPS $4 / \mathrm{SC}_{6}-\beta-\mathrm{CD}-\mathrm{NH}_{2}$ hybrid assemblies was investigated by fluorescence microscopy analysis of Hela cells, and AuNPs@TPPS $4 / \mathrm{SC}_{6}-\beta-\mathrm{CD}-\mathrm{NH}_{2}$ assemblies were mainly localized in the cytoplasm region. To evaluate the feasibility of using a 
ternary AuNPs@TPPS $4 \mathrm{SC}_{6}-\beta-\mathrm{CD}-\mathrm{NH}_{2}$ system for dual PTT-PDT action, HeLa cells were treated with AuNPs@TPPS $4 / \mathrm{SC}_{6}-\beta-\mathrm{CD}-\mathrm{NH}_{2}$ NPs and either kept in the dark or irradiated with $532 \mathrm{~nm}$ neodymium-doped yttrium aluminium garnet (Nd-YAG) pulsed laser and then by visible light for $30 \mathrm{~min}$. AuNPs@TPPS $4 / \mathrm{SC}_{6}-\beta-\mathrm{CD}-\mathrm{NH}_{2}$ showed scarce dark toxicity while single components, binary $\mathrm{TPPS}_{4} / \mathrm{SC}_{6}-\beta-\mathrm{CD}-\mathrm{NH}_{2}$ and AuNPs@SC $6-\beta-\mathrm{CD}-\mathrm{NH}_{2}$ systems, showed some dark toxicity. After PTT treatment, the toxicity was almost unaltered, except for the ternary system ( $30 \%$ cell death), demonstrating that AuNPs were playing a role in the cell photodamage. Finally, after PTT-PDT treatment, the cells incubated with the ternary AuNPs@TPPS $4 / \mathrm{SC}_{6}-\beta-\mathrm{CD}-\mathrm{NH}_{2}$ system showed a further increase of toxicity ( $45 \%$ cell death), which was higher with respect to the PTT-PDT effect on the cells incubated with binary systems (Figure 60).

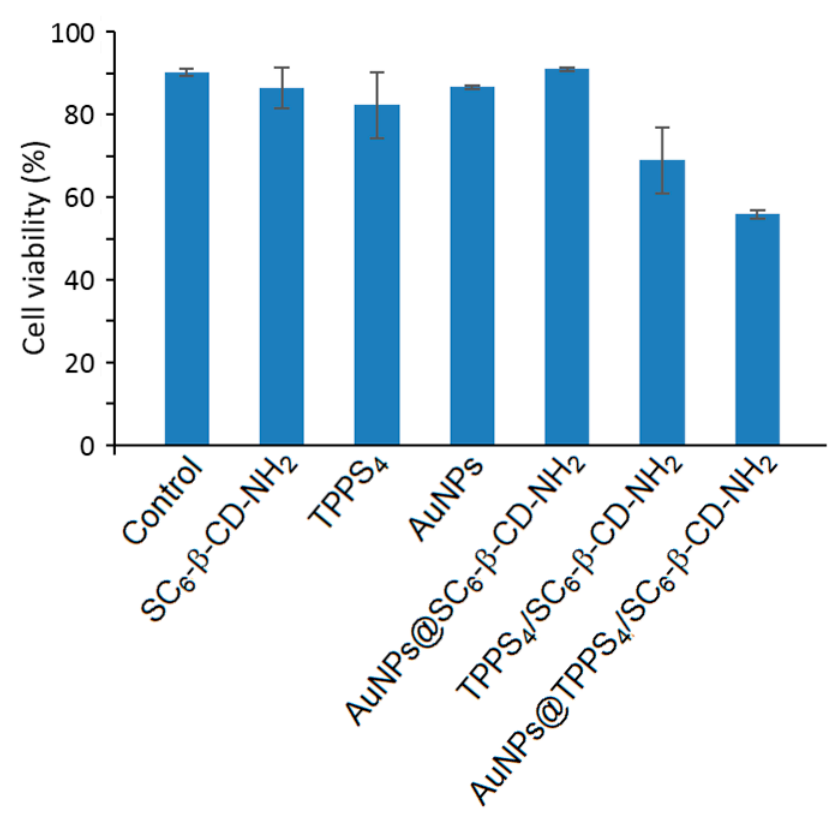

Figure 60. HeLa cell viability (MTS assay). Cells treated with $\mathrm{SC}_{6}-\beta-\mathrm{CD}-\mathrm{NH}_{2}, \mathrm{TPPS}_{4}$, gold nanoparticles (AuNPs), AuNPs@SC $6-\beta-C D-N_{2}$, TPPS $_{4} / \mathrm{SC}_{6}-\beta-\mathrm{CD}-\mathrm{NH}_{2}$, and AuNPs@TPPS4/SC6- $\beta-\mathrm{CD}-\mathrm{NH}_{2}$ compared to negative control (cell untreated). Cells washed in PBS (10 mM, pH 7.4) and analyzed in the dark and after photothermal (PTT)-PDT bimodal treatment. Adapted from Trapani; Romeo; Parisi; Sciortino; Patane; Villari; Mazzaglia [197].

As complementary information and concerning the elaboration of supramolecular nanoassemblies based on CD-PS systems into other types of nanoparticles, we can also mention the work of $\mathrm{Xu}$ et al. [198] in 2016, who described host-guest interactions between di- $\beta$-CD-modified PpIX (PpIX-CD $\mathrm{C}_{2}$ ) and azobenzene (AZO)-focused hydrophobic/hydrophilic hyperbranched polymers, leading to the formation of PpIX-bridged Janus particles via self-assembly (PpIX-CD $@$ @AZO Janus particles). The obtained supramolecular Janus particles (average size of around $10 \mathrm{~nm}$ ) were used to build large vesicles (up to $694 \mathrm{~nm}$ ) by aggregation. UV irradiation $(\lambda=365 \mathrm{~nm})$ caused vesicles destruction because of the trans-cis isomerization of the AZO unit. A decrease of $25 \%$ in the absorbance of the main Soret band indicated some PpIX degradation, but less than free PpIX, in favor of a protection (photostability) effect induced by vesicles. The conversion rate of triiodide ion was measured in buffer solution at $86 \%$ after $1 \mathrm{~h}$ of irradiation, indicating a high ${ }^{1} \mathrm{O}_{2}$ quantum yield production.

\subsection{Cyclodextrins with Fullerenes}

Many researchers, in their quest for the development of a better suitable PS for anticancer PDT treatment, pursue their efforts and grapple with this challenge by trying to develop new original PSs. 
Among these, one can cite the use of fullerenes. Fullerenes are carbon molecules whose shape can be close to a sphere, an ellipsoid, a tube, or a ring. They are composed of hexagonal rings (such as graphite) but also pentagonal rings, which give the possibility of closed structures. Fullerenes are natural molecules (found in soot) that were identified in 1985 by Kroto et al. [199] who received the Nobel Chemistry Prize in 1996 for this discovery. Fullerenes are extracted from the soot using a multistep procedure. After dissolution of the soot in appropriate organic solvents (solution containing up to $70 \%$ of $C_{60}$ ([60]Fullerene) and $15 \%$ of $C_{70}$ ([70]Fullerene), as well as other fullerenes), each fullerene fraction is separated using chromatography.

[60]Fullerene is the most stable form of fullerene whose composition includes 60 carbon atoms forming 20 hexagons and 12 pentagons, with a carbon atom at the top of each polygon and a bond at each side of the polygon. Each hexagon is adjacent to three hexagons and three pentagons, and each pentagon is surrounded by five hexagons (Figure 61). [60]Fullerene has the same shape as a traditional football with sewn panels.

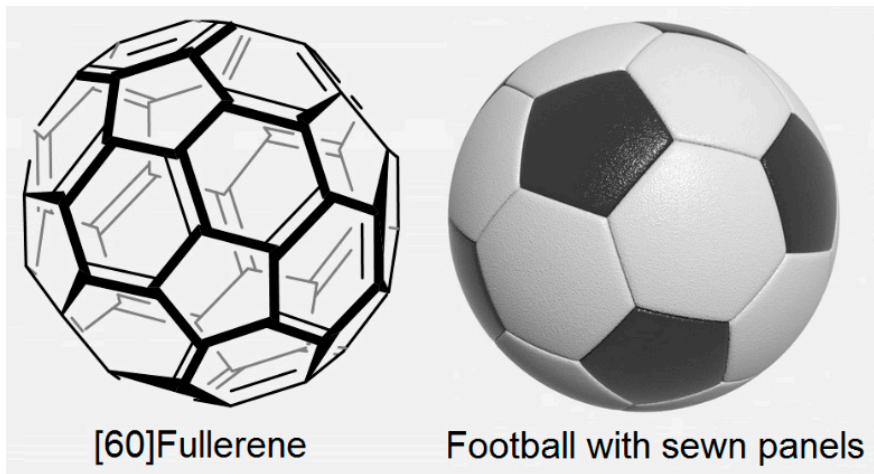

Figure 61. Three-dimensional (3D) representation of [60]Fullerene and a football with sewn panels.

Over three decades have passed since the discovery of fullerenes, and the interest for medical applications generated by them over the years has increased considerably [200-204]. Fullerenes combine many very interesting properties, making them good candidates for developing suitable PSs for PDT application [205-208]. These interesting properties include: (1) a higher photostability and a lower photobleaching compared to tetrapyrroles (porphyrinoid PSs) and synthetic dyes (non-porphyrinoid PSs); (2) both type I (free radicals) and type II $\left({ }^{1} \mathrm{O}_{2}\right)$ ROS generation compared to largely type II for tetrapyrroles; (3) an increase of both overall quantum yield and ROS production; (4) an extension of their absorption spectrum further into the red wavelengths; and (5) an ability to self-assemble into vesicles and functionalize with the aim of improving drug delivery. In spite of all these benefits, pristine [60]Fullerene is poorly soluble in water and biological media and self-assembles into nano-aggregates, limiting its photoactivity [209]. Therefore, it appears obvious that the combination of fullerenes and CDs would be a reasonable alternative for developing ideal PSs for use in anticancer PDT treatment.

Between 2008-2017, Ikeda et al. focused on the application of cyclodextrin / fullerenes inclusion complexes in PDT [210-216]. In 2008, Ikeda et al. synthesized lipid membrane-incorporated fullerenes $\left(\right.$ LMIC $_{\mathrm{x}}: \mathrm{x}=60$ or 70 ) with high concentrations of fullerenes $\left(\mathrm{C}_{\mathrm{x}}\right)$ through a simple and time-saving approach [211]. The method was based on an exchange reaction where $C_{x}$ was transferred from the $\mathrm{C}_{\mathrm{x}}-\gamma-\mathrm{CD}$ complex to the liposomes. The elaborated $\mathrm{LMIC}_{60}$ and $\mathrm{LMIC}_{70}$ possessed an average diameter of about $100 \mathrm{~nm}$. The authors also proved the efficiency of their guest exchange method for the preparation of the lipid membrane-incorporated fullerenes $\left(\mathrm{LMIC}_{\mathrm{x}}\right)$ in comparison to the conventional injection and premixing approaches [212]. $\mathrm{LMIC}_{60}$ and $\mathrm{LMIC}_{70}$ prepared by the guest exchange approach displayed a higher PDT activity accompanied with a better stability and solubility as compared to those prepared by the premixing one (Figure 62). $\gamma$-CD were employed in this method 
to embrace the fullerene in the first step and facilitate the transfer of this fullerene from the cavity of the CD to the liposomes or lipid membrane, where only fullerene was the PS fulfilling the PDT effect.

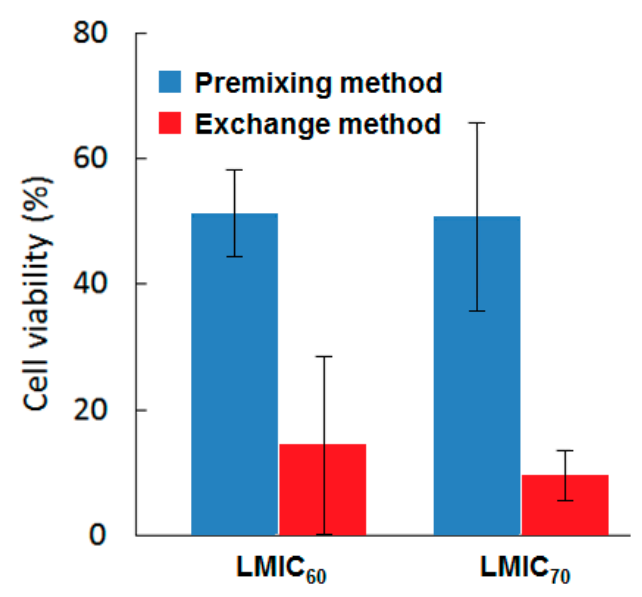

Figure 62. Cell viability following treatment with lipid membrane-incorporated fullerenes $\mathrm{LMIC}_{60}$ and $\mathrm{LMIC}_{70}$, prepared by the exchange and premixing methods, under excitation at 350-500 $\mathrm{nm}$ for $2 \mathrm{~h}$ in the case of $\mathrm{LMIC}_{60}$ and $30 \mathrm{~min}$ for $\left.\mathrm{LMIC}_{70}\right)\left(\left[\mathrm{C}_{60}\right]=2 \mathrm{mM}\right.$ and $\left.\left[\mathrm{C}_{70}\right]=0.3 \mathrm{mM}\right)$. Adapted from Ikeda [212].

To investigate the localization and the mode of internalization of the $\mathrm{LMIC}_{\mathrm{x}}$, only the liposomes were labeled by fluorochrome, and were incubated with HeLa cells. Fullerene was avoided, since it can quench fluorochrome. It appeared that only cationic liposomes were uptaken by the cells via endocytosis to be finally localized into the lysosomes. After $24 \mathrm{~h}$ of incubation with HeLa cells, both $\mathrm{LMIC}_{60}$ and $\mathrm{LMIC}_{70}$ revealed no dark toxicity. When excited at a wavelength between 350-500 nm, $\mathrm{LMIC}_{60}$ induced an $85 \%$ decrease of cell viability. However, when PDT was performed at a wavelength longer than $400 \mathrm{~nm}(400-740 \mathrm{~nm})$, only $\mathrm{LMIC}_{70}$ was able to induce a significant decrease in the cell viability by $89 \%$ versus only $19 \%$ of reduction in the case of $\mathrm{LMIC}_{60}$. This difference in the performance was due to the greater production of ${ }^{1} \mathrm{O}_{2}$ by $\mathrm{LMIC}_{60}$. Both $\mathrm{LMIC}_{60}$ and $\mathrm{LMIC}_{70}$ induced an early apoptotic cell death.

Ikeda et al. synthesized an inclusion complex that was constituted of fullerene $C_{x}(x=60$ or 70$)$ and $\gamma$-CD to implement the same concept but on the cellular membrane [214] (Figure 63). The intracellular uptake of both $\mathrm{C}_{60}$ and $\mathrm{C}_{70}$ from $\mathrm{C}_{60}-\gamma-\mathrm{CD}$ and $\mathrm{C}_{60}-\gamma-\mathrm{CD}$ inclusion complexes, respectively, was studied using human cervical HeLa cells $\left(\left[\mathrm{C}_{60}\right]=\left[\mathrm{C}_{70}\right]=20 \mu \mathrm{M}\right)$. At $4{ }^{\circ} \mathrm{C}$ and $37^{\circ} \mathrm{C}, \mathrm{C}_{60}-\gamma-\mathrm{CD}$ preserved its encapsulated structure, as no transfer of $\mathrm{C}_{60}$ into the cells occurred. However, under the same conditions, $\mathrm{C}_{70}$ from $\mathrm{C}_{70}-\gamma-\mathrm{CD}$ were well incorporated into HeLa cells. Especially at $37^{\circ} \mathrm{C}$, $60 \% \mathrm{C}_{70}-\gamma-\mathrm{CD}$ was uptaken by the cells after only $5 \mathrm{~min}$ of incubation. The stability and solubility $\mathrm{C}_{70}-\gamma-\mathrm{CD}$ was lower than that of the $\mathrm{C}_{60}-\gamma-\mathrm{CD}$ complex. The incorporation mechanism was the direct exchange reaction from the $C_{70}-\gamma-C D$ complex to the cell membrane. The fluorescence of rhodamine B 1,2-dihexadecanoyl-sn-glycero-3-phosphoethanolamine (RhB-DHPE) that was used to stain the HeLa cells was only quenched in the presence of $C_{70}-\gamma-C D$. This result confirmed that $C_{70}$ and RhB-DHPE coexisted in the cellular membrane. Under visible light irradiation $(\lambda=400-700 \mathrm{~nm}$, $54 \mathrm{~mW} / \mathrm{cm}^{2}$ ), the PDT efficiency against HeLa cells agreed with the results of the cellular uptake. In the dark, both complexes were not cytotoxic. Yet, as compared with the $\mathrm{C}_{60}-\gamma-\mathrm{CD}$ complex and 5 -Aminolevulinic acid (5-ALA) as a reference, only $C_{70}-\gamma-C D$ triggered a drastic decrease of $75 \%$ of the cell viability, with only $1 \mu \mathrm{M}$ of fullerene. 


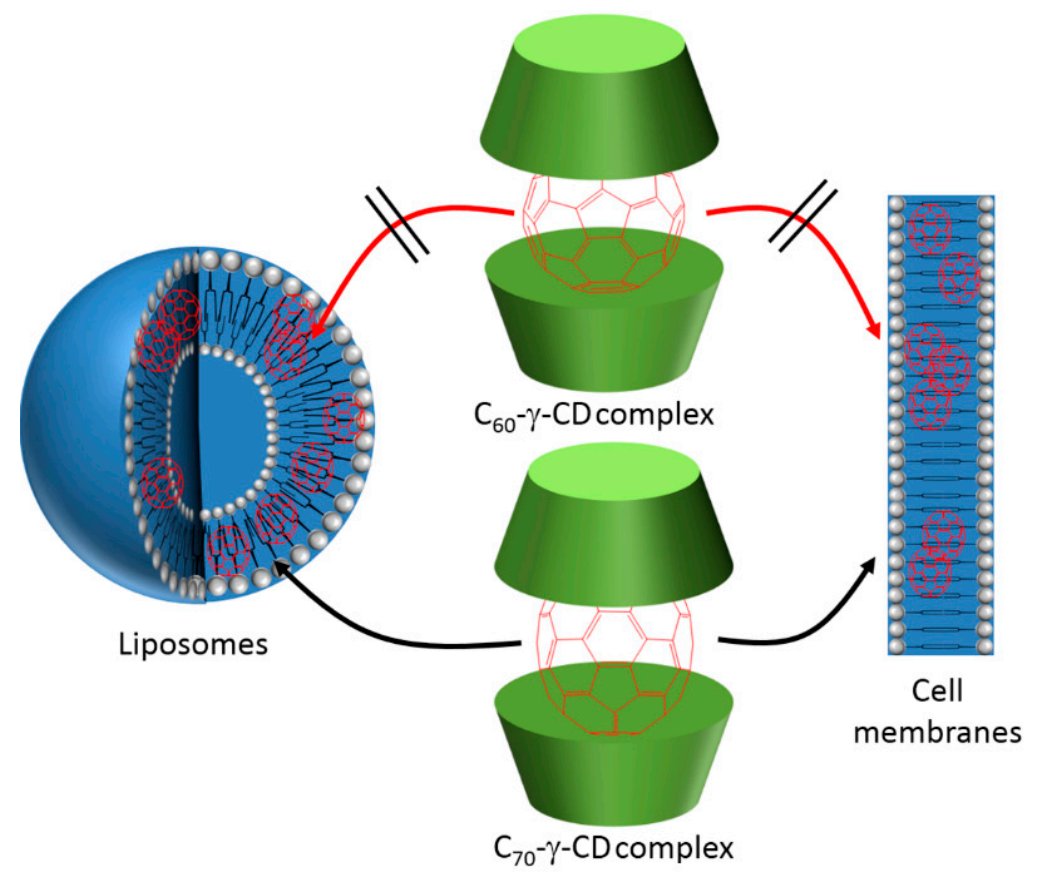

Figure 63. Schematic illustration of the exchange reaction from $\gamma$-CD cavity to the liposomal and cell membranes at $37^{\circ} \mathrm{C}$. Adapted from Ikeda; Matsumoto; Akiyama; Kikuchi; Ogawa; Takeya [214].

Encouraged and inspired by the good PDT activity obtained with $\operatorname{LMIC}_{70}(\lambda>400 \mathrm{~nm})$ and $\mathrm{C}_{70}-\gamma-\mathrm{CD}$, the same team dedicated their efforts to improving this system for a higher stability and a more selective drug-delivery [215]. In this study, their cerasome-incorporated $\mathrm{C}_{70}\left(\mathrm{CIC}_{70}\right)$ system was based on encapsulating the $C_{70}$ into a surface cross-linked liposomal bilayer covered with a polysiloxane surface (cerasome). This system was formed by the transfer of $C_{70}$ from the cavities of the $\gamma$-CD to occupy the vesicles of the cerasomes. The stability of the cerasomes was enhanced compared with the general liposomes by the deposition of silica on the surface of the cerasomes. $\mathrm{C}_{70}$ acted as a fluorescence quencher in the presence of $\mathrm{RhB}$, which confirmed the encapsulation of this fullerene in the lipid membrane of the cerasomes. A complete transfer of $C_{70}$ from the $\gamma$-CD cavities into the cerasomes was achieved at $25^{\circ} \mathrm{C}$ after $1 \mathrm{~min}$. The $\mathrm{CIC}_{70}$ system possessed a diameter of about $170 \mathrm{~nm}$, which was considered suitable for implementing an enhanced permeability and retention (EPR) effect. In addition, $\mathrm{CIC}_{70}$ held high surface positive charges $(+50.8 \mathrm{mV})$ that induced a good cellular uptake, yet was still slightly lower than that of $\mathrm{LMIC}_{70}(+57.2 \mathrm{mV})$. The presence of $\mathrm{C}_{70}$ improved the morphological stability of the cerasomes. For their application in PDT toward HeLa cells, $\mathrm{CIC}_{70}$ appeared to be non-cytotoxic in darkness and induced a forceful PDT effect that was as good as that displayed by $\mathrm{LMIC}_{70}$ under visible light irradiation $\left(57 \mathrm{~mW} / \mathrm{cm}^{2}, 400-740 \mathrm{~nm}\right)$ (Figure 64).

On this basis, Ikeda et al. [216] used a $\gamma$-CD derivative holding primary amine groups as $\mathrm{pH}$ responsive functions to carry their $\mathrm{C}_{60}\left(\mathrm{C}_{60}-\gamma-\mathrm{CD}-\mathrm{NH}_{2}\right)$. To validate the efficiency of the $\gamma-\mathrm{CD}-\mathrm{NH}_{2}$ carrier compared with $\gamma-\mathrm{CD}$, the in vitro PDT activity of $\mathrm{C}_{60}-\gamma-\mathrm{CD}-\mathrm{NH}_{2}$ and $\mathrm{C}_{60}-\gamma-\mathrm{CD}$ toward HeLa cells under visible light illumination (400-500 nm) was assessed. The experiments were conducted at two $\mathrm{pH}$ values, 7.4 and 6.4, which correspond respectively to the extracellular $\mathrm{pH}$ of normal and neoplastic cells. Both $\mathrm{C}_{60}-\gamma-\mathrm{CD}-\mathrm{NH}_{2}$ and $\mathrm{C}_{60}-\gamma-\mathrm{CD}$ exhibited no dark toxicity, and negligible photoinduced toxicity was attained with $\mathrm{C}_{60}-\gamma-\mathrm{CD}$ under both $\mathrm{pH}$ conditions. As for $\mathrm{C}_{60}-\gamma-\mathrm{CD}-\mathrm{NH}_{2}$, it was photoactive in destroying HeLa cells at both $\mathrm{pH}$ values, with an enhanced activity witnessed at $\mathrm{pH} 6.4$ (Figure 65). Thus, it was revealed that as the $\mathrm{pH}$ started to become more acidic, the amine groups of the $\gamma-\mathrm{CD}-\mathrm{NH}_{2}$ became gradually protonated up to a critical $\mathrm{pH}$, i.e., 6.7 , where the $\mathrm{C}_{60}$ was rapidly squeezed out of the $\gamma-\mathrm{CD}-\mathrm{NH}_{2}$ into the extracellular region. The released $\mathrm{C}_{60}$ were rapidly 
uptaken by the cells through either endocytosis or direct insertion to the cellular membrane (Figure 66). This $\gamma$-CD-NH $\mathrm{N}_{2}$ system represented a smart carrier of $\mathrm{C}_{60}$ for a more efficient application in PDT.

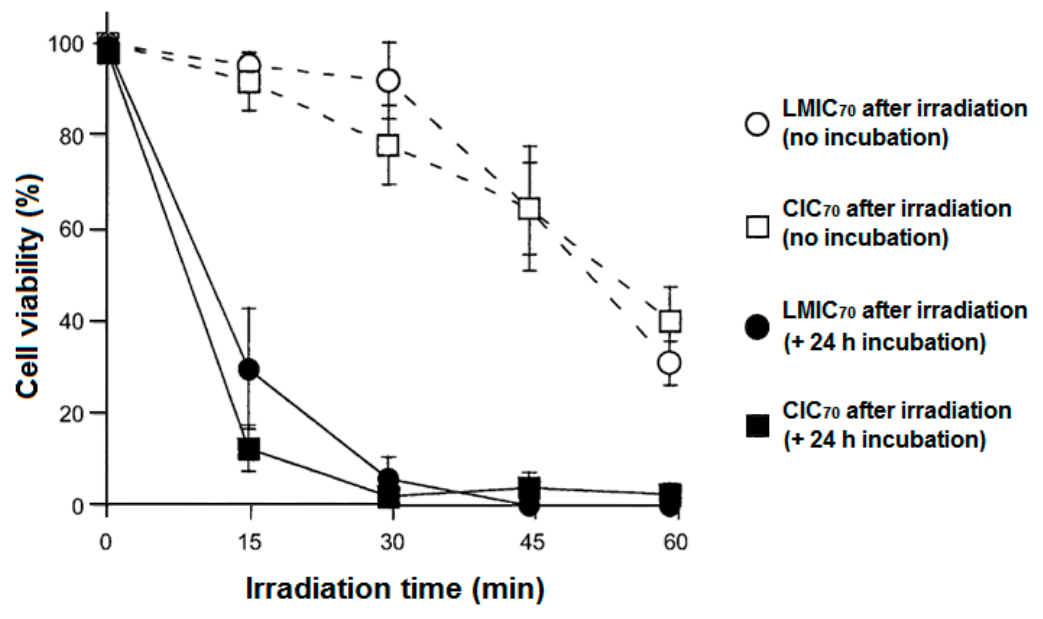

Figure 64. HeLa cell viability as a function of irradiation time $\left(\lambda>400 \mathrm{~nm}\right.$ at $\left.35^{\circ} \mathrm{C}\right)$. Cells treated with $\mathrm{LMIC}_{70}$ and $\mathrm{CIC}_{70}$ and stained with propidium iodide immediately after irradiation and subsequent $24 \mathrm{~h}$ incubation $(n=3)$. Adapted from Ikeda; Nagano; Akiyama; Matsumoto; Ito; Mukai; Hashizume; Kikuchi; Katagiri; Ogawa; Takeya [215].

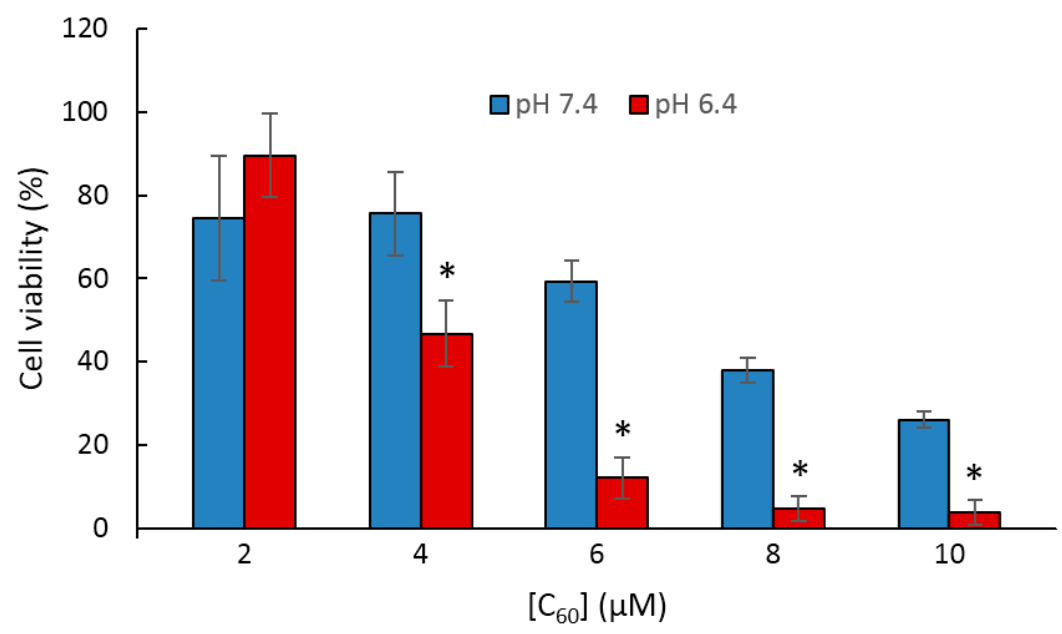

Figure 65. Cell viability of HeLa cells treated with $\mathrm{C}_{60}-\gamma-\mathrm{CD}-\mathrm{NH}_{2}$ after irradiation $(\lambda=400-500 \mathrm{~nm}$ for $30 \mathrm{~min}) .{ }^{*} p<0.005$ as compared to the PDT activity at $\mathrm{pH}$ 7.4. Adapted from Nobusawa; Akiyama; Ikeda; Naito [216].

In 2013, Ikeda et al. addressed the problem of the stability and solubility of the $\mathrm{C}_{\mathrm{x}}-\gamma-\mathrm{CD}$ inclusion complexes that affected their performance in PDT [213]. To form a stable inclusion complex, the authors used $\mathrm{C}_{60}$ derivatives holding nitrogen atom-containing groups, namely $\mathrm{N}$-methylpyrrolidine (MePyrr, amino group), $\mathrm{N}, \mathrm{N}$-dimethylpyrrolidinium iodide ( $\mathrm{Me}_{2}$ Pyrr, ammonium group), and $\mathrm{N}$-acetylpyrrolidine (AcPyrr, amide group) instead of $\mathrm{C}_{60}$ (Figure 67a). Compared with $\mathrm{C}_{60}-\gamma-\mathrm{CD}$, all of the $\gamma$-CD-complexed $\mathrm{C}_{60}$ derivatives (MePyrr- $\mathrm{C}_{60}-\gamma-\mathrm{CD}$, $\mathrm{Me}_{2}$ Pyrr- $\mathrm{C}_{60}-\gamma-\mathrm{CD}$ and AcPyrr- $\mathrm{C}_{60}-\gamma-\mathrm{CD}$ ) were found similarly water-soluble but more stable. In the absence of an irradiation source, the complexes were non-cytotoxic. The photoirradiation was performed at high wavelengths $(610-720 \mathrm{~nm})$. Under irradiation, $\mathrm{Me}_{2} \mathrm{Pyrr} \mathrm{C}_{60}-\gamma-\mathrm{CD}$ followed by AcPyrr- $\mathrm{C}_{60}-\gamma-\mathrm{CD}$ complexes exhibited a superior PDT activity against HeLa cells as compared to Photofrin ${ }^{\circledR}-\gamma-\mathrm{CD}$, $\mathrm{C}_{60}-\gamma-\mathrm{CD}, \mathrm{C}_{70}-\gamma-\mathrm{CD}$ and MePyrr- $\gamma-\mathrm{CD}$ (Figure $67 \mathrm{~b}$ ). This superior photoactivity, especially for 
$\mathrm{Me}_{2}$ Pyrr- $\mathrm{C}_{60}-\gamma-\mathrm{CD}$, was attributed to the increased cellular uptake caused by the cationic nature of the surface of this complex vs. the other two neutral complexes MePyrr- $\gamma-\mathrm{CD}$ and AcPyrr-C $60-\gamma-\mathrm{CD}_{\text {. }}$ In addition, higher levels of ${ }^{1} \mathrm{O}_{2}$ were elaborated by $\mathrm{Me}_{2} \mathrm{Pyrr}-\mathrm{C}_{60}-\gamma-\mathrm{CD}$. The suppressed PDT activity of MePyrr- $\gamma$-CD complex was imputed to the low ${ }^{1} \mathrm{O}_{2}$ production caused by the quenching effect of the triplet excited state of this complex by the lone pair of the electrons on the amino groups.
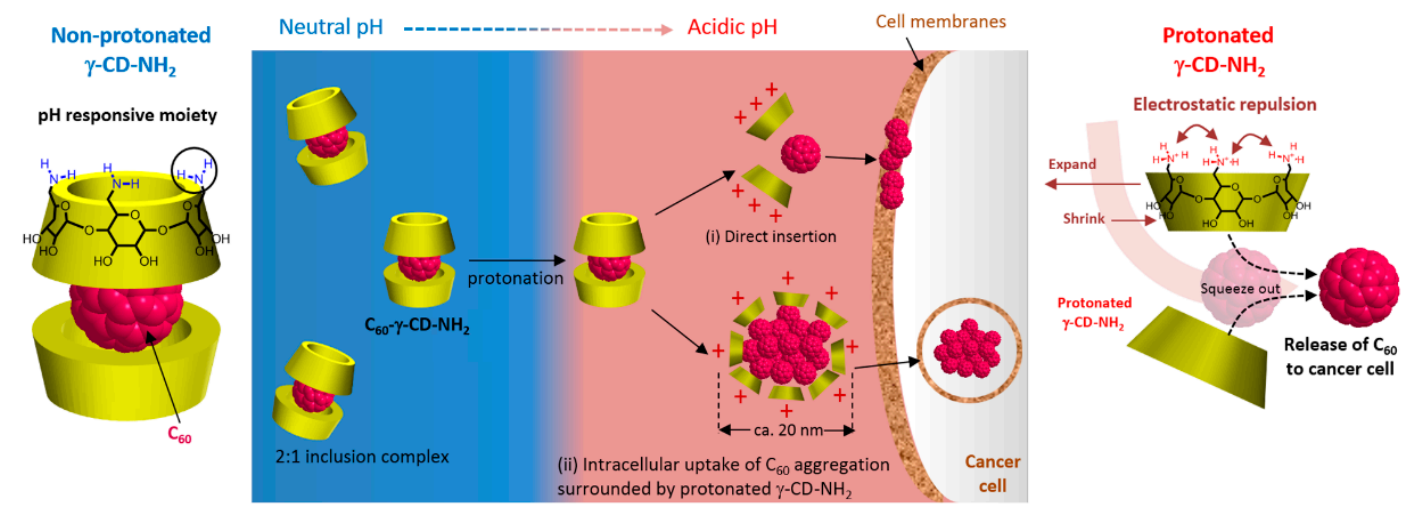

Figure 66. Schematic representation of efficient cellular uptake mechanisms and 2:1 $\mathrm{C}_{60}-\gamma-\mathrm{CD}^{-\mathrm{NH}_{2}}$ inclusion complex under neutral and acidic $\mathrm{pH}$. Adapted from Nobusawa; Akiyama; Ikeda; Naito [216].

(a)

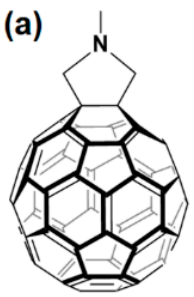

MePyrr-C 60

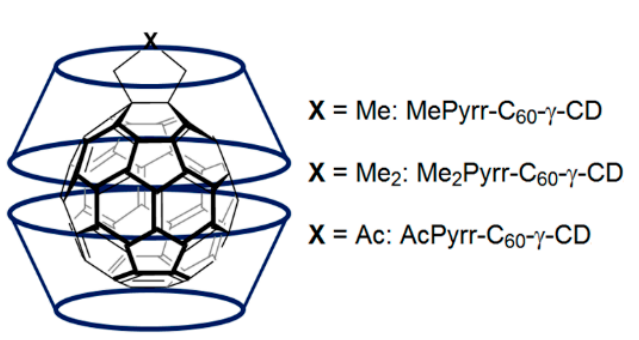

(b)

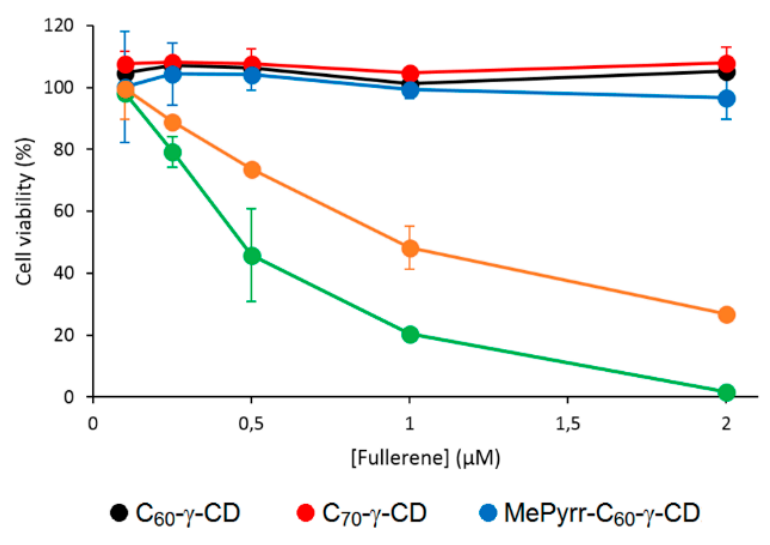

- $\mathrm{Me}_{2}$ Pyrr-C $_{60-\gamma-C D}$ AcPyrr-C $60-\gamma-C D$

Figure 67. (a) Chemical structure of $C_{60}$ derivatives and $C_{60}$ derivatives- $\gamma-C D$ inclusion complexes. (b) Concentration-dependent cytotoxicity of $\mathrm{C}_{60}-\gamma-\mathrm{CD}, \mathrm{C}_{70}-\gamma-\mathrm{CD}, N$-methylpyrrolidine (MePyrr)- $\mathrm{C}_{60}-\gamma-\mathrm{CD}, \mathrm{N}, \mathrm{N}$-dimethylpyrrolidinium iodide ( $\mathrm{Me}_{2}$ Pyrr)- $\mathrm{C}_{60}-\gamma-\mathrm{CD}$, and $\mathrm{N}$-acetylpyrrolidine (AcPyrr)- $\mathrm{C}_{60}-\gamma-\mathrm{CD}$ on Hela cells under irradiation $(\lambda=610-740 \mathrm{~nm}$ for $30 \mathrm{~min})$. Adapted from Ikeda; Iizuka; Maekubo; Aono; Kikuchi; Akiyama; Konishi; Ogawa; Ishida-Kitagawa; Tatebe; Shiozaki [213].

After they proved that using $\mathrm{C}_{60}$ derivatives with the $\gamma$-CD improved the cellular uptake and therefore the PDT activity compared with $C_{60}-\gamma-C D$ and $C_{60}-\gamma-C D$, Ikeda et al. used those $\gamma$-CD-complexed $\mathrm{C}_{60}$ derivatives to prepare lipid membrane-incorporated $\mathrm{C}_{60}$ derivatives by an exchange method [210]. The $C_{60}$ derivatives were transferred from the two cavities of $\gamma$-CD into the lipid membranes of the liposomes. In a similar trend, $\mathrm{Me}_{2} \mathrm{Pyrr}-\mathrm{C}_{60}-\gamma-\mathrm{CD}$ incorporated into the lipid membranes $\left(\mathrm{Me}_{2}\right.$ Pyrr-LMIC 60 ) resulted in the higher PDT activity toward HeLa cells under excitation between $610-740 \mathrm{~nm}$ as compared to the other $\mathrm{C}_{60}$ derivatives. The cationic nature of the incorporated $\mathrm{Me}_{2}$ Pyrr- $\mathrm{C}_{60}$ did not induce any large effect on the surface potential of the $\mathrm{Me}_{2}$ Pyrr-LMIC 60 that might 
affect their internalization into the cells. Thus, the intercellular uptake of all of the tested liposomes was comparable. The source of this higher PDT activity of $\mathrm{Me}_{2}$ Pyrr-LMIC 60 was the greater ability to produce ${ }^{1} \mathrm{O}_{2}$, since even more ${ }^{1} \mathrm{O}_{2}$ was generated by $\mathrm{Me}_{2}$ Pyrr-LMIC $\mathrm{C}_{60}$ than that produced by the $\mathrm{Me}_{2}$ Pyrr- $\mathrm{C}_{60}-\gamma-\mathrm{CD}$ inclusion complex.

The good photophysical properties of fullerenes nominate them as potential PSs in PDT. However, their scarce solubility in aqueous media hinders their biological application. To overcome this issue, Iizumi et al. [217] prepared water-soluble fullerene derivatives. The unmodified $\mathrm{C}_{60}$ and $\mathrm{C}_{70}$ were dispersed in water using $\gamma-C D\left(C_{60}-\gamma-C D\right.$ and $\left.C_{70}-\gamma-C D\right)$ or poly(vinylpyrrolidone) $\left(\mathrm{C}_{60}-\mathrm{PVP}\right)$ (Figure 68a). In $\mathrm{C}_{60}-\gamma-\mathrm{CD}$ and $\mathrm{C}_{70}-\gamma-\mathrm{CD}$ complexes, both fullerenes produced an appreciable amount of ${ }^{1} \mathrm{O}_{2}$ in water as compared to Rose Bengal (RB). Yet, the produced ${ }^{1} \mathrm{O}_{2}$ was less than that produced by fullerenes alone in organic solvents, most probably due to their inclusion into the cavities of $\gamma$-CD. This might have disrupted the efficient contact and accordingly the energy transfer between fullerenes and the molecular oxygen. Lower levels of ${ }^{1} \mathrm{O}_{2}$ were produced by $\mathrm{C}_{60}$ in $\mathrm{C}_{60}$-PVP. The assumption that $\mathrm{C}_{60}$ tended to aggregate with the PVP dispersant while it formed a stable complex with $\gamma$-CD as monomers was possibly the reason behind the difference in ${ }^{1} \mathrm{O}_{2}$ generation. Dark toxicity and phototoxicity $\left(\lambda=633 \mathrm{~nm}, 3 \mathrm{~mW} / \mathrm{cm}^{2}\right)$ were performed on the rat fibroblast cell line 5RP7 in the presence of $\mathrm{C}_{60}-\gamma-\mathrm{CD}, \mathrm{C}_{70}-\gamma-\mathrm{CD}$ and $\mathrm{C}_{60}-\mathrm{PVP}$ with fullerene concentration fixed at $10 \mu \mathrm{M}$. Slight dark toxicity was revealed in all cases. Nevertheless, and in coherence with the ${ }^{1} \mathrm{O}_{2}$ results, $C_{70}-\gamma-C D$ exhibited a massive phototoxic impact leaving only $12 \%$ of the cells alive (Figure $68 \mathrm{~b}$ ). Although $\mathrm{C}_{60}-\gamma-\mathrm{CD}$ was proved analogous to $\mathrm{C}_{70}-\gamma-\mathrm{CD}$ in terms of the ${ }^{1} \mathrm{O}_{2}$ generation, a much lower PDT effect was observed ( $66 \%$ of cell survival). This was most probably due the much lower extinction coefficient of $\mathrm{C}_{60}-\gamma-\mathrm{CD}$ at $633 \mathrm{~nm}$. Conversely, $\mathrm{C}_{60}-\mathrm{PVP}$ mediated no cell death under irradiation. Thus, the phototoxicities of $C_{60}$ and $C_{70}$ were greatly influenced by their dispersed forms.

(a)

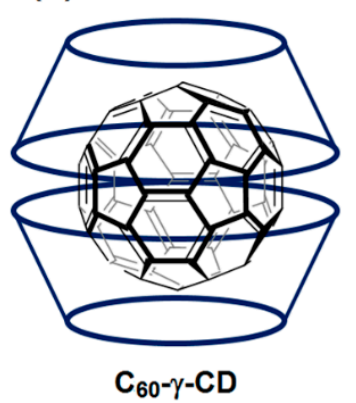

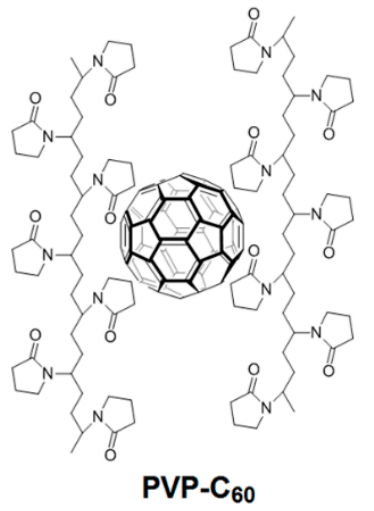

PVP-C 60

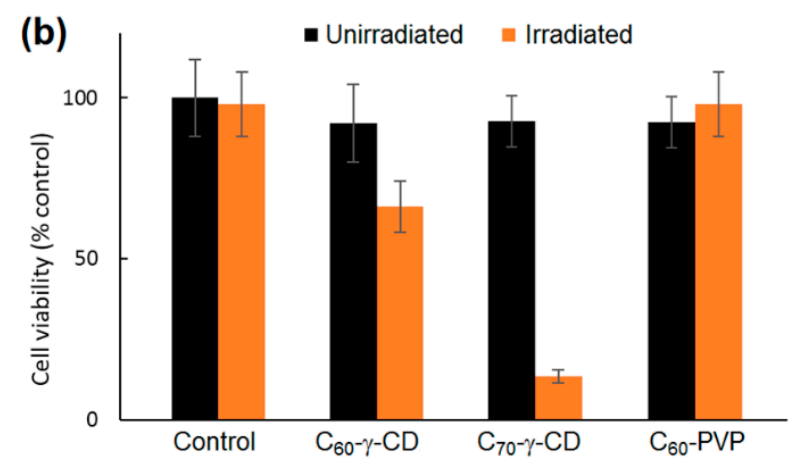

Figure 68. (a) Chemical structure of unmodified $C_{60}$ and $C_{70}$ dispersed in water using $\gamma-C D\left(C_{60}-\gamma-C D\right)$ and poly(vinylpyrrolidone) $\left(\mathrm{C}_{60}-\mathrm{PVP}\right)$. (b) $5 \mathrm{RP7}$ cell viability (WST-1 assay). Cells treated with $\mathrm{C}_{60}-\gamma-\mathrm{CD}$, $\mathrm{C}_{70}-\gamma-\mathrm{CD}$, and $\mathrm{C}_{60}-\mathrm{PVP}$ aqueous solutions under irradiation $\left(\lambda=633 \mathrm{~nm}, 3 \mathrm{~mW} / \mathrm{cm}^{2}\right.$ for $\left.1 \mathrm{~h}\right)$ compared to negative control (cell untreated). Adapted from Iizumi; Okazaki; Zhang; Yudasaka; Iijima [217]. 
In 2011, Iohara et al. [218] prepared $\mathrm{C}_{60}-\mathrm{HP}-\beta-\mathrm{CD}$ NPs by a co-grinding method. The authors compared the different properties of those NPs to $\mathrm{C}_{60}$ dispersed in poly(vinylpyrrolidone) (PVP). It appeared that when HP- $\beta-C D$ was used as a dispersant for $\mathrm{C}_{60}$, a much lower mean particle diameter was attained $(90 \mathrm{~nm})$ than the one obtained in PVP $(215 \mathrm{~nm})$. This outcome agreed with the results obtained by lizum et al. [217]. ${ }^{1} \mathrm{O}_{2}$ was already proved to be elaborated from $\mathrm{C}_{60}-\mathrm{HP}-\beta-\mathrm{CD}$ NPs through a type-II mechanism. Yet, in addition to ${ }^{1} \mathrm{O}_{2}$, the authors revealed the great aptitude of those NPs to generate multiple ROS, including $\mathrm{HO}^{\bullet}$ and $\mathrm{O}_{2}{ }^{\bullet-}$ under visible light irradiation through a type I reaction. The increase in the particle size due to the aggregation caused a restricted penetration of light that consequently led to a gradual loss of the capability of $\mathrm{C}_{60}-\mathrm{HP}-\beta-\mathrm{CD} N P$ s to produce ROS (Figure 69). $\mathrm{C}_{60}-\mathrm{PVP}$ and $\mathrm{C}_{60}$ alone produced lower levels of $\mathrm{HO}^{\bullet}$ and $\mathrm{O}_{2}{ }^{\bullet-}$, and barely generated ${ }^{1} \mathrm{O}_{2}$. In the dark, $\mathrm{C}_{60}, \mathrm{C}_{60}-\mathrm{PVP}$, and $\mathrm{C}_{60}-\mathrm{HP}-\beta-\mathrm{CD}$ did not cause the death of HeLa cells, even at high concentrations. $\mathrm{C}_{60}$ remained non-toxic, even under visible light irradiation. In contrary, $\mathrm{C}_{60}-\mathrm{PVP}$ and $\mathrm{C}_{60}-\mathrm{HP}-\beta-\mathrm{CD}$ prompted an interesting dose-dependent phototoxic effect. Bringing up their high capacity to produce different ROS, it was not surprising that $\mathrm{C}_{60}-\mathrm{HP}-\beta-\mathrm{CD}$ NPs induced the most significant PDT effect among all. Those results assured the crucial role of HP- $\beta-C D$ in elaborating such a stable and efficient system.


Figure 69. Particle size dependencies of $\mathrm{C}_{60}$ for the generation of (a) $\mathrm{HO} \bullet$ and (b) ${ }^{1} \mathrm{O}_{2}$ after visible light irradiation supplied from a fluorescence lamp (3500 lux, $\lambda=400-700 \mathrm{~nm}, 2 \mathrm{~cm}$ from the bottom) for $15 \mathrm{~min}$. Each point represents the mean \pm S.E. of three to five experiments. Adapted from Iohara; Hiratsuka; Hirayama; Takeshita; Motoyama; Arima; Uekama [218].

Many scientific efforts were devoted to render the fullerenes water-soluble for biological applications. Those attempts include the solubilization of those fullerenes by CDs through inclusion complexes, as previously presented by Ikeda et al. in their water-soluble host-guest fullerene-liposomes. On a similar track, Altaf et al. [219] prepared their $\mathrm{C}_{60}$-HSA NPs where the $\mathrm{C}_{60}$ were transferred from the $\mathrm{C}_{60} / \mathrm{HP}-\beta-\mathrm{CD}$ NPs to the human serum albumin (HSA). The elaborated $\mathrm{C}_{60}$-HSA NPs did not aggregate and exhibited a narrow size distribution and good dispersion stability. When linked to $\mathrm{C}_{60}$, the fluorescence intensity of HSA decreased. $\mathrm{C}_{60}$-HSA held a slightly improved high-affinity binding and a larger scavenging activity, and produced much more multiple ROS under visible light $\left({ }^{1} \mathrm{O}_{2}\right.$ and $\left.\mathrm{O}_{2}{ }^{\bullet-}\right)$ than HSA alone. HSA, $\mathrm{C}_{60}$-HSA, and $\mathrm{C}_{60}-\mathrm{HP}-\beta-\mathrm{CD}$ did not exhibit dark cellular toxicity. However, the visible light-induced PDT effect of $\mathrm{C}_{60}$-HSA NPs toward A549 cells was interesting, and analogous to that displayed by $\mathrm{C}_{60}-\mathrm{HP}-\beta-\mathrm{CD}$ NPs, and negligible in the case of HSA alone (Figure 70). In conclusion, $\beta$-CD helped elaborate a potential drug delivery system for PDT.

In vitro and in vivo experiments were also conducted on $C_{60} / \mathrm{HP}-\beta-\mathrm{CD}$ NPs to assess their photosensitizing activity for PDT [220]. In those NPs, $\mathrm{C}_{60}$ partially occupied the hydrophobic cavity of CD. Under visible light irradiation, this system generated a high level of ${ }^{1} \mathrm{O}_{2}\left(\phi_{\Delta}=0.96\right.$ in benzene) that even exceeded that produced by PpIX ( $\phi_{\Delta}=0.56$ in PBS). In addition, $\mathrm{O}_{2}{ }^{\bullet-}$ was also produced by the $\mathrm{C}_{60}$ component of the NPs. The generation of both types of ROS was dose-dependent, and it 
progressively and proportionally increased with the increase of the irradiation time and the energy of the light. In vitro, only when illuminated by visible light, $\mathrm{C}_{60}-\mathrm{HP}-\beta-\mathrm{CD}$ NPs caused remarkable photoinduced toxicity toward HeLa and A549 cells, with $\mathrm{IC}_{50}$ values of $10 \mu \mathrm{M}$ and $60 \mu \mathrm{M}$, respectively. $\mathrm{C}_{60}-\mathrm{HP}-\beta-\mathrm{CD}$ NPs acted better as PDT PS than 5-ALA, which was probably due to the greater ROS production. Moreover, the authors investigated the most appropriate parameters for an efficient in vivo PDT. In the presence of $\mathrm{C}_{60}-\mathrm{HP}-\beta-\mathrm{CD} N \mathrm{Ns}\left(2 \mathrm{mg} / \mathrm{Kg}\right.$ of $\left.\mathrm{C}_{60}\right), 12$ times repeated visible light irradiation $\left(\lambda=400-700 \mathrm{~nm}, 350 \mathrm{~mW} / \mathrm{cm}^{2}\right)$ for short period (15 s) with a total light dose of $63 \mathrm{~J} / \mathrm{cm}^{2}$ efficiently suppressed the growth of the sarcoma S-180 cells in ddY mice without causing any skin damage or major hyperthermia (Figure 71).

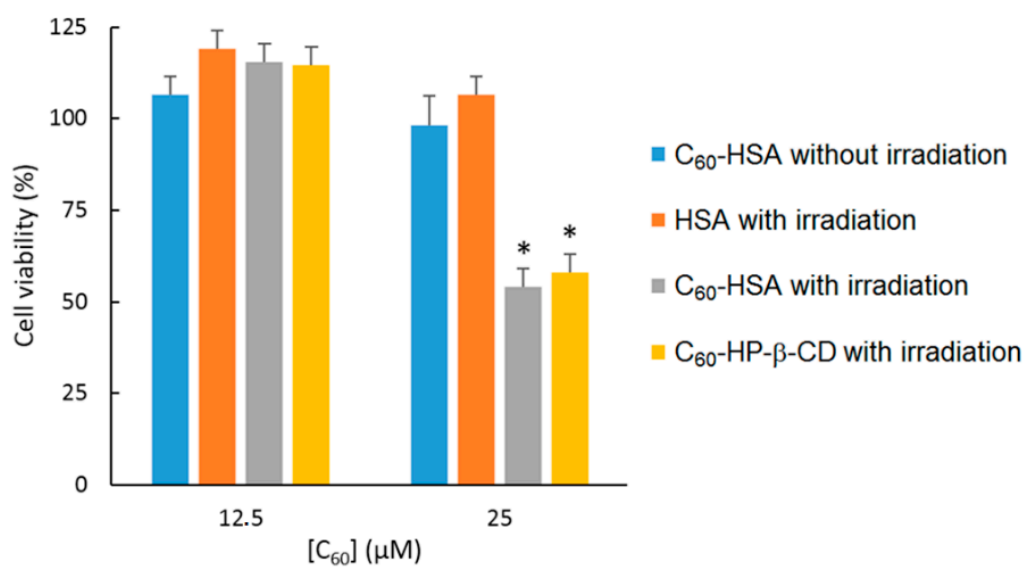

Figure 70. PDT activity of human serum albumin (HSA) solution alone, HSA-C 60 solution, and $\mathrm{C}_{60}-\mathrm{HP}-\beta-\mathrm{CD}$ NPs on A549 cells in the dark or after irradiation $\left(\lambda=400-700 \mathrm{~nm}, 35 \mathrm{~mW} / \mathrm{cm}^{2}\right.$ for $30 \mathrm{~min}$ ). Each point represents the mean $\pm \mathrm{SE}$ of five experiments. ${ }^{*} p<0.05$ vs. HAS alone solution. Adapted from Altaf; Aldawsari; Banjar; Makoto; Daisuke; Masaki; Kaneto; Fumitoshi [219].

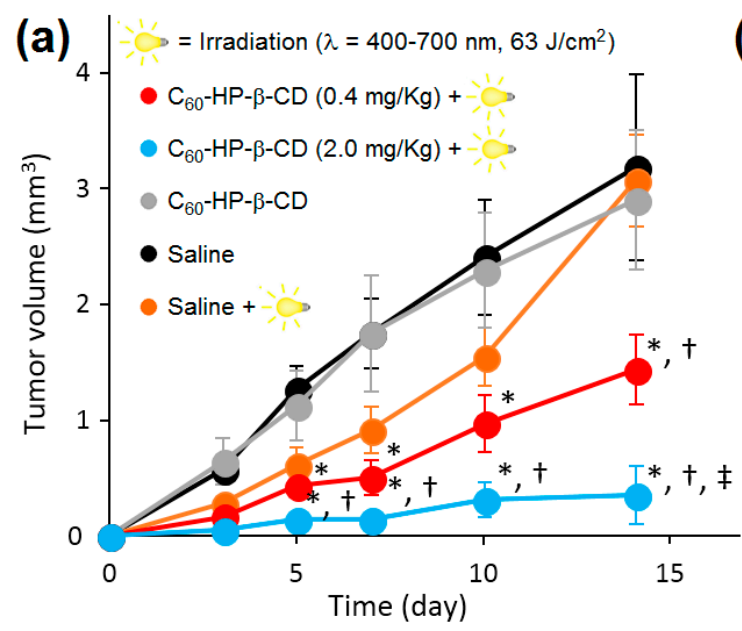

(b)

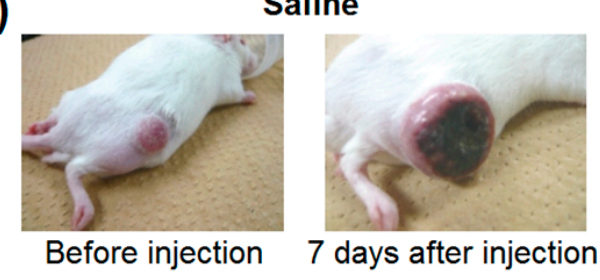

PDT with $\mathrm{C}_{60}-\mathrm{HP}-\beta-\mathrm{CD}$

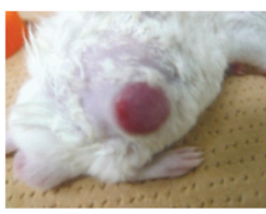

Before PDT

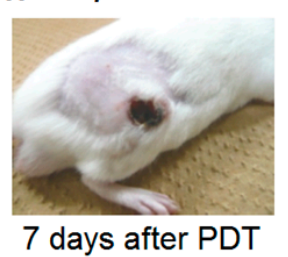

Figure 71. PDT effect of $\mathrm{C}_{60}-\mathrm{HP}-\beta-\mathrm{CD} N \mathrm{NS}(\mathbf{a})$ on tumor growth and $(\mathbf{b})$ changes in body weight of ddY mice in the dark or after irradiation from a xenon light source $\left(\lambda=400-700 \mathrm{~nm}, 63 \mathrm{~J} / \mathrm{cm}^{2}, 350 \mathrm{~mW} / \mathrm{cm}^{2}\right)$. Each point represents the mean \pm S.E. of six to nine experiments. ${ }^{*} p<0.05$ vs. saline. ${ }^{\dagger} p<0.05$ vs. saline plus light irradiation. ${ }^{\ddagger} p<0.05$ vs. $\mathrm{C}_{60}-\mathrm{HP}-\beta-\mathrm{CD}(0.4 \mathrm{mg} / \mathrm{Kg})$ plus light irradiation $\left(63 \mathrm{~J} / \mathrm{cm}^{2}\right)$. Adapted and reproduced from Altaf; Aldawsari; Banjar; Iohara; Anraku; Uekama; Hirayama [220].

Zhao et al. also addressed in their study the problem of the lack of solubility of fullerene in water [221]. The authors prepared a supramolecular complex that was constituted of fullerene and $\gamma$-CD. This complex appeared to be water-soluble at room temperature, but tended to aggregate 
when heated at $85{ }^{\circ} \mathrm{C}$ (Figure 72). The aggregated complexes were much more incorporated into the lens epithelial cells HLE B-3. In darkness and under visible light illumination, the monomeric and aggregated $\mathrm{C}_{60}-\gamma-\mathrm{CD}$ displayed no toxicity. Nevertheless, under UV-A irradiation, the viability of the HLE B-3 cells exposed to the monomeric $\mathrm{C}_{60}-\gamma-\mathrm{CD}$ decreased sharply to less than $10 \%$ in a dose-dependent manner. As for the aggregated fullerenes, the PDT efficiency was gradually lost with the gradual growth of the aggregates, and finally vanished when the cells were treated with the largest aggregates attained after $150 \mathrm{~min}$ of heating at $85^{\circ} \mathrm{C}$. The production of ${ }^{1} \mathrm{O}_{2}$ followed the same trend, where the maximum amount was generated by $\mathrm{C}_{60}-\gamma-\mathrm{CD}$, and decreased proportionally with the increasing aggregate size (Figure 73). After UVA irradiation, the ${ }^{1} \mathrm{O}_{2}$ was generated by $\mathrm{C}_{60}-\gamma-\mathrm{CD}$ inside the cells, and it targeted the intracellular proteins in HLE B-3 cells. This outcome was confirmed by the presence of high amounts of protein peroxides in the cells, which led to their damage by the induced apoptosis.
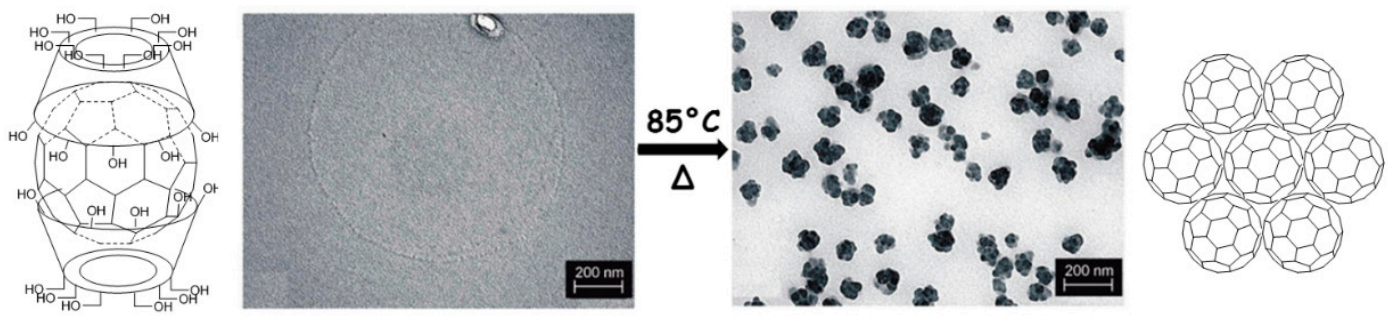

Figure 72. Visual and TEM images of $\mathrm{C}_{60}-\gamma-\mathrm{CD}$ and $\mathrm{C}_{60}$ aggregates after $150 \mathrm{~min}$ of heating at $85^{\circ} \mathrm{C}$. Reproduced and adapted by permission of The American Chemical Society [221].

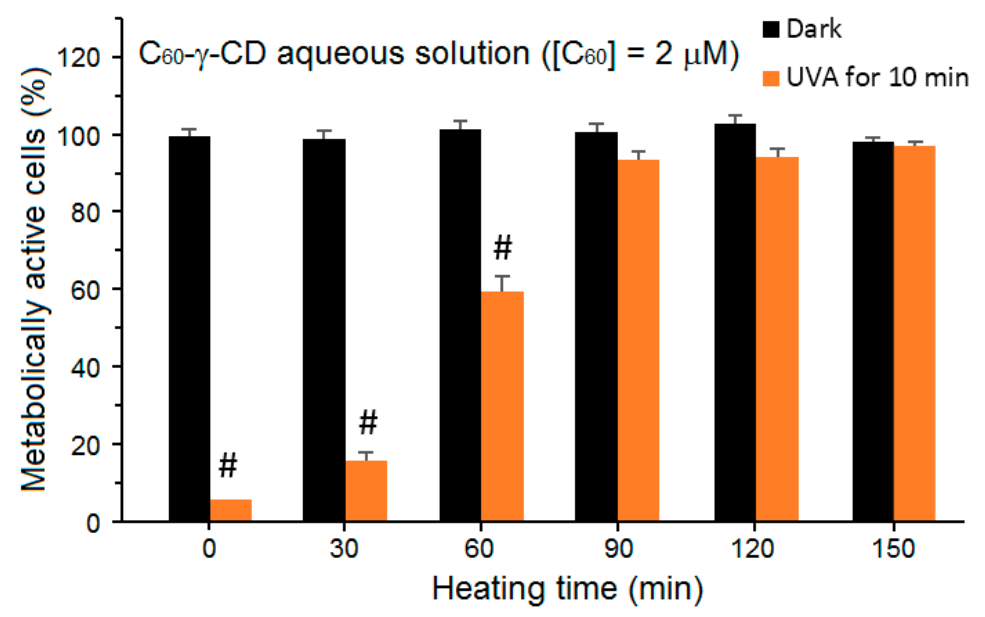

Figure 73. Effect of $2-\mu \mathrm{M}$ fullerene water solutions as a function of heating time on the viability of HLE B-3 cells irradiated with UVA. Results were presented as the means \pm SEMs from three independent experiments in quadruplicate. ${ }^{* *} p<0.01$ and ${ }^{*} p<0.05$ as compared with cells without fullerene treated and in the dark. ${ }^{\#} p<0.01$ as compared with corresponding cells in the dark. Adapted from Zhao; He; Chignell; Yin; Andley; Roberts [221].

In their approach, Wang et al. [222] associated the fullerene $C_{60}$ to the outside of the $\beta$-CD molecule to yield a water-soluble exclusion complex rather than embedding it in the cavities. $\mathrm{C}_{60}$ and $\beta-\mathrm{CD}$ were linked together via diaminotriethylene glycol as a hydrophilic spacer. Both the hydrophilic spacer and $\beta-C D$ maintained an enhanced solubility of $\mathrm{C}_{60}$ in water. The absorption profile and thus the basic structure of $C_{60}$ remained intact after being conjugated to $\beta-C D$. On the one hand, when this $C_{60}-\beta-C D$ was introduced in different concentrations up to $200 \mu \mathrm{g} / \mathrm{mL}$ into the human neuroblastoma SH-SY5Y cells, a negligible dark toxicity was witnessed. On the other hand, under irradiation with visible light $(\lambda \geq 400 \mathrm{~nm}, 20 \mathrm{~min}), \mathrm{C}_{60}-\beta-C D$ revealed a dose-dependent phototoxicity against the tumor 
cells (Figure 74a). After investigating the in vitro cytotoxicity and phototoxicity of their $\mathrm{C}_{60}-\beta-\mathrm{CD}$, the authors aimed to assess the dispersion distribution of the $C_{60}-\beta-C D$ throughout the living body. For actions to serve this goal, they labeled $C_{60}-\beta-C D$ with a NIR-dye, i.e., NIR-797, and injected it into hepatic $\mathrm{H} 22$ tumor-bearing mice. At $96 \mathrm{~h}$ post-injection, $\mathrm{C}_{60}-\beta-\mathrm{CD}$ was massively localized in the tumor and scarcely in the liver (Figure $74 \mathrm{~b}$ ). $C_{60}-\beta-C D$ appeared to circulate throughout the blood with a half-life of about $4 \mathrm{~h}$, leaving behind no acute or subacute toxicity in the different organs of the mice's body. Only in the presence of visible light and nicotinamide adenine dinucleotide (NADH), which is a reducing agent that naturally assists in the photocleavage of DNA, was $C_{60}-\beta-C D$ was active toward the cleavage of pBR322 plasmid DNA into form II (Figure 74c). Both the ability of $\mathrm{C}_{60}-\beta-\mathrm{CD}$ to cleave DNA and kill tumor cells by PDT were due to the action of ROS, precisely $\mathrm{HO}^{\bullet}$ and $\mathrm{O}_{2}{ }^{\bullet}$, which were significantly produced by the excited PS.

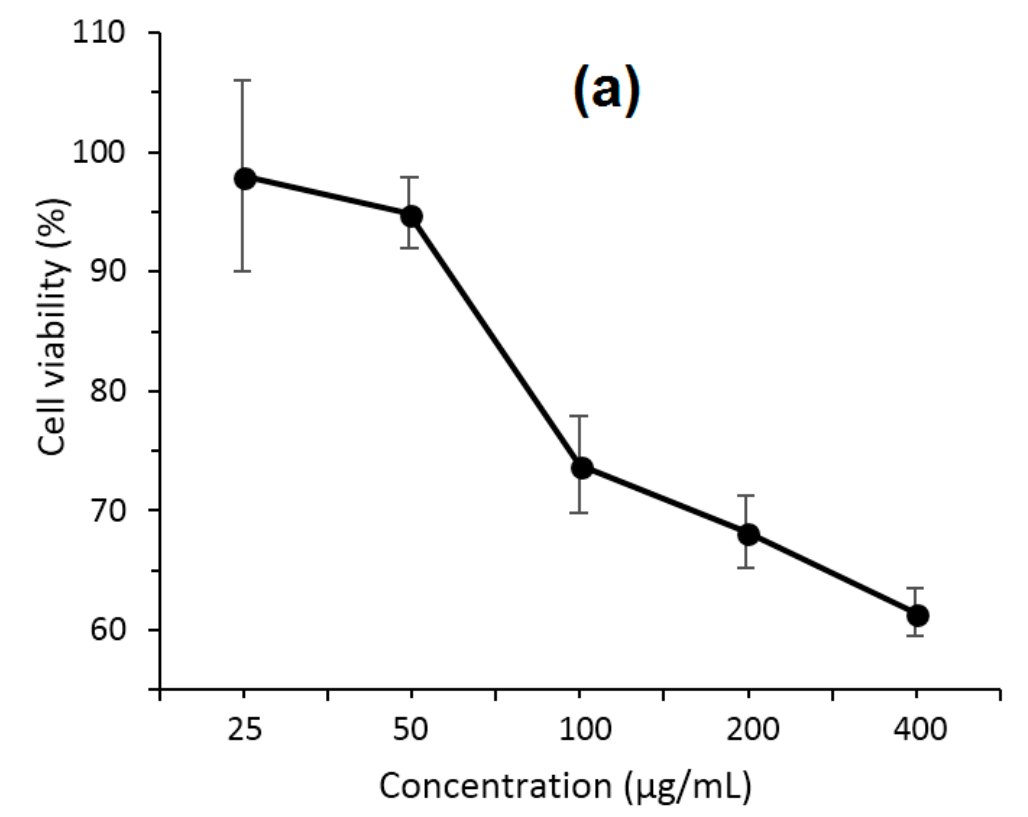

(b)

(c)
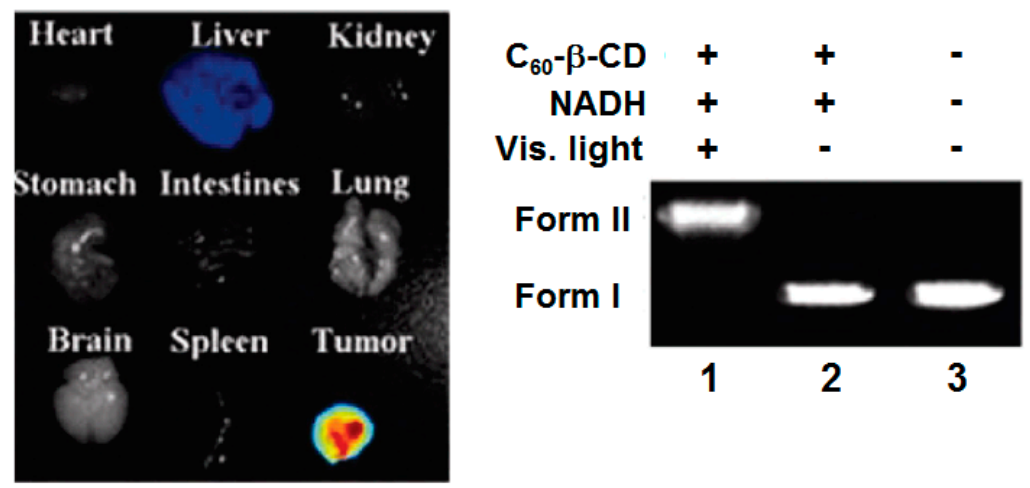

Figure 74. (a) In vitro cytotoxicity of $\mathrm{C}_{60}-\beta-\mathrm{CD}$ against human neuroblastoma SH-SY5Y cells upon visible light for $20 \mathrm{~min}$. (b) Near Infrared Fluorescence (NIRF) images of different organs at $96 \mathrm{~h}$ after tail-vein injection of the NIR-797-labeled $\mathrm{C}_{60}-\beta-C D$. (c) Photoinduced DNA cleavage behavior of $\mathrm{C}_{60}-\beta-C D$. The pBR322 supercoiled plasmid was incubated with each chemical for $4 \mathrm{~h}$ at room temperature. Lane 1: pBR322 DNA $(0.017 \mu \mathrm{g} / \mu \mathrm{L})$ with $\mathrm{C}_{60}-\beta-\mathrm{CD}(33 \mu \mathrm{mol} / \mathrm{L}), \mathrm{NADH}(330 \mu \mathrm{mol} / \mathrm{L})$, incubated under visible light irradiation. Lane 2: pBR322 DNA $(0.017 \mu \mathrm{g} / \mu \mathrm{L})$ with $\mathrm{C}_{60}-\mathrm{CD}(33 \mu \mathrm{mol} / \mathrm{L})$, $\mathrm{NADH}(330 \mu \mathrm{mol} / \mathrm{L})$, incubated in dark. Lane 3: pBR322 DNA $(0.017 \mu \mathrm{g} / \mu \mathrm{L})$ incubated in the dark. Reproduced and adapted by permission of The John Wiley and Sons [222]. 
To overcome the water-solubility problem of fullerene $\mathrm{C}_{60}$ and enhance its phototoxicity, Zhang et al. manipulated $\mathrm{C}_{60}$ via the pre-used $C D$-functionalization tactic [223]. However, instead of working with unmodified $\gamma$-CD, they used $\gamma$-CD polymer $(\gamma-C D-P)$ to form their inclusion complex $\left(\mathrm{C}_{60}-\gamma\right.$-CD-P) (Figure $\left.75 \mathrm{a}\right)$. In this system, monomeric $\mathrm{C}_{60}$ occupied the hydrophobic cavities of $\gamma$-CD-P. Similar to $\beta$-CD and $\gamma$-CD, $\gamma$-CD-P successfully rendered $\mathrm{C}_{60}$ water-soluble, and the absorption spectrum of this inclusion complex displayed the characteristic peaks of $\mathrm{C}_{60}$. However, those peaks were red-shifted as compared to the absorption peaks obtained from $\mathrm{C}_{60}-\gamma-\mathrm{CD}-\mathrm{P}$. However, $\gamma$-CD-P appeared to be capable of forming inclusion complexes easier than $\gamma$-CD. In addition, $\mathrm{C}_{60}$ in the $\mathrm{C}_{60}-\gamma-\mathrm{CD}-\mathrm{P}$ complex remained well-dispersed in water without forming aggregates, even at high concentrations of the complex due to the supramolecular interaction with $\gamma$-CD-P, which was an advantage over the other $\mathrm{C}_{60}$ inclusion complexes with $\mathrm{CD}$. The $\mathrm{C}_{60}-\gamma-\mathrm{CD}-\mathrm{P}$ complex efficiently produced ${ }^{1} \mathrm{O}_{2}$ only under UVA light, unlike $\mathrm{C}_{60}-\beta-\mathrm{CD}$, which can generate ${ }^{1} \mathrm{O}_{2}$ under both visible and UVA lights. Those complexes were studied in vitro (MTT assay) with mouse melanoma cell lines B16-F10. $\gamma$-CD-P increased the biocompatibility of $\mathrm{C}_{60}$, as no cytotoxic was observed when the cells were exposed to different concentrations of $\mathrm{C}_{60}-\gamma-\mathrm{CD}-\mathrm{P}\left(\left[\mathrm{C}_{60}\right]=0.5-20 \mu \mathrm{M}\right)$ after $48 \mathrm{~h}$ of incubation in the dark. Due to the non-aggregated nature of the $\mathrm{C}_{60}$ enclosed into $\gamma$-CD-P and in agreement with the significant ${ }^{1} \mathrm{O}_{2}$ production, $\mathrm{C}_{60}-\gamma$-CD-P exhibited a superior phototoxic effect than $\mathrm{C}_{60}$ toward the tumor cells under UVA irradiation (Figure 75b).

(a)

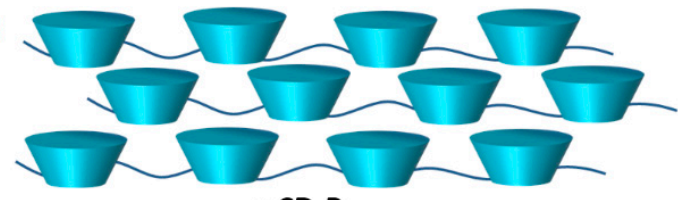
$\gamma$-CD-P $\mathrm{C}_{60}$
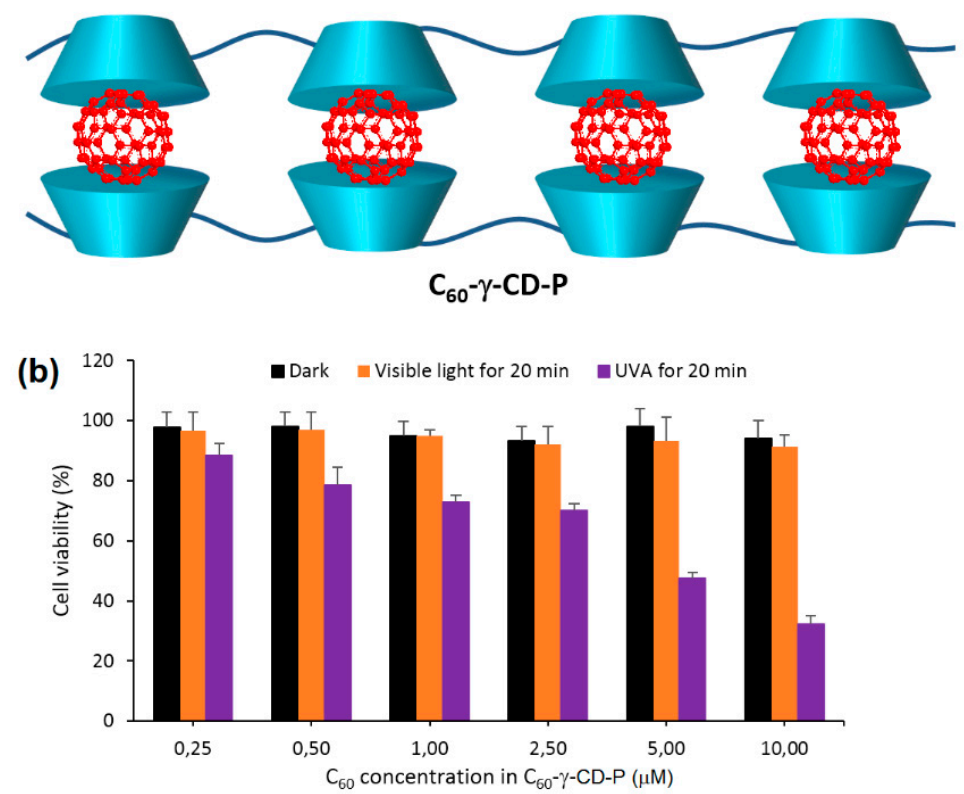

Figure 75. (a) Schematic illustration of $\gamma$-CD polymer $\left(\gamma\right.$-CD-P), $C_{60}$, and $C_{60}-\gamma$-CD-P. (b) Effect of different concentration of $\mathrm{C}_{60}-\gamma-\mathrm{CD}-\mathrm{P}$ exposure on the B16-F10 cell viability irradiated with UV-A from two fluorescent PUV-A lamps (Philips, PL-L36W) or two cool white visible light lamps (Philips, TLD36W) for 20 min. Adapted from Zhang; Gong; Liu; Piao; Sun; Diao [223].

\section{Conclusions and Perspectives}

As a conclusion, we can notice that all of the papers describing the use of CDs stress how important CD-PS systems are in improving PDT efficiency. Various CD-PS systems have been developed and can 
be formed by three types of binding mode of PSs with CDs, which are non-covalent binding (CD-PS inclusion complexes), covalent binding (CD-PS conjugates), and non-specific external binding (CD-PS nanoassemblies). For porphyrinoid PSs, it was found that CD-PS inclusion complexes can: (1) improve PDT efficiency $[120,121,126]$ compared with free PSs; (2) reduce some drawbacks of PSs such as their lack of water solubility [120,121,124-126] and self-aggregation [124,127]; (3) induce a lower cytotoxicity than free PSs in some cases [120]; (4) lead to a better or different cellular uptake [125,129] even in spheroids [128]; (5) modify the intracellular distribution [127]; and (6) induce an acceleration of the PS diffusion into the biological media [127]. Similar results are also obtained for non-porphyrinoid PSs.

Moreover, some CD-PS conjugates and nanoassemblies have proven their usefulness to encapsulate (1) chemotherapeutic drugs allowing both PDT and chemotherapy with a synergistic effect $[140,141,144,167,171,183]$, or (2) NO photodonor, enabling an amplified PDT effect due to the simultaneous photorelease of two cytotoxic species $\left({ }^{1} \mathrm{O}_{2}\right.$ and $\left.\mathrm{NO} \mathrm{O}^{\bullet}\right)[145,177]$.

In addition, the combination of CD-PS systems with NPs leads to passive-targeting PDT treatment, thanks to the EPR effect of NPs. NIR excitation-type NPs (UCNPs) allow also to reach deeper tumors due to their better penetration into biological tissues [73,192-194], and AuNPs enable doing PTT and PDT simultaneously [197].

With the aim of improving the selectivity of all of these CD-PS systems, we believe that in the near future, new CD-PS systems combined to active targeting agents will emerge. In this regard, few articles already describe the grafting of active targeting agents on CD-PS systems, i.e., grafting of cell penetrating peptide $\mathrm{R}_{6} \mathrm{H}_{4}$ [224], membrane-permeable and mitochondria-targeted peptide RLA [225], CD44-targeted hyaluronic acid [226], folate-targeted folic acid [227], and asialoglycoprotein-targeted sugars (galactose [228] and lactobionic acid [229]).

Author Contributions: Conceptualisation, Frochot C., Acherar, S.; Writing Review, all authors, Bibliography, Baros F., Vanderesse R.; Figures and Schemes, Colombeau L.

Funding: This research received no external funding.

Conflicts of Interest: The authors declare no conflict of interest.

\section{References}

1. Naghavi, M. Global, regional, and national age-sex specific mortality for 264 causes of death, 1980-2016: A systematic analysis for the Global Burden of Disease Study 2016. Lancet 2016, 390, 1151-1210. [CrossRef]

2. Ferlay, J.; Soerjomataram, I.; Dikshit, R.; Eser, S.; Mathers, C.; Rebelo, M.; Parkin, D.M.; Forman, D.; Bray, F. Cancer incidence and mortality worldwide: Sources, methods and major patterns in GLOBOCAN 2012. Int. J. Cancer 2015, 136, E359-E386. [CrossRef] [PubMed]

3. WHO. Global Action Plan for the Prevention and Control of NCDs 2013-2020; WHO: Geneva, Switzerland, 2013; 55p, Available online: http:/ / www.who.int/nmh/publications/ncd-action-plan/en/ (accessed on 20 July 2018).

4. Institute for Health Metrics and Evaluation. Global Burden of Disease Collaborative Network. Global Burden of Disease Study 2016 (GBD 2016) Results. 2017. Available online: http:/ /ghdx.healthdata.org/gbd-resultstool (accessed on 20 July 2018).

5. Gupta, M.; Dahiya, J.; Marwaha, R.K.; Dureja, H. Therapies in cancer treatment: An overview. Int. J. Pharm. Pharm. Sci. 2015, 7, 1-9.

6. DeVita, V.T., Jr.; Rosenberg, S.A. Two hundred years of cancer research. N. Engl. J. Med. 2012, 366, $2207-2214$. [CrossRef] [PubMed]

7. Wyld, L.; Audisio, R.A.; Poston, G.J. The evolution of cancer surgery and future perspectives. Nat. Rev. Clin. Oncol. 2015, 12, 115-124. [CrossRef] [PubMed]

8. Foster, D.; Shaikh, M.F.; Gleeson, E.; Babcock, B.D.; Ringold, D.; Bowne, W.B. Palliative surgery for advanced cancer: Identifying evidence-based criteria for patient selection: Case report and review of literature. J. Palliat. Med. 2015, 19, 22-29. [CrossRef] [PubMed]

9. Baskar, R.; Lee, K.A.; Yeo, R.; Yeoh, K.W. Cancer and radiation therapy: Current advances and future directions. Int. J. Med. Sci. 2012, 9, 193-199. [CrossRef] [PubMed] 
10. Baumann, M.; Krause, M.; Overgaard, J.; Debus, J.; Bentzen, S.M.; Daartz, J.; Richter, C.; Zips, D.; Bortfeld, T. Radiation oncology in the era of precision medicine. Nat. Rev. Cancer 2016, 16, 234. [CrossRef] [PubMed]

11. Chabner, B.A.; Roberts, T.G. Chemotherapy and the war on cancer. Nat. Rev. Cancer 2005, 5, 65-72. [CrossRef] [PubMed]

12. Koury, J.; Lucero, M.; Cato, C.; Chang, L.; Geiger, J.; Henry, D.; Hernandez, J.; Hung, F.; Kaur, P.; Teskey, G.; et al. Immunotherapies: Exploiting the Immune System for Cancer Treatment. J. Immunol. Res. 2018, 2018, 9585614. [CrossRef] [PubMed]

13. Moore, C.D.; Chen, I. Immunotherapy in cancer treatment: A review of checkpoint inhibitors. US Pharm. 2018, 43, 27-31.

14. Fairchild, A.; Tirumani, S.H.; Rosenthal, M.H.; Howard, S.A.; Krajewski, K.M.; Nishino, M.; Shinagare, A.B.; Jagannathan, J.P.; Ramaiya, N.H. Hormonal therapy in oncology: A primer for the radiologist. AJR Am. J. Roentgenol. 2015, 204, W620-W630. [CrossRef] [PubMed]

15. Das, S.K.; Menezes, M.E.; Bhatia, S.; Wang, X.Y.; Emdad, L.; Sarkar, D.; Fisher, P.B. Gene therapies for cancer: Strategies, challenges and successes. J. Cell. Physiol. 2015, 230, 259-271. [CrossRef] [PubMed]

16. Kumar, S.R.; Markusic, D.M.; Biswas, M.; High, K.A.; Herzog, R.W. Clinical development of gene therapy: Results and lessons from recent successes. Mol. Ther. Methods Clin. Dev. 2016, 3, 16034. [CrossRef] [PubMed]

17. Yu, C.-H.; Lin, H.-P.; Cheng, S.-J.; Sun, A.; Chen, H.-M. Cryotherapy for oral precancers and cancers. J. Formos. Med. Assoc. 2014, 113, 272-277. [CrossRef] [PubMed]

18. Baudino, T.A. Targeted Cancer Therapy: The Next Generation of Cancer Treatment. Curr. Drug Discov. Technol. 2015, 12, 3-20. [CrossRef] [PubMed]

19. Padma, V.V. An overview of targeted cancer therapy. Biomedicine 2015, 5, 19. [CrossRef] [PubMed]

20. Truong, S.N.; Van Pham, P. Stem cell technology and engineering for cancer treatment. Biomed. Res. Ther. 2015, 2, 13. [CrossRef]

21. Mitku, W.; Tesfaye, W. Review on stem cell therapy and their role in cancer treatment. Int. J. Biotechnol. Bioeng. 2017, 3, 71-79. [CrossRef]

22. Sethi, M.; Chakarvarti, S.K. Hyperthermia techniques for cancer treatment: A review. Int. J. PharmTech Res. 2015, 8, 292-299.

23. Mellal, I.; Oukaira, A.; Kengene, E.; Lakhssassi, A. Thermal therapy modalities for cancer treatment: A review and future perspectives. Int. J. Appl. Sci. 2017, 4, 14. [CrossRef]

24. Dougherty, T.J. Photodynamic therapy (PDT) of malignant tumors. Crit. Rev. Oncol. Hematol. 1984, 2, 83-116. [CrossRef]

25. Zhang, J.; Jiang, C.; Figueiro Longo, J.P.; Azevedo, R.B.; Zhang, H.; Muehlmann, L.A. An updated overview on the development of new photosensitizers for anticancer photodynamic therapy. Acta Pharm. Sin. B 2018, 8, 137-146. [CrossRef] [PubMed]

26. Van Straten, D.; Mashayekhi, V.; de Bruijn, H.S.; Oliveira, S.; Robinson, D.J. Oncologic photodynamic therapy: Basic principles, current clinical status and future directions. Cancers 2017, 9, 19. [CrossRef] [PubMed]

27. Macdonald, I.J.; Dougherty, T.J. Basic principles of photodynamic therapy. J. Porphyr. Phthalocyanines 2001, 5, 105-129. [CrossRef]

28. Zhou, Z.; Song, J.; Nie, L.; Chen, X. Reactive oxygen species generating systems meeting challenges of photodynamic cancer therapy. Chem. Soc. Rev. 2016, 45, 6597-6626. [CrossRef] [PubMed]

29. Dabrowski, J. Reactive oxygen species in photodynamic therapy: Mechanisms of their generation and potentiation. Adv. Inorg. Chem. 2017, 70, 343-394.

30. Li, B.; Lin, L.; Lin, H.; Wilson, B.C. Photosensitized singlet oxygen generation and detection: Recent advances and future perspectives in cancer photodynamic therapy. J. Biophotonics 2016, 9, 1314-1325. [CrossRef] [PubMed]

31. Mroz, P.; Yaroslavsky, A.; Kharkwal, G.B.; Hamblin, M.R. Cell death pathways in photodynamic therapy of cancer. Cancers 2011, 3, 2516-2539. [CrossRef] [PubMed]

32. Kubiak, M.; Lysenko, L.; Gerber, H.; Nowak, R. Cell reactions and immune responses to photodynamic therapy in oncology. Postępy Higieny i Medycyny Doświadczalnej 2016, 70, 735-742. [CrossRef] [PubMed]

33. Gold, M.H. History of Photodynamic Therapy. In Photodynamic Therapy in Dermatology; Gold, M.H., Ed.; Springer: New York, NY, USA, 2011; pp. 1-4.

34. Abdel-Kader, M.H. Photodynamic Therapy. From Theory to Application; Springer Science \& Business Media: Berlin/Heidelberg, Germany, 2014; p. 312. 
35. Ackroyd, R.; Kelty, C.; Brown, N.; Reed, M. The history of photodetection and photodynamic therapy. Photochem. Photobiol. 2001, 74, 656-669. [CrossRef]

36. Pathak, M.A.; Fitzpatrick, T.B. The evolution of photochemotherapy with psoralens and UVA (PUVA): 2000 BC to 1992 AD. J. Photochem. Photobiol. B Biol. 1992, 14, 3-22. [CrossRef]

37. Kelly, J.F.; Snell, M.E. Hematoporphyrin derivative: A possible aid in the diagnosis and therapy of carcinoma of the bladder. J. Urol. 1976, 115, 150-151. [CrossRef]

38. Dougherty, T.J.; Kaufman, J.E.; Goldfarb, A.; Weishaupt, K.R.; Boyle, D.; Mittleman, A. Photoradiation therapy for the treatment of malignant tumors. Cancer Res. 1978, 38, 2628-2635. [PubMed]

39. Dougherty, T.J.; Henderson, B.W. Photodynamic Therapy: Basic Principles and Clinical Applications; M. Dekker: New York, NY, USA, 1992; p. 459.

40. Filonenko, E.V.; Serova, L.G. Photodynamic therapy in clinical practice. Biomed. Photonics 2016, 5, $26-37$.

41. Biyıklığlu, Z.; Kantekin, H. Synthesis and spectroscopic properties of a series of octacationic water-soluble phthalocyanines. Synth. Met. 2011, 161, 943-948. [CrossRef]

42. Arslanoğlu, Y.; Nyokong, T. Synthesis and photophysical studies of monocarboxy phthalocyanines containing quaternizable groups. Polyhedron 2011, 30, 2733-2739. [CrossRef]

43. Li, H.; Jensen, T.J.; Fronczek, F.R.; Vicente, M.G.H. Syntheses and properties of a series of cationic water-soluble phthalocyanines. J. Med. Chem. 2008, 51, 502-511. [CrossRef] [PubMed]

44. Jinadasa, R.G.; Zhou, Z.; Vicente, M.G.; Smith, K.M. Syntheses and cellular investigations of di-aspartate and aspartate-lysine chlorin e(6) conjugates. Org. Biomol. Chem. 2016, 14, 1049-1064. [CrossRef] [PubMed]

45. Meng, Z.; Yu, B.; Han, G.; Liu, M.; Shan, B.; Dong, G.; Miao, Z.; Jia, N.; Tan, Z.; Li, B.; et al. Chlorin p6-based water-soluble amino acid derivatives as potent photosensitizers for photodynamic therapy. J. Med. Chem. 2016, 59, 4999-5010. [CrossRef] [PubMed]

46. Kamarulzaman, E.; Gazzali, A.; Acherar, S.; Frochot, C.; Barberi-Heyob, M.; Boura, C.; Chaimbault, P.; Sibille, E.; Wahab, H.; Vanderesse, R. New peptide-conjugated chlorin-type photosensitizer targeting neuropilin-1 for anti-vascular targeted photodynamic therapy. Int. J. Mol. Sci. 2015, 16, 24059-24080. [CrossRef] [PubMed]

47. Ranyuk, E.; Cauchon, N.; Klarskov, K.; Guerin, B.; van Lier, J.E. Phthalocyanine-peptide conjugates: Receptor-targeting bifunctional agents for imaging and photodynamic therapy. J. Med. Chem. 2013, 56, 1520-1534. [CrossRef] [PubMed]

48. Kato, A.; Kataoka, H.; Yano, S.; Hayashi, K.; Hayashi, N.; Tanaka, M.; Naitoh, I.; Ban, T.; Miyabe, K.; Kondo, H.; et al. Maltotriose conjugation to a chlorin derivative enhances the antitumor effects of photodynamic therapy in peritoneal dissemination of pancreatic cancer. Mol. Cancer Ther. 2017, 16, 1124-1132. [CrossRef] [PubMed]

49. Narumi, A.; Tsuji, T.; Shinohara, K.; Yamazaki, H.; Kikuchi, M.; Kawaguchi, S.; Mae, T.; Ikeda, A.; Sakai, Y.; Kataoka, H.; et al. Maltotriose-conjugation to a fluorinated chlorin derivative generating a PDT photosensitizer with improved water-solubility. Org. Biomol. Chem. 2016, 14, 3608-3613. [CrossRef] [PubMed]

50. Nishie, H.; Kataoka, H.; Yano, S.; Kikuchi, J.I.; Hayashi, N.; Narumi, A.; Nomoto, A.; Kubota, E.; Joh, T. A next-generation bifunctional photosensitizer with improved water-solubility for photodynamic therapy and diagnosis. Oncotarget 2016, 7, 74259-74268. [CrossRef] [PubMed]

51. Zhou, X.Q.; Meng, L.B.; Huang, Q.; Li, J.; Zheng, K.; Zhang, F.L.; Liu, J.Y.; Xue, J.P. Synthesis and in vitro anticancer activity of zinc(II) phthalocyanines conjugated with coumarin derivatives for dual photodynamic and chemotherapy. ChemMedChem 2015, 10, 304-311. [CrossRef] [PubMed]

52. Bovis, M.J.; Woodhams, J.H.; Loizidou, M.; Scheglmann, D.; Bown, S.G.; Macrobert, A.J. Improved in vivo delivery of m-THPC via pegylated liposomes for use in photodynamic therapy. J. Control. Release 2012, 157, 196-205. [CrossRef] [PubMed]

53. Hinger, D.; Gräfe, S.; Navarro, F.; Spingler, B.; Pandiarajan, D.; Walt, H.; Couffin, A.-C.; Maake, C. Lipid nanoemulsions and liposomes improve photodynamic treatment efficacy and tolerance in CAL-33 tumor bearing nude mice. J. Nanobiotechnol. 2016, 14, 71. [CrossRef] [PubMed]

54. Jia, X.; Yang, F.F.; Li, J.; Liu, J.Y.; Xue, J.P. Synthesis and in vitro photodynamic activity of oligomeric ethylene glycol-quinoline substituted zinc(II) phthalocyanine derivatives. J. Med. Chem. 2013, 56, 5797-5805. [CrossRef] [PubMed] 
55. Bechet, D.; Couleaud, P.; Frochot, C.; Viriot, M.L.; Guillemin, F.; Barberi-Heyob, M. Nanoparticles as vehicles for delivery of photodynamic therapy agents. Trends Biotechnol. 2008, 26, 612-621. [CrossRef] [PubMed]

56. Debele, T.A.; Peng, S.; Tsai, H.C. Drug Carrier for Photodynamic Cancer Therapy. Int. J. Mol. Sci. 2015, 16, 22094-22136. [CrossRef] [PubMed]

57. Deda, D.K.; Araki, K. Nanotechnology, light and chemical action: An effective combination to kill cancer cells. J. Braz. Chem. Soc. 2015, 26, 2448-2470. [CrossRef]

58. Hong, E.J.; Choi, D.G.; Shim, M.S. Targeted and effective photodynamic therapy for cancer using functionalized nanomaterials. Acta Pharm. Sin. B 2016, 6, 297-307. [CrossRef] [PubMed]

59. Li, L.; Huh, K.M. Polymeric nanocarrier systems for photodynamic therapy. Biomater. Res. 2014, $18,19$. [CrossRef] [PubMed]

60. Paszko, E.; Ehrhardt, C.; Senge, M.O.; Kelleher, D.P.; Reynolds, J.V. Nanodrug applications in photodynamic therapy. Photodiagn. Photodyn. Ther. 2011, 8, 14-29. [CrossRef] [PubMed]

61. Maheriya, P.M. A promising candidate in enhancing oral bioavailability of poorly water soluble drugs. MOJ Bioequivalence Availab. 2016, 3, 30-63. [CrossRef]

62. Lakkakula, J.R.; Krause, R.W.M. A vision for cyclodextrin nanoparticles in drug delivery systems and pharmaceutical applications. Nanomedicine 2014, 9, 877-894. [CrossRef] [PubMed]

63. Chordiya Mayur, A.; Senthilkumaran, K. Cyclodextrin in drug delivery: A review. J. Pharm. Pharm. Sci. 2012, 1, 19-29.

64. Tiwari, G.; Tiwari, R.; Rai, A.K. Cyclodextrins in delivery systems: Applications. J. Pharm. Bioallied Sci. 2010, 2, 72-79. [CrossRef] [PubMed]

65. Zhang, J.; Ma, P.X. Cyclodextrin-based supramolecular systems for drug delivery: Recent progress and future perspective. Adv. Drug Deliv. Rev. 2013, 65, 1215-1233. [CrossRef] [PubMed]

66. Crini, G. Review: A History of Cyclodextrins. Chem. Rev. 2014, 114, 10940-10975. [CrossRef] [PubMed]

67. Huang, J.R.; Zhuang, H.N.; Jin, Z.Y. Cyclodextrin Chemistry; World Scientific/ChemicallndustryPress: Beijing, China, 2013; p. 292.

68. Loftsson, T.; Duchêne, D. Cyclodextrins and their pharmaceutical applications. Int. J. Pharm. 2007, 329, 1-11. [CrossRef] [PubMed]

69. Fourmentin, S.; Crini, G.; Lichtfouse, E. Cyclodextrin Applications in Medicine, Food, Environment and Liquid Crystals; Springer International Publishing: Basel, Switzerland, 2015; p. 240.

70. Hedges, A. Chapter 22-Cyclodextrins: Properties and Applications. In Starch, 3rd ed.; Academic Press: San Diego, CA, USA, 2009; pp. 833-851.

71. Jin, Z.Y. Preparation and Application in Industry; World Scientific Publishing Co. Pte. Ltd.: Singapore, 2018; p. 285.

72. Sharma, N.; Baldi, A. Exploring versatile applications of cyclodextrins: An overview. Drug Deliv. 2016, 23, 729-747. [CrossRef] [PubMed]

73. Tian, G.; Ren, W.; Yan, L.; Jian, S.; Gu, Z.; Zhou, L.; Jin, S.; Yin, W.; Li, S.; Zhao, Y. Red-emitting upconverting nanoparticles for photodynamic therapy in cancer cells under near-infrared excitation. Small 2013, 9, 1928-1938. [CrossRef]

74. Szejtli, J. Medicinal applications of cyclodextrins. Med. Res. Rev. 1994, 14, 353-386. [CrossRef] [PubMed]

75. Akasha, A.A.; Elwahedi, M.A.; Eldeeb, A.M. Cyclodextrins and their pharmaceutical applications. PharmaTutor 2014, 2, 40-46.

76. Di Cagno, M. The potential of cyclodextrins as novel active pharmaceutical ingredients: A short overview. Molecules 2017, 22, 1. [CrossRef] [PubMed]

77. Jansook, P.; Ogawa, N.; Loftsson, T. Cyclodextrins: Structure, physicochemical properties and pharmaceutical applications. Int. J. Pharm. 2018, 535, 272-284. [CrossRef] [PubMed]

78. Dos Santos, C.; Buera, P.; Mazzobre, F. Novel trends in cyclodextrins encapsulation. Applications in food science. Curr. Opin. Food Sci. 2017, 16, 106-113. [CrossRef]

79. Fenyvesi, E.; Vikmon, M.; Szente, L. Cyclodextrins in food technology and human nutrition: Benefits and limitations. Crit. Rev. Food Sci. Nutr. 2016, 56, 1981-2004. [CrossRef] [PubMed]

80. Kfoury, M.; Auezova, L.; Greige-Gerges, H.; Fourmentin, S. Promising applications of cyclodextrins in food: Improvement of essential oils retention, controlled release and antiradical activity. Carbohydr. Polym. 2015, 131, 264-272. [CrossRef] [PubMed] 
81. Li, Z.; Chen, S.; Gu, Z.; Chen, J.; Wu, J. Alpha-cyclodextrin: Enzymatic production and food applications. Trends Food Sci. Technol. 2014, 35, 151-160. [CrossRef]

82. Feng, T.; Zhuang, H.; Yang, N. Applications in Cosmetics. In Cyclodextrins; World Scientific: Singapore, 2018; pp. 143-207.

83. Chandrul, K.K. Role of macromolecules in chromatography: Cyclodextrines. J. Chem. Pharm. Res. 2011, 3, 822-828.

84. Tang, J.; Zhang, S.; Lin, Y.; Zhou, J.; Pang, L.; Nie, X.; Zhou, B.; Tang, W. Engineering cyclodextrin clicked chiral stationary phase for high-efficiency enantiomer separation. Sci. Rep. 2015, 5, 11523. [CrossRef] [PubMed]

85. Tang, W.; Ng, S.C.; Sun, D. Modified Cyclodextrins for Chiral Separation; Springer: Heidelberg, Germany, 2013; p. 258.

86. Wang, Y.; Chen, H.; Xiao, Y.; Ng, C.H.; Oh, T.S.; Tan, T.T.; Ng, S.C. Preparation of cyclodextrin chiral stationary phases by organic soluble catalytic 'click' chemistry. Nat. Protoc. 2011, 6, 935-942. [CrossRef] [PubMed]

87. Xiao, Y.; Ng, S.C.; Tan, T.T.; Wang, Y. Recent development of cyclodextrin chiral stationary phases and their applications in chromatography. J. Chromatogr. A 2012, 1269, 52-68. [CrossRef] [PubMed]

88. Zhang, X.; Zhang, Y.; Armstrong, D.W. 8.10 Chromatographic Separations and Analysis: Cyclodextrin Mediated HPLC, GC and CE Enantiomeric Separations. In Comprehensive Chirality; Carreira, E.M., Yamamoto, H., Eds.; Elsevier Ltd.: New York, NY, USA, 2012; Volume 8, pp. 177-199.

89. Bai, C.C.; Tian, B.R.; Zhao, T.; Huang, Q.; Wang, Z.Z. Cyclodextrin-catalyzed organic synthesis: Reactions, mechanisms, and applications. Molecules 2017, 22, 1475. [CrossRef] [PubMed]

90. Bhosale, S.V.; Bhosale, S.V. beta-Cyclodextrin as a catalyst in organic synthesis. Mini-Rev. Org. Chem. 2007, 4, 231-242. [CrossRef]

91. Hapiot, F.; Ponchel, A.; Tilloy, S.; Monflier, E. Cyclodextrins and their applications in aqueous-phase metal-catalyzed reactions. C. R. Chim. 2011, 14, 149-166. [CrossRef]

92. Singh, M.; Sharma, R.; Banerjee, U.C. Biotechnological applications of cyclodextrins. Biotechnol. Adv. 2002, 20, 341-359. [CrossRef]

93. Szejtli, J. The cyclodextrins and their applications in biotechnology. Carbohydr. Polym. 1990, 12, 375-392. [CrossRef]

94. Bhaskara-Amrit, U.R.; Agrawal, P.B.; Warmoeskerken, M. Applications of $\beta$-cyclodextrins in textiles. Autex Res. J. 2011, 11, 94-101.

95. Voncina, B.; Vivod, V. Cyclodextrins in Textile Finishing; Intech Open Science: Valencia, Spain, 2013; Volume 3, pp. 53-75.

96. Xu, J. Applications in the Textile Industry. In Cyclodextrins; Jin, Z.-Y., Ed.; World Scientific: Singapore, 2018; pp. 209-230.

97. Krause, R.W.M.; Mamba, B.B.; Bambo, F.M.; Malefetse, T.J. 9. Cyclodextrin polymers: Synthesis and application in water treatment. In Cyclodextrins: Chemistry and Physics; Hu, J., Ed.; Transworld Research Network: Kerala, India, 2010; pp. 1-25.

98. Morin-Crini, N.; Crini, G. Environmental applications of water-insoluble $\beta$-cyclodextrin-epichlorohydrin polymers. Prog. Polym. Sci. 2013, 38, 344-368. [CrossRef]

99. Cheirsilp, B.; Rakmai, J. Inclusion complex formation of cyclodextrin with its guest and their applications. Biol. Eng. Med. 2016, 2, 1-6. [CrossRef]

100. Das, S.K.; Rajabalaya, R.; David, S.; Gani, N.; Khanam, J.; Nanda, A. Cyclodextrins-The molecular container. Res. J. Pharm. Biol. Chem. Sci. 2013, 4, 1694-1720.

101. Dodziuk, H. Molecules with Holes-Cyclodextrins. In Cyclodextrins and Their Complexes: Chemistry, Analytical Methods, Applications; Dodziuk, H., Ed.; Wiley-VCH Verlag GmbH \& Co. KGaA: Weinheim, Germany, 2006; pp. 1-30.

102. Patil, J.S.; Kadam, D.V.; Marapur, S.C.; Kamalapur, M.V. Inclusion complex system; a noveltechnique to improve the solubility and bioavailability of poorly soluble drugs: A review. Int. J. Pharm. Sci. Rev. Res. 2010, 2, 29-34.

103. Zarzycki, P.K.; Fenert, B.; Głód, B.K. 17-Cyclodextrins-based nanocomplexes for encapsulation of bioactive compounds in food, cosmetics, and pharmaceutical products: Principles of supramolecular complexes formation, their influence on the antioxidative properties of target chemicals, and recent advances in selected industrial applications A2-Grumezescu, Alexandru Mihai. In Encapsulations; Grumezescu, A.M., Ed.; Academic Press: Cambridge, MA, USA, 2016; Volume 2, pp. 717-767. 
104. Iacovino, R.; Caso, J.V.; Donato, C.D.; Malgieri, G.; Palmieri, M.; Russo, L.; Isernia, C. Cyclodextrins as complexing agents: Preparation and applications. Curr. Org. Chem. 2017, 21, 162-176. [CrossRef]

105. Cramer, F.; Saenger, W.; Spatz, H.C. Inclusion compounds. XIX.1a The formation of inclusion compounds of beta-cyclodextrin in aqueous solutions. Thermodynamics and kinetics. J. Am. Chem. Soc. 1967, 89, 14-20. [CrossRef]

106. Gidwani, B.; Vyas, A. A comprehensive review on cyclodextrin-based carriers for oelivery of Chemotherapeutic Cytotoxic Anticancer Drugs. BioMed Res. Int. 2015, 2015, 15. [CrossRef] [PubMed]

107. Morgan, A.R.; Garbo, G.B.; Sehker, P.; Selman, S.H. Cyclodextrin for administration of anti-cancer agents. In Proceedings of the Sixth International Cyclodextrin Symposium, Chicago, IL, USA, 21-24 April 1992.

108. Guo, X.L.; An, W.T.; Shuang, S.M.; Cheng, F.Q.; Dong, C. Study on spectroscopic characterization of meso-tetrakis (4-hydroxyphenyl) porphyrin (THPP) in $\beta$-cyclodextrin and its derivatives. J. Photochem. Photobiol. A Chem. 2005, 173, 258-263. [CrossRef]

109. Desroches, M.C.; Kasselouri, A.; Bourdon, O.; Chaminade, P.; Blais, J.; Prognon, P. A direct sensitized fluorimetric determination of 5,10,15,20-tetra(m-hydroxyphenyl)chlorin [m-THPC (Foscan)(R)] in human plasma using a cyclodextrin inclusion complex. Analyst 2001, 126, 923-927. [CrossRef] [PubMed]

110. Mosinger, J.; Deumié, M.; Lang, K.; Kubát, P.; Wagnerová, D.M. Supramolecular sensitizer: Complexation of meso-tetrakis(4-sulfonatophenyl)porphyrin with 2-hydroxypropyl-cyclodextrins. J. Photochem. Photobiol. A Chem. 2000, 130, 13-20. [CrossRef]

111. Mosinger, J.; Kliment, V.; Sejbal, J.; Kubát, P.; Lang, K. Host-guest complexes of anionic porphyrin sensitizers with cyclodextrins. J. Porphyr. Phthalocyanines 2002, 6, 514-526. [CrossRef]

112. Tau, P.; Ogunsipe, A.O.; Maree, S.; Maree, M.D.; Nyokong, T. Influence of cyclodextrins on the fluorescence, photostability and singlet oxygen quantum yields of zinc phthalocyanine and naphthalocyanine complexes. J. Porphyr. Phthalocyanines 2003, 07, 439-446. [CrossRef]

113. Valeron Bergh, V.J.; Hjorth Tonnesen, H. Interaction between the photosensitizer lumichrome and human serum albumin: Effect of excipients. Pharm. Dev. Technol. 2017, 22, 992-1000. [CrossRef] [PubMed]

114. Ribó, J.M.; Farrera, J.-A.; Valero, M.L.; Virgili, A. Self-assembly of cyclodextrins with meso-tetrakis (4-sulfonatophenyl) porphyrin in aqueous solution. Tetrahedron 1995, 51, 3705-3712. [CrossRef]

115. Dai, X.H.; Dong, C.M.; Fa, H.B.; Yan, D.Y.; Wei, Y. Supramolecular polypseudorotaxanes composed of star-shaped porphyrin-cored poly(epsilon-caprolactone) and $\alpha$-cyclodextrin. Biomacromolecules 2006, 7 , 3527-3533. [CrossRef] [PubMed]

116. Ikeda, A.; Hino, S.; Mae, T.; Tsuchiya, Y.; Sugikawa, K.; Tsukamoto, M.; Yasuhara, K.; Shigeto, H.; Funabashi, H.; Kuroda, A.; et al. Porphyrin-uptake in liposomes and living cells using an exchange method with cyclodextrin. RSC Adv. 2015, 5, 105279-105287. [CrossRef]

117. Arun, K.T.; Jayaram, D.T.; Avirah, R.R.; Ramaiah, D. $\beta$-Cyclodextrin as a photosensitizer carrier: Effect on photophysical properties and chemical reactivity of squaraine dyes. J. Phys. Chem. B 2011, 115, 7122-7128. [CrossRef] [PubMed]

118. Karar, M.; Paul, S.; Mallick, A.; Majumdar, T. Shipment of a photodynamic therapy agent into model membrane and its controlled release: A photophysical approach. Chem. Phys. Lipids 2018, 210, 122-128. [CrossRef] [PubMed]

119. Sortino, S.; Scaiano, J.C.; De Guidi, G.; Monti, S. Effect of $\beta$-cyclodextrin complexation on the photochemical and photosensitizing properties of tolmetin: A steady-state and time-resolved study. Photochem. Photobiol. 1999, 70, 549-556. [PubMed]

120. Kolarova, H.; Mosinger, J.; Lenobel, R.; Kejlova, K.; Jirova, D.; Strnad, M. In vitro toxicity testing of supramolecular sensitizers for photodynamic therapy. Toxicol. In Vitro 2003, 17, 775-778. [CrossRef]

121. Kolarova, H.; Macecek, J.; Nevrelova, P.; Huf, M.; Tomecka, M.; Bajgar, R.; Mosinger, J.; Strnad, M. Photodynamic therapy with zinc-tetra(p-sulfophenyl)porphyrin bound to cyclodextrin induces single strand breaks of cellular DNA in G361 melanoma cells. Toxicol. In Vitro 2005, 19, 971-974. [CrossRef] [PubMed]

122. Leng, X.B.; Choi, C.F.; Lo, P.C.; Ng, D.K.P. Assembling a mixed phthalocyanine-porphyrin array in aqueous media through host-guest interactions. Org. Lett. 2007, 9, 231-234. [CrossRef] [PubMed]

123. Silva, A.R.A.; Simioni, A.R.; Tedesco, A.C. Photophysical and complexation studies of chloro-aluminum phthalocyanine with $\beta$-cyclodextrin and hydroxypropyl- $\beta$-cyclodextrin. J. Nanosci. Nanotechnol. 2011, 11, 4046-4055. [CrossRef] [PubMed] 
124. Lu, S.; Ma, Y.J.; Xuan, H.Y.; Wang, A.; Zhao, B.; Li, X.D.; Zhou, J.H.; Lin, Y.; Zhou, L.; Wei, S.H. A novel assembling complex of hydrobobic phthalocyanine-cyclodextrin: Preparation, characterization, molecular modeling, and in vitro activity. RSC Adv. 2014, 4, 59759-59763. [CrossRef]

125. Lu, S.; Wang, A.; Ma, Y.J.; Xuan, H.Y.; Zhao, B.; Li, X.D.; Zhou, J.H.; Zhou, L.; Wei, S.H. Cyclodextrin type dependent host-guest interaction mode with phthalocyanine and their influence on photodynamic activity to cancer. Carbohydr. Polym. 2016, 148, 236-242. [CrossRef] [PubMed]

126. Paul, S.; Heng, P.W.S.; Chan, L.W. pH-dependent complexation of hydroxypropyl- $\beta$-cyclodextrin with chlorin e6: Effect on solubility and aggregation in relation to photodynamic efficacy. J. Pharm. Pharmacol. 2015, 68, 439-449. [CrossRef] [PubMed]

127. Yankovsky, I.; Bastien, E.; Yakavets, I.; Khludeyev, I.; Lassalle, H.P.; Gräfe, S.; Bezdetnaya, L.; Zorin, V. Inclusion complexation with $\beta$-cyclodextrin derivatives alters photodynamic activity and biodistribution of meta-tetra(hydroxyphenyl)chlorin. Eur. J. Pharm. Sci. 2016, 91, 172-182. [CrossRef] [PubMed]

128. Yakavets, I.; Yankovsky, I.; Millard, M.; Lamy, L.; Lassalle, H.P.; Wiehe, A.; Zorin, V.; Bezdetnaya, L. The alteration of temoporfin distribution in multicellular tumor spheroids by b-cyclodextrins. Int. J. Pharm. 2017, 529, 568-575. [CrossRef] [PubMed]

129. Ikeda, A.; Satake, S.; Mae, T.; Ueda, M.; Sugikawa, K.; Shigeto, H.; Funabashi, H.; Kuroda, A. Photodynamic activities of porphyrin derivative-cyclodextrin complexes by photoirradiation. ACS Med. Chem. Lett. 2017, 8, 555-559. [CrossRef] [PubMed]

130. Yano, S.; Hirohara, S.; Obata, M.; Hagiya, Y.; Ogura, S.; Ikeda, A.; Kataoka, H.; Tanaka, M.; Joh, T. Current states and future views in photodynamic therapy. J. Photochem. Photobiol. C 2011, 12, 46-67. [CrossRef]

131. Bruzell, E.M.; Morisbak, E.; Tonnesen, H.H. Studies on curcumin and curcuminoids. XXIX. Photoinduced cytotoxicity of curcumin in selected aqueous preparations. Photochem. Photobiol. Sci. 2005, 4, 523-530. [CrossRef] [PubMed]

132. Zhang, L.M.; Dong, X.P.; Lu, D.; Liu, S.H.; Ding, D.; Kong, D.L.; Fan, A.P.; Wang, Z.; Zhao, Y.J. Controlled ROS production by corannulene: The vehicle makes a difference. Biomater. Sci. 2017, 5, 1236-1240. [CrossRef] [PubMed]

133. Ruebner, A.; Kirsch, D.; Andrees, S.; Decker, W.; Roeder, B.; Spengler, B.; Kaufmann, R.; Moser, J.G. Dimeric cyclodextrin carriers with high binding affinity to porphyrinoid photosensitizers. J. Incl. Phenom. Mol. Recognit. Chem. 1997, 27, 69-84. [CrossRef]

134. Ruebner, A.; Moser, J.G.; Kirsch, D.; Spengler, B.; Andrees, S.; Roehrs, S. Synthesis of $\beta$-cyclodextrin dimers as carrier systems for photodynamic therapy of cancer. J. Incl. Phenom. Mol. Recognit. Chem. 1996, 25, 35-38. [CrossRef]

135. Ruebner, A.; Yang, Z.W.; Leung, D.; Breslow, R. A cyclodextrin dimer with a photocleavable linker as a possible carrier for the photosensitizer in photodynamic tumor therapy. Proc. Natl. Acad. Sci. USA 1999, 96, 14692-14693. [CrossRef] [PubMed]

136. Baugh, S.D.; Yang, Z.; Leung, D.K.; Wilson, D.M.; Breslow, R. Cyclodextrin dimers as cleavable carriers of photodynamic sensitizers. J. Am. Chem. Soc. 2001, 123, 12488-12494. [CrossRef] [PubMed]

137. Kirejev, V.; Goncalves, A.R.; Aggelidou, C.; Manet, I.; Martensson, J.; Yannakopoulou, K.; Ericson, M.B. Photophysics and ex vivo biodistribution of $\beta$-cyclodextrin-meso-tetra(m-hydroxyphenyl)-porphyrin conjugate for biomedical applications. Photochem. Photobiol. Sci. 2014, 13, 1185-1191. [CrossRef] [PubMed]

138. Liu, G.; Xu, X.; Chen, Y.; Wu, X.; Wu, H.; Liu, Y. A highly efficient supramolecular photoswitch for singlet oxygen generation in water. Chem. Commun. 2016, 52, 7966-7969. [CrossRef] [PubMed]

139. Králová, J.; Synytsya, A.; Pouckova, P.; Koc, M.; Dvorak, M.; Kral, V. Novel porphyrin conjugates with a potent photodynamic antitumor effect: Differential efficacy of mono- and bis- $\beta$-cyclodextrin derivatives in vitro and in vivo. Photochem. Photobiol. 2006, 82, 432-438. [CrossRef] [PubMed]

140. Králová, J.; Kejik, Z.; Briza, T.; Pouckova, P.; Kral, A.; Martasek, P.; Kral, V. Porphyrin-cyclodextrin conjugates as a nanosystem for versatile drug delivery and multimodal cancer therapy. J. Med. Chem. 2010, 53, 128-138. [CrossRef] [PubMed]

141. Kejik, Z.; Briza, T.; Kralova, J.; Pouckova, P.; Kral, A.; Martasek, P.; Kral, V. Coordination conjugates of therapeutic proteins with drug carriers: A new approach for versatile advanced drug delivery. Bioorg. Med. Chem. Lett. 2011, 21, 5514-5520. [CrossRef] [PubMed] 
142. Lau, J.T.F.; Lo, P.C.; Fong, W.P.; Ng, D.K.P. Preparation and photodynamic activities of silicon(IV) phthalocyanines substituted with permethylated $\beta$-cyclodextrins. Chem. Eur. J. 2011, 17, 7569-7577. [CrossRef] [PubMed]

143. Lau, J.T.F.; Lo, P.C.; Tsang, Y.M.; Fong, W.P.; Ng, D.K.P. Unsymmetrical $\beta$-cyclodextrin-conjugated silicon(IV) phthalocyanines as highly potent photosensitisers for photodynamic therapy. Chem. Commun. 2011, 47, 9657-9659. [CrossRef] [PubMed]

144. Aggelidou, C.; Theodossiou, T.A.; Yannakopoulou, K. Protoporphyrin IX- $\beta$-cyclodextrin bimodal conjugate: Nanosized drug transporter and potent phototoxin. Photochem. Photobiol. 2013, 89, 1011-1019. [CrossRef] [PubMed]

145. Fraix, A.; Goncalves, A.R.; Cardile, V.; Graziano, A.C.; Theodossiou, T.A.; Yannakopoulou, K.; Sortino, S. A multifunctional bichromophoric nanoaggregate for fluorescence imaging and simultaneous photogeneration of RNOS and ROS. Chem. Asian J. 2013, 8, 2634-2641. [CrossRef] [PubMed]

146. Theodossiou, T.A.; Goncalves, A.R.; Yannakopoulou, K.; Skarpen, E.; Berg, K. Photochemical internalization of tamoxifens transported by a "Trojan-horse" nanoconjugate into breast-cancer cell lines. Angew. Chem. Int. Ed. Engl. 2015, 54, 4885-4889. [CrossRef] [PubMed]

147. Lourenço, L.M.O.; Pereira, P.M.R.; Maciel, E.; Valega, M.; Domingues, F.M.J.; Domingues, M.R.M.; Neves, M.; Cavaleiro, J.A.S.; Fernandes, R.; Tome, J.P.C. Amphiphilic phthalocyanine-cyclodextrin conjugates for cancer photodynamic therapy. Chem. Commun. 2014, 50, 8363-8366. [CrossRef] [PubMed]

148. Barata, J.F.B.; Zamarron, A.; Neves, M.; Faustino, M.A.F.; Tome, A.C.; Cavaleiro, J.A.S.; Roder, B.; Juarranz, A.; Sanz-Rodriiguez, F. Photodynamic effects induced by meso-tris(pentafluorophenyl)corrole and its cyclodextrin conjugates on cytoskeletal components of HeLa cells. Eur. J. Med. Chem. 2015, 92, 135-144. [CrossRef] [PubMed]

149. Ou, Z.Z.; Chen, J.R.; Wang, X.S.; Zhang, B.W.; Cao, Y. Synthesis of a water-soluble cyclodextrin modified hypocrellin and ESR study of its photodynamic therapy properties. New J. Chem. 2002, 26, 1130-1136. [CrossRef]

150. Cao, G.J.; Rong, R.X.; Wang, Y.N.; Xu, Q.; Wang, K.R.; Li, X.L. Synthesis and photodynamic therapy of mono-mannose modified perylene bisimide bridged permethyl-b-CDs. Dyes Pigments 2017, 136, 569-576. [CrossRef]

151. Mazzaglia, A. Photodynamic tumor therapy with cyclodextrin nanoassemblies. In Cyclodextrins in Pharmaceutics, Cosmetics, and Biomedicine; John Wiley \& Sons, Inc.: Hoboken, NJ, USA, 2011; pp. 343-361.

152. Mazzaglia, A.; Micali, N.; Scolaro, L.M.; Sciortino, M.T.; Sortino, S.; Villari, V. Design of photosensitizer/cyclodextrin nanoassemblies: Spectroscopy, intracellular delivery and photodamage. J. Porphyr. Phthalocyanines 2010, 14, 661-677. [CrossRef]

153. Mendez-Ardoy, A.; Urbiola, K.; Aranda, C.; Ortiz-Mellet, C.; Garcia-Fernandez, J.M.; de Ilarduya, C.T. Polycationic amphiphilic cyclodextrin-based nanoparticles for therapeutic gene delivery. Nanomedicine 2011, 6, 1697-1707. [CrossRef] [PubMed]

154. Parrot-Lopez, H.; Perret, F.; Bertino-Ghera, B. Amphiphilic cyclodextrins and their applications. Preparation of nanoparticles based on amphiphilic cyclodextrins for biomedical applications. Ann. Pharm. Fr. 2010, 68, 12-26. [CrossRef] [PubMed]

155. Zerkoune, L.; Angelova, A.; Lesieur, S. Nano-assemblies of modified cyclodextrins and their complexes with guest molecules: Incorporation in nanostructured membranes and amphiphile nanoarchitectonics design. Nanomaterials 2014, 4, 741-765. [CrossRef] [PubMed]

156. Bonnet, V.; Gervaise, C.; Djedaini-Pilard, F.; Furlan, A.; Sarazin, C. Cyclodextrin nanoassemblies: A promising tool for drug delivery. Drug Discov. Today 2015, 20, 1120-1126. [CrossRef] [PubMed]

157. Varan, G.; Varan, C.; Erdogar, N.; Hincal, A.A.; Bilensoy, E. Amphiphilic cyclodextrin nanoparticles. Int. J. Pharm. 2017, 531, 457-469. [CrossRef] [PubMed]

158. Roux, M.; Perly, B.; Djedaini-Pilard, F. Self-assemblies of amphiphilic cyclodextrins. Eur. Biophys. J. 2007, 36, 861-867. [CrossRef] [PubMed]

159. Sallas, F.; Darcy, R. Amphiphilic cyclodextrins-Advances in synthesis and supramolecular chemistry. Eur. J. Org. Chem. 2008, 2008, 957-969. [CrossRef]

160. Sun, T.; Guo, Q.; Zhang, C.; Hao, J.; Xing, P.; Su, J.; Li, S.; Hao, A.; Liu, G. Self-assembled vesicles prepared from amphiphilic cyclodextrins as drug carriers. Langmuir 2012, 28, 8625-8636. [CrossRef] [PubMed] 
161. Jabbari, A.; Sadeghian, H. Amphiphilic cyclodextrins, synthesis, utilities and application of molecular modeling in their design. In Recent Advances in Novel Drug Carrier Systems; Intech Open Sciences: London, UK, 2012; pp. 332-354.

162. Mazzaglia, A.; Angelini, N.; Darcy, R.; Donohue, R.; Lombardo, D.; Micali, N.; Sciortino, M.T.; Villari, V.; Scolaro, L.M. Novel heterotopic colloids of anionic porphyrins entangled in cationic amphiphilic cyclodextrins: Spectroscopic investigation and intracellular delivery. Chem. Eur. J. 2003, 9, 5762-5769. [CrossRef] [PubMed]

163. Mazzaglia, A.; Angelini, N.; Lombardo, D.; Micali, N.; Patane, S.; Villari, V.; Scolaro, L.M. Amphiphilic cyclodextrin carriers embedding porphyrins: Charge and size modulation of colloidal stability in heterotopic aggregates. J. Phys. Chem. B 2005, 109, 7258-7265. [CrossRef] [PubMed]

164. Sortino, S.; Mazzaglia, A.; Scolaro, L.M.; Merlo, F.M.; Valveri, V.; Sciortino, M.T. Nanoparticles of cationic amphiphilic cyclodextrins entangling anionic porphyrins as carrier-sensitizer system in photodynamic cancer therapy. Biomaterials 2006, 27, 4256-4265. [CrossRef] [PubMed]

165. Mazzaglia, A.; Valerio, A.; Micali, N.; Villari, V.; Quaglia, F.; Castriciano, M.A.; Scolaro, L.M.; Giuffre, M.; Siracusano, G.; Sciortino, M.T. Effective cell uptake of nanoassemblies of a fluorescent amphiphilic cyclodextrin and an anionic porphyrin. Chem. Commun. 2011, 47, 9140-9142. [CrossRef] [PubMed]

166. Conte, C.; Scala, A.; Siracusano, G.; Leone, N.; Patane, S.; Ungaro, F.; Miro, A.; Sciortino, M.T.; Quaglia, F.; Mazzaglia, A. Nanoassembly of an amphiphilic cyclodextrin and $\mathrm{Zn}(\mathrm{II})$-phthalocyanine with the potential for photodynamic therapy of cancer. RSC Adv. 2014, 4, 43903-43911. [CrossRef]

167. Conte, C.; Scala, A.; Siracusano, G.; Sortino, G.; Pennisi, R.; Piperno, A.; Miro, A.; Ungaro, F.; Sciortino, M.T.; Quaglia, F; et al. Nanoassemblies based on non-ionic amphiphilic cyclodextrin hosting Zn(II)-phthalocyanine and docetaxel: Design, physicochemical properties and intracellular effects. Colloids Surf. B Biointerfaces 2016, 146, 590-597. [CrossRef] [PubMed]

168. Mazzaglia, A.; Micali, N.; Villari, V.; Zagami, R.; Pennisi, R.M.; Mellet, C.O.; Fernandez, J.M.G.; Sciortino, M.T.; Scolaro, L.M. A novel potential nanophototherapeutic based on the assembly of an amphiphilic cationic $\beta$-cyclodextrin and an anionic porphyrin. J. Porphyr. Phthalocyanines 2017, 21, 398-405. [CrossRef]

169. Chen, X.; Chen, L.; Yao, X.; Zhang, Z.; He, C.; Zhang, J.; Chen, X. Dual responsive supramolecular nanogels for intracellular drug delivery. Chem. Commun. 2014, 50, 3789-3791. [CrossRef] [PubMed]

170. Martin, C.; Aibani, N.; Callan, J.F.; Callan, B. Recent advances in amphiphilic polymers for simultaneous delivery of hydrophobic and hydrophilic drugs. Ther. Deliv. 2016, 7, 15-31. [CrossRef] [PubMed]

171. Zhang, W.; Li, Y.; Sun, J.-H.; Tan, C.-P.; Ji, L.-N.; Mao, Z.-W. Supramolecular self-assembled nanoparticles for chemo-photodynamic dual therapy against cisplatin resistant cancer cells. Chem. Commun. 2015, 51, 1807-1810. [CrossRef] [PubMed]

172. Antoniuk, I.; Amiel, C. Cyclodextrin- mediated hierarchical self- assembly and its potential in drug delivery applications. J. Pharm. Sci. 2016, 105, 2570-2588. [CrossRef] [PubMed]

173. Xiong, H.; Zhou, D.; Zheng, X.; Qi, Y.; Wang, Y.; Jing, X.; Huang, Y. Stable amphiphilic supramolecular self-assembly based on cyclodextrin and carborane for the efficient photodynamic therapy. Chem. Commun. 2017, 53, 3422-3425. [CrossRef] [PubMed]

174. Voskuhl, J.; Kauscher, U.; Gruener, M.; Frisch, H.; Wibbeling, B.; Strassert, C.A.; Ravoo, B.J. A soft supramolecular carrier with enhanced singlet oxygen photosensitizing properties. Soft Matter 2013, 9, 2453-2457. [CrossRef]

175. Kauscher, U.; Ravoo, B.J. A self-assembled cyclodextrin nanocarrier for photoreactive squaraine. Beilstein J. Org. Chem. 2016, 12, 2535-2542. [CrossRef] [PubMed]

176. Wintgens, V.; Layre, A.M.; Hourdet, D.; Amiel, C. Cyclodextrin polymer nanoassemblies: Strategies for stability improvement. Biomacromolecules 2012, 13, 528-534. [CrossRef] [PubMed]

177. Fraix, A.; Gref, R.; Sortino, S. A multi-photoresponsive supramolecular hydrogel with dual-color fluorescence and dual-modal photodynamic action. J. Mater. Chem. B 2014, 2, 3443-3449. [CrossRef]

178. Kandoth, N.; Kirejev, V.; Monti, S.; Gref, R.; Ericson, M.B.; Sortino, S. Two-photon fluorescence imaging and bimodal phototherapy of epidermal cancer cells with biocompatible self-assembled polymer nanoparticles. Biomacromolecules 2014, 15, 1768-1776. [CrossRef] [PubMed]

179. Lee, J.M.; Oh, K.T.; Youn, Y.S.; Lee, E.S. Highly enhanced phototoxicity of chlorin e6-conjugated poly $(\beta$-cyclodextrin) with gas forming capacity at an acidic tumor extracellular $\mathrm{pH}$ and its in vitro evaluation. Polym. Adv. Technol. 2015, 27, 162-168. [CrossRef] 
180. Kirakci, K.; Šícha, V.; Holub, J.; Kubát, P.; Lang, K. Luminescent hydrogel particles prepared by self-assembly of $\beta$-cyclodextrin polymer and octahedral molybdenum cluster complexes. Inorg. Chem. 2014, 53, 13012-13018. [CrossRef] [PubMed]

181. Liu, F.; Ma, Y.F.; Xu, L.; Liu, L.C.; Zhang, W.A. Redox-responsive supramolecular amphiphiles constructed via host-guest interactions for photodynamic therapy. Biomater. Sci. 2015, 3, 1218-1227. [CrossRef] [PubMed]

182. Tong, H.; Chen, Y.; Li, Z.; Li, H.; Chen, T.; Jin, Q.; Ji, J. Glutathione activatable photosensitizer-conjugated pseudopolyrotaxane nanocarriers for photodynamic theranostics. Small 2016, 12, 6223-6232. [CrossRef] [PubMed]

183. Xu, T.T.; Li, J.H.; Cheng, F.R.; Zhang, Y.X.; Cao, J.; Gao, W.X.; He, B. Fabrication of a polypseudorotaxane nanoparticle with synergistic photodynamic and chemotherapy. Chin. Chem. Lett. 2017, 28, 1885-1888. [CrossRef]

184. Jin, H.; Dai, X.-H.; Wu, C.; Pan, J.-M.; Wang, X.-H.; Yan, Y.-S.; Liu, D.-M.; Sun, L. Rational design of shear-thinning supramolecular hydrogels with porphyrin for controlled chemotherapeutics release and photodynamic therapy. Eur. Polym. J. 2015, 66, 149-159. [CrossRef]

185. Wang, C.; Tao, H.; Cheng, L.; Liu, Z. Near-infrared light induced in vivo photodynamic therapy of cancer based on upconversion nanoparticles. Biomaterials 2011, 32, 6145-6154. [CrossRef] [PubMed]

186. Detty, M.R.; Gibson, S.L.; Wagner, S.J. Current clinical and preclinical photosensitizers for use in photodynamic therapy. J. Med. Chem. 2004, 47, 3897-3915. [CrossRef] [PubMed]

187. Weissleder, R.; Ntziachristos, V. Shedding light onto live molecular targets. Nat. Med. 2003, 9, $123-128$. [CrossRef] [PubMed]

188. Lovell, J.F.; Liu, T.W.; Chen, J.; Zheng, G. Activatable photosensitizers for imaging and therapy. Chem. Rev. 2010, 110, 2839-2857. [CrossRef] [PubMed]

189. Auzel, F. Upconversion and anti-Stokes processes with $\mathrm{f}$ and $\mathrm{d}$ ions in solids. Chem. Rev. 2004, 104, $139-174$. [CrossRef] [PubMed]

190. Haase, M.; Schafer, H. Upconverting nanoparticles. Angew. Chem. Int. Ed. Engl. 2011, 50, 5808-5829. [CrossRef] [PubMed]

191. Wang, F.; Liu, X. Recent advances in the chemistry of lanthanide-doped upconversion nanocrystals. Chem. Soc. Rev. 2009, 38, 976-989. [CrossRef] [PubMed]

192. Wang, A.; Jin, W.; Chen, E.; Zhou, J.; Zhou, L.; Wei, S. Drug delivery function of carboxymethyl- $\beta$-cyclodextrin modified upconversion nanoparticles for adamantine phthalocyanine and their NIR-triggered cancer treatment. Dalton Trans. 2016, 45, 3853-3862. [CrossRef] [PubMed]

193. Wang, H.; Han, R.L.; Yang, L.M.; Shi, J.H.; Liu, Z.J.; Hu, Y.; Wang, Y.; Liu, S.J.; Gan, Y. Design and synthesis of core-shell-shell upconversion nanoparticles for NIR-induced drug release, photodynamic therapy, and cell imaging. ACS Appl. Mater. Interfaces 2016, 8, 4416-4423. [CrossRef] [PubMed]

194. Han, R.; Shi, J.; Liu, Z.; Wang, H.; Wang, Y. Fabrication of mesoporous-silica-coated upconverting nanoparticles with ultrafast photosensitizer loading and $808 \mathrm{~nm}$ NIR-light-triggering capability for photodynamic therapy. Chem. Asian J. 2017, 12, 2197-2201. [CrossRef] [PubMed]

195. Dong, H.; Li, Y.; Wen, H.; Xu, M.; Liu, L.; Li, Z.; Guo, F.; Shi, D. Highly efficient drug delivery nanosystem via L-phenylalanine triggering based on supramolecular polymer micelles. Macromol. Rapid Commun. 2011, 32, 540-545. [CrossRef] [PubMed]

196. Ma, X.; Sreejith, S.; Zhao, Y.L. Spacer intercalated disassembly and photodynamic activity of zinc phthalocyanine inside nanochannels of mesoporous silica nanoparticles. ACS Appl. Mater. Interfaces 2013, 5, 12860-12868. [CrossRef] [PubMed]

197. Trapani, M.; Romeo, A.; Parisi, T.; Sciortino, M.T.; Patane, S.; Villari, V.; Mazzaglia, A. Supramolecular hybrid assemblies based on gold nanoparticles, amphiphilic cyclodextrin and porphyrins with combined phototherapeutic action. RSC Adv. 2013, 3, 5607-5614. [CrossRef]

198. Xu, Y.Q.; Wang, L.; Zhu, X.Y.; Wang, C.Q. Hierarchical self-assembly of protoporphyrin IX-bridged Janus particles into photoresponsive vesicles. RSC Adv. 2016, 6, 31053-31058. [CrossRef]

199. Kroto, H.W.; Heath, J.R.; O’Brien, S.C.; Curl, R.F.; Smalley, R.E. C60: Buckminsterfullerene. Nature 1985, 318, 162. [CrossRef]

200. Bosi, S.; Da Ros, T.; Spalluto, G.; Prato, M. Fullerene derivatives: An attractive tool for biological applications. Eur. J. Med. Chem. 2003, 38, 913-923. [CrossRef] [PubMed] 
201. Bakry, R.; Vallant, R.M.; Najam-ul-Haq, M.; Rainer, M.; Szabo, Z.; Huck, C.W.; Bonn, G.K. Medicinal applications of fullerenes. Int. J. Nanomed. 2007, 2, 639-649.

202. Dellinger, A.; Zhou, Z.; Connor, J.; Madhankumar, A.B.; Pamujula, S.; Sayes, C.M.; Kepley, C.L. Application of fullerenes in nanomedicine: An update. Nanomedicine 2013, 8, 1191-1208. [CrossRef] [PubMed]

203. Thakral, S.; Thakral, N.K. Potential medical applications of fullerenes: An overview. In Bio-Nanotechnology: A Revolution in Food, Biomedical and Health Sciences; Blackwell Publishing Ltd.: Oxford, UK, 2013; pp. 424-441.

204. Medicinal Chemistry and Pharmacological Potential of Fullerenes and Carbon Nanotubes; Cataldo, F.; da Ros, T., Eds.; Springer: Dordrecht, The Netherlands, 2008; p. 408.

205. Huang, Y.-Y.; Sharma, S.K.; Yin, R.; Agrawal, T.; Chiang, L.Y.; Hamblin, M.R. Functionalized Fullerenes in Photodynamic Therapy. J. Biomed. Nanotechnol. 2014, 10, 1918-1936. [CrossRef] [PubMed]

206. Mroz, P.; Tegos, G.P.; Gali, H.; Wharton, T.; Sarna, T.; Hamblin, M.R. Photodynamic therapy with fullerenes. Photochem. Photobiol. Sci. 2007, 6, 1139-1149. [CrossRef] [PubMed]

207. Mroz, P.; Tegos, G.P.; Gali, H.; Wharton, T.; Sarna, T.; Hamblin, M.R. Fullerenes as Photosensitizers in Photodynamic Therapy. In Medicinal Chemistry and Pharmacological Potential of Fullerenes and Carbon Nanotubes; Cataldo, F., Da Ros, T., Eds.; Springer: Dordrecht, The Netherlands, 2008; pp. 79-106.

208. Sharma, S.K.; Chiang, L.Y.; Hamblin, M.R. Photodynamic therapy with fullerenes in vivo: Reality or a dream? Nanomedicine 2011, 6, 1813-1825. [CrossRef] [PubMed]

209. Hotze, E.M.; Labille, J.; Alvarez, P.; Wiesner, M.R. Mechanisms of photochemistry and reactive oxygen production by fullerene suspensions in water. Environ. Sci. Technol. 2008, 42, 4175-4180. [CrossRef] [PubMed]

210. Ikeda, A.; Mae, T.; Ueda, M.; Sugikawa, K.; Shigeto, H.; Funabashi, H.; Kuroda, A.; Akiyama, M. Improved photodynamic activities of liposome-incorporated [60]fullerene derivatives bearing a polar group. Chem. Commun. 2017, 53, 2966-2969. [CrossRef] [PubMed]

211. Doi, Y.; Ikeda, A.; Akiyama, M.; Nagano, M.; Shigematsu, T.; Ogawa, T.; Takeya, T.; Nagasaki, T. Intracellular uptake and photodynamic activity of water-soluble [60]- and [70]fullerenes Incorporated in liposomes. Chem. Eur. J. 2008, 14, 8892-8897. [CrossRef] [PubMed]

212. Ikeda, A. Photodynamic activity of fullerenes and other molecules incorporated into lipid membranes by exchange. Chem. Rec. 2016, 16, 249-260. [CrossRef] [PubMed]

213. Ikeda, A.; Iizuka, T.; Maekubo, N.; Aono, R.; Kikuchi, J.; Akiyama, M.; Konishi, T.; Ogawa, T.; Ishida-Kitagawa, N.; Tatebe, H.; et al. Cyclodextrin complexed [60]fullerene derivatives with high levels of photodynamic activity by long wavelength excitation. ACS Med. Chem. Lett. 2013, 4, 752-756. [CrossRef] [PubMed]

214. Ikeda, A.; Matsumoto, M.; Akiyama, M.; Kikuchi, J.; Ogawa, T.; Takeya, T. Direct and short-time uptake of [70]fullerene into the cell membrane using an exchange reaction from a [70]fullerene-g-cyclodextrin complex and the resulting photodynamic activity. Chem. Commun. 2009, 1547-1549. [CrossRef] [PubMed]

215. Ikeda, A.; Nagano, M.; Akiyama, M.; Matsumoto, M.; Ito, S.; Mukai, M.; Hashizume, M.; Kikuchi, J.; Katagiri, K.; Ogawa, T.; et al. Photodynamic activity of C70 caged within surface-cross-linked liposomes. Chem. Asian J. 2009, 4, 199-205. [CrossRef] [PubMed]

216. Nobusawa, K.; Akiyama, M.; Ikeda, A.; Naito, M. pH responsive smart carrier of [60]fullerene with 6-amino-cyclodextrin inclusion complex for photodynamic therapy. J. Mater. Chem. 2012, 22, 22610-22613. [CrossRef]

217. Iizumi, Y.; Okazaki, T.; Zhang, M.; Yudasaka, M.; Iijima, S. High efficiencies for singlet oxygen generation of fullerenes and their phototoxicity. Bull. Chem. Soc. Jpn. 2008, 81, 1584-1588. [CrossRef]

218. Iohara, D.; Hiratsuka, M.; Hirayama, F.; Takeshita, K.; Motoyama, K.; Arima, H.; Uekama, K. Evaluation of photodynamic activity of C60/2-hydroxypropyl- $\beta$-cyclodextrin nanoparticles. J. Pharm. Sci. 2011, 101, 3390-3397. [CrossRef] [PubMed]

219. Altaf, A.; Aldawsari, H.; Banjar, Z.M.; Makoto, A.; Daisuke, I.; Masaki, O.; Kaneto, U.; Fumitoshi, H. Preparation of soluble stable C-60/human serum albumin nanoparticles via cyclodextrin complexation and their reactive oxygen production characteristics. Life Sci. 2013, 93, 277-282.

220. Altaf, A.; Aldawsari, H.; Banjar, Z.M.; Iohara, D.; Anraku, M.; Uekama, K.; Hirayama, F. Potential use of $\mathrm{C}_{60} / 2$-hydroxypropyl- $\beta$-cyclodextrin nanoparticles as a new photosensitizer in the treatment of cancer. Int. J. Photoenergy 2014, 2014, 8. [CrossRef] 
221. Zhao, B.Z.; He, Y.Y.; Chignell, C.F.; Yin, J.J.; Andley, U.; Roberts, J.E. Difference in phototoxicity of cyclodextrin complexed fullerene [(g-CyD)(2)/C-60] and its aggregated derivatives toward human lens epithelial cells. Chem. Res. Toxicol. 2009, 22, 660-667. [CrossRef] [PubMed]

222. Wang, J.J.; Zhang, Z.H.; Wu, W.; Jiang, X.Q. Synthesis of $\beta$-cyclodextrin-[60]fullerene conjugate and its DNA cleavage performance. Chin. J. Chem. 2014, 32, 78-84. [CrossRef]

223. Zhang, W.; Gong, X.D.; Liu, C.; Piao, Y.Z.; Sun, Y.; Diao, G.W. Water-soluble inclusion complex of fullerene with g-cyclodextrin polymer for photodynamic therapy. J. Mater. Chem. B 2014, 2, 5107-5115. [CrossRef]

224. Tong, H.; Wang, Y.; Li, H.; Jin, Q.; Ji, J. Dual pH-responsive 5-aminolevulinic acid pseudopolyrotaxane prodrug micelles for enhanced photodynamic therapy. Chem. Commun. 2016, 52, 3966-3969. [CrossRef] [PubMed]

225. Liu, J.J.; Liang, H.N.; Li, M.H.; Luo, Z.; Zhang, J.X.; Guo, X.M.; Cai, K.Y. Tumor acidity activating multifunctional nanoplatform for NIR-mediated multiple enhanced photodynamic and photothermal tumor therapy. Biomaterials 2018, 157, 107-124. [CrossRef] [PubMed]

226. Chen, W.H.; Luo, G.F.; Qiu, W.X.; Lei, Q.; Liu, L.H.; Wang, S.B.; Zhang, X.Z. Mesoporous silica-based versatile theranostic nanoplatform constructed by layer-by-layer assembly for excellent photodynamic/chemo therapy. Biomaterials 2017, 117, 54-65. [CrossRef] [PubMed]

227. Chai, S.; Guo, Y.; Zhang, Z.; Chai, Z.; Ma, Y.; Qi, L. Cyclodextrin-gated mesoporous silica nanoparticles as drug carriers for red light-induced drug release. Nanotechnology 2017, 28, 145101. [CrossRef] [PubMed]

228. Hu, X.L.; Zang, Y.; Li, J.; Chen, G.R.; James, T.D.; He, X.P.; Tian, H. Targeted multimodal theranostics via biorecognition controlled aggregation of metallic nanoparticle composites. Chem. Sci. 2016, 7, 4004-4008. [CrossRef]

229. Luo, G.F.; Chen, W.H.; Lei, Q.; Qiu, W.X.; Liu, Y.X.; Cheng, Y.J.; Zhang, X.Z. A triple-collaborative strategy for high-performance tumor therapy by multifunctional mesoporous silica-coated gold nanorods. Adv. Funct. Mater. 2016, 26, 4339-4350. [CrossRef]

(C) 2018 by the authors. Licensee MDPI, Basel, Switzerland. This article is an open access article distributed under the terms and conditions of the Creative Commons Attribution (CC BY) license (http:/ / creativecommons.org/licenses/by/4.0/). 